\title{
PROGNOSTIC FACTORS AND UNDERLYING MECHANISMS IN CHRONIC LOW BACK PAIN
}

Marije Vos-van der Hulst 
Address of correspondence:

Marije Vos - van der Hulst

Sint Maartenskliniek

PO Box 9011

6522 JV Nijmegen

The Netherlands

+31 (0)243659911

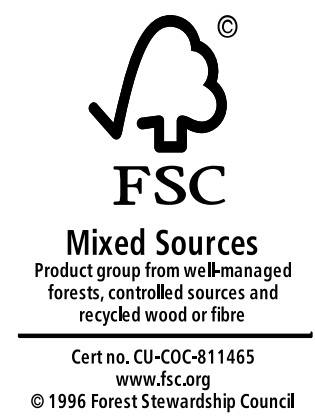

Layout and printed by Gildeprint Drukkerijen, Enschede, The Netherlands Cover image designed by Tjeerd van der Hulst

ISBN 978-90-365-2881-8

(c) M. Vos-van der Hulst, Enschede, The Netherlands, 2009.

All rights reserved. No part of this book may be reproduced, stored in a retrieval system, or transmitted in any form or by any means, electronic, mechanical, photocopying, recording, or otherwise, without the prior written permission of the holder of the copyright. 


\title{
PROGNOSTIC FACTORS AND UNDERLYING MECHANISMS IN CHRONIC LOW BACK PAIN
}

\author{
PROEFSCHRIFT
}

ter verkrijging van

de graad van doctor aan de Universiteit Twente,

op gezag van de rector magnificus, prof.dr.H. Brinksma, volgens besluit van het College voor Promoties in het openbaar te verdedigen op vrijdag 6 november 2009 om 15.00 uur

door

Marije Vos-van der Hulst

geboren op 15 mei 1974

te Groningen 


\section{Dit proefschrift is goedgekeurd door:}

Prof.dr.M.M.R.Vollenbroek-Hutten (eerste promotor)

Prof.dr.ir.H.J.Hermens (tweede promotor) 
De promotiecommissie is als volgt samengesteld:

Voorzitter en secretaris

Prof.dr.ir.A.J.Mouthaan

Universiteit Twente

Promotoren

Prof.dr.M.M.R.Vollenbroek-Hutten

Universiteit Twente

Prof.dr.H.J.Hermens

Universiteit Twente

Leden

Prof.dr.J.S.Rietman

Universiteit Twente

Prof.dr.J.M.Pieters

Universiteit Twente

Prof.dr.J.H.van Dieën

Vrije Universiteit Amsterdam

Prof.dr.med.sci.T. Graven-Nielsen

Aalborg University Denemarken

Prof.dr.R.J.E.M. Smeets

Universiteit Maastricht

Paranimfen

Dr. J.F.M. Fleuren

Drs. M. Kouwenhoven 
This study was supported by grants from "ZON-MW" and the "Joris foundation"

\title{
(1) ZonMw
}

The publication of this thesis was generously supported by:

Roessingh Research and Development, Enschede

Het Roessingh, center for rehabilitation, Enschede

Chair Biomedical Signals and Systems, University of Twente, Enschede

D.H. Heijne Stichting / Basko Healthcare

Nederlandse Vereniging van Rugpatiënten "de Wervelkolom"

Covidien Nederland B.V.

Anna Fonds

Bauerfeind Benelux B.V.

Ottobock

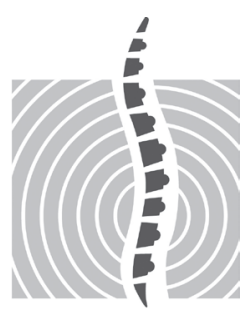

\section{COVIDIEN}

\author{
positive results for life
}

\section{Anna \\ Fonds}

DBauerfeind

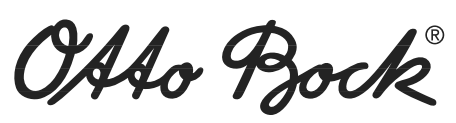

QUALITY FOR LIFE 


\section{Contents}

Chapter one Introduction 9

Chapter two A systematic review of sociodemographic, physical, and psychological predictors of multidisciplinary rehabilitation- or, back school treatment outcome in patients with chronic low back pain

Chapter three Multidisciplinary rehabilitation treatment of patients with chronic low back pain: A prognostic model for its outcome

Chapter four Back muscle activation patterns in chronic low back pain during walking: a "guarding" hypothesis

Chapter five Lumbar - and abdominal muscle activity during walking in subjects with chronic low back pain: Support of the "guarding" hypothesis?

Chapter six Relationships between coping strategies and lumbar muscle activity in subjects with chronic low back pain

Chapter seven General discussion

Summary

Samenvatting

Dankwoord 


\section{Chapter 1}

Introduction

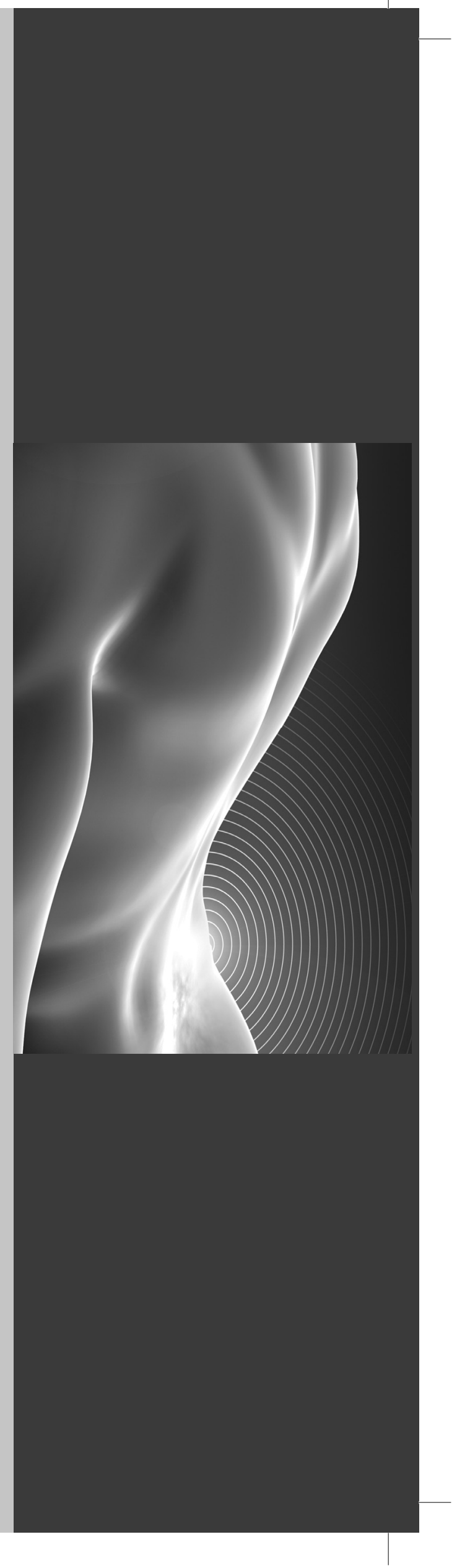


regel 1 regel 2 regel 3 regel 4 regel 5 regel 6 regel 7 regel 8 regel 9 regel 10 regel 11 regel 12 regel 13 regel 14 regel 15 regel 16 regel 17 regel 18 regel 19 regel 20 regel 21 regel 22 regel 23 regel 24 regel 25 regel 26 regel 27 regel 28 regel 29 regel 30 regel 31 regel 32 regel 33 regel 34 regel 35 regel 36 regel 37 regel 38
Low back pain (LBP) is defined as pain localised between the $12^{\text {th }}$ rib and the inferior gluteal folds, with or without leg pain ${ }^{25 ; 31 ; 4}$. LBP has a life time prevalence of $60-85 \%$. At any moment, about $15 \%$ of adults have LBP. Most cases are nonspecific, but in about $10 \%$ of cases a specific cause is identified ${ }^{25}$. In the majority of the cases, LBP is a self-limiting disease and $90 \%$ of the attacks of low back pain recover within $6-8$ weeks ${ }^{46}$. A minority (5 - 10\%) of subjects with nonspecific LBP eventually develop chronic low back pain (CLBP). This group, however, accounts for $70-90 \%$ of the societal costs of low back pain ${ }^{13 ; 31}$. Despite the update of LBP treatment guidelines, the societal costs attributed to LBP are still high ${ }^{3}$. The majority of costs results from lost work productivity and less from direct treatment ${ }^{8}$.

General consensus exists to approach the problem of CLBP from a biopsychosocial perspective 46;47. The International Classification of functioning, Disability and Handicap (ICF) also provides a view of biological, individual and social perspectives of health by identifying three levels of functioning: at the level of the body (part), the whole person, and the whole person in a social context ${ }^{50}$. Within this framework, dysfunction can occur at one or more of these levels: at the impairment level, i.e. problems in body function or structure, at the activity level, i.e. execution of a task, and/or at the participation level, i.e. involvement in a social life situation.

Starting from this biopsychosocial perspective, a variety of multidisciplinary treatments has been developed aimed at improving activity and participation of subjects with CLBP. Several systematic reviews ${ }^{10 ; 16 ; 23 ; 24 ; 3 ; 34}$ and meta-analyses ${ }^{9 ; 42}$ have been published concerning the effectiveness of such treatments and a best evidence synthesis from these reviews shows that multidisciplinary treatments have beneficial short- term effects in function, but no longterm effects ${ }^{41}$. This is a disappointing conclusion for patients, professionals and society, as recurrence of symptoms and loss of function have a negative impact on quality of life and also place a substantial economic burden on society.

One of the explanations for this limited effectiveness could be the fact that the heterogeneous CLBP population receives a generic multidisciplinary treatment, which makes it unlikely that all patients will benefit from the same treatment. Subjects with the same medical diagnosis of CLBP are not similar and thus may need different treatments ${ }^{38}$. Considering the biopsychosocial mechanisms in CLBP, it is considered important to gain more insight in the role of various biopsychosocial variables in subjects with CLBP, to be able to further optimize treatment strategies to the individual patient's needs. 
Therefore, the main aim of this thesis is to gain insight in biopsychosocial mechanisms in subjects with CLBP, both in differences with respect to asymptomatic controls as well as in relation to treatment outcome. Insight in these aspects is expected to eventually enhance a better match of treatment to the patient's characteristics and contribute positively to future optimization of multidisciplinary treatments.

Concerning the biopsychosocial aspects in relation to treatment outcome, it is important to have a clear view on which variables are prognostic for treatment outcome in CLBP. Knowledge of prognostic factors will facilitate individual selection of the most suitable treatment. Published reviews of prognostic variables show great variability in study population, type of treatment,

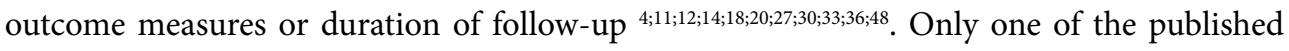
systematic reviews addresses the concept of multidimensionality by including prognostic factors from different domains (i.e. sociodemographic, physical and psychological) ${ }^{12}$. This systematic review, however, only focused on the outcome measure "return to work". Although this is an important outcome measure in rehabilitation, it is also important to include activity limitation and participation as outcome measures. Therefore, a systematic review focusing on prognostic factors from multiple domains and treatment outcome measured as activity limitation or participation restriction ${ }^{50}$ is performed (chapter 2).

It is important to validate a priori defined prognostic factors from the literature, for a specific CLBP population and rehabilitation treatment. The consistent biopsychosocial prognostic factors for multidisciplinary treatment outcome as found in chapter 2, are therefore evaluated in a confirmative study (chapter 3). The objective of this study is to determine if treatment outcome in CLBP can be predicted by a predefined multivariate prognostic model. Furthermore, the value of potentially prognostic work-related and psychological factors, like fear-avoidance beliefs and depression, is explored. Understanding of factors that predict treatment outcome is important, to enable clinicians to better select patients for the most suitable treatment modality.

Besides biopsychosocial prognostic factors, insight in underlying biopsychosocial processes in subjects with CLBP is important. Rehabilitation treatment of chronic pain is founded on hypotheses of these processes. Knowledge of these mechanisms in subjects with CLBP is therefore important to enable development of adequate treatment modules matched to specific patient characteristics, with different prognoses.

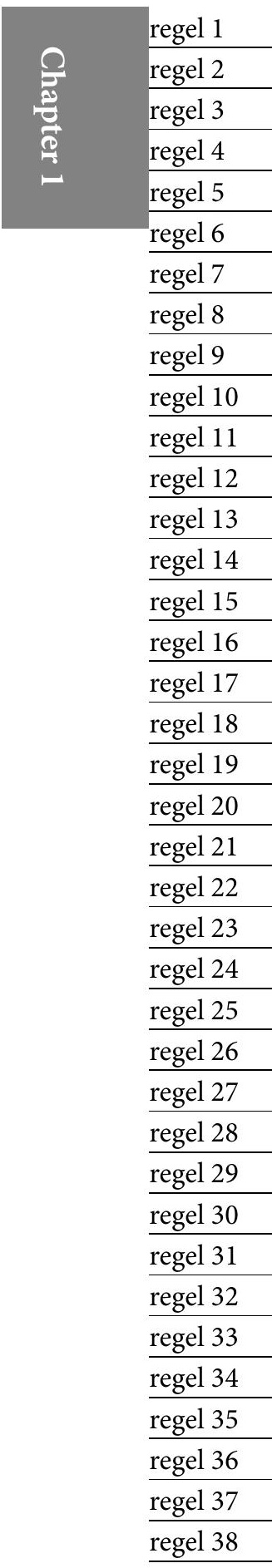


regel 1 regel 2 regel 3 regel 4 regel 5 regel 6 regel 7 regel 8 regel 9 regel 10 regel 11 regel 12 regel 13 regel 14 regel 15 regel 16 regel 17 regel 18 regel 19 regel 20 regel 21 regel 22 regel 23 regel 24 regel 25 regel 26 regel 27 regel 28 regel 29 regel 30 regel 31 regel 32 regel 33 regel 34 regel 35 regel 36 regel 37 regel 38
Concerning physical processes, scientific studies have shown that trunk muscle activity differs between subjects with CLBP and healthy controls. Two famous pain models hypothesize different relationships between pain and muscle activity, i.e. the pain spasm pain model - in expanded form also called the vicious cycle model ${ }^{37}{ }^{22}$ - and the pain adaptation model ${ }^{28}$. In the pain-spasm-pain model it is hypothesized that acute pain results in increased muscle activity which reduces painful movements. In turn, increased muscle activity will cause more pain, leading to a "vicious cycle" of pain-spasm-pain. In contrast, the pain-adaptation model hypothesizes that pain leads to reduced muscle activity, in particular of the agonist muscles. Antagonistic muscles show a concomitant increase in muscle activity, which protects the painful area from further injury and pain. Both physiological models thus describe a protective mechanism in the acute phase of injury. Reviews however, have shown that evidence for these models is conflicting and clinically may be more applicable in the acute pain situation ${ }^{19 ; 35339}$. In these reviews new hypotheses have been proposed, i.e. that changes in muscle activity in LBP may serve to increase joint control and spinal stability ${ }^{35}$. As such, these changes may be interpreted as a "guarding" mechanism, a concept introduced by Main and Watson ${ }^{29}$. Guarded movement has been described as abnormalities in muscle action in subjects with CLBP during physical activity, although a clear definition of guarding in subjects with CLBP has not been given in literature. For instance, guarded movements in subjects with CLBP have been characterized by insufficient muscle relaxation during flexion ${ }^{1 ; 15 ; 9}$. It is considered an adaptation mechanism in response to acute pain, which in the long run may result in persistent movement changes ${ }^{43}$.

It is not known however, whether this guarding mechanism also exists during other daily functional tasks such as walking. To further explore a possible guarding mechanism, differences in lumbar muscle activity between subjects with CLBP and asymptomatic controls during walking are studied in chapter 4 . Because both the abdominal- and lumbar muscles are required for spinal stability ${ }^{6}$, co-activation of abdominal -and lumbar muscles is also likely to contribute to guarding. Up till now, however, no studies have investigated this co-activation in subjects with CLBP during walking. Differences in abdominal- and lumbar muscle activity between subjects with CLBP and asymptomatic controls are studied in chapter 5. In addition, velocity induced changes in trunk muscle activity are investigated. As spinal motion increases with greater walking velocities ${ }^{7}$, this will in turn demand changes in trunk muscle activity to control this increased range of motion ${ }^{2}$. One may assume that increasing walking velocity may elicit more guarded movements. The results of the study investigating this are also described in chapter 5 . 
Besides these physical processes, psychological factors are hypothesized to be also important within the biopsychosocial concept of chronic pain. Various models hypothesize a relationship between psychological factors and physical performance, for example in the fear-avoidance model ${ }^{26 ; 44}$ and in the avoidance-endurance model ${ }^{17}$. As such, it is also hypothesized that psychological factors are related to changes in trunk muscle activity ${ }^{49}$. Both models 17:26;44 assume that physical changes are influenced by coping responses (i.e. purposeful efforts to manage the negative impact of stress ${ }^{21}$ ). Coping can be divided into passive (e.g. avoidance) or active - (e.g. persistent) behavior ${ }^{5}$. Avoidance coping (i.e. avoiding daily activities because of fear of pain/ (re)injury) is described in the fear-avoidance model. Additionally, persistent coping (i.e. carrying on with daily activities despite pain) is described in the avoidance endurance model. Avoidance coping is assumed to result in avoidance behaviour which may lead to disuse and deconditioning with muscular insufficiency ${ }^{44: 45}$. Persistent coping is assumed to be present in subjects, who tend to finish all activities in spite of severe pain. This leads to persistent/endurance coping, with physical overload of muscles, muscle hyperactivity and increased pain. The study in chapter 6 explores the relation between lumbar muscle activity and coping strategies. It is investigated whether strategies as "avoidance -" and "persistent" coping are differentially related to lumbar muscle activity during walking.

Finally, in chapter 7 a general discussion capturing the results of the different studies in this thesis is presented. The consistent biopsychosocial prognostic factors in relation to treatment outcome are shown. Underlying physical mechanisms, measured by changes in trunk muscle activity and a possible relation with psychological factors in subjects with CLBP, are discussed. Methodological issues and recommendations for future research are provided. Finally, the contribution of knowledge of biopsychosocial mechanisms in subjects with CLBP to future optimization of multidisciplinary treatments is discussed.

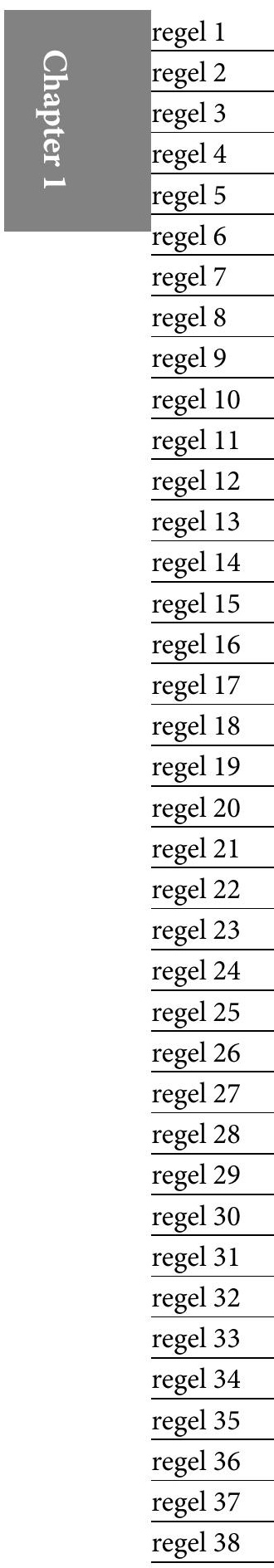


regel 1

regel 2

regel 3

regel 4

regel 5

regel 6

regel 7

regel 8

regel 9

regel 10

regel 11

regel 12

regel 13

regel 14

regel 15

regel 16

regel 17

regel 18

regel 19

regel 20

regel 21

regel 22

regel 23

regel 24

regel 25

regel 26

regel 27

regel 28

regel 29

regel 30

regel 31

regel 32

regel 33

regel 34

regel 35

regel 36

regel 37

regel 38

\section{References}

1. Ahern DK, Follick MJ, Council JR, Laser-Wolston N, and Litchman H. Comparison of lumbar paravertebral EMG patterns in chronic low back pain patients and non-patient controls. Pain 1988;34:153-60.

2. Anders C, Wagner H, Puta C, Grassme R, Petrovitch A, and Scholle HC. Trunk muscle activation patterns during walking at different speeds. J Electromyogr Kinesiol 2007;17:245-52.

3. Asche CV, Kirkness CS, McAdam-Marx C, and Fritz JM. The societal costs of low back pain: data published between 2001 and 2007. J Pain Palliat Care Pharmacother 2007;21:25-33.

4. Borge JA, Leboeuf-Yde C, and Lothe J. Prognostic values of physical examination findings in patients with chronic low back pain treated conservatively: a systematic literature review. J Manipulative Physiol Ther 2001;24:292-5.

5. Brown GK and Nicassio PM. Development of a questionnaire for the assessment of active and passive coping strategies in chronic pain patients. Pain 1987;31:53-64.

6. Cholewicki J, Panjabi MM, and Khachatryan A. Stabilizing function of trunk flexor-extensor muscles around a neutral spine posture. Spine 1997;22:2207-12.

7. Crosbie J, Vachalathiti R, and Smith R. Age, gender and speed effects on spinal kinematics during walking. Gait \& Posture 1997;5:13-20.

8. Dagenais S, Caro J, and Haldeman S. A systematic review of low back pain cost of illness studies in the United States and internationally. Spine J 2008;8:8-20.

9. Di Fabio, RP. Efficacy of comprehensive rehabilitation programs and back school for patients with low back pain: a meta-analysis. Physical Therapy 1995;75:865-878.

10. Faas A. Exercises: which ones are worth trying, for which patients, and when? Spine 1996;21:28748; discussion 2878-9.

11. Feuerstein, M. and Beattie, P. Biobehavioral factors affecting pain and disability in low back pain: mechanisms and assessment. Physical therapy 1995;75:267-280.

12. Feuerstein M, Menz L., Zastowney TR, and Barron, B. Chronic pain and disability:Vocational outcomes following multidisciplinary rehabilitation. Journal of Occupational Rehabilitation 1994;4:229-251.

13. Frymoyer JW. Predicting disability from low back pain. Clin Orthop Relat Res 1992;279:101-9.

14. Gatchel RJ and Gardea MA. Psychosocial issues: their importance in predicting disability, response to treatment, and search for compensation. Neurol Clin 1999;17:149-66.

15. Geisser ME, Haig AJ, Wallbom AS, and Wiggert EA. Pain-related fear, lumbar flexion, and dynamic EMG among persons with chronic musculoskeletal low back pain. Clin J Pain 2004;20:61-9.

16. Guzman J, Esmail R, Karjalainen K, Malmivaara A, Irvin E, and Bombardier C. Multidisciplinary rehabilitation for chronic low back pain: systematic review. BMJ 2001;322:1511-6.

17. Hasenbring M. Attentional control of pain and the process of chronification. Prog Brain Res 2000; 129:525-34.

18. Hasenbring M. Predictors of efficacy of treatment in chronic low back pain. Current Opinion in Anaesthesiology 1998;11:553-558.

19. Hodges PW and Moseley GL. Pain and motor control of the lumbopelvic region: effect and possible mechanisms. J Electromyogr Kinesiol 2003;13:361-70.

20. Hunter J. Medical history and chronic pain. The Clinical Journal of Pain 2001;17: S20-S25.

21. Jensen MP, Turner JA, Romano JM, and Karoly P. Coping with chronic pain: a critical review of the literature. Pain 1991;47:249-83.

22. Johansson H and Sojka P. Pathophysiological mechanisms involved in genesis and spread of muscular tension in occupational muscle pain and in chronic musculoskeletal pain syndromes: a hypothesis. Med Hypotheses 1991;35:196-203.

23. Karjalainen K, Malmivaara A, van Tulder M et al. Multidisciplinary biopsychosocial rehabilitation for subacute low back pain in working-age adults: a systematic review within the framework of the Cochrane Collaboration Back Review Group. Spine 2001;26:262-9. 
24. Koes BW, Tulder MW van, Windt DAWM. van der, and Bouter LM. The efficacy of back schools: a review of randomized clinical trials. J Clin Epidemiol 1994;47:851-862.

25. Krismer $M$ and van Tulder M. Strategies for prevention and management of musculoskeletal conditions. Low back pain (nonspecific). Best Pract Res Clin Rheumatol 2007;21:77-91.

26. Lethem J, Slade PD, Troup JD, and Bentley G. Outline of a Fear-Avoidance Model of exaggerated pain perception--I. Behav Res Ther 1983;21:401-8.

27. Love AW and Peck CL. The MMPI and psychological factors in chronic low back pain: a review. Pain 1987;28:1-12.

28. Lund JP, Donga R, Widmer CG, and Stohler CS. The pain-adaptation model: a discussion of the relationship between chronic musculoskeletal pain and motor activity. Can J Physiol Pharmacol 1991;69:683-94.

29. Main CJ, Watson PJ. Guarded movements: development of chronicity. J Musculoskeletal Pain 1996;4:163-70.

30. McCracken LM and Turk DC. Behavioral and cognitive-behavioral treatment for chronic pain: outcome, predictors of outcome, and treatment process. Spine 2002;27:2564-73.

31. Nachemson AL. Newest knowledge of low back pain. A critical look. Clin Orthop Relat Res 1992;279:8-20.

32. Nentwig CG.Effectiveness of the back school. A review of the results of evidence-based evaluation. Orthopade 1999;28:958-65.

33. Rohling ML, Binder LM, Langinrichsen-Rohling J. Money matters: A meta-analytic review of the association between financial compensation and the experience and treatment of chronic pain. Health Psychol 1995;14:537-547. .

34. Schonstein E, Kenny DT, Keating J, and Koes BW. Work conditioning, work hardening and functional restoration for workers with back and neck pain. Cochrane Database Syst Rev 2003;CD001822.

35. Sterling M, Jull G, and Wright A. The effect of musculoskeletal pain on motor activity and control. J Pain 2001;2:135-45.

36. Teasell RW. Compensation and chronic pain. Clin J Pain 2001;17:S46-64.

37. Travell J, Rinzter S, and Herman M. Pain and disability of the shoulder and arm. JAMA 1942;120:417-22.

38. Turk DC. The potential of treatment matching for subgroups of patients with chronic pain: lumping versus splitting. Clin J Pain 2005;21:44-55; discussion 69-72.

39. van Dieen JH, Selen LP, and Cholewicki J. Trunk muscle activation in low-back pain patients, an analysis of the literature. J Electromyogr Kinesiol 2003;13:333-51.

40. van Tulder M, Malmivaara A, Esmail R, and Koes B. Exercise therapy for low back pain: a systematic review within the framework of the cochrane collaboration back review group. Spine 2000;25:2784-96.

41. van Tulder MW, Koes B, and Malmivaara A. Outcome of non-invasive treatment modalities on back pain: an evidence-based review. Eur Spine J 2006;15 Suppl 1:S64-81.

42. van Tulder MW, Ostelo R, Vlaeyen JW, Linton SJ, Morley SJ, and Assendelft WJ. Behavioral treatment for chronic low back pain: a systematic review within the framework of the Cochrane Back Review Group. Spine 2001;26:270-81.

43. Verbunt JA, Seelen HA, Vlaeyen JW et al. Disuse and deconditioning in chronic low back pain: concepts and hypotheses on contributing mechanisms. Eur J Pain 2003;7:9-21.

44. Vlaeyen JW, Kole-Snijders AM, Boeren RG, and van Eek H. Fear of movement/(re)injury in chronic low back pain and its relation to behavioral performance. Pain 1995;62:363-72.

45. Vlaeyen JW and Linton SJ. Fear-avoidance and its consequences in chronic musculoskeletal pain: a state of the art. Pain 2000;85:317-32.

46. Waddell G. The biopsychosocial model. In: Waddell G, ed. The back pain revolution. Edinburgh, Chruchill Livingston, 2004.

47. Waddell G. Biopsychosocial analysis of low back pain. Baillieres Clin Rheumatol 1992;6:523-57.

48. Walsh NE and Dumitru D. The influence of compensation on recovery from low back pain. Occup Med 1988;3:109-21.

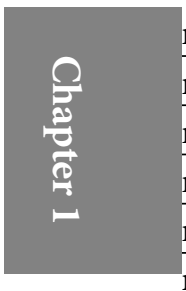

regel 1

regel 2

regel 3

regel 4

regel 5

regel 6

regel 7

regel 8

regel 9

regel 10

regel 11

regel 12

regel 13

regel 14

regel 15

regel 16

regel 17

regel 18

regel 19

regel 20

regel 21

regel 22

regel 23

regel 24

regel 25

regel 26

regel 27

regel 28

regel 29

regel 30

regel 31

regel 32

regel 33

regel 34

regel 35

regel 36

regel 37

regel 38 
regel 1

regel 2

regel 3

regel 4

regel 5

regel 6

regel 7

regel 8

regel 9

regel 10

regel 11

regel 12

regel 13

regel 14

regel 15

regel 16

regel 17

regel 18

regel 19

regel 20

regel 21

regel 22

regel 23

regel 24

regel 25

regel 26

regel 27

regel 28

regel 29

regel 30

regel 31

regel 32

regel 33

regel 34

regel 35

regel 36

regel 37

regel 38

49. Watson PJ, Booker CK, and Main CJ. Evidence for the role of psychological factors in abnormal paraspinal activity in patients with chronic low back pain. Journal of Musculoskeletal Pain 1997;5:41-56.

50. World Health Organization. International Classification of Functioning, Disability and Health. ICF checklist. 2001. [World Health Organisation web site]. Available at: http://www.who.int/ classifications/icf/en/. Accessed March, 2009. 


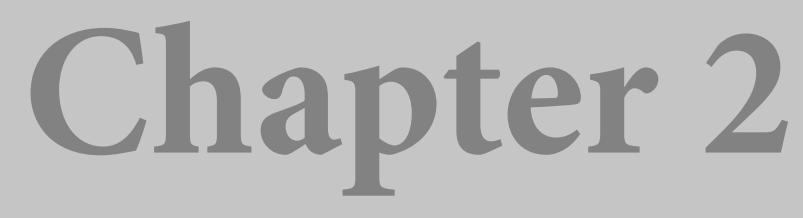

A systematic review of sociodemographic, physical, and psychological predictors of multidisciplinary rehabilitationor, back school treatment outcome in patients with chronic low back pain

Marije van der Hulst, Miriam MR Vollenbroek-Hutten, Maarten J IJzerman 
regel 1

regel 2

regel 3

regel 4

regel 5

regel 6

regel 7

regel 8

regel 9

regel 10

regel 11

regel 12

regel 13

regel 14

regel 15

regel 16

regel 17

regel 18

regel 19

regel 20

regel 21

regel 22

regel 23

regel 24

regel 25

regel 26

regel 27

regel 28

regel 29

regel 30

regel 31

regel 32

regel 33

regel 34

regel 35

regel 36

regel 37

regel 38

\begin{abstract}
Study design: A systematic review.

Objective: To determine predictors of outcome of multidisciplinary rehabilitation- or back school treatment for patients with chronic low back pain.

Background: Numerous reviews have been performed to gain insight into which patients benefit from which treatment. However, no review has systematically focused on predictors from multiple domains (i.e., sociodemographic, physical, and psychological), or on treatment outcome measured as activity limitation or participation restriction.
\end{abstract}

Methods: Studies were found by searching medical and psychological databases, and screening references. Two reviewers independently assessed the methodological quality using standard criteria. Studies were only included if they met a predefined level of internal validity. A qualitative analysis was performed.

Results: Heterogeneity among studies in patient characteristics, predictors, treatment, and outcomes limited evidence. All reviewed studies were descriptive or exploratory in nature. Consistent evidence was found for the predictive value of pain intensity (more pain $\rightarrow$ worse outcome), several work-related parameters (e.g., high satisfaction $\rightarrow$ better outcome), and coping style (less active coping $\rightarrow$ better outcome). Other sociodemographic and physical variables consistently lacked predictive value. No consistent evidence was found for other psychological variables.

Conclusions: It is impossible to define a generic set of predictors of outcome of multidisciplinary rehabilitation and back schools for patients with chronic low back pain because the reviewed studies were descriptive or exploratory in nature, and most predictors were only studied once. Nevertheless, for several predictors, consistent evidence was found. Large confirmatory studies are needed to test the value of these predictors. 


\section{Introduction}

Chronic low back pain (CLBP) is a complex problem, and multiple authors have emphasized the biopsychosocial influences on the development of chronicity 14;20;22;23;62;72;76. The multidimensional approach of CLBP has now been widely recognized. A variety of multidisciplinary treatments have been developed that focus on restoration of functional activity. Several systematic reviews ${ }^{18 ; 26 ; 37 ; 38 ; 77 ; 55}$ and meta-analyses ${ }^{15 ; 69}$ have been published. The conclusions are not uniform, and the efficacy of multidisciplinary treatment of CLBP is not yet clearly proven.

One of the explanations for this limited evidence could be the heterogeneity of the CLBP population, which makes it unlikely that one treatment benefits all ${ }^{64}$. Because of this result, it is important to understand which subtypes of patients benefit from which treatment module. Unfortunately, there is insufficient knowledge about the prognosis of different subgroups of patients ${ }^{20 ; 69}$. To improve this insight, several reviews have been performed that study predictive factors of treatment outcome of chronic (low back) pain.

Regarding the non-systematic reviews, a great variability is found in study population, type of treatment, outcome measures, or duration of follow-up ${ }^{20 ; 23 ; 30 ; 31 ; 43 ; 46 ; 60 ; 75}$ First, the patient characteristics differ. Some describe the heterogeneous pain population and do not focus specifically on low back pain (LBP) ${ }^{31 ; 46 ; 52 ; 60 ; 75}$. Others do not confine themselves to either acute or chronic LBP ${ }^{23 ; 31 ; 60}$ or specific or nonspecific CLBP ${ }^{21 ; 31 ; 60}$. Second, most studies investigate a variety of outcome measures (e.g., pain reduction, return to work). Third, several studies include different and often poorly defined treatments (e.g., conservative, multimodal, surgical $)^{8,20 ; 23 ; 30 ; 31 ; 52}$. Fourth, studies differ in duration of follow up. Finally, the studies include different potential predictors in the analyses, thus making comparison difficult ${ }^{30}$. Based on this result, it is difficult to draw a final conclusion about prognostic factors of treatment outcome, and systematic reviews are necessary.

Moreover, 3 of the published reviews are systematic reviews ${ }^{8 ; 21 ; 52}$ and study predictive factors of multidisciplinary treatment outcome of patients with CLBP. Only one of these reviews ${ }^{21}$ addressed the concept of multidimensionality by including prognostic factors from different domains (i.e., sociodemographic, physical, and psychological). However, this review did not focus on outcome measures as disability and handicap but only on return-to-work-rate. Therefore, there is a need for a systematic review focusing on prognostic factors from multiple domains, and the outcome measures disability and handicap. It is expected that gained insight from this review will facilitate patient classification into more homogeneous subgroups, which are likely to benefit from rehabilitation treatment ${ }^{24 ; 36 ; 43 ; 57 ; 59 ; 63-65 ; 73}$. regel 1

regel 2

regel 3

regel 4

regel 5

regel 6

regel 9

regel 10

regel 11

regel 12

regel 13

regel 14

regel 15

regel 16

regel 17

regel 18

regel 19

regel 20

regel 21

regel 22

regel 23

regel 24

regel 25

regel 26

regel 27

regel 28

regel 29

regel 30

regel 31

regel 32

regel 33

regel 34

regel 35

regel 36

regel 37

regel 38 
regel 1 regel 2 regel 3 regel 4 regel 5 regel 6 regel 7 regel 8 regel 9 regel 10 regel 11 regel 12 regel 13 regel 14 regel 15 regel 16 regel 17 regel 18 regel 19 regel 20 regel 21 regel 22 regel 23 regel 24 regel 25 regel 26 regel 27 regel 28 regel 29 regel 30 regel 31 regel 32 regel 33 regel 34 regel 35 regel 36 regel 37 regel 38

The objective of this systematic review is to determine which factors (i.e., sociodemographic, physical, and psychological) predict outcome of rehabilitation treatment (i.e., multidisciplinary treatment, or back schools) of patients with nonspecific CLBP. Outcome is defined as activity limitation (i.e., difficulties an individual may have in executing activities) and participation restriction (i.e., problems an individual may have in life situations). ${ }^{78}$

\section{Methods}

\section{The review process}

In the first stage of the review process, two reviewers (M.v.d.H. and M.V.-H.) selected the studies to be included in the systematic review ${ }^{4 ; 68}$. In the second stage, both reviewers independently assessed the methodological quality of the studies and excluded studies which were not internally valid from the final review. Disagreements concerning inclusion and quality assessment of studies were resolved by consensus, and a third independent reviewer (M.IJ.) could be consulted to make the final decision. From a practical point of view, articles were not blinded for authors, institution, journal, results, or conclusions.

\section{Search strategy}

\section{Appropriate studies were traced by:}

- A computer-aided search of the Medline, Psychinfo, Picarta, Web of Science, The Cochrane Library databases up to August 2003, and the Embase and Cinahl up to September 2003.

- Screening references given in relevant, identified publications (reviews, included articles).

- Manual search of relevant journals: Spine (to August 2003) and Pain (to August 2003), American Pain Society bulletin to August 2003 (www.ampainsoc.org).

- Recommended literature by experts in the field .

The most relevant used key words were: LBP, chronic, predictor, prognosis, treatment, therapy, rehabilitation, multidisciplinary, functional restoration, outcome, and effect. Articles published in English, German, French, or Dutch were included.

\section{Inclusion and exclusion criteria}

Types of studies. (Non) randomized controlled trials (RCT) and prospective cohort studies were included. RCT were included if data concerning prognostic factors for treatment outcome could be extracted from the study cohort. 
Types of participants. Subjects between 18 and 65 years of age, with as primary complaint chronic nonspecific LBP (more than 12 weeks continual or recurrent episodes of LBP) ${ }^{19669}$. LBP is defined as pain under the scapulas, above the cleft of the buttocks, with or without radiation to the lower extremities ${ }^{19 ; 67}$. Excluded were subjects with specific causes of LBP (e.g., inflammatory disease, radicular syndrome), back surgery in the last 6 months, or a medical contraindication for active rehabilitation.

Types of interventions. Multidisciplinary treatments and back schools were included. Multidisciplinary treatment was defined as physician consultation in addition to psychological, social, or vocational intervention, or a combination of these interventions ${ }^{37}$. Back schools at least consisted of an education and skills program, and included an exercise regimen. Instructions were given in groups, supervised by a physiotherapist or other (para) medical therapist ${ }^{38}$. Excluded were all other treatments or if nerve blocks were an additional component of the intervention.

Types of baseline measures. Only baseline measures of predictive factors were included because the time of assessment of the potential predictor (i.e., at baseline or during therapy) may influence the prognostic value for treatment outcome ${ }^{30}$.

Types of outcome measures. Studies were included if at least one of the outcome measures was a measurement of activity limitation (i.e., difficulties an individual may have in executing activities) and/or participation restriction (i.e., problems an individual may experience in daily life situations) ${ }^{78}$.

\section{Criteria for methodological quality}

There are no widely accepted quality criteria for assessing the methodological quality of prognostic studies ${ }^{2 ; 11}$. Therefore, we used criteria as proposed by the Cochrane Collaboration for observational studies ${ }^{12}$, Altman ${ }^{2}$, and van der Windt et al ${ }^{66}$ completed with criteria used in other systematic reviews of prognostic factors [E. Beeks and J van Limbeek, unpublished data, December 1999] 13:14;3950 (Appendix 1). Each criterion was graded as: yes, no, partially, not applicable or can't tell (i.e., insufficient information provided). Internal validity was assessed by a subset of the quality criteria, adapted from Côté et al ${ }^{13}$ (Appendix 2). If any of these criteria was scored as "no", the study was rejected from the analysis.

\section{Data extraction}

Prognostic determinants were classified into 3 main domains: sociodemographic, physical, and psychological variables. Outcomes were classified as activity limitation or participation restriction. Studies were classified according to the phase of investigation (Phases I-III) 
regel 1

regel 2

regel 3

regel 4

regel 5

regel 6

regel 7

regel 8

regel 9

regel 10

regel 11

regel 12

regel 13

regel 14

regel 15

regel 16

regel 17

regel 18

regel 19

regel 20

regel 21

regel 22

regel 23

regel 24

regel 25

regel 26

regel 27

regel 28

regel 29

regel 30

regel 31

regel 32

regel 33

regel 34

regel 35

regel 36

regel 37

regel 38

3;13. Phase I studies are descriptive, exploratory studies that seek an association between a prognostic marker and a certain outcome variable. Phase II studies are exploratory studies which value a set of prognostic variables to discriminate between high-and low risk patients or to indicate which patients are likely to benefit from therapy. Phase III studies are confirmatory studies which attempt to confirm a priori stated hypotheses of the value of a set of prognostic markers in predicting outcome. The study population will be classified into patients recruited from a population of employees and patients seeking treatment at a rehabilitation center because these might differ with respect to prognosis ${ }^{13}$.

\section{Data analysis}

If possible, statistical pooling will be performed. Otherwise, the results of the internal valid studies will be described qualitatively, with the overall conclusion of best evidence defined as: "two or more studies reporting consistent results on the finding, or $75 \%$ of the studies reporting similar conclusions" ${ }^{13}$. Results are statistically significant if $P \leq 0.05$. 


\section{Results}

regel 1

regel 2

regel 3

\section{Selection of studies}

The flow chart of the total search and study selection is shown in Figure 1. In the first stage of the review process, the inclusion criteria were applied. Four articles $6: 35 ; 44 ; 56$ did not provide sufficient information about the studied population to apply the inclusion criteria. An attempt was made to contact the first authors for clarification, which was successful in 3 cases ${ }^{6 ; 35 ; 44}$. Of these 4 articles, 3 were excluded. One was excluded because "chronicity" was not defined, and the author could not be contacted ${ }^{56}$. The other 2 were excluded because they studied a mixed population of patients with other primary locations of pain than the back ${ }^{6 ; 35}$. The fourth article was included because the author confirmed that "chronicity" was defined as pain duration longer than 3 months ${ }^{44}$. The first stage yielded 24 articles.

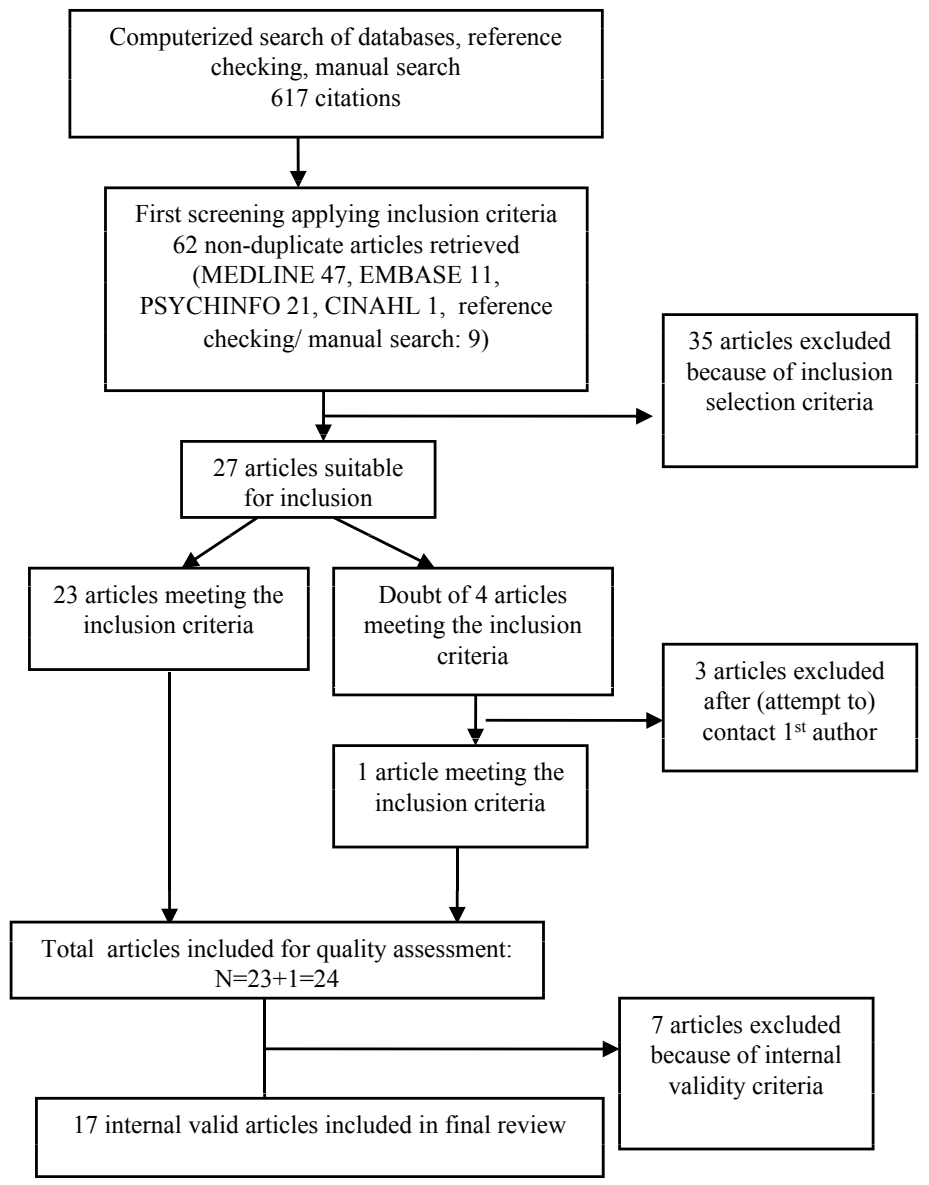

Figure 1: Flow diagram of papers accepted and rejected during the selection process. regel 4

regel 5

regel 6

regel 20

regel 21

regel 22

regel 23

regel 24

regel 25

regel 26

regel 27

regel 28

regel 29

regel 30

regel 31

regel 32

regel 33

regel 34

regel 35

regel 36

regel 37

regel 38 


\begin{tabular}{|c|}
\hline regel 2 \\
\hline regel 3 \\
\hline regel 4 \\
\hline regel 5 \\
\hline regel 6 \\
\hline regel 7 \\
\hline regel 8 \\
\hline regel 9 \\
\hline regel 10 \\
\hline regel 11 \\
\hline regel 12 \\
\hline regel 13 \\
\hline regel 14 \\
\hline regel 15 \\
\hline regel 16 \\
\hline regel 17 \\
\hline regel 18 \\
\hline regel 19 \\
\hline regel 20 \\
\hline regel 21 \\
\hline regel 22 \\
\hline regel 23 \\
\hline regel 24 \\
\hline regel 25 \\
\hline regel 26 \\
\hline regel 27 \\
\hline regel 28 \\
\hline regel 29 \\
\hline regel 30 \\
\hline regel 31 \\
\hline regel 32 \\
\hline regel 33 \\
\hline regel 34 \\
\hline regel 35 \\
\hline regel 36 \\
\hline regel 37 \\
\hline regel 38 \\
\hline
\end{tabular}

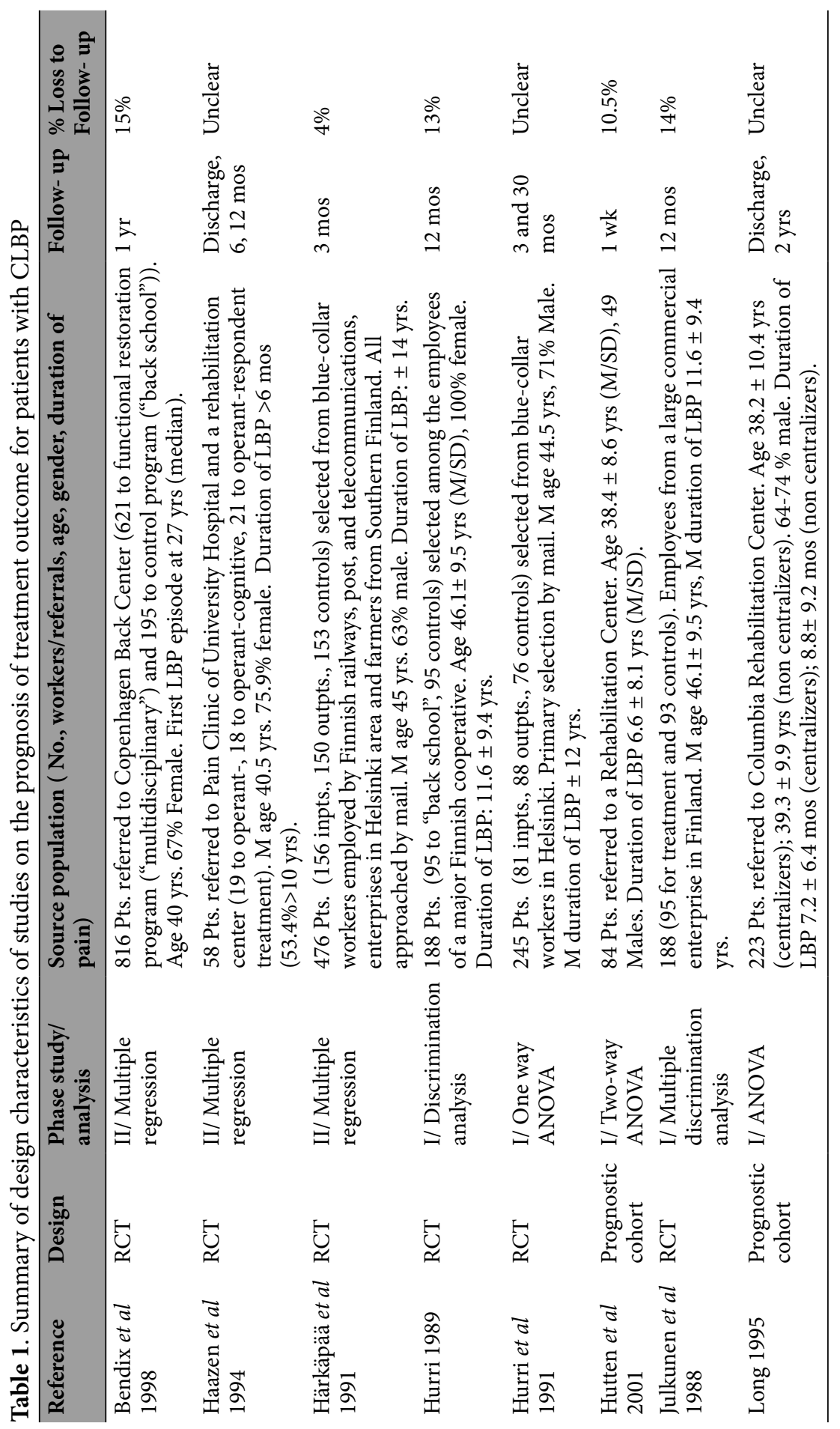


Predictors of multidisciplinary rehabilitation

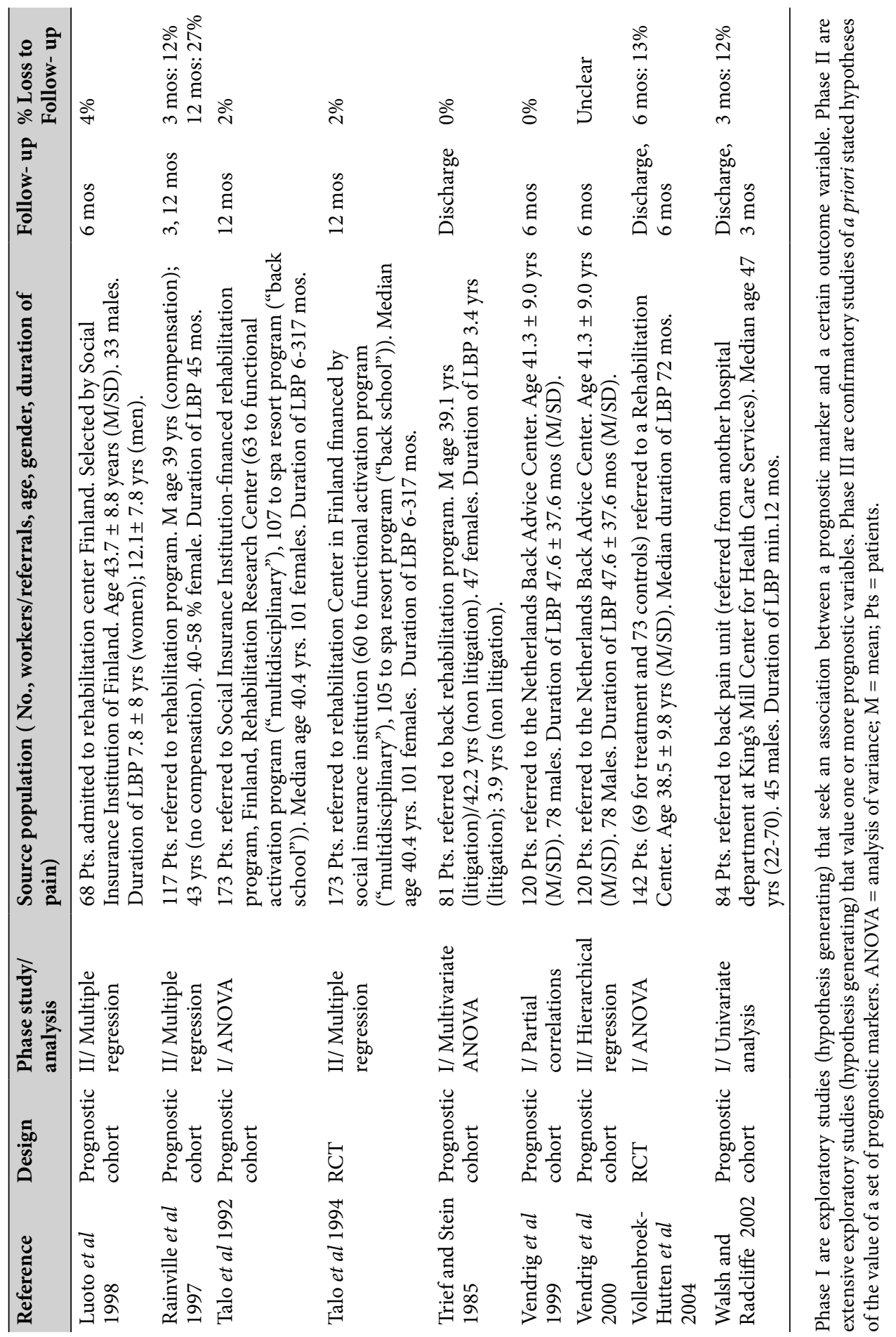

regel 1

regel 2

regel 3

regel 4

regel 5

regel 6

赵

regel 7

regel 8

regel 9

regel 10

regel 11

regel 12

regel 13

regel 14

regel 15

regel 16

regel 17

regel 18

regel 19

regel 20

regel 21

regel 22

regel 23

regel 24

regel 25

regel 26

regel 27

regel 28

regel 29

regel 30

regel 31

regel 32

regel 33

regel 34

regel 35

regel 36

regel 37

regel 38 
regel 1

regel 2

regel 3

regel 4

regel 5

regel 6

regel 7

regel 8

regel 9

regel 10

regel 11

regel 12

regel 13

regel 14

regel 15

regel 16

regel 17

regel 18

regel 19

regel 20

regel 21

regel 22

regel 23

regel 24

regel 25

regel 26

regel 27

regel 28

regel 29

regel 30

regel 31

regel 32

regel 33

regel 34

regel 35

regel 36

regel 37

regel 38

The second stage consisted of applying the methodological quality criteria to these 24 studies. Of these studies, $7 \mathrm{did}$ not meet the quality cutoff point for internal validity ${ }^{7: 10 ; 16 ; 28 ; 45 ; 48 ; 49}$, leaving 17 internal valid studies (24 studies -7) for inclusion in the final review. Of the 7 studies, 3 were excluded because the inclusion and exclusion criteria were, although at first sight appropriate, not well defined ${ }^{7: 28 ; 4}$. Two studies were excluded because the participation rate and percentage follow-up were insufficient ${ }^{10: 16}$. Invalid or unreliable outcome measurement was the reason for excluding the other 2 studies ${ }^{45 ; 4}$. The quality assessment of all studies is available from the author. Final consensus was reached without needing to consult the third reviewer.

\section{Study characteristics}

The main characteristics of the study populations of the 17 included internal valid studies are shown in Table 1.

Types of studies. Of the 17 studies that were included, 8 were RCT's ${ }^{5 ; 27 ; 29 ; 32 ; 33 ; 36 ; 58 ; 73}$ and 9 were prognostic cohorts $34 ; 41 ; 44 ; 1 ; 59 ; 61 ; 70 ; 71 ; 74$. Ten studies were classified as Phase I $I^{32-34 ; 36 ; 11 ; 5 ; 61 ; 71 ; 73 ; 74}$ and 7 as Phase II studies ${ }^{5 ; 27 ; 29 ; 44 ; 51 ; 58 ; 70}$. No studies were classified as Phase III.

Types of participants. Four studies included patients recruited from a population of employees ${ }^{29 ; 32 ; 33 ; 36}$ and 13 studies included patients seeking treatment at a rehabilitation center. Sample sizes varied from 58 to 476 cases, with most studies including approximately 100 cases. The mean age of studied patients is about $40-45$ years. The ratio of male-to-female differed per study, with one study including only females ${ }^{32}$. The duration of LBP varied from 3 months to a maximum of 26 years.

Types of interventions. Six articles studied back schools ${ }^{32 ; 34 ; 36 ; 4 ; 51 ; 73}, 3$ studied back schools versus multidisciplinary treatment ${ }^{5 ; 5859}$ and 8 studied multidisciplinary treatment alone 27:29;33;41;61;70;1;77 . Although the basic principles of multidisciplinary treatment and back schools are comparable, there is a large variety in duration, setting (inpatient or outpatient), and implementation between the studied interventions. For example, multidisciplinary treatment at one center may be based on cognitive behavioral concepts but in another, on operant behavioral ones. Also, several back schools offer consultation of a psychologist if needed, and others did not.

Follow-up. Outcome was measured after different periods of follow-up. The shortest followup period was set at discharge ${ }^{61}$, and the longest at 30 months ${ }^{33}$. The percentage loss to follow-up varied from $0 \%{ }^{61 ; 71}$ to $27 \%{ }^{51}$, in 4 articles the percentage was unclear ${ }^{27333 ; 1 ; 70}$. 
Types of baseline measures. In total, 79 prognostic factors were studied. The number of relevant predictors differed substantially per author (Figure 2). Most studies focused on 1 to 3 prognostic variables. Five authors studied more than 9 variables ${ }^{5 ; 27: 29 ; 32 ; 58}$, with a maximum of 19 variables studied by Bendix et al ${ }^{5}$.

Sociodemographic variables were studied in 8 articles $5 ; 27 ; 29 ; 32 ; 51 ; 58 ; 61 ; 70$, physical variables in 7 5;32-34;41;44;73 and psychological variables in 10 27;29;34;36;58;59;70;71;73;74. Four articles studied "other" predictors, which includes baseline measurements of activity and participation limitation $5 ; 27 ; 29 ; 74$.

After classifying predictors into 3 main domains (i.e., sociodemographic, physical, and psychological), it was clear that none of the authors studied predictors from these 3 domains simultaneously. Nine articles studied predictors from one domain ${ }^{33 ; 36 ; 41 ; 44 ; 51 ; 59 ; 61 ; 71 ; 74}$ and 8 predictors from two domains $5 ; 27: 29 ; 32 ; 34 ; 58 ; 70 ; 73$.

Types of outcome measures. In total, 19 outcome measures were used to measure the domains activity limitation or participation restriction. Eight different measures were used to measure activity limitation and 11 to measure participation restriction. Only 3 authors studied more than one outcome measure. Talo et al studied $7{ }^{59}$ and $4{ }^{58}$ different outcome measures and Walsh and Radcliffe $2^{74}$. Figure 2 gives an overview of the number of prognostic factors and outcome measures per study. Three authors studied measures of participation restriction $^{58 ; 59 ; 61}$, and the others studied measures of activity limitation $5 ; 27 ; 29 ; 32-34 ; 36 ; 41 ; 44 ; 51 ; 70 ; 71 ; 73 ; 74$.

regel 1

regel 2

regel 3

regel 4

regel 5

regel 6

regel 7

regel 8

regel 9

regel 10

regel 11

regel 12

regel 13

regel 14

regel 15

regel 16

regel 17

regel 18

regel 19

regel 20

regel 21

regel 22

regel 23

regel 24

regel 25

regel 26

regel 27

regel 28

regel 29

regel 30

regel 31

regel 32

regel 33

regel 34

regel 35

regel 36

regel 37

regel 38 
regel 1

regel 2

regel 3

regel 4

regel 5

regel 6

regel 7

regel 8

regel 9

regel 10

regel 11

regel 12

regel 13

regel 14

regel 15

regel 16

regel 17

regel 18

regel 19

regel 20

regel 21

regel 22

regel 23

regel 24

regel 25

regel 26

regel 27

regel 28

regel 29

regel 30

regel 31

regel 32

regel 33

regel 34

regel 35

regel 36

regel 37

regel 38

number of predictors and outcomes per author

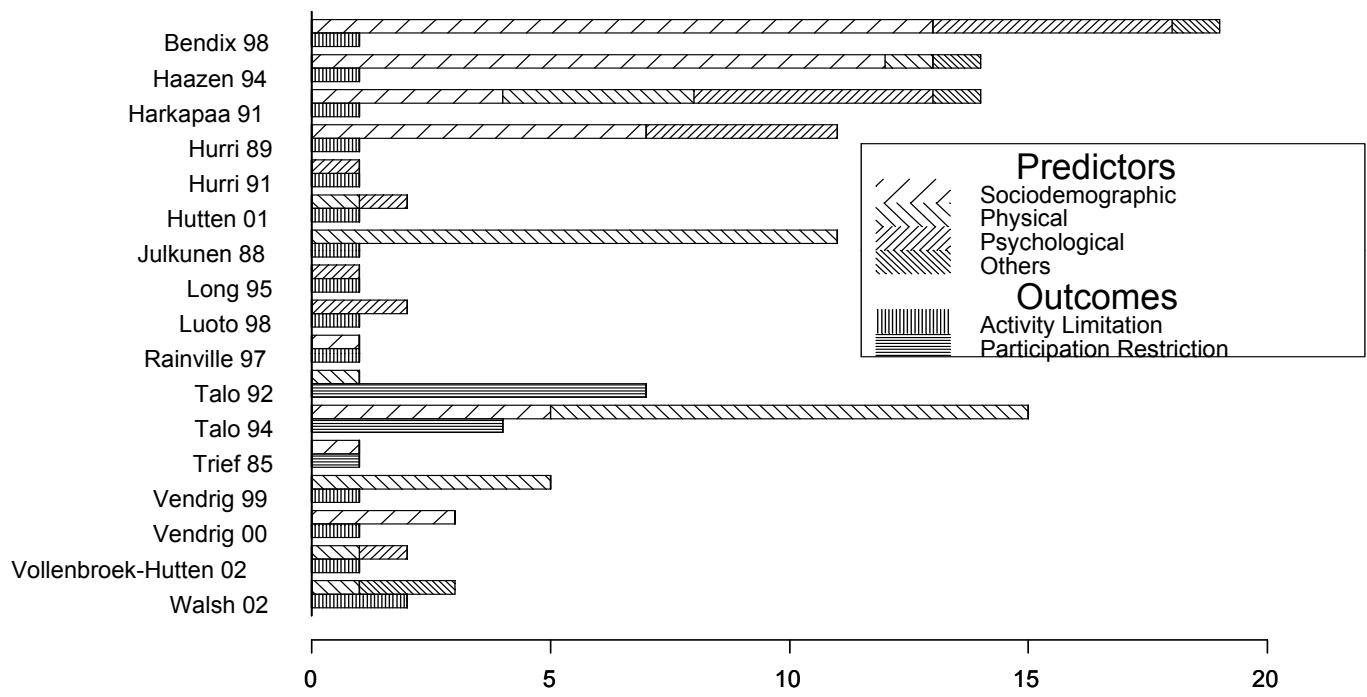

Figure 2: Number of predictors and outcome measures per study, classified by type of predictor (i.e.,sociodemographic, physical, psychological, others) and type of outcome measure (i.e.,activity limitation, participation restriction).

\section{Overall level of evidence}

Table 2 provides an overview of the available evidence for the different prognostic factors per treatment (back schools/multidisciplinary) and outcome measure (activity limitation/ participation restriction). From the table it is clear that none of the articles, with the exception of $2^{34 ; 73}$, studied the relation of a specific predictor, treatment and outcome measure more than once. This means that evidence in this study is limited. Consistent conclusions can only be drawn if predictors, treatments, and outcomes are grouped together in comparable domains. The heterogeneity of the study population, prognostic factors, and outcome measures precluded statistical pooling of the results and necessitated a qualitative summary of the results.

\section{Sociodemographic predictors}

Consistent evidence was found that personal characteristics like age ${ }^{5,27 ; 29 ; 70}$ and gender $5 ; 27 ; 29$ were not predictive. Height and weight also lacked predictive value, although evidence was weak ${ }^{5}$. 
For health related variables (e.g., smoking), different variables were studied, most lacking predictive value ${ }^{5 ; 27 ; 29 ; 32}$. Different results were found for use of medication at baseline. One article studied back schools and found no predictive value at 12 months ${ }^{32}$. Another article studied multidisciplinary treatment and found a negative predictive value for outcome at discharge and at 6 months ${ }^{27}$. However, in this study, the explained variance in outcome that could be attributed to medication was only $10 \%$ at 6 -month and $0 \%$ at 12 -month follow-up ${ }^{27}$. Thus, both articles showed that use of medication had no predictive value at 1 year, but no conclusion could be drawn for shorter follow-ups.

Pain related variables were studied by 6 authors ${ }^{5 ; 27 ; 29 ; 32 ; 58 ; 70}$. Pain duration consistently lacked predictive value 5,$27 ; 29 ; 70$. Consistent results were also found for the negative predictive value of pain intensity ${ }^{5 ; 58}$, although not for pain intensity in the leg ${ }^{5}$. Higher pain intensity at baseline predicted worse outcome. Talo et al ${ }^{58} \mathrm{drew}$ the same conclusion for pain interference (i.e., if patients have more interference with activities, the outcome was worse). It is noteworthy that Talo et al ${ }^{58}$ studied different outcome measures and patient groups (e.g., "fit" and "unfit" patients with CLBP), and these results were only found for specific outcome measures and patient groups.

Not predictive for outcome are social status related variables ${ }^{5 ; 27 ; 32 ; 58 ; 70}$. There was one study that found that "better functioning in leisure time" was, in combination with other prognostic factors, predictive for better outcome ${ }^{58}$.

Concerning work related variables $5 ; 27 ; 32 ; 5158 ; 61$, evidence was found for corresponding variables measuring subjective work capacity and experience. The "ability to-" "functioning at-" ${ }^{58}$, "adjustment at-" ${ }^{58}$ and "satisfaction of work" ${ }^{32}$ were all positive predictors for outcome of both treatment methods. The only exception was the variable "ability to work", which showed different predictive values for different treatments or outcome measures 5;27. "Physical strenuousness of the job" consistently lacked predictive value ${ }^{5 ; 32}$, and "vibrations in the job" showed inconsistent results for different treatments ${ }^{5}$.

Sick leave was an inconsistent predictor: a negative predictive value in one study ${ }^{5}$ was not confirmed in another ${ }^{32}$. The variable "compensation" showed comparable results: varying from a negative predictive value ${ }^{51}$, no predictive value ${ }^{61}$, to a positive predictive value ${ }^{27}$ for treatment effect. 


\begin{tabular}{|c|}
\hline regel 2 \\
\hline regel 3 \\
\hline regel 4 \\
\hline regel 5 \\
\hline regel 6 \\
\hline regel 7 \\
\hline regel 8 \\
\hline regel 9 \\
\hline regel 10 \\
\hline regel 11 \\
\hline regel 12 \\
\hline regel 13 \\
\hline regel 14 \\
\hline regel 15 \\
\hline regel 16 \\
\hline regel 17 \\
\hline regel 18 \\
\hline regel 19 \\
\hline regel 20 \\
\hline regel 21 \\
\hline regel 22 \\
\hline regel 23 \\
\hline regel 24 \\
\hline regel 25 \\
\hline regel 26 \\
\hline regel 27 \\
\hline regel 28 \\
\hline regel 29 \\
\hline regel 30 \\
\hline regel 31 \\
\hline regel 32 \\
\hline regel 33 \\
\hline regel 34 \\
\hline regel 35 \\
\hline regel 36 \\
\hline regel 37 \\
\hline regel 38 \\
\hline
\end{tabular}

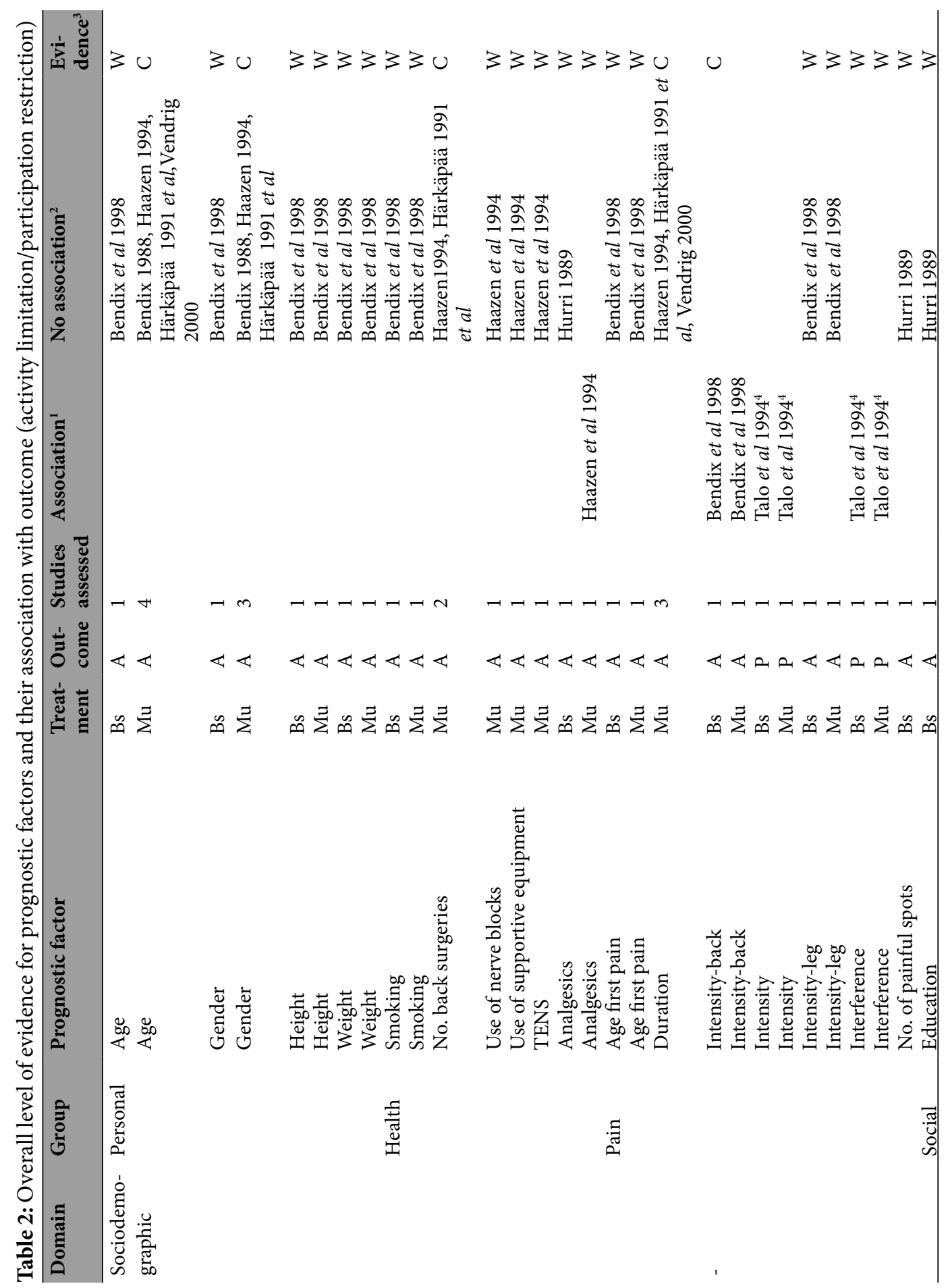


Predictors of multidisciplinary rehabilitation

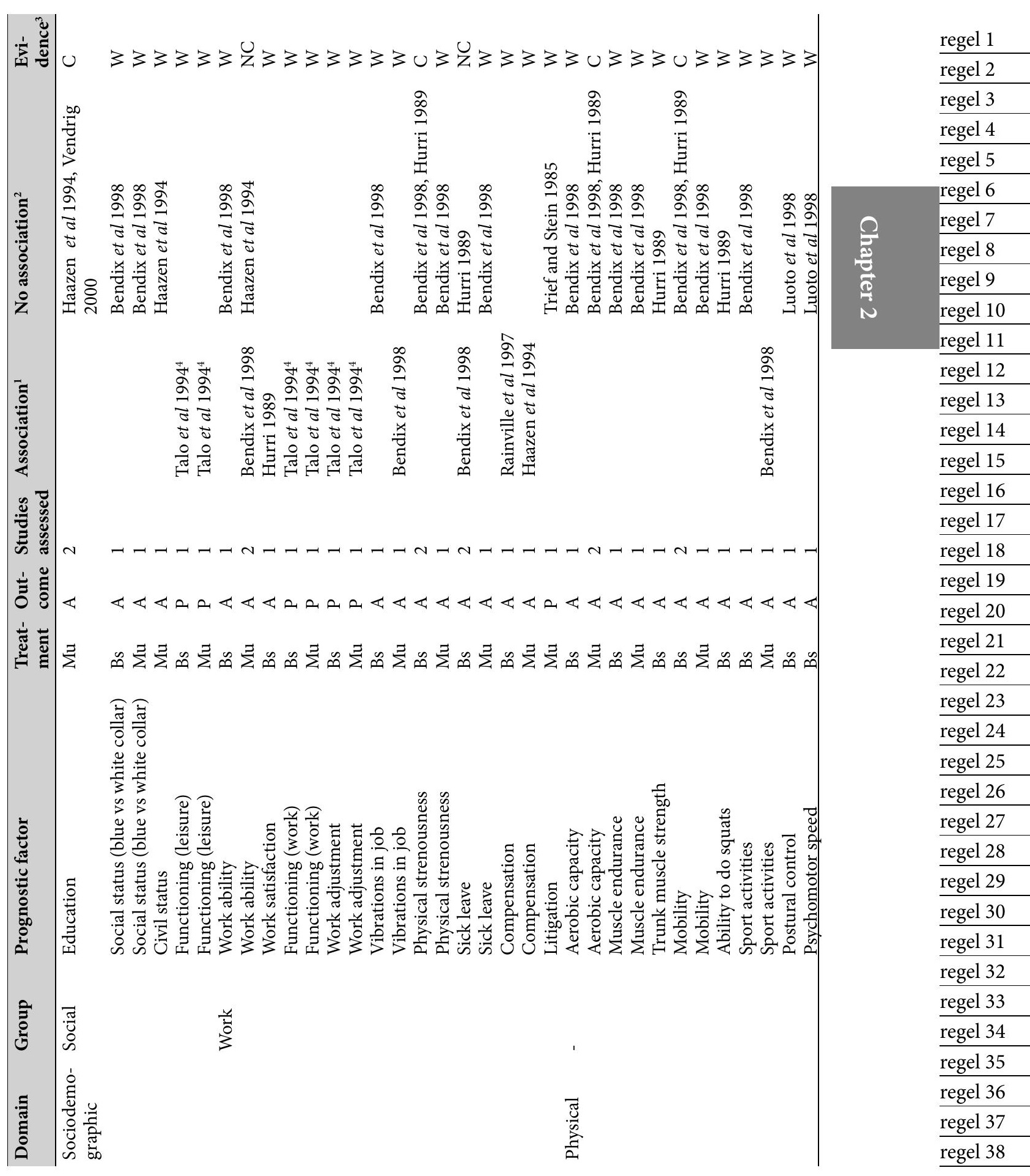


Chapter 2

$\begin{array}{r}\text { regel } 1 \\ \hline \text { regel } 2 \\ \hline \text { regel } 3 \\ \hline \text { regel } 4 \\ \hline \text { regel } 5 \\ \hline \text { regel } 6 \\ \hline \text { regel } 7 \\ \hline \text { regel } 8 \\ \hline \text { regel } 9 \\ \hline \text { regel } 10 \\ \hline \text { regel } 11 \\ \hline \text { regel } 12 \\ \hline \text { regel } 13 \\ \hline \text { regel } 14 \\ \hline \text { regel } 15 \\ \hline \text { regel } 16 \\ \hline \text { regel } 17 \\ \hline \text { regel } 18 \\ \hline \text { regel } 19 \\ \hline \text { regel } 35 \\ \hline \text { regel } 20 \\ \hline \text { regel } 21 \\ \hline \text { regel } 36 \\ \hline \text { regel } 23 \\ \hline \text { regel } 24 \\ \hline \text { regel } 25 \\ \hline \text { regel } 26 \\ \hline \text { regel } 27 \\ \hline \text { regel } 28 \\ \hline \text { regel } 29 \\ \hline \text { regel } 30 \\ \hline \text { regel } 31 \\ \hline \text { regel } 33 \\ \hline \text { regel } \\ \hline \text { regel } \\ \hline \text { regel } \\ \hline \text { regel } \\ \hline \text { regel } \\ \hline \text { regel } \\ \hline \text { regel }\end{array}$

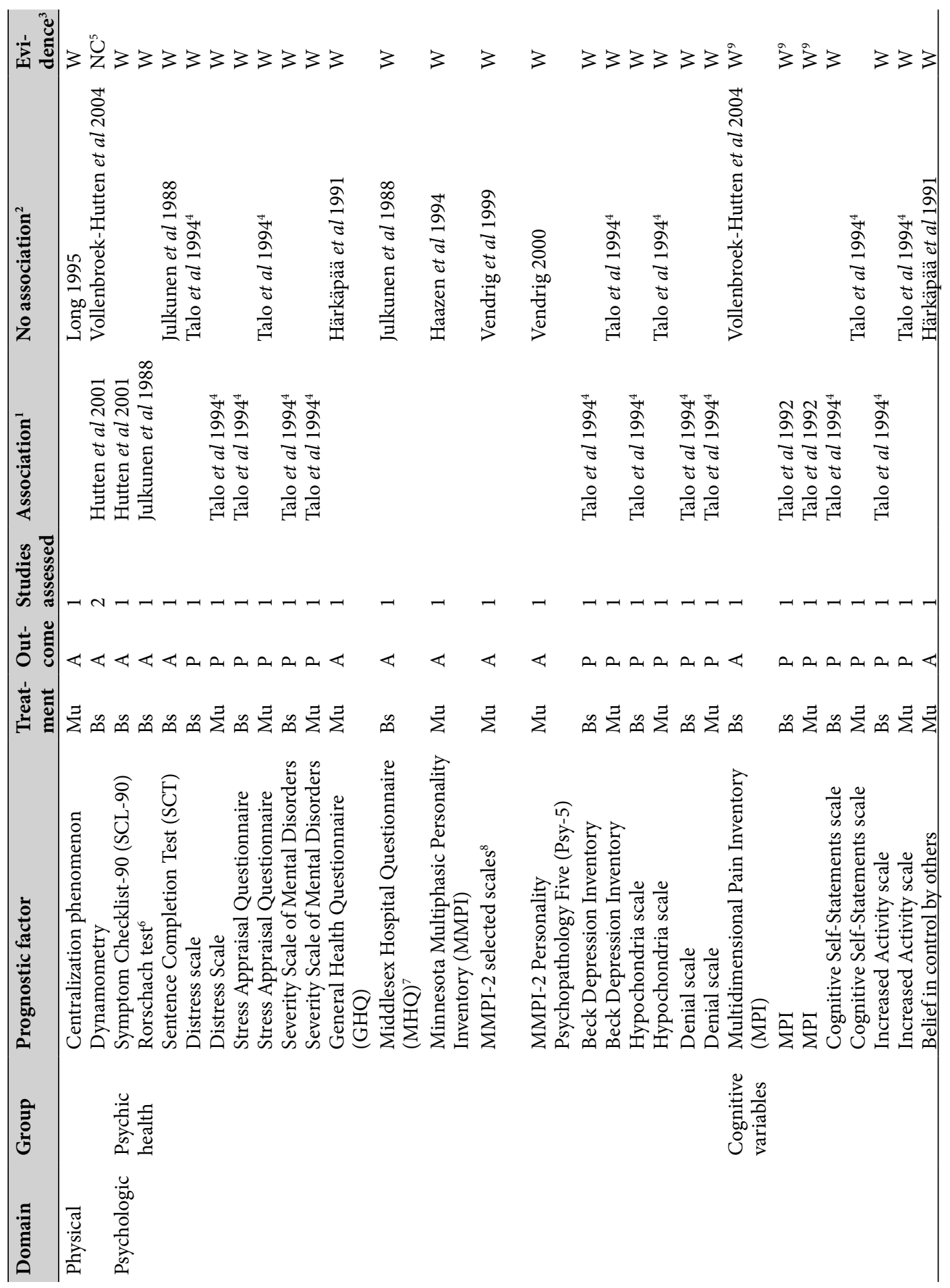


Predictors of multidisciplinary rehabilitation

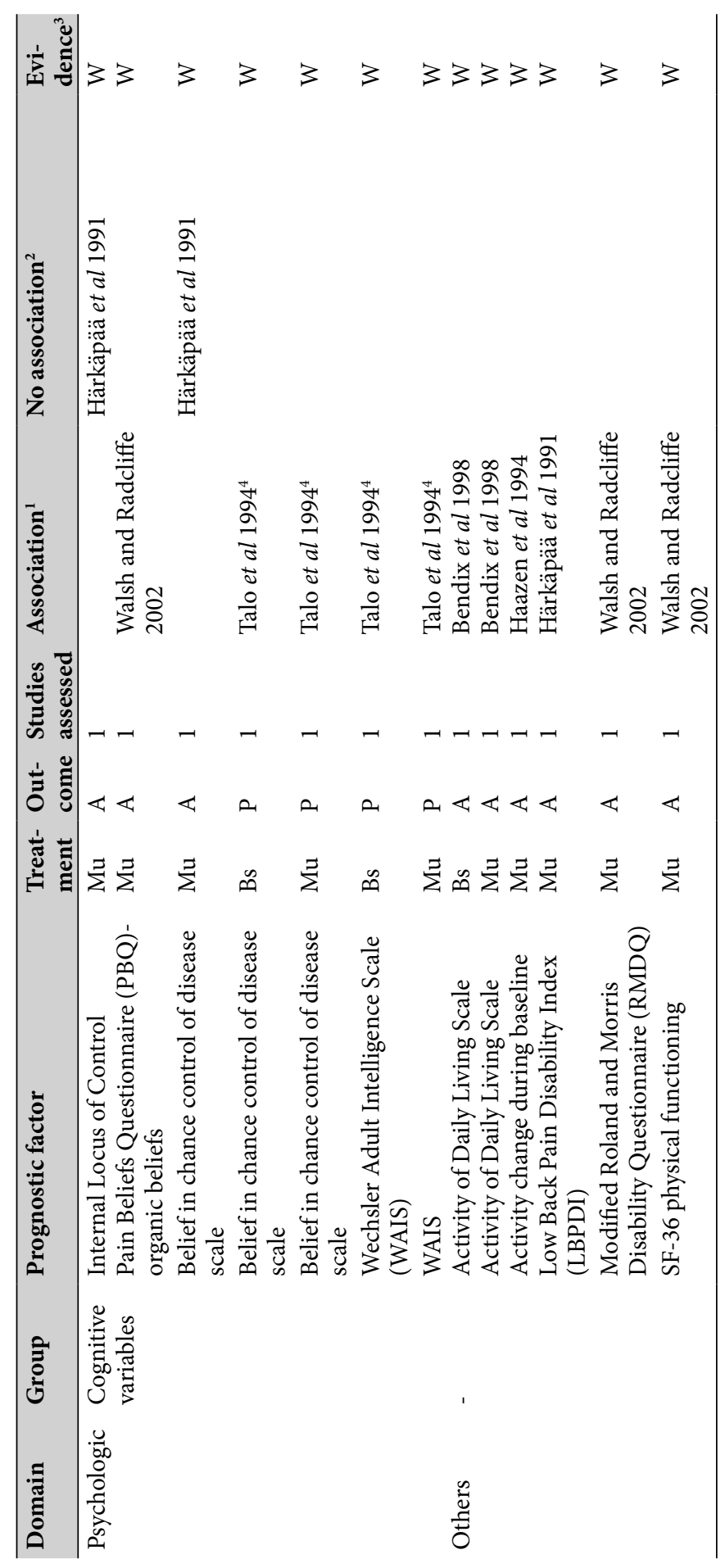

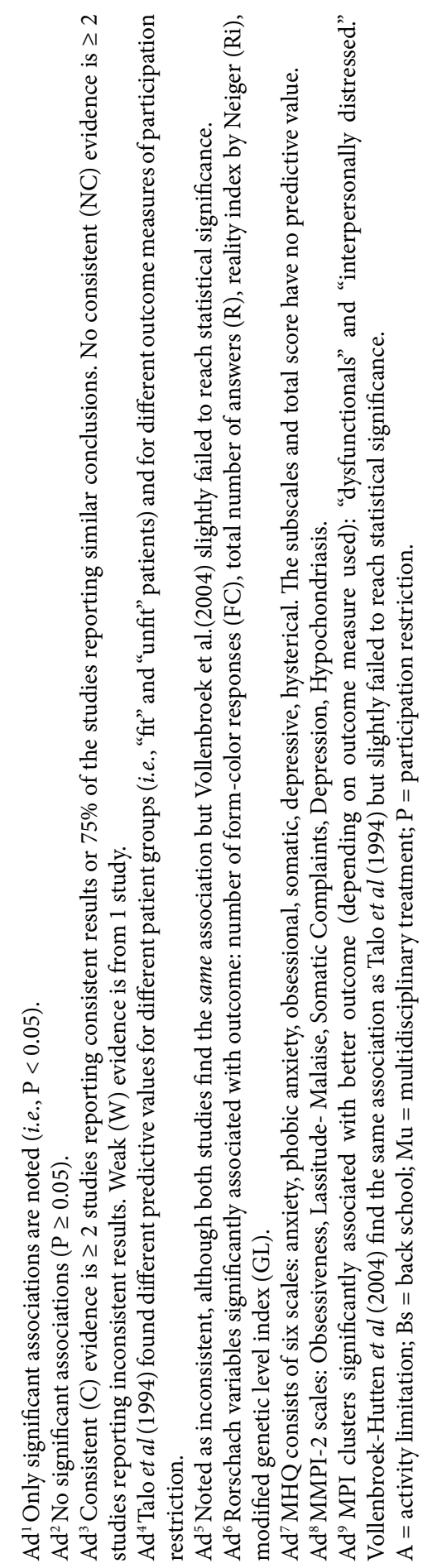

regel 1

regel 2

regel 3

regel 4

regel 5

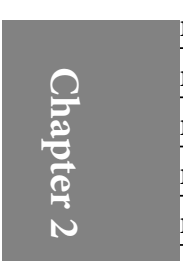

regel 6

regel 7

regel 8

regel 9

regel 10

regel 11

regel 12

regel 13

regel 14

regel 15

regel 16

regel 17

regel 18

regel 19

regel 20

regel 21

regel 22

regel 23

regel 24

regel 25

regel 26

regel 27

regel 28

regel 29

regel 30

regel 31

regel 32

regel 33

regel 34

regel 35

regel 36

regel 37

regel 38 
regel 1

regel 2

regel 3

regel 4

regel 5

regel 6

regel 7

regel 8

regel 9

regel 10

regel 11

regel 12

regel 13

regel 14

regel 15

regel 16

regel 17

regel 18

regel 19

regel 20

regel 21

regel 22

regel 23

regel 24

regel 25

regel 26

regel 27

regel 28

regel 29

regel 30

regel 31

regel 32

regel 33

regel 34

regel 35

regel 36

regel 37

regel 38

\section{Physical predictors}

Physical variables were studied by 7 authors ${ }^{5 ; 32-34 ; 41 ; 44 ; 73}$ and, overall, these were not predictive. Physical variables as strength, endurance, or mobility had no prognostic value ${ }^{5 ; 32 ; 33}$. A trend was found for performance on a dynamometer ${ }^{34 ; 73}$. A dynamometer measures angular position, velocity and torque of the 3 primary movement axes of the back. Patients with an "expected" performance (i.e., lower than healthy subjects but with consistent test behavior) have better outcome following a back school treatment ${ }^{34}$. The same trend was found in another study, although the results were not significant ${ }^{73}$. Postural control, psychomotor speed ${ }^{44}$, or the centralization phenomenon according to Long ${ }^{41}$ were not predictive either. One study found that participation in sports predicted better outcome ${ }^{5}$.

\section{Psychological predictors}

A variety of measures of psychic health and cognitive variables were studied $27: 29 ; 34 ; 36 ; 58 ; 59 ; 70 ; 71 ; 73 ; 74$. No consistent results were found for the predictive value of measures of overall level of psychic health. Psychic health was measured with a variety of scales measuring overall psycho neuroticism. All scales were only studied once, except for the Minnesota Multiphasic Personality Inventory (MMPI), which was included in 3 studies ${ }^{27 ; 70 ; 71}$. The MMPI provides patient profiles of psychopathology by combining scales ${ }^{43}$ and was not associated with treatment success ${ }^{27}$. However, 2 articles used an alternative approach by examining the predictive value of individual scales of the MMPI-2, the successor of the MMPI. Scores on the MMPI-2 "Personality Psychopathology Five Scales" were not associated with outcome either ${ }^{70}$. In another article concerning the same study, the author found that high scores on several other scales of the MMPI-2 (i.e., obsessiveness, depression, hypochondriasis, lassitudemalaise, somatic complaints) were associated with worse outcome ${ }^{71}$, although the explained variance was low, and the results slightly failed to reach statistical significance $(\mathrm{P}<0.06)$.

Other scales, including the Middlesex Hospital Questionnaire (MHQ) ${ }^{36}$, the Sentence Completion Test (SCT) ${ }^{36}$ and the General Health Questionnaire (GHQ) ${ }^{29}$, were not predictive either, with exception of the Symptom Check List $-90^{34}$ and the Rorschach inkblot test ${ }^{36}$. A total score more than 198 on the Symptom Check List -90 was a negative predictor for outcome ${ }^{34}$.The Rorschach inkblot is used as a diagnostic tool for psychiatric diagnoses and for particular psychological symptoms ${ }^{77}$. Several Rorschach variables were associated with better outcome. As the author explained, patients with "good cognitive, intellectual capacity with undisturbed reality testing" were more likely to respond well to treatment ${ }^{36}$.

Although measures of overall psycho neuroticism were studied only once, several aspects of psychic health (i.e., depression, hypochondriasis, and obsessiveness) were studied more frequently. However, consistent results were not found for any of these variables. 
Depression was measured with the Beck Depression Inventory ${ }^{58}$ but also with the MMPI2 scale depression ${ }^{71}$ and the MHQ ${ }^{36}$. One study found that high levels of depression were associated with worse outcome ${ }^{71}$, although the correlations were low and slightly failed to reach statistical significance $(\mathrm{P}<0.06)$. Another study found no association ${ }^{36}$, and Talo et al ${ }^{58}$ showed different results for multidisciplinary or back school treatment. Also, no consistent results were found for the variable "obsessiveness", studied by the MMPI- ${ }^{71}$ and the MHQ ${ }^{36}$. The same was true for hypochondriasis; 2 authors found a negative predictive value ${ }^{58 ; 71}$ and again, Talo et al ${ }^{58}$ found different results for multidisciplinary or back school treatment.

Cognitive related variables, such as coping and beliefs, were studied in 5 articles ${ }^{29 ; 58: 59 ; 73 ; 74}$. The Multidimensional Pain Inventory (MPI) was classified as cognitive variable because one of the measured aspects is coping behavior. However, it may also be classified as a measure of psychic health because it also measures pain-relevant psychosocial aspects ${ }^{42}$.

Although studies included different measures of coping variables, all showed that low levels of active coping skills at baseline were predictive of better outcome ${ }^{58: 59 ; 73}$. Talo ${ }^{59}$ and Vollenbroek ${ }^{73}$ et al used the MPI which showed that patients characterized as "dysfunctional " and "interpersonally distressed" had better outcomes after back school treatment than "adaptive copers" ${ }^{59}$. The results by Vollenbroek et ${ }^{73}$ failed to reach significance due to small subgroups. Patients who are "dysfunctional" and "interpersonally distressed" are both characterized by high psychological distress, pain intensity, and interference with daily activities and low levels of life control. In contrast, "adaptive copers" have relatively low levels of psychological distress, pain intensity, and interference and higher life control. Active coping was also studied by the Cognitive Self-Statements scale and the Increased Activity Scale, with higher scores referring to more active coping ${ }^{58}$. In accordance with aforementioned results, Talo et a $l^{58}$ found that lower active coping skills, measured with the Cognitive Self-Statements scale, were associated with better outcome after back school treatment, although no predictive value was found for multidisciplinary treatment. In general, the Increased Activity Scale had no predictive value, although it was positively associated with the outcome measure "panel assessment" after back school treatment.

Disease related beliefs were studied in 3 articles ${ }^{29 ; 58 ; 74}$, but no consistent results were found, and most variables were only studied once. Different beliefs were measured, like the belief that the disease can be controlled by chance, or by others, or by oneself (internal locus of control). The first 2 variables could also be classified as passive coping strategies and the last as an active coping strategy. Concerning belief in chance, Härkäpää et al ${ }^{29}$ found no predictive value in contrast to Talo et $a^{58}$ who showed that belief in chance was associated with worse outcome after both multidisciplinary and back school treatment. Belief in control by others regel 1

regel 2

regel 3

regel 4

regel 5

regel 6

regel 7

regel 8

regel 9

regel 10

regel 11

regel 12

regel 13

regel 14

regel 15

regel 16

regel 17

regel 18

regel 19

regel 20

regel 21

regel 22

regel 23

regel 24

regel 25

regel 26

regel 27

regel 28

regel 29

regel 30

regel 31

regel 32

regel 33

regel 34

regel 35

regel 36

regel 37

regel 38 
regel 1

regel 2

regel 3

regel 4

regel 5

regel 6

regel 7

regel 8

regel 9

regel 10

regel 11

regel 12

regel 13

regel 14

regel 15

regel 16

regel 17

regel 18

regel 19

regel 20

regel 21

regel 22

regel 23

regel 24

regel 25

regel 26

regel 27

regel 28

regel 29

regel 30

regel 31

regel 32

regel 33

regel 34

regel 35

regel 36

regel 37

regel 38 had no value either ${ }^{29}$. One study found that belief in control of back pain was a positive predictor for better outcome ${ }^{29}$, although it slightly failed to reach statistical significance $(\mathrm{P}<$ 0.059). Finally, strong beliefs in an organic cause of pain (and not a psychological one) were associated with better outcome, although the correlation was low ${ }^{74}$.

Intelligence, which was also classified as a cognitive variable, was studied only once ${ }^{58}$ and showed contradictory results within that study. Intelligence was either positively or negatively associated with outcome, or not associated with outcome at all, depending on the patient groups (those who are "fit" or "unfit") or outcome measure used.

\section{Other predictors}

Different authors included baseline scores of different measurements of activity limitation as predictors of outcome ${ }^{5 ; 27 ; 29 ; 74}$. All showed that high baseline scores predicted higher reduction in scores after treatment. In general, this result implies that patients who have more limitations at baseline will benefit most from treatment. One exception is the physical functioning scale of the Short-Form-36. High baseline scores on this Short-Form-36 scale (i.e., better physical functioning) predicted higher reduction after treatment (i.e., worse outcome) ${ }^{74}$.

\section{Sub analyses and the influence on the level of evidence}

The level of evidence hardly changed if the results were analyzed for Phase I and II studies, or for different subpopulations. In general, evidence became weaker. If only positive findings from Phase II studies ${ }^{5,27 ; 29 ; 44 ; 51 ; 58 ; 70}$ were included (there were no Phase III studies), evidence was limited because less prognostic factors were studied. The prognostic value of "dynamometry" and the "MPI" was not found because the articles that studied these variables were excluded from the analysis ${ }^{34 ; 59 ; 73}$. Furthermore, the inconsistent predictive value of psycho neuroticism scales changed into consistent evidence having no predictive value.

The results were analyzed for the 2 predefined subpopulations, "employees" and "referrals to a rehabilitation center". Only 4 of the 17 studies studied a population of employees ${ }^{29 ; 32333 ; 36}$, so it was not possible to draw conclusions about the overall evidence for this particular subgroup. For referrals to a rehabilitation center, the overall conclusion did not change. 


\section{Discussion}

This systematic review summarizes the results of 17 internal valid studies focusing on the prognostic value of various factors for (back school or multidisciplinary) treatment outcome in patients with CLBP. All studies were classified as Phase I or II (exploring the value of one or more prognostic factors) and none as Phase III (testing a prognostic model). Outcome was measured as activity limitation or participation restriction. Because of heterogeneity in study population, number of prognostic factors, treatment and outcomes, a meta-analysis could not be performed ${ }^{1-3 ; 9 ; 25 ; 54}$, and a qualitative analysis was done to support our final conclusion.

\section{Sociodemographic predictors}

For sociodemographic variables, this study showed no prognostic value for personal, health, and social status related variables. Other reviews confirm that in general, these variables have no value ${ }^{46}$ or will only explain a small portion of the variance in outcome measures ${ }^{30}$. Some reviews show weak evidence of these prognostic variables as conclusions are drawn from only one or 2 included studies ${ }^{20 ; 21: 23 ; 31}$.

The predictive value of pain intensity or interference shown in this study is confirmed by other reviews as well ${ }^{20 ; 21233 ; 3}$. Not only is higher pain intensity related with worse outcome 21:23:30, but higher interference of pain with activities is also associated with reduced treatment success ${ }^{20 ; 23 ; 30}$.

Concerning work related variables, this study showed no consistent evidence for sick leave or receiving compensation. However, other reviews find that both variables are negative predictors for return to work ${ }^{20 ; 30 ; 3152 ; 75}$. Two reviews ${ }^{52 ; 60}$ show that compensation is also associated with reduced treatment response. However, McCracken and Turk ${ }^{46}$ find inconsistent results that they explain by the often unclear definitions used for compensation, what obscures the prognostic role in treatment outcome. This result could also be an explanation for the inconsistency found in this study.

On the other hand, the present study showed a consistent trend that parameters measuring subjective work capacity, like the ability to or adjustment at work, predicted better outcome. This trend is in line with other reviews ${ }^{23 ; 30 ; 46 ; 75}$. In these reviews, the variables "less work disability" ${ }^{20}$, "availability of the job at return" ${ }^{21 ; 30 ; 4}$, and "longer time in the job" ${ }^{21}$ are all related with better outcome. regel 1

regel 2

regel 3

regel 4

regel 5

regel 6

regel 11

regel 12

regel 13

regel 14

regel 15

regel 16

regel 17

regel 18

regel 19

regel 20

regel 21

regel 22

regel 23

regel 24

regel 25

regel 26

regel 27

regel 28

regel 29

regel 30

regel 31

regel 32

regel 33

regel 34

regel 35

regel 36

regel 37

regel 38 
regel 1 regel 2 regel 3 regel 4 regel 5 regel 6 regel 7 regel 8 regel 9 regel 10 regel 11 regel 12 regel 13 regel 14 regel 15 regel 16 regel 17 regel 18 regel 19 regel 20 regel 21 regel 22 regel 23 regel 24 regel 25 regel 26 regel 27 regel 28 regel 29 regel 30 regel 31 regel 32 regel 33 regel 34 regel 35 regel 36 regel 37 regel 38

\section{Physical predictors}

Considering physical variables, this study found no predictive value. This finding is confirmed by other reviews, who show that these variables are of minor importance ${ }^{30 ; 46}$ or find only weak evidence $^{8 ; 21}$.

\section{Psychological predictors}

For psychological variables, this study showed no consistent evidence for overall level of psychic health. Only 2 other reviews looked at overall psycho neuroticism level ${ }^{43: 46}$, and both also concluded that it shows inconsistent predictive value. It is striking that in contrast to current practice, included in 3 studies ${ }^{36 ; 70 ; 71}$, the prognostic value of individual scales of psycho neuroticism (e.g., MMPI-2) is described instead of the overall level of psychopathology.

Looking at the individual aspects of psychic health, our study showed that depression was an inconsistent predictor. This result is in contrast with other reviews showing that depression is a negative predictor. High levels of depression at baseline are associated with worse outcome 20;23;46 and reduction of depressive symptoms is related to better outcome ${ }^{30 ; 46}$. This effect suggests that depressed patients have more to gain from treatment. No clear explanation can be given for the discrepancy between our study and the other reviews.

For cognitive variables, this study concluded that low levels of active coping at baseline were related to better outcome. This result was reflected by the fact that patients, classified by the MPI as "dysfunctionals" or "interpersonally distressed", benefit more from treatment than "adaptive copers". These findings are in accordance with Turk and Okifuji ${ }^{64}$, who reviewed studies using the MPI classification and found comparable results. It could be that patients with poor functional profiles ("dysfunctionals" and "interpersonally distressed") benefit more from treatment than "adaptive copers", who have less to gain. Treatment helps the first group reducing distress and improving adequate coping skills. This hypothesis agrees with another review, which shows that adoption of a more active self-management orientation to pain is associated with better treatment outcome ${ }^{46}$.

Our results that "dysfunctionals" and "interpersonally distressed" (both with high levels of pain and low perceived life control) are likely to benefit from treatment may seem contradictory with our finding that higher pain intensity and interference predicts worse outcome. However, the MPI defines subgroups based on multiple aspects of chronic pain ${ }^{23 ; 64}$. It is possible that the predictive value of pain intensity and interference varies with coping ability. In that case, patients with low perceived life control may benefit from treatment despite the high level of pain intensity. It could be that coping with pain is a more important prognostic factor than pain intensity alone. 
We could not draw conclusions regarding the value of disease related beliefs because most authors studied different measures of beliefs. Only "belief in chance control of disease" was studied twice ${ }^{29 ; 58}$, showing inconsistent results. However, both articles differed in outcome measure and population studied, which may explain the inconsistency. Other reviews show consistent results that maladaptive beliefs (e.g., catastrophizing) are associated with poor outcome and stronger beliefs in control with better outcome ${ }^{30 ; 4}$.

\section{Other predictors}

Our results showed that a high level of perceived disability at baseline was related to better outcome, which is in contrast with other studies showing it to be associated with worse outcome 20:23;30:46. An explanation for our results could be that it is a reflection of the phenomenon "regression to the mean". Or, it is possible that persons which high levels of activity limitation "have more to gain" with treatment, which leads to better outcome ${ }^{40}$. It was shown before that a decrease in perceived disability during treatment is related with treatment success ${ }^{46}$.

\section{Limitations and recommendations}

Several limitations of this review must be considered. First, publication bias cannot be excluded ${ }^{17}$. Second, the review process must be considered. It is known that the risk of missing prognostic studies because of difficulties searching the literature is higher than for randomized trials ${ }^{1}$. Third, the criteria and operationalization list we used for quality assessment is subject for debate because a generally accepted criteria list for assessing prognostic studies does not exist yet. However, the used criteria were based on frequently used checklists, thus, it is unlikely that relevant criteria would have been missed. General consensus of a methodological criteria list for prognostic studies is needed. We recommend, in accordance with Altman ${ }^{2}$ and Scholten-Peeters et al ${ }^{53}$, to include the following criteria in this list: identified population (criterion 2), defined inclusion and exclusion criteria (criterion 3), valid and reliable measurements of prognostic (criterion 8) and outcome variables (criterion 15), explicitly described and standardized intervention (criterion 12), drop outs acceptable (criteria 5+17), follow-up sufficiently long (criterion 19), appropriate analysis (criterion 21), and adjustment for important prognostic factors. Finally, evidence was limited because there were only 2 prognostic cohorts studying the exact same prognostic factors, intervention and outcome measures ${ }^{34 ; 73}$. However, we could draw general conclusions about prognostic variables from comparable domains for certain types of intervention and outcome measures.

To facilitate future prognostic studies of treatment outcome, 2 things are important. Future research is necessary to confirm the generated hypotheses derived from the descriptive (Phase I) and exploratory (Phase II) studies. In the current literature, there is a lack of confirmatory (Phase III) studies, which study a priori stated hypotheses of the value of a set of prognostic regel 1

regel 2

regel 3

regel 4

regel 5

regel 6

regel 7

regel 8

regel 9

regel 10

regel 11

regel 12

regel 13

regel 14

regel 15

regel 16

regel 17

regel 18

regel 19

regel 20

regel 21

regel 22

regel 23

regel 24

regel 25

regel 26

regel 27

regel 28

regel 29

regel 30

regel 31

regel 32

regel 33

regel 34

regel 35

regel 36

regel 37

regel 38 
regel 1

regel 2

regel 3

regel 4

regel 5

regel 6

regel 7

regel 8

regel 9 regel 10

regel 11

regel 12

regel 13

regel 14

regel 15

regel 16

regel 17

regel 18

regel 19

regel 20

regel 21

regel 22

regel 23

regel 24

regel 25

regel 26

regel 27

regel 28

regel 29

regel 30

regel 31

regel 32

regel 33

regel 34

regel 35

regel 36

regel 37

regel 38 markers ${ }^{13}$. Besides understanding which prognostic factors predict outcome of treatment, insight in treatment process variables should be improved. This result will help to understand why and how specific prognostic factors are associated with treatment outcome. The knowledge of treatment process variables will enable the development of adequate treatment modules matched to specific patient characteristics, with different prognoses. It is assumed that tailoring different interventions to different subgroups of patients will enhance treatment effects ${ }^{64}$.

\section{Conclusion and clinical implications}

In addition to the physician experience, knowledge of prognostic factors may be very useful (i.e., patients with favorable prognostic factors are likely to benefit from treatment and those with unfavorable prognostic factors are not). It is likely that defining subgroups of patients may have to be based on multiaxial assessment of functioning because it is shown that prognostic factors from several domains are of value for predicting outcome. However, a generic set of predictors of outcome in multidisciplinary rehabilitation and back school for patients with CLBP cannot be defined.

With caution, several guidelines based on several consistent predictive factors of rehabilitation outcome in patients with nonspecific CLBP may be given. Physicians seeing patients with high pain intensity, problems at work (e.g., functioning at work, dissatisfaction) should be aware that these patients are likely to have poor treatment outcome. In addition, the low use of active coping skills and high perceived limitations of activity at baseline may predict better treatment outcome. Other sociodemographic and physical variables probably should not play a role in the treatment decision because these consistently lacked predictive values. The value of other psychological variables is not clear because no consistent evidence was found.

\section{Acknowledgement}

The authors thank the Joris Foundation for its financial support. 


\section{Key points}

regel 1

regel 2

- The evidence of prognostic factors for multidisciplinary and back school treatment outcome in patients with CLBP has been reviewed systematically by examination of prospective studies.

- Conclusions were based on seventeen internally valid studies, which all explored the value of prognostic factors (Phase I or II), and none tested a prognostic model (Phase III).

- Study heterogeneity necessitated a qualitative summary of the results and limited evidence.

- Pain intensity, several work-related parameters, and coping style were consistently associated with outcome. Other sociodemographic and physical variables consistently showed no association with outcome. No consistent evidence was found for the predictive value of other psychological variables.

- Future confirmatory studies of prognostic factors and studies of treatment process variables may lead to improved interventions and higher treatment success. regel 3

regel 4

regel 5

regel 6 
regel 1

regel 2

regel 3

regel 4

regel 5

regel 6

regel 7

regel 8

regel 9

regel 10

regel 11

regel 12

regel 13

regel 14

regel 15

regel 16

regel 17

regel 18

regel 19

regel 20

regel 21

regel 22

regel 23

regel 24

regel 25

regel 26

regel 27

regel 28

regel 29

regel 30

regel 31

regel 32

regel 33

regel 34

regel 35

regel 36

regel 37

regel 38

\section{References}

1. Altman DG. Systematic reviews of evaluations of prognostic variables. In: Egger M, Davey Smith G, Altman DG, eds. Systematic reviews in health care. Meta-analysis in context. London: BMJ Publishing Group, 2001:228-47.

2. Altman DG. Systematic reviews of evaluations of prognostic variables. BMJ 2001;323:224-8.

3. Altman DG and Lyman GH. Methodological challenges in the evaluation of prognostic factors in breast cancer. Breast Cancer Res Treat 1998;52:289-303.

4. Assendelft WJ, van Tulder MW, Scholten RJ, and Bouter LM. [The practice of systematic reviews. II. Searching and selection of studies]. Ned Tijdschr Geneeskd 1999;143:656-61.

5. Bendix AF, Bendix T, and Haestrup C. Can it be predicted which patients with chronic low back pain should be offered tertiary rehabilitation in a functional restoration program? A search for demographic, socioeconomic, and physical predictors. Spine 1998;23:1775-83; discussion 17834.

6. Bergstrom G, Jensen IB, Bodin L, Linton SJ, Nygren AL. The impact of psychologically different patient groups on outcome after a vocational rehabilitation program for long-term spinal pain patients. Pain 2001; 93: 229-37.

7. Blake, C. and Garrett, M. Impact of litigation on quality of life outcomes in patients with chronic low back pain. Ir J Med Sci 1997;166:124-126.

8. Borge JA, Leboeuf-Yde C, and Lothe J. Prognostic values of physical examination findings in patients with chronic low back pain treated conservatively: a systematic literature review. J Manipulative Physiol Ther 2001;24:292-5.

9. Buettner P, Garbe C, and Guggenmoos-Holzmann I. Problems in defining cutoff points of continuous prognostic factors: example of tumor thickness in primary cutaneous melanoma. J Clin Epidemiol 1997;50:1201-10.

10. Carmody TP. Psychosocial subgroups, coping, and chronic low-back pain. Journal of Clinical Psychology in Medical Settings 2001; 8:137-148.

11. Clarke M, Oxman AD. Collecting data. Cochrane Reviewers Handbook [updated April 2002]; Section 5. In: The Cochrane Library, Issue 2, 2002. Oxford: Update software. Updated quarterly.

12. Cochrane Collaboration. Etiology and prognosis: critical appraisal form for observational studies.[Cochrane Collaboration web site.]Available at: http://www.cochrane.dk/nrsmg. Accessed August 1, 2002.

13. Côté P, Cassidy JD, Carroll L, Frank JW, Bombardier C. A systematic review of the prognosis of acute whiplash and a new conceptual framework to synthesize the literature. Spine 2001;26:E44558 .

14. Crook J, Milner R, Schultz IZ, and Stringer B. Determinants of occupational disability following a low back injury: a critical review of the literature. J Occup Rehabil 2002;12:277-95.

15. Di Fabio RP. Efficacy of comprehensive rehabilitation programs and back school for patients with low back pain: a meta-analysis. Physical Therapy 1995;75:865-78.

16. Dozois DJA, Dobson KS, Wong M, Hughes D, Long, A. Predictive utility of the CSQ in low back pain: Individual vs. composite measures. Pain 1996; 66:171-80.

17. Easterbrook PJ, Berlin JA, Gopalan R, and Matthews DR. Publication bias in clinical research. Lancet 1991;337:867-72.

18. Faas A. Exercises: which ones are worth trying, for which patients, and when? Spine 1996;21:28748; discussion 2878-9.

19. Faas A, Chavannes AW, Koes BW, van den Hoogen JMM, Mens JMA, Smeele LJM, Romeijnders ACM, van der Laan, JR. NHG-Standaard Lage-Rugpijn. Huisarts en Wetenschap 1996;39:18-31.

20. Feuerstein M, Beattie P. Biobehavioral factors affecting pain and disability in low back pain: mechanisms and assessment. Phys Ther 1995;75:267-80.

21. Feuerstein M, Menz L, Zastowney TR, Barron B. Chronic pain and disability: Vocational outcomes following multidisciplinary rehabilitation. J Occup Rehabil 1994;4:229-251.

22. Gatchel RJ. A biopsychosocial overview of pretreatment screening of patients with pain. Clin J Pain 2001;17:192-9. 
23. Gatchel RJ and Gardea MA. Psychosocial issues: their importance in predicting disability, response to treatment, and search for compensation. Neurol Clin 1999;17:149-66.

24. Gatchel RJ, Noe CE, Pulliam C et al. A preliminary study of multidimensional pain inventory profile differences in predicting treatment outcome in a heterogeneous cohort of patients with chronic pain. Clin J Pain 2002;18:139-43.

25. Greener J and Langhorne P. Systematic reviews in rehabilitation for stroke: issues and approaches to addressing them. Clin Rehabil 2002;16:69-74.

26. Guzman J, Esmail R, Karjalainen K, Malmivaara A, Irvin E, and Bombardier C. Multidisciplinary rehabilitation for chronic low back pain: systematic review. BMJ 2001;322:1511-6.

27. Haazen IWCJ, Vlaeyen JWS, Kole-Snijders AMJ, van Eek H, van Es FD. Behavioral rehabilitation of chronic low back pain: searching for predictors of treatment outcome. Journal of Rehabilitation Sciences 1994:34-43.

28. Härkäpää, K, Järvikoski, A., and Estlander, A. M. Health optimism and control beliefs as predictors for treatment outcome of a multimodal back treatment program. Psychology and Health 12, 123-134. 96.

29. Harkapaa K, Jarvikoski A, Mellin G, Hurri H, and Luoma J. Health locus of control beliefs and psychological distress as predictors for treatment outcome in low-back pain patients: results of a 3-month follow-up of a controlled intervention study. Pain 1991;46:35-41.

30. Hasenbring, M. Predictors of efficacy of treatment in chronic low back pain. Current Opinion in Anaesthesiology 1998;11:553-58.

31. Hunter, J. Medical history and chronic pain. Clin J Pain 2001;17:S20-S25.

32. Hurri H. The Swedish back school on chronic low back pain II: Part II. Factors predicting the outcome. Scand J Rehabil Med 1989;21:41-4.

33. Hurri H, Mellin G, Korhonen O, Harjula R, Harkapaa K, Luoma J. Aerobic capacity among chronic low-back-pain patients. J Spinal Disord 1991;4:34-8.

34. Hutten MM, Hermens HJ, Zilvold G. Differences in treatment outcome between subgroups of patients with chronic low back pain using lumbar dynamometry and psychological aspects. Clin Rehabil 2001;15:479-88.

35. Jensen IB, Bodin L, Ljungqvist T, Gunnar Bergstrom K, and Nygren A. Assessing the needs of patients in pain: a matter of opinion? Spine 2000;25:2816-23.

36. Julkunen J, Hurri H, and Kankainen J. Psychological factors in the treatment of chronic low back pain. Follow-up study of a back school intervention. Psychother Psychosom 1988;50:173-81.

37. Karjalainen K, Malmivaara A, van Tulder M et al. Multidisciplinary biopsychosocial rehabilitation for subacute low back pain in working-age adults: a systematic review within the framework of the Cochrane Collaboration Back Review Group. Spine 2001;26:262-9.

38. Koes BW, van Tulder MW, van der Windt DAWM, Bouter LM. The efficacy of back schools: a review of randomized clinical trials. J Clin Epidemiol 1994;47:851-62.

39. Kwakkel G, Wagenaar RC, Kollen BJ, and Lankhorst GJ. Predicting disability in stroke--a critical review of the literature. Age Ageing 1996;25:479-89.

40. Lofland KR, Burns JW, Tsoutsouris J, Maird MM, Blonsky ER, Hejna WF. Predictors of outcome following multidisciplinary treatment of chronic pain: Effects of changes in perceived disability and depression. International Journal of Rehabilitation and Health 1997;3:221-32.

41. Long AL. The centralization phenomenon. Its usefulness as a predictor or outcome in conservative treatment of chronic low back pain (a pilot study). Spine 1995;20:2513-20; discussion 2521.

42. Lousberg R, Van Breukelen GJ, Groenman NH, Schmidt AJ, Arntz A, and Winter FA. Psychometric properties of the Multidimensional Pain Inventory, Dutch language version (MPIDLV). Behav Res Ther 1999;37:167-82.

43. Love AW and Peck CL. The MMPI and psychological factors in chronic low back pain: a review. Pain 1987;28:1-12.

44. Luoto S, Taimela S, Alaranta H, Hurri H. Psychomotor speed and postural control in chronic low-back pain patients and healthy controls: determinants and predictive value for functional restoration outcome. European Journal of Physical Medicine and Rehabilitation 1998; 8:81-86.

45. Mannion AF, Müntener M, Taimela S, Dvorak J. A randomized clinical trial of three active therapies for chronic low back pain. Spine 1999;24:2435-48. 
regel 1

regel 2

regel 3

regel 4

regel 5

regel 6

regel 7

regel 8

regel 9

regel 10

regel 11

regel 12

regel 13

regel 14

regel 15

regel 16

regel 17

regel 18

regel 19

regel 20

regel 21

regel 22

regel 23

regel 24

regel 25

regel 26

regel 27

regel 28

regel 29

regel 30

regel 31

regel 32

regel 33

regel 34

regel 35

regel 36

regel 37

regel 38

46. McCracken LM and Turk DC. Behavioral and cognitive-behavioral treatment for chronic pain: outcome, predictors of outcome, and treatment process. Spine 2002;27:2564-73.

47. Nentwig CG. Effectiveness of the back school. A review of the results of evidence-based evaluation. Orthopade 1999;28:958-65.

48. O'Farrell V, Tate N, Aitken C. Attitudes and prognosis in chronic low back pain. J Psychosom Res 1993;37: 415-22.

49. Peebles JE, Moore RJ. Illness schemata in patients with low back pain: Predictions of rehabilitation success. Pain Clinic 2000;12:237-46.

50. Pincus T, Burton AK, Vogel S, and Field AP. A systematic review of psychological factors as predictors of chronicity/disability in prospective cohorts of low back pain. Spine 2002;27:E10920.

51. Rainville J, Sobel J, Hartigan C, Wright A. The effect of compensation involvement on the reporting of pain and disability by patients referred for rehabilitation of chronic low back pain. Spine 1997;22:2016-24.

52. Rohling ML, Binder LM, Langinrichsen-Rohling J. Money matters: A meta-analytic review of the association between financial compensation and the experience and treatment of chronic pain. Health Psychol 1995;14:537-47.

53. Scholten-Peeters GG, Verhagen AP, Bekkering GE et al. Prognostic factors of whiplash-associated disorders: a systematic review of prospective cohort studies. Pain 2003;104:303-22.

54. Scholten RJ, Assendelft WJ, Kostense PJ, and Bouter LM. [The practice of systematic reviews. V. Heterogeneity between studies and subgroup analysis]. Ned Tijdschr Geneeskd 1999;143:843-8.

55. Schonstein E, Kenny DT, Keating J, and Koes BW. Work conditioning, work hardening and functional restoration for workers with back and neck pain. Cochrane Database Syst Rev 2003;CD001822.

56. Strategier LD, Chwalisz K, Altmaier EM. Multidimensional assessment of chronic low back pain: predicting treatment outcomes. Journal of Clinical Psychology in Medical Settings 1997;4: 91110 .

57. Talo S, Forssell H, Heikkonen S, Puukka P. Integrative group therapy outcome related to psychosocial characteristics in patients with chronic pain. Int J Rehabil Res 2001;24:25-33.

58. Talo S, Puukka P, Rytokoski U, Ronnemaa T, Kallio V. Can treatment outcome of chronic low back pain be predicted? Psychological disease consequences clarifying the issue. Clin J Pain 1994;10:107-21.

59. Talo S, Rytokoski U, Puukka P. Patient classification, a key to evaluate pain treatment: a psychological study in chronic low back pain patients. Spine 1992;17:998-1011.

60. Teasell RW. Compensation and chronic pain. Clin J Pain 2001;17:S46-64.

61. Trief P, Stein N. Pending litigation and rehabilitation outcome of chronic back pain. Arch Phys Med Rehabil 1985;66: 95-9.

62. Truchon M. Determinants of chronic disability related to low back pain: towards an integrative biopsychosocial model. Disabil Rehabil 2001;23:758-67.

63. Turk DC. Customizing treatment for chronic pain patients: who, what, and why. Clin J Pain 1990;6:255-70.

64. Turk DC, Okifuji A. Directions in prescriptive chronic pain management based on diagnostic characteristics of the patient. American Pain Society Bulletin 1998. Available at: http://www. ampainsoc.org/pub/bulletin /sep98 /resupdate.htm. Accessed August 15, 2002.

65. Turk DC, Rudy TE. Towards an empirically derived taxonomy of chronic pain patients: Integration of psychological assessment data. J Consult Clin Psychol 1988;56:233-38.

66. van der Windt DA, Zeegers MP, Kemper HC, Assendelft WJ, and Scholten RJ. Practice of systematic reviews. VI. Searching, selection and methodological evaluation of etiological research]. Ned Tijdschr Geneeskd 2000;144:1210-4.

67. van Tulder M, Malmivaara A, Esmail R, and Koes B. Exercise therapy for low back pain: a systematic review within the framework of the cochrane collaboration back review group. Spine 2000;25:2784-96. 
68. van Tulder MW, Assendelft WJ, Koes BW, and Bouter LM. Method guidelines for systematic reviews in the Cochrane Collaboration Back Review Group for Spinal Disorders. Spine 1997;22:2323-30.

69. van Tulder MW, Ostelo R, Vlaeyen JW, Linton SJ, Morley SJ, and Assendelft WJ. Behavioral treatment for chronic low back pain: a systematic review within the framework of the Cochrane Back Review Group. Spine 2001;26:270-81.

70. Vendrig AA. MMPI-2 Personality Psychopathology Five (PSY-5) and prediction of treatment outcome for patients with chronic back pain. J Pers Assess 2000;74:423-38.

71. Vendrig AA, Derksen JJL, de Mey HR. Utility of selected MMPI-2 scales in the outcome prediction for patients with chronic back pain. Psychol Assess 1999;11:381-85.

72. Vlaeyen JW and Linton SJ. Fear-avoidance and its consequences in chronic musculoskeletal pain: a state of the art. Pain 2000;85:317-32.

73. Vollenbroek-Hutten MM, Hermens HJ, Wever D, Gorter M, Rinket J, and Ijzerman MJ. Differences in outcome of a multidisciplinary treatment between subgroups of chronic low back pain patients defined using two multiaxial assessment instruments: the multidimensional pain inventory and lumbar dynamometry. Clin Rehabil 2004;18:566-79.

74. Walsh DA, Radcliffe JC. Pain beliefs and perceived physical disability of patients with chronic low back pain. Pain 2002; 97:23-31.

75. Walsh NE and Dumitru D. The influence of compensation on recovery from low back pain. Occup Med 1988;3:109-21.

76. Weiser S, Cedraschi C. Psychosocial issues in the prevention of chronic low back pain: a literature review. Baiilieres Clin Rheumatol 1992;6:657-84.

77. Wood JM, Lilienfeld SO, Garb HN, and Nezworski MT. The Rorschach test in clinical diagnosis: a critical review, with a backward look at Garfield (1947). J Clin Psychol 2000;56:395-430; discussion 431-4.

78. World Health Organization. International Classification of Functioning, Disability and Health. ICF checklist. 2001. [World Health Organisation web site]. Available at: http://www3.who.int/ icf/icftemplate.cfm. Accessed August 1, 2002.

regel 1

regel 2

regel 3

regel 4

regel 5

regel 6

regel 8

regel 9

regel 10

regel 11

regel 12

regel 13

regel 14

regel 15

regel 16

regel 17

regel 18

regel 19

regel 20

regel 21

regel 22

regel 23

regel 24

regel 25

regel 26

regel 27

regel 28

regel 29

regel 30

regel 31

regel 32

regel 33

regel 34

regel 35

regel 36

regel 37

regel 38 
regel 1

regel 2

regel 3

regel 4

regel 5

regel 6

regel 7

regel 8

regel 9

regel 10

regel 11

regel 12

regel 13

regel 14

regel 15

regel 16

regel 17

regel 18

regel 19

regel 20

regel 21

regel 22

regel 23

regel 24

regel 25

regel 26

regel 27

regel 28

regel 29

regel 30

regel 31

regel 32

regel 33

regel 34

regel 35

regel 36

regel 37

regel 38

\section{Appendix 1}

\section{Criteria list for methodological quality assessment}

1. The research question is well stated

Patient selection:

2. The population is well identified $\left({ }^{*}\right)$

3. The inclusion and exclusion criteria are defined and appropriate $\left(^{*}\right)$

4. For RCT: treatment allocation

a) Was a method of randomization performed?

b) Was the treatment allocation concealed?

5. Participation rate is reported and appropriate $\left(^{*}\right)$

6. Are all subjects representative of the same underlying population?

7. Are the various groups comparable at baseline?

\section{Prognostic factors:}

8. The methods used to measure the baseline prognostic variables are valid and reliable $\left.{ }^{*}\right)$

9. The prognostic factor(s) is (are) measured in a standardized way

10. Other relevant prognostic factors are measured

Interventions:

11. Additional treatment effects during period of observation are avoided or comparable

12. The intervention(s) is (are) explicitly described

13. The compliance is acceptable in all groups

Outcome measurement:

14. The same data collection is used for all members of the cohort

15. The methods used to measure the outcome are defined and measurable $\left(^{*}\right)$

16. The methods used to measure the outcome are valid and reliable $\left(^{\star}\right)$

17. \% Follow-up is reported, explained, and reasonable $\left(^{*}\right)$

18. Loss to follow-up is equal in different groups

19. The duration of follow-up is adequate

a) Was a short-term follow-up measurement performed?

b) Was a long-term follow-up measurement performed?

Statistics:

20. The sample size provides adequate statistical power

21. Was the statistical methodology appropriate for the research question and study design?

22. An intention-to-treat analysis is performed

23. Control for statistical significance

24. Control for multicollinearity

25. The results are verifiable from the data 


\section{General:}

26. Was bias or random error likely to have been avoided? $\left(^{*}\right)$

ad $\left({ }^{*}\right)$ criteria of internal validity

regel 1

regel 2

regel 3

regel 4

regel 5

regel 6

\section{Appendix 2}

\section{Internal validity criteria}

- The source population was well identified (criterion 2)

- Inclusion and exclusion criteria were defined and appropriate (criterion 3)

- The methods used to measure the prognostic factors were valid and reliable (criterion 8)

- The outcome was well defined and measurable (criterion 15)

- The measures of outcome were valid and reliable (criterion 16)

- The participation rate and percentage follow-up was reported and appropriate (together at least $60 \%$ ), or a comparative analysis of participants and non participants was presented (criteria 5+17)

- Was bias or random error likely to have been avoided? (criterion 26)

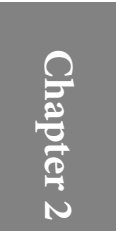

regel 7

regel 8

regel 9

regel 10

regel 11

regel 12

regel 13

regel 14

regel 15

regel 16

regel 17

regel 18

regel 19

regel 20

regel 21

regel 22

regel 23

regel 24

regel 25

regel 26

regel 27

regel 28

regel 29

regel 30

regel 31

regel 32

regel 33

regel 34

regel 35

regel 36

regel 37

regel 38 
regel 1

regel 2

regel 3

regel 4

regel 5

regel 6

regel 7

regel 8

regel 9

regel 10

regel 11

regel 12

regel 13

regel 14

regel 15

regel 16

regel 17

regel 18

regel 19

regel 20

regel 21

regel 22

regel 23

regel 24

regel 25

regel 26

regel 27

regel 28

regel 29

regel 30

regel 31

regel 32

regel 33

regel 34

regel 35

regel 36

regel 37

regel 38 


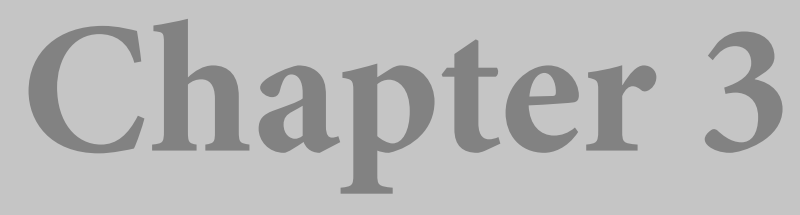

Multidisciplinary rehabilitation treatment of patients with chronic low back pain: a prognostic model for its outcome

Marije van der Hulst, Miriam MR Vollenbroek-Hutten, Karin GM Groothuis-Oudshoorn, Hermie J Hermens

Clin J Pain 2008;24:421-430 
Chapter 3

regel 1

regel 2

regel 3

regel 4

regel 5

regel 6

regel 7

regel 8

regel 9

regel 10

regel 11

regel 12

regel 13

regel 14

regel 15

regel 16

regel 17

regel 18

regel 19

regel 20

regel 21

regel 22

regel 23

regel 24

regel 25

regel 26

regel 27

regel 28

regel 29

regel 30

regel 31

regel 32

regel 33

regel 34

regel 35

regel 36

regel 37

regel 38

\begin{abstract}
Objectives: (1) To determine if treatment outcome in chronic low back pain can be predicted by a predefined multivariate prognostic model based on consistent predictors from literature and (2) to explore the value of potentially prognostic factors further.

Methods: Data were derived from a randomized controlled trial on the effect of a multidisciplinary rehabilitation program for chronic low back pain compared with usual care. The primary outcome measure was the Roland and Morris Disability Questionnaire and secondary outcomes were the Physical and Mental Component Summary Scales, derived from the Short Form Health Survey. Outcomes were expressed as the differences between baseline and follow-up ( $8 \mathrm{wk}$ and $6 \mathrm{mo}$ ) values. A confirmatory and an exploratory model were defined. Baseline predictors included in the confirmatory model were pain intensity, work status, and Multidimensional Pain Inventory subgroup membership. The exploratory model included sick leave, compensation, depression, and fear-avoidance beliefs. Statistical analysis was performed using multiple linear regression analysis.
\end{abstract}

Results: One hundred and sixty-three patients participated in the study. More pain was prognostic for more improvement in the rehabilitation group. No value was found for work status or the Multidimensional Pain Inventory subgroups. For the exploratory model, more depression and fear-avoidance beliefs predicted more improvement following rehabilitation. The explained variance ranged from $18.5 \%$ to $43.8 \%$ depending on the length of follow-up evaluation, the treatment group, and the outcome variable of interest.

Conclusions: The results of this study do not support the construction of a clinical prediction model. Future confirmative studies of homogeneous rehabilitation treatments and outcome measures are needed to shed more light on relevant prognostic factors. 


\section{Introduction}

The chronic low back pain (CLBP) population is a heterogeneous one. Various treatment programs exist and it is obvious that 1 treatment does not fit all. Understanding of the factors that predict treatment outcome is important, and may enable clinicians to better select patients for the most suitable treatment modality.

There is a large research literature base concerning predictors of rehabilitation outcome in patients with chronic pain, focusing on different populations, treatments, and outcome measures. A recent systematic literature review of baseline predictors of rehabilitation treatment outcome in CLBP ${ }^{53}$ showed that general evidence was limited owing to study heterogeneity. Treatment outcome, defined as activity limitation (ie, difficulties an individual may have in executing activities) and participation restriction (ie, problems an individual may experience in involvement in life situations), conforms the International Classification of Functioning, Disability and Health (ICF) model ${ }^{66}$. Despite this heterogeneity, consistent evidence was found for several predictors. Higher pain intensity at baseline predicted worse outcome, whereas several work-related parameters (eg, work satisfaction) predicted better outcome. Among the psychological predictors, one of the measurement scales with potentially predictive value was the Multidimensional Pain Inventory (MPI), which identifies subgroups of patients with different characteristics ${ }^{28}$. In general, more improvement was seen in the subgroups "dysfunctional" (DYS) and "interpersonally distressed" (ID), compared with the "adaptive copers" (AC). DYS and ID patients are both characterized by high affective distress, high pain intensity and low levels of life control. The DYS subtype has a highly supportive environment in contrast to the ID subtype, which has a low level of environmental support. The AC subtype shows relatively low levels of psychological distress, pain intensity, and interference and high perceived life control. Other sociodemographic, psychologic, and physical variables lacked consistent predictive value. Remarkably, none of the authors studied predictors from these 3 domains simultaneously.

The above-mentioned systematic review focused specifically on multidisciplinary rehabilitation and the outcomes as proposed in the ICF model. There are also numerous reviews that have studied other predictive factors for different treatment modalities or outcome measures. Consistent results were found for maladaptive beliefs ${ }^{24 ; 35}$ and depression ${ }^{14 ; 17 ; 35}$; both were associated with poor outcome. Sick leave or compensation status were predictive of less return to work ${ }^{14 ; 24,26 ; 40 ; 60}$ and of reduced treatment response in general ${ }^{40 ; 48}$.

Surprisingly, in the systematic review ${ }^{53}$, no studies were included that investigated the predictive value of fear-avoidance measures at baseline in CLBP. According to the fear- regel 1

regel 2

regel 3

regel 4

regel 5

regel 6

regel 7

regel 8

regel 9

regel 10

regel 11

regel 12

regel 13

regel 14

regel 15

regel 16

regel 17

regel 18

regel 19

regel 20

regel 21

regel 22

regel 23

regel 24

regel 25

regel 26

regel 27

regel 28

regel 29

regel 30

regel 31

regel 32

regel 33

regel 34

regel 35

regel 36

regel 37

regel 38 
regel 1 regel 2 regel 3 regel 4 regel 5 regel 6 regel 7 regel 8 regel 9 regel 10 regel 11 regel 12 regel 13 regel 14 regel 15 regel 16 regel 17 regel 18 regel 19 regel 20 regel 21 regel 22 regel 23 regel 24 regel 25 regel 26 regel 27 regel 28 regel 29 regel 30 regel 31 regel 32 regel 33 regel 34 regel 35 regel 36 regel 37 regel 38 avoidance model ${ }^{29 ; 56}$, a pain stimulus may lead to pain-related fear, avoidance behavior and eventually disuse and disability. It has been shown that reduction of pain-related or movement-related fear during treatment is associated with improvement after active ${ }^{33}$ and cognitive behavioral therapy ${ }^{65}$. The inclusion of fear as a possible important predictor for treatment outcome was also suggested in 2 reviews of (cognitive) behavioral treatment of patients with chronic pain ${ }^{35 ; 57}$. Moreover, Schultz et al ${ }^{43}$ pointed out that important missing determinants in their prognostic model for occupational low back disability were coping and fear-avoidance measures.

To confirm the value of consistent predictors found in the systematic review ${ }^{53}$, these variables should be tested in a longitudinal cohort study with a priori formulated hypotheses ${ }^{4}$. A previously published controlled clinical trial ${ }^{59}$ studying the effectiveness of a multidisciplinary back school program was reanalyzed for this purpose. In short, the results of the trial showed no significant differences in improvement between the treatment and the control group for measures of activity limitation and health-related quality of life. However, subgroup analyses gave some first indications that multiaxial measurement instruments [eg, using the MPIDutch Version (MPI-DLV)], might be useful in identifying subgroups with differences in treatment effects.

The objective of this study is to determine whether multidisciplinary rehabilitation outcome in CLBP, in comparison with usual care, can be predicted by a multivariate prognostic model on the basis of consistent predictors from literature (ie, pain, work status, and MPI classification). Furthermore, the value of other predictors was explored (ie, sick leave, compensation, depression, and fear-avoidance beliefs). The primary outcome measure in this study was activity limitation. Secondary outcomes included health-related quality of life. This study was a reanalysis of data from a controlled clinical trial. This allows for conclusions concerning prognostic factors for a specific treatment, as these may differ as a function of treatment. Our hypothesis was that patients with CLBP with less pain, who are able to work and are classified as DYS or ID, will improve more after multidisciplinary rehabilitation, compared to those with more pain, who are not able to work, and are classified as AC. 


\section{Materials and Methods}

\section{Patients}

Patients with nonspecific CLBP, who were admitted to an outpatient multidisciplinary back rehabilitation program by a physician in physical medicine and rehabilitation, were asked to participate in this study. Inclusion criteria were similar to the criteria for rehabilitation: duration of pain longer than 3 months, age between 18 and 60 years, and no surgery of the spine in the past 3 months. Patients with structural pathology like active radiculopathy, tumor of the spine, or severe deformities (spondylolisthesis grade 3) and patients with a medical contraindication for physical training were excluded.

\section{Design}

Data from a randomized controlled trial of a low back multidisciplinary rehabilitation program ${ }^{59}$ were used for analysis. The original trial aimed at evaluating the effectiveness of rehabilitation. In this study, a multivariate predictive model was tested for outcome directly and 4 months after treatment.

\section{Protocol}

Patients who met the inclusion criteria and were willing to participate gave informed consent. After the baseline measurements, which were administered by the same researcher, patients were randomized to either the control group (ie, waiting list) or the treatment group. Randomization was performed using the minimization method as described by Pocock ${ }^{38}$ and balanced for sex, work status, and low back muscle function as estimated by dynamometry (by using the Isostation B200 ${ }^{25}$ ). To enable an adequate assignment procedure, a computer program was used. Patients were not blinded for the group they were randomized to, but the researchers conducting the measurements were. Measurements were performed before randomization (T0), in the week after treatment (T1), and 4 months after treatment (T5). For the control group, T1 was equal to 8 weeks after T0 and T5 was equal to 6 months after T0. Patients randomized to the control group (ie, waiting list) were allowed to apply for usual health care facilities outside the rehabilitation center. The medical consumption of the control group was assessed at T1 and every subsequent month till T5 by a questionnaire sent home. They could enter the back rehabilitation program after the 6-month follow-up period.

\section{Treatment}

Patients who were allocated to the treatment group began participating in the Roessingh Back Rehabilitation Program (RRP) within 2 to 3 weeks. The RRP was based on the Swedish back school ${ }^{67}$ and multidimensional pain programs ${ }^{16}$. It assumes that many patients with CLBP develop a deconditioning syndrome. Deconditioning is hypothesized as part of a regel 1

regel 2

regel 3

regel 4

regel 5

regel 6

regel 7

regel 8

regel 9

regel 10

regel 11

regel 12

regel 13

regel 14

regel 15

regel 16

regel 17

regel 18

regel 19

regel 20

regel 21

regel 22

regel 23

regel 24

regel 25

regel 26

regel 27

regel 28

regel 29

regel 30

regel 31

regel 32

regel 33

regel 34

regel 35

regel 36

regel 37

regel 38 
regel 1 regel 2 regel 3 regel 4 regel 5 regel 6 regel 7 regel 8 regel 9 regel 10 regel 11 regel 12 regel 13 regel 14 regel 15 regel 16 regel 17 regel 18 regel 19 regel 20 regel 21 regel 22 regel 23 regel 24 regel 25 regel 26 regel 27 regel 28 regel 29 regel 30 regel 31 regel 32 regel 33 regel 34 regel 35 regel 36 regel 37 regel 38 vicious circle consisting of back pain, inactivity owing to back pain and fear, lowered physical capacity, and overloading. During treatment one tries to influence the patient's health and perceived disabilities by upgrading physical conditioning and activity level, by reducing fear of movement, and upgrading knowledge about back pain. The treatment program consists of a combination of physiotherapy, sport, education, and occupational rehabilitation. Education aims at enlarging the patients' knowledge of development of chronic back pain and how to influence recovery by physical training. Education also aims at teaching skills concerning the optimum use of any remaining physical capabilities.

The RRP is provided on the basis of a standardized protocol. Patients are not allowed to be absent more than $10 \%$ of the time. A RRP group consists of 8 patients and comprises 3 hours of conditional training and sport, 0.5 hours of swimming, 1.5 hours of occupational therapy, and 4 hours of physiotherapy each week for 7 weeks. Patients with problems at work, related to back pain, may also receive individual occupational rehabilitation after the program. Treatment is under the supervision of a specialist in physical and rehabilitation medicine and conducted by a team consisting of a physiotherapist, an occupational therapist, a sport therapist, and, if necessary, a psychologist and dietician.

\section{Measurement protocol}

Predictor variables

On the basis of our hypothesis, 2 multivariate predictive models were tested. Model 1 was a confirmatory model and included the consistent predictors (ie, pain, work status, and MPI classification) found in the systematic review ${ }^{53}$. Model 2 was exploratory and included the other predictors (ie, sick leave, compensation, depression, and fear-avoidance beliefs). The selection of variables, was, therefore, not on the basis of significant univariate associations, but was hypothesis driven. This is the preferable method if study power is sufficient ${ }^{3}$. Treatment modality was added as an independent factor to both models as it was expected to impact the outcome.

- Treatment was defined as "back rehabilitation" or "usual care".

- For current pain intensity, the Visual Analogue Scale (VAS, range: 0 to 10) was used. The VAS has been found to be valid, reliable, and responsive to change ${ }^{49}$.

- Work status was measured by a questionnaire, developed for this study, with the following response options: "yes"= full-time or- part-time work; "no"= not able to work because of illness (predominantly CLBP), unemployment, retirement, or involvement around the household.

- The MPI, originally developed by Kerns et al ${ }^{28}$, was used to measure psychosocial aspects of pain. The MPI-Dutch Version (MPI-DLV) has shown to be valid and reliable ${ }^{32}$. The profile classifications (ie, DYS, ID and AC) as described by Turk 
and Rudy ${ }^{50}$, were used. These clusters were replicated for the Dutch version of the MPI ${ }^{30 ; 31}$ in which a fourth cluster was added, labeled "average" (AV), which shares characteristics with the other profiles. In general, the AV type experiences less pain severity and interference, and more pain control compared with the ID and DYS type. An additional category of "anomalous" (AN) exists for patients who cannot be classified into one of the mentioned profile types.

- Sick leave was reported by the employee who scored the number of days of sick leave in the past 8 weeks, normalized to a full time job ( 0 to 40 hours/wk).

- Receiving financial compensation was scored by a questionnaire, developed for this study with the following response options: "yes" = compensation from the employer or government because of (chronic) illness or pain, "no"= no compensation. In the Netherlands, the employer is responsible for $70 \%$ of the salary during the first 2 years of illness. Afterwards, financial compensation is provided by the government. The amount depends on the percentage of lost work ability, assessed by a physician specialized in work and insurance.

- Depression was measured with the Symptom Checklist-90 subscale depression (SCL-90-Dep) (range: 16 to 80). The SCL-90-Dep consists of 16 items, each scored on a 5-point Likert scale with scoring alternatives ranging from "totally not" to "very". Validity and reliability has been supported for both the overall score ${ }^{510}$ and for the SCL-90-Dep ${ }^{5}$.

- Fear of physical activity or (re)injury was measured with the Tampa Scale of Kinesiofobia-Dutch Version (TSK-DV, range 17 to 68), which has been found to be internally consistent and valid ${ }^{21}$. It consists of 17 items, each scored on a 4-point Likert scale with scoring alternatives ranging from "strongly disagree" to "strongly agree".

\section{Outcome parameters}

For primary and secondary outcomes, the difference in scores between T1 - T0 and T5 -T0 were used. Change scores were chosen because a reduction of 2 or more points on the Roland Morris Disability Questionnaire (RMDQ) is defined as a clinically relevant change ${ }^{11 ; 36}$. The primary outcome parameter in the present study was the RMDQ. The RMDQ ${ }^{41}$ was derived from the Sickness Impact Profile (SIP) ${ }^{8}$, using 24 yes/no items of the Sickness Impact Profile relevant for back pain. An individual patient's score can vary from 0 (no disability) to 24 (severe disability). The RMDQ-Dutch version is a reliable ${ }^{12}$ and valid instrument to assess functional status in CLBP and is responsive to change ${ }^{19}$. regel 1

regel 2

regel 3

regel 4

regel 5

regel 6

regel 7

regel 8

regel 9

regel 10

regel 11

regel 12

regel 13

regel 14

regel 15

regel 16

regel 17

regel 18

regel 19

regel 20

regel 21

regel 22

regel 23

regel 24

regel 25

regel 26

regel 27

regel 28

regel 29

regel 30

regel 31

regel 32

regel 33

regel 34

regel 35

regel 36

regel 37

regel 38 
regel 1 regel 2 regel 3 regel 4 regel 5 regel 6 regel 7 regel 8 regel 9 regel 10 regel 11 regel 12 regel 13 regel 14 regel 15 regel 16 regel 17 regel 18 regel 19 regel 20 regel 21 regel 22 regel 23 regel 24 regel 25 regel 26 regel 27 regel 28 regel 29 regel 30 regel 31 regel 32 regel 33 regel 34 regel 35 regel 36 regel 37 regel 38

As secondary outcome parameter, "health related quality of life" was measured with the Dutch translation of the Short Form Health Survey (SF-36) ${ }^{1}$, originally developed by Ware and Sherbourne ${ }^{64}$. It is a self-report questionnaire that contains 36 items, measuring 8 domains of health. Outcome is expressed on a scale from 0 to 100 , with higher scores indicating higher levels of functioning. Psychometric properties have been found to be adequate ${ }^{1 ; 1354 ; 55}$. Physical component scale (PCS) and mental component scale (MCS) health measures can be derived and scored using principal component analysis ${ }^{61}$. Each scale has a range from 0 to 100 . The mean norms in the general US population with CLBP are 46 (PCS) and 48 (MCS) ${ }^{61}$. Very low scores on the PCS indicate severe physical dysfunction, severe social and role limitation, distressful back pain, frequent tiredness, and unfavorable evaluation of health status. Very low scores on the MCS indicate frequent psychological distress and severe social and role limitation because of emotional problems. The PCS and MCS have a reliability comparable with the original SF- $36{ }^{62}$ and validity is sufficient ${ }^{63}$. A clinically relevant improvement for these scales has not yet been defined.

\section{Data analysis}

Baseline values of predictor and outcome variables of both groups were calculated. Baseline differences between groups were tested with independent $t$ tests or the Mann-Whitney $U$ test for continuous data and $\mathrm{X}^{2}$ tests for categorical data. Collinearity between variables was checked with scatter plots or correlation coefficients for continuous variables and with cross tables for categorical variables. Multiple imputation methods were used to complete missing data using the algorithm MICE VI.13 in S-Plus ${ }^{5152}$. The algorithm MICE is a so-called Fully Conditional Specification Method. Imputation was carried out for all variables with 1 or more missing values. If data are missing at random, the multiple imputation technique is an appropriate method to deal with missing data ${ }^{42}$.

Firstly, model 1 and 2 were analyzed using multivariate linear regression analysis for the total group (ie, back rehabilitation and usual care). Baseline values of outcome measures were included to correct for a regression to the mean effect ${ }^{6}$. Model 1 was nested in model 2 . In step 1, variables from model 1 (baseline value of outcome, treatment, pain, work status, and MPI-DLV) were entered and in step 2, variables from model 2 (sick leave, compensation, SCL-90-Dep, and TSK-DLV). In step 3, interactions of predictors with treatment were added. Significance level was set at $\mathrm{P}=0.05$.

The 5-profile classifications of the MPI (ie, ID, DYS, AC, AV, and AN) were dichotomized into 2 groups: ID/DYS versus AC/AV/AN. This dichotomization was necessary to reduce the number of predictor variables and thus the chance of a type I error. This choice was considered legitimate as literature has shown that ID/DYS profiles both benefit more from treatment than 
the AC/AV profiles ${ }^{47559}$. Furthermore, ID and DYS subtypes share common characteristics of high pain intensity and low levels of control, in contrast to AC and AV with lower levels of pain intensity and interference, but higher life control.

For the categorical variables, the following coding was used:

- Treatment: (0) usual care, (1) back rehabilitation

- MPI: (0) AC/AV/AN, (1) ID/DYS

- Work status: (0) not working, (1) working

- Compensation: (0) no compensation, (1) receiving compensation

Second, interactions between treatment modality and prognostic variables from the models were studied for statistical significance $(\mathrm{P}<0.05)$ to determine the value of the prognostic variables for the specific treatment.

Unstandardized $\beta$ coefficients and standard errors will be presented. To give an indication of the predictive power of the model, the percentage of explained variance $\left(\mathrm{R}^{2}\right)$ of the complete model and of the significant predictors for rehabilitation treatment will be shown. Linear assumptions will be checked with residual and normal probability plots. If prediction of outcome is possible, the models will be internally validated by bootstrapping.

\section{Results}

\section{Study population}

All patients who were admitted to the back rehabilitation program met the inclusion criteria, of which $<5 \%$ refused to participate. Of the 163 patients who were included in the trial, 21 patients were lost during follow up (13\%). There was no difference in loss to follow-up between the groups ${ }^{59}$. The number of missing variables per case was marginal. The only exception was the variable sick leave, which was missing in 48 cases. Under the hypothesis that the data were missing at random, multiple imputation techniques were used to be able to build a prognostic model ${ }^{51 ; 52}$ for the total study group $(\mathrm{N}=163)$. Baseline characteristics are reported in Table 1 . There were no significant differences in baseline characteristics between the treatment and the control group implying that randomization appeared to be successful.

\section{Cointerventions}

The mean medical consumption in the usual care group was low with the exception of physical therapy. The mean number of visits to the physiotherapist was 11 to 15 times, but these visits were mainly attributed to only a few patients. Results of the questionnaire sent home monthly showed that the mean number of visits to specialists, general practitioners, manual therapists or other therapy forms was about $0.1(\mathrm{SD}<1)$ and thereby negligible. The mean number of

regel 1

regel 2

regel 3

regel 4

regel 5

regel 6

regel 7

regel 8

regel 9

regel 10

regel 11

regel 12

regel 13

regel 14

regel 15

regel 16

regel 17

regel 18

regel 19

regel 20

regel 21

regel 22

regel 23

regel 24

regel 25

regel 26

regel 27

regel 28

regel 29

regel 30

regel 31

regel 32

regel 33

regel 34

regel 35

regel 36

regel 37

regel 38 
Chapter 3

regel 1

regel 2

regel 3

regel 4

regel 5

regel 6

regel 7

regel 8

regel 9

regel 10

regel 11

regel 12

regel 13

regel 14

regel 15

regel 16

regel 17

regel 18

regel 19

regel 20

regel 21

regel 22

regel 23

regel 24

regel 25

regel 26

regel 27

regel 28

regel 29

regel 30

regel 31

regel 32

regel 33

regel 34

regel 35

regel 36

regel 37

regel 38 visits to the physiotherapist was slightly higher and about $0.5(\mathrm{SD}=3)$, but also considered negligible.

Table 1. Baseline characteristics (mean and SD or percentages) of the back rehabilitation (RRP) and usual care group (nonimputated data)

\begin{tabular}{|c|c|c|c|}
\hline & & $\begin{array}{l}\text { RRP } \\
N=79\end{array}$ & $\begin{array}{l}\text { Usual care } \\
\mathrm{N}=84\end{array}$ \\
\hline Age $(y)$ & & $38(10)$ & $40(10)$ \\
\hline Duration of symptoms (mo) & $\operatorname{median}^{\star} /$ range & $72(380)$ & $48(559)$ \\
\hline $\begin{array}{l}\text { Sex } \\
\text { Male } \\
\text { Female }\end{array}$ & & $\begin{array}{l}60 \% \\
40 \%\end{array}$ & $\begin{array}{l}62 \% \\
38 \%\end{array}$ \\
\hline RMDQ (0-24) & & $13(4)$ & $13(5)$ \\
\hline SF-36: PCS (0-100) & & $31(7)$ & $32(7)$ \\
\hline SF-36: MCS (0-100) & & $49(10)$ & $52(10)$ \\
\hline VAS $(0-100)$ & $\operatorname{median}^{\star} /$ range & $5(0-10)$ & $5(1-9)$ \\
\hline $\begin{array}{l}\text { MPI -DLV } \\
\text { Dysfunctional } \\
\text { Interpersonally Distressed } \\
\text { Adaptive copers } \\
\text { Average } \\
\text { Anomalous }\end{array}$ & & $\begin{array}{l}30 \% \\
12 \% \\
15 \% \\
39 \% \\
4 \%\end{array}$ & $\begin{array}{l}26 \% \\
15 \% \\
26 \% \\
31 \% \\
2 \%\end{array}$ \\
\hline $\begin{array}{l}\text { Work status } \\
\text { Working } \\
\text { Not working }\end{array}$ & & $\begin{array}{l}21 \% \\
79 \%\end{array}$ & $\begin{array}{l}20 \% \\
80 \%\end{array}$ \\
\hline $\begin{array}{l}\text { Sick leave }[0-40 \mathrm{~h}(\mathrm{~s}) / \mathrm{wk}] \\
\text { Compensation } \\
\text { Yes } \\
\text { No }\end{array}$ & $\operatorname{median}^{\star} /$ range & $26(0-40)$ & $20(0-40)$ \\
\hline $\begin{array}{l}\text { SCL-90 total score (90-450) } \\
\text { SCL-90-Dep (16-80) } \\
\text { TSK (17-68) }\end{array}$ & & $\begin{array}{l}140(39) \\
25(9) \\
39(7)\end{array}$ & $\begin{array}{l}136(35) \\
24(8) \\
39(7)\end{array}$ \\
\hline
\end{tabular}

* The median value for duration of complaints is reported as this parameter is not normally distributed, MCS indicates Mental Component Scale; MPI-DLV, Multidimensional Pain Inventory Dutch Language Version; PCS, Physical Component Scale; RMDQ, Roland Disability Questionnaire; RRP, Roessingh Back Rehabilitation Program; SF-36, Short Form Health Survey; SCL-90, Symptom Check List; SCL-90-Dep, Symptom Check List subscale depression; TSK, Tampa Scale for Kinesiofobia; VAS, Visual Analogue Scale.

\section{Outcome}

Outcome variables are reported in Table 2. The mean RMDQ, PCS, and MCS scores for both groups are largely similar at admission. At 8 weeks and 6 months follow up, patients with CLBP experienced on average less activity limitation and higher health-related quality of life than at baseline, regardless of the type of treatment. 
Table 2. Outcome parameters [mean and SD, number of cases $(\mathrm{N})$ ] of the back rehabilitation $(\mathrm{N}=79)$ and usual care group $(\mathrm{N}=84)$ at baseline (T0), discharge (T1) and 4-months followup after treatment (T5) (nonimputated data)

\begin{tabular}{lllll}
\hline Outcome & Group & Baseline & T1 & T5 \\
\hline RMDQ & RRP & $13(4), \mathrm{N}=79$ & $11(5), \mathrm{N}=72$ & $10(5), \mathrm{N}=68$ \\
& Usual care & $13(4), \mathrm{N}=83$ & $13(5), \mathrm{N}=79$ & $11(5), \mathrm{N}=72$ \\
SF-36: PCS & RRP & $31(7), \mathrm{N}=73$ & $35(8), \mathrm{N}=66$ & $37(9), \mathrm{N}=64$ \\
& Usual care & $32(7), \mathrm{N}=81$ & $33(9), \mathrm{N}=75$ & $35(9), \mathrm{N}=67$ \\
SF-36: MCS & RRP & $49(10), \mathrm{N}=73$ & $53(9), \mathrm{N}=66$ & $54(9), \mathrm{N}=64$ \\
& Usual care & $52(10), \mathrm{N}=81$ & $52(10), \mathrm{N}=75$ & $53(10), \mathrm{N}=67$ \\
\hline
\end{tabular}

MCS indicates Mental Component Scale; PCS, Physical Component Scale; RMDQ, Roland Disability Questionnaire; RRP, Roessingh Back Rehabilitation Program; SF-36, Short Form Health Survey.

\section{Prognostic factors for change in outcome}

Owing to high collinearity between the categorical variables "work status" and "compensation", the variable compensation was left out of the model. The variable work status was preferred to compensation as it had showed consistent results in literature for the outcomes of interest ${ }^{53}$. Most patients working received no compensation and most patients not working did. Model 1 (the confirmative model) was nested in model 2 (the exploratory model). The complete models are presented in Table 3 . Table 3 presents the predictor model without interactions and Table 4 the final model including interactions with treatment. Overall, the percentage of explained variance for the different outcome measures was moderately low and varied from $18.5 \%$ to $42.3 \%$.

\section{Predictors for change in outcome regardless of treatment modality (Table 3)}

For the primary outcome variable (RMDQ), participation in back rehabilitation and a higher baseline RMDQ score both predicted improvement at short-term follow-up. Higher RMDQ scores at baseline predicted improvement for the long term as well. For the secondary outcome parameters (PCS and MCS), higher baseline values predicted deterioration at short-term and long-term follow-up, whereas participation in back rehabilitation predicted an improvement for the PCS in the short term. Being at work predicted an improvement for the PCS in the long term, whereas higher depression scores predicted deterioration for the MCS at shortterm and long-term follow-up.

regel 1

regel 2

regel 3

regel 4

regel 5

regel 6

regel 7

regel 8

regel 9

regel 10

regel 11

regel 12

regel 13

regel 14

regel 15

regel 16

regel 17

regel 18

regel 19

regel 20

regel 21

regel 22

regel 23

regel 24

regel 25

regel 26

regel 27

regel 28

regel 29

regel 30

regel 31

regel 32

regel 33

regel 34

regel 35

regel 36

regel 37

regel 38 
regel 1

regel 2

regel 3

regel 4

regel 5

regel 6

regel 7

regel 8

regel 9

regel 10

regel 11

regel 12

regel 13

regel 14

regel 15

regel 16

regel 17

regel 18

regel 19

regel 20

regel 21

regel 22

regel 23

regel 24

regel 25

regel 26

regel 27

regel 28

regel 29

regel 30

regel 31

regel 32

regel 33

regel 34

regel 35

regel 36

regel 37

regel 38
Table 3. Complete predictor model for change in outcome regardless of treatment (imputated data)

\begin{tabular}{|c|c|c|c|c|c|c|}
\hline \multirow{3}{*}{$\begin{array}{l}\text { Outcomes } \\
\text { Follow-up } \\
\text { Predictors }\end{array}$} & \multicolumn{2}{|c|}{ RMDQ } & \multicolumn{2}{|l|}{ PCS } & \multicolumn{2}{|l|}{ MCS } \\
\hline & T1-T0 & T5-T0 & T1-T0 & T5-T0 & T1-T0 & T5-T0 \\
\hline & $\beta(\mathrm{SE})$ & $\beta$ (SE) & $\beta$ (SE) & $\beta(\mathrm{SE})$ & $\beta(\mathrm{SE})$ & $\beta$ (SE) \\
\hline Intercept & $4.59(2.19)$ & $2.02(2.57)$ & $14.63(5.33)$ & $19.14(6.46)$ & $57.85(8.54)$ & $51.27(9.47)$ \\
\hline Treatment $^{1}$ & $-1.89(0.67)^{\star *}$ & $-0.63(0.71)$ & $2.34(1.15)^{*}$ & $1.35(1.28)$ & $0.55(1.37)$ & $1.47(1.47)$ \\
\hline Pain & $-0.19(0.17)$ & $-0.11(0.19)$ & $0.18(0.30)$ & $0.20(0.37)$ & $0.34(0.32)$ & $-0.13(0.36)$ \\
\hline Work status ${ }^{2}$ & $-0.52(1.08)$ & $-1.72(1.31)$ & $1.61(1.88)$ & $6.16(2.20)^{\star \star}$ & $-1.51(2.29)$ & $-1.31(2.71)$ \\
\hline MPI-DLV 3 & $-0.76(0.80)$ & $-1.31(0.92)$ & $0.94(1.39)$ & $1.54(1.51)$ & $-2.45(1.57)$ & $-0.78(1.69)$ \\
\hline Baseline value $^{4}$ & $-0.35(0.10)^{\star \star \star}$ & $-0.38(0.11)^{\star * *}$ & $-0.38(0.10)^{\star * *}$ & $-0.54(0.11)^{\star \star \star}$ & $-0.87(0.10)^{\star \star \star}$ & $-0.83(0.10)^{\star * *}$ \\
\hline Sick leave & $0.03(0.03)$ & $-0.01(0.03)$ & $-0.03(0.04)$ & $0.08(0.05)$ & $-0.04(0.05)$ & $-0.07(0.07)$ \\
\hline SCL-90-Dep & $0.04(0.05)$ & $0.01(0.05)$ & $-0.09(0.08)$ & $-0.03(0.10)$ & $-0.29(0.13)^{\star}$ & $-0.35(0.13)^{\star *}$ \\
\hline TSK & $-0.07(0.05)$ & $0.05(0.06)$ & $-0.02(0.08)$ & $-0.05(0.11)$ & $-0.11(0.10)$ & $0.10(0.12)$ \\
\hline $\mathbf{R}^{2}$ & $23.5 \%$ & $19.0 \%$ & $18.5 \%$ & $24.2 \%$ & $42.3 \%$ & $39.0 \%$ \\
\hline
\end{tabular}

Outcome is expressed as change between discharge (T1) or 4-mo follow-up after treatment (T5) and baseline (T0).

$\beta$ indicates regression coefficient; MCS, Mental Component Scale (derived from Short Form Health Survey); MPI-DLV, Multidimensional Pain Inventory Dutch Language version; PCS, Physical Component Scale; $\mathrm{R}^{2}$, percentage of explained variance; RRP, Roessingh Back Rehabilitation Program; RMDQ, Roland Disability Questionnaire; SCL-90-Dep, Symptom Check List, subscale depression; SE, standard error; TSK, Tampa Scale for Kinesiofobia; VAS, Visual Analogue Scale.

${ }^{1}$ Treatment: $0=$ usual care, $1=$ back rehabilitation.

${ }^{2}$ Work status: $0=$ not working, $1=$ working.

${ }^{3}$ MPI-DLV: 0 = Adaptive Coper/Average/Anomalous, $1=$ Interpersonally Distressed/Dysfunctional.

${ }^{4}$ Baseline value RMDQ, PCS, MCS.

${ }^{*} \mathrm{P}$ value $<0.05,{ }^{* *} \mathrm{P}$ value $<0.01,{ }^{* *} \mathrm{P}$ value $<0.005$.

$\beta$ positive: unfavorable change in RMDQ (favorable in PCS/MCS) per unit of the independent predictor.

$\beta$ negative: favorable change in RMDQ (unfavorable in PCS/MCS) per unit of the independent predictor.

\section{Predictors for change in outcome for a specific treatment (Table 4)}

Interactions of several prognostic variables with the variable treatment were significant, depending on the outcome measure and duration of follow-up. A significant interaction with treatment implies that a variable has a different prognostic value for outcome of back rehabilitation treatment compared with usual care. The percentage of explained variance added by the significant interactions was very low and varied from $2.2 \%$ to $4.9 \%$. Owing to these low percentages, the value of the prognostic model was very modest. Therefore, internal validation had limited additional value and was not carried out. 
Table 4. Complete predictor model for treatment outcome: prognostic variables and interactions with treatment (imputated data).

\begin{tabular}{|c|c|c|c|c|c|c|}
\hline \multirow{2}{*}{$\begin{array}{l}\text { Outcomes } \\
\text { Follow-up } \\
\text { Predictors }\end{array}$} & \multicolumn{2}{|l|}{ RMDQ } & \multicolumn{2}{|l|}{ PCS } & \multicolumn{2}{|l|}{ MCS } \\
\hline & $\begin{array}{l}\text { t1-t0 } \\
\beta \text { (SE) }\end{array}$ & $\begin{array}{l}\text { t5-t0 } \\
\beta \text { (SE) }\end{array}$ & $\begin{array}{l}\text { t1-t0 } \\
\beta \text { (SE) }\end{array}$ & $\begin{array}{l}\text { t5-t0 } \\
\beta \text { (SE) }\end{array}$ & $\begin{array}{l}\text { t1-t0 } \\
\beta \text { (SE) }\end{array}$ & $\begin{array}{l}\text { t5-t0 } \\
\beta \text { (SE) }\end{array}$ \\
\hline Intercept & $1.75(2.93)$ & $-3.17(3.40)$ & $23.29(6.40)$ & $27.55(7.88)$ & $59.17(9.67)$ & $47.62(11.32)$ \\
\hline Treatment $^{1}$ & $4.87(4.45)$ & $10.22(4.60)^{*}$ & $-16.93(7.91)^{*}$ & $-17.08(9.59)$ & $-1.05(9.53)$ & $7.85(10.65)$ \\
\hline Pain & $-0.19(0.22)$ & $-0.34(0.24)$ & $-0.35(0.40)$ & $0.32(0.46)$ & $0.49(0.48)$ & $-0.54(0.52)$ \\
\hline Work status ${ }^{2}$ & $-1.74(1.45)$ & $-3.20(1.71)$ & $1.56(2.49)$ & $7.93(3.20)^{\star}$ & $-2.29(3.12)$ & $-0.08(3.81)$ \\
\hline MPI-DLV ${ }^{3}$ & $-0.54(1.08)$ & $-1.70(1.27)$ & $-0.15(1.73)$ & $1.20(2.03)$ & $-0.27(2.17)$ & $1.77(2.41)$ \\
\hline Baseline value $^{4}$ & $-0.36(0.10)^{* * *}$ & $-0.40(0.11)^{\star * *}$ & $-0.39(0.10)^{\star * *}$ & $-0.55(0.11)^{* * *}$ & $-0.88(0.10)^{\star * *}$ & $-0.83(0.10)^{\star * *}$ \\
\hline Sick leave & $0.03(0.03)$ & $-0.02(0.04)$ & $-0.04(0.06)$ & $0.07(0.08)$ & $-0.04(0.07)$ & $-0.02(0.10)$ \\
\hline SCL-90-Dep & $0.13(0.07)$ & $0.17(0.07)^{\star}$ & $-0.15(0.11)$ & $-0.12(0.14)$ & $-0.40(0.16)^{\star}$ & $-0.42(0.18)^{\star}$ \\
\hline TSK & $0.016(0.07)$ & $0.13(0.08)$ & $-0.11(0.12)$ & $-0.23(0.15)$ & $-0.12(0.15)$ & $0.23(0.18)$ \\
\hline $\begin{array}{l}\text { Treatment } \mathrm{x} \\
\text { Pain }\end{array}$ & $0.01(0.33)$ & $0.43(0.34)$ & $1.07(0.54)^{\star 5}$ & $-0.17(0.62)$ & $-0.16(0.72)$ & $0.94(0.71)$ \\
\hline $\begin{array}{l}\text { Treatment } \mathrm{x} \\
\text { work status }\end{array}$ & $2.31(2.08)$ & $2.96(2.22)$ & $0.15(3.44)$ & $-3.98(4.29)$ & $1.89(4.54)$ & $-1.25(4.73)$ \\
\hline $\begin{array}{l}\text { Treatment } x \\
\text { MPI-DLV }\end{array}$ & $-0.51(1.51)$ & $0.24(1.59)$ & $1.54(2.59)$ & $0.83(2.95)$ & $-4.33(3.26)$ & $-5.76(3.57)$ \\
\hline $\begin{array}{l}\text { Treatment } \mathrm{x} \\
\text { sick leave }\end{array}$ & $-0.01(0.05)$ & $0.00(0.06)$ & $0.06(0.08)$ & $0.04(0.10)$ & $0.01(0.11)$ & $-0.06(0.12)$ \\
\hline $\begin{array}{l}\text { Treatment } x \\
\text { SCL-90-dep }\end{array}$ & $-0.15(0.10)$ & $-0.28(0.10)^{\star * 6}$ & $0.11(0.16)$ & $0.14(0.22)$ & $0.16(0.21)$ & $0.10(0.24)$ \\
\hline $\begin{array}{l}\text { Treatment } \mathrm{x} \\
\text { TSK }\end{array}$ & $-0.08(0.10)$ & $-0.18(0.10)$ & $0.24(0.17)$ & $0.39(0.19)^{\star 7}$ & $-0.01(0.21)$ & $-0.24(0.22)$ \\
\hline $\mathbf{R}^{2}$ & $28.9 \%$ & $29.5 \%$ & $26.6 \%$ & $30.2 \%$ & $43.8 \%$ & $41.8 \%$ \\
\hline
\end{tabular}

regel 1

regel 2

regel 3

regel 4

regel 5

regel 6

regel 7

regel 8

regel 9

regel 10

regel 11

regel 12

regel 13

regel 14

regel 15

regel 16

regel 17

regel 18

regel 19

regel 20

regel 21

regel 22

regel 23

regel 24

regel 25

regel 26

regel 27

regel 28

regel 29

regel 30

regel 31

regel 32

regel 33

regel 34

regel 35

regel 36

regel 37

regel 38 
regel 1 regel 2 regel 3 regel 4 regel 5 regel 6 regel 7 regel 8 regel 9 regel 10 regel 11 regel 12 regel 13 regel 14 regel 15 regel 16 regel 17 regel 18 regel 19 regel 20 regel 21 regel 22 regel 23 regel 24 regel 25 regel 26 regel 27 regel 28 regel 29 regel 30 regel 31 regel 32 regel 33 regel 34 regel 35 regel 36 regel 37 regel 38
Pain intensity showed significant interactions with treatment, but the MPI and work status did not. More pain at baseline was predictive of improvement in physical health (PCS) after back rehabilitation for short-term follow up (T1). A higher baseline VAS score of approximately 3 points predicted an improvement of 2 points for the PCS. Depression and fear-avoidance beliefs (TSK) also showed significant interactions with treatment. Higher depression scores at baseline were prognostic for improvement after back rehabilitation in the long term (T5). A 20-point higher baseline score predicted a decrease of 2 points for the RMDQ. If persons with SCL-depression scores higher than the average of a chronic pain population $(>28)^{5}$ were classified as depressed, depressed persons showed mean RMDQ scores of 15 at baseline and 10 at long-term follow-up. Those with low depression scores $(\leq 28)$ showed mean RMDQ scores of 12 at both baseline and long-term follow-up. Finally, a higher level of fear-avoidance beliefs also predicted improvement after back rehabilitation at long-term follow-up. A TSK score of 6 points higher at baseline predicted an improvement of 1 point for the PCS.

\section{Discussion}

The results of this study showed very limited predictive value of a predefined multivariate prognostic model for patients with CLBP, for multidisciplinary rehabilitation outcome compared with usual care. The percentage of explained variance of the models was moderately low and varied from $18.5 \%$ to $43.8 \%$. Our hypothesis that less pain, the ability to work, and classification as DYS or ID predict more improvement after rehabilitation treatment was not supported. However, the value of several predefined predictors for improvement after rehabilitation treatment was partly confirmed.

\section{Prognostic factors for change in treatment outcome - confirmatory model (Model 1)}

For the confirmatory model, pain had a different prognostic value for the rehabilitation and usual care group than we hypothesized. Higher pain intensity predicted improvement in physical health (PCS) after back rehabilitation, which was different from the findings of others ${ }^{7 ; 46}$. It was not clear what caused this discrepancy. The main difference with our study was that different outcome measures were used [ie, ADL scores (Activity of Daily Living) 7 and Million/WHO (World Health Organization) Handicap Indexes ${ }^{46}$, which may have influenced the prognostic value of pain. Although the direction of the prognostic value was different than expected, the results supported that pain intensity had prognostic value for change in outcome after rehabilitation. 
The results showed that "being at work" does not affect improvement after rehabilitation. However, being at work predicted improvement for the PCS in long term, regardless of treatment. It could be that those at work are healthier and more physically active, which may be related to higher physical well being. However, the lack of prognostic value for improvement after rehabilitation should be interpreted with caution. There was only a small percentage of patients at work (20\%), which might have limited the predictive power of this variable. Another explanation may be that work status was not the same as "work ability". For example, the category "not working" also included persons who were retired or involved around the household. These people $(\mathrm{N}=10)$ may have been able to work that may have biased the results. This possible misclassification was checked by reanalyzing the data. Classifying "household" or "retired" as "working" did not change overall results. Therefore, possible bias caused by misclassification seems to be small.

No significant interaction between the MPI and the treatment was found, which is inconsistent with our hypothesis. This means that improvement after rehabilitation treatment did not differ between the MPI subgroups. We expected that DYS and ID profiles would improve more after rehabilitation than AC profiles as measured with the RMDQ, which was based on the results of Talo et a ${ }^{47}$ and Vollenbroek-Hutten et al ${ }^{59}$. Other studies ${ }^{9 ; 18}$, however, involving other patient groups than only CLBP, but the same outcome parameters, have also found no significant predictive value for treatment outcome.

Another explanation could be that dichotomizing the MPI (ID/DYS vs. AC/AV/AN) resulted in loss of discriminative ability and thus predictive power. Owing to the small sample size of the study group, dichotomization was necessary to reduce the number of predictor variables. Voerman et al ${ }^{58}$ also collapsed the ID and DYS together and were able to prove more improvement after treatment for the ID/DYS compared with the AC/AV profiles in people with neck-shoulder complaints. Future studies of larger comparable patient samples and outcome measures are needed to study the value of all different MPI profiles, besides other relevant prognostic factors.

\section{Prognostic factors for change in treatment outcome - exploratory model (Model 2)}

For the exploratory model, depression and fear-avoidance beliefs showed prognostic value for improvement after rehabilitation. Higher depression scores at baseline predicted improvement for the RMDQ after rehabilitation in the long term. Patients who were more depressed at baseline also had a better absolute outcome at follow-up [mean RMDQ (T5) $=10$ ] than those who were less depressed at baseline [mean RMDQ (T5) = 12]. This is in contrast to the literature that has shown that more depressive symptoms are prognostic for worse outcome. Most studies ${ }^{14 ; 3539}$, however, used return to work as outcome measure, which regel 1

regel 2

regel 3

regel 4

regel 5

regel 6

regel 7

regel 8

regel 9

regel 10

regel 11

regel 12

regel 13

regel 14

regel 15

regel 16

regel 17

regel 18

regel 19

regel 20

regel 21

regel 22

regel 23

regel 24

regel 25

regel 26

regel 27

regel 28

regel 29

regel 30

regel 31

regel 32

regel 33

regel 34

regel 35

regel 36

regel 37

regel 38 
regel 1 regel 2 regel 3 regel 4 regel 5 regel 6 regel 7 regel 8 regel 9 regel 10 regel 11 regel 12 regel 13 regel 14 regel 15 regel 16 regel 17 regel 18 regel 19 regel 20 regel 21 regel 22 regel 23 regel 24 regel 25 regel 26 regel 27 regel 28 regel 29 regel 30 regel 31 regel 32 regel 33 regel 34 regel 35 regel 36 regel 37 regel 38 may explain the difference. It may be that more depressed patients gain more from treatment, although this does not necessarily lead to return to work. Also, our study population had lower mean scores (SCL-Dep $=25$ ) than a norm population of patients with chronic pain $(\text { SCL-Dep }=30)^{5}$. So, the included patients had only mild depressive symptoms that may have influenced its prognostic value. It is interesting that more depressive symptoms were not predictive of mental health after rehabilitation, although depression predicted worsening for the MCS at follow-up, regardless of treatment. This could be because of the lack of difference in treatment effect between the 2 groups as measured with the MCS.

Furthermore, more fear avoidance beliefs predicted improvement in the PCS after rehabilitation in the long term. This is in line with what we expected. The RRP has shown to reduce the amount of fear-avoidance beliefs significantly ${ }^{59}$. This finding supports one of the theoretical principles the RRP is based on, that is, reduction of fear-avoidance beliefs improves physical functioning of patients and lessens the deconditioning syndrome.

Sick leave had no predictive value in this study. The number of missing values of this variable was high (48/163 cases), and missing values were completed with imputation techniques. Inevitably, this caused increased unreliability in the independent variable and is a possible explanation for not finding a significant prognostic value. Also, the validity of this measure could be questioned. The reported amount of sick leave showed great discrepancies between employer and employee, so it is uncertain if the employees' report was the most valid measure of sick leave.

\section{Methodological considerations}

The very low use of services by the usual care group (eg, "waiting list group") may suggest that this group did not need much treatment. However, from a clinical point of view, this is not likely. The results showed that the usual care group did not use other services (mainly physiotherapy), during the waiting list period. Almost all patients already had had monodisciplinary treatment (eg, physiotherapy) before referral without success. The knowledge that rehabilitation treatment would start at the end of the trial possibly explains the low use of medical services in the usual care group.

The percentages of explained variance of the prognostic models were low and an accurate prediction of outcome was, therefore, not possible. However, these low percentages have also been found in other multivariate prognostic models of treatment outcome (activity limitation or health-related quality of life) in chronic (low back) pain 15;20:22:33;34;37;45;46. A few authors showed percentages of explained variance up to $60 \%$ to $70 \%{ }^{2 ; 23 ; 27 ; 65}$. Woby et al ${ }^{65}$ were able to explain $71 \%$ of variance. They found that reduction of fear-avoidance beliefs and increased 
perceptions of control over pain were uniquely related to reductions in disability of CLBP after cognitive-behavioral treatment. The main differences with our study is that Woby et al ${ }^{65}$ studied a different type of treatment (cognitive-behavioral), studied changes in predictors instead of baseline values, and did not include a control group. It is likely that including changes in predictor values contributes to a higher level of explained variance because the effects of treatment processes are included in the prognostic model. However, knowledge of the predictive value of baseline, and not change of, parameters is preferred to be able to select patients for a suitable treatment modality.

Different explanations might contribute to the relatively low predictive power found in this study. First, there may be other important factors that were not investigated in this study. The problem is that there is no clear consensus regarding the predictors that should be used. It is also possible that the variance in outcome measures was too small for accurate prediction. This was most evident for the MCS, for which no predictors of treatment were found. For the MCS, mean differences before and after treatment were comparable with the differences at baseline between the 2 groups. Changes in the MCS in time were, therefore, probably too small to find significant prognostic factors.

The use of change scores as outcome measure is debatable, both from a clinical and a statistical point of view. Clinically, improvement in outcome parameters does not necessarily mean that the persons recover. For instance, persons may show a large improvement for the RMDQ, but still have high absolute scores (ie, experience more limitation) after treatment. These persons have a poorer prognosis than those with less improvement, but lower absolute scores (ie, less limitation) after treatment. Statistically, change scores can be influenced unduly by baseline levels ${ }^{3}$. It may be argued to use absolute scores as outcome measures instead. However, if analyzed with multiple regression analysis or analysis of covariance, it makes no difference if absolute outcomes or change scores are used ${ }^{6 ; 4}$. Both absolute outcomes (T1, T5) and change scores are influenced by their baseline scores. To correct for a possible regression to the mean effect, the analysis of covariance or multiple regression analysis should include baseline levels of the outcome measures ${ }^{6}$ as was carried out in this study. However, even multiple regression analysis does not correct for the strong correlation between baseline and change in outcome. The regression coefficients of the baseline values of the RMDQ, PCS, and MCS probably do not truly predict improvement, but reflect this statistical phenomenon. This study also showed that these baseline values contributed to relatively high percentages of explained variance, which may have overestimated the explained variance of the prognostic model. It was not the purpose of this study to explore the predictive value of baseline levels of the outcome measures. Inclusion of the baseline levels was needed to correct for baseline heterogeneity. regel 1

regel 2

regel 3

regel 4

regel 5

regel 6

regel 7

regel 8

regel 9

regel 10

regel 11

regel 12

regel 13

regel 14

regel 15

regel 16

regel 17

regel 18

regel 19

regel 20

regel 21

regel 22

regel 23

regel 24

regel 25

regel 26

regel 27

regel 28

regel 29

regel 30

regel 31

regel 32

regel 33

regel 34

regel 35

regel 36

regel 37

regel 38 
regel 1

regel 2

regel 3

regel 4

regel 5

regel 6

regel 7

regel 8

regel 9

regel 10

regel 11

regel 12

regel 13

regel 14

regel 15

regel 16

regel 17

regel 18

regel 19

regel 20

regel 21

regel 22

regel 23

regel 24

regel 25

regel 26

regel 27

regel 28

regel 29

regel 30

regel 31

regel 32

regel 33

regel 34

regel 35

regel 36

regel 37

regel 38

\section{Conclusions}

The results of this study did not support the construction of a clinical prediction model. However, this study showed that high scores of pain intensity, depression, and fear-avoidance beliefs may contribute to the prediction of improvement after a rehabilitation program for patients with CLBP.

\section{Future recommendations}

A generic set of predictors may be difficult to find. Prognostic factors should be tested and compared for the same population, treatment and outcome measures before it is possible to develop a generic prediction model. This underlines the importance of (inter)national consensus about treatment modality and outcome measures. Even if consensus is reached about outcome measures, it is likely that rehabilitation treatments will differ. This is partly because of its multidisciplinary character. The first step may be to conduct confirmative studies of prognostic factors in CLBP for a specific rehabilitation treatment in an effort to increase treatment homogeneity.

\section{Acknowledgement}

The authors thank the Joris Foundation for its financial support. 


\section{References}

regel 1

regel 2

1. Aaronson NK, Muller M, Cohen PD et al. Translation, validation, and norming of the Dutch language version of the SF-36 Health Survey in community and chronic disease populations. J Clin Epidemiol 1998;51:1055-68.

2. Altmaier E.M, Russell DW, Kao CF, Lehmann T, and Weinstein JN. Role of self-efficacy in rehabilitation outcome among chronic low back pain patients. Journal of Counseling Psychology 1993;40:335-9.

3. Altman DG. Chapter 11:Relation between two continuous variables. In: Altman DG, ed. Practical Statistics for Medical Research. London: Chapman \& Hall/CRC, 1999:277-324.

4. Altman DG and Lyman GH. Methodological challenges in the evaluation of prognostic factors in breast cancer. Breast Cancer Res Treat 1998;52:289-303.

5. Arrindell WA, Ettema JHM. Symptom Checklist SCL-90: Handleiding bij een multidimensionele psychopathologie-indicator. Lisse: Swets \& Zeitlinger; 1986.

6. Barnett AG, van der Pols JC, and Dobson AJ. Regression to the mean: what it is and how to deal with it. Int J Epidemiol 2005;34:215-20.

7. Bendix AF, Bendix T, and Haestrup C. Can it be predicted which patients with chronic low back pain should be offered tertiary rehabilitation in a functional restoration program? A search for demographic, socioeconomic, and physical predictors. Spine 1998;23:1775-83; discussion 17834.

8. Bergner M, Bobbitt RA, Kressel S, Pollard WE, Gilson BS, and Morris JR. The sickness impact profile: conceptual formulation and methodology for the development of a health status measure. Int J Health Serv 1976;6:393-415.

9. Bergstrom G, Jensen B, Bodin L, Linton SJ, and Nygren AL. The impact of psychologically different patient groups om outcome after a vocational rehabilitation program for long-term spinal pain patients. Pain 2001;93:229-237.

10. Bernstein IH, Jaremko ME, and Hinkley BS. On the utility of the SCL-90-R with low-back pain patients. Spine 1994;19:42-8.

11. Bombardier C, Hayden J, and Beaton DE. Minimal clinically important difference. Low back pain: outcome measures. J Rheumatol 2001;28:431-8.

12. Brouwer S, Kuijer W, Dijkstra PU, Goeken LN, Groothoff JW, and Geertzen JH. Reliability and stability of the Roland Morris Disability Questionnaire: intra class correlation and limits of agreement. Disabil Rehabil 2004;26:162-5.

13. Essink Bot ML, Krabbe PF, Bonsel GJ, and Aaronson NK. An empirical comparison of four generic health status measures. The Nottingham Health Profile, the Medical Outcomes Study 36-item Short-Form Health Survey, the COOP/WONCA charts, and the EuroQol instrument. Med Care 1997;35:522-37.

14. Feuerstein M. and Beattie P. Biobehavioral factors affecting pain and disability in low back pain: mechanisms and assessment. Physical therapy 1995;75:267-280.

15. Fisher $\mathrm{K}$ and Johnston $\mathrm{M}$. Emotional distress and control cognitions as mediators of the impact of chronic pain on disability. British Journal of Health Psychology 1998;3:225-36.

16. Fordyce WE, Roberts AH, and Sternbach RA. The behavioral management of chronic pain: a response to critics. Pain 1985;22:113-25.

17. Gatchel RJ and Gardea MA. Psychosocial issues: their importance in predicting disability, response to treatment, and search for compensation. Neurol Clin 1999;17:149-66.

18. Gatchel RJ, Noe CE, Pulliam C et al. A preliminary study of multidimensional pain inventory profile differences in predicting treatment outcome in a heterogeneous cohort of patients with chronic pain. Clin J Pain 2002;18:139-43.

19. Gommans IHB, Koes BW, and van Tulder MW. Validiteit en responsiviteit Nederlandstalige Roland Disability Questionnaire. Vragenlijst naar functionele status bij patiënten met lagerugpijn. Nederlands Tijdschrift voor Fysiotherapie 1997;2:28-33.

20. Goossens ME, Vlaeyen JW, Hidding A, Kole-Snijders A, and Evers SM. Treatment expectancy affects the outcome of cognitive-behavioral interventions in chronic pain. Clin J Pain 2005;21:1826; discussion 69-72. regel 3

regel 4

regel 5

regel 6

regel 7

regel 8

regel 9

regel 10

regel 11

regel 12

regel 13

regel 14

regel 15

regel 16

regel 17

regel 18

regel 19

regel 20

regel 21

regel 22

regel 23

regel 24

regel 25

regel 26

regel 27

regel 28

regel 29

regel 30

regel 31

regel 32

regel 33

regel 34

regel 35

regel 36

regel 37

regel 38 
regel 1

regel 2

regel 3

regel 4

regel 5

regel 6

regel 7

regel 8

regel 9

regel 10

regel 11

regel 12

regel 13

regel 14

regel 15

regel 16

regel 17

regel 18

regel 19

regel 20

regel 21

regel 22

regel 23

regel 24

regel 25

regel 26

regel 27

regel 28

regel 29

regel 30

regel 31

regel 32

regel 33

regel 34

regel 35

regel 36

regel 37

regel 38
21. Goubert L, Crombez G, Vlaeyen JWS, Van Damme S, Van den Broeck A, and Van Houdenhove B. De Tampa Schaal voor kinesiofobie: psychometrische karakteristieken en normering . Gedrag \& Gezondheid 2000;28:54-63.

22. Grahn B, Ekdahl C, and Borgquist L. Motivation as a predictor of changes in quality of life and working ability in multidisciplinary rehabilitation. A two-year follow-up of a prospective controlled study in patients with prolonged musculoskeletal disorders. Disabil Rehabil 2000;22:639-54.

23. Haazen IWCJ, Vlaeyen JWS, Kole-Snijders AMJ, van Eek H, van Es FD. Behavioral rehabilitation of chronic low back pain: searching for predictors of treatment outcome. Journal of Rehabilitation Sciences 1994:34-43.

24. Hasenbring, M. Predictors of efficacy of treatment in chronic low back pain. Current Opinion in Anaesthesiology 1998;11:553-58.

25. Hirsch G, Beach G, Cooke C, Menard M, and Locke S. Relationship between performance on lumbar dynamometry and Waddell score in a population with low-back pain. Spine 1991;16:1039-43.

26. Hunter, J. Medical history and chronic pain. Clin J Pain 2001;17:S20-S25.

27. Jensen MP, Turner JA, and Romano JM. Correlates of improvement in multidisciplinary treatment of chronic pain. J Consult Clin Psychol 1994;62:172-9.

28. Kerns RD, Turk DC, and Rudy TE. The West Haven-Yale Multidimensional Pain Inventory (WHYMPI). Pain 1985;23:345-56.

29. Lethem J, Slade PD, Troup JD, and Bentley G. Outline of a Fear-Avoidance Model of exaggerated pain perception--I. Behav Res Ther 1983;21:401-8.

30. Lousberg, R. Chronic Pain, Multiaxial diagnostics and behavioral mechanisms. Academic Dissertation. Maastricht, The Netherlands: Datawyse University Press; 1994.

31. Lousberg R, Groenman N, and Schmidt A. Profile characteristics of the MPI-DLV clusters of pain patients. J Clin Psychol 1996;52:161-7.

32. Lousberg R, Van Breukelen GJ, Groenman NH, Schmidt AJ, Arntz A, and Winter FA. Psychometric properties of the Multidimensional Pain Inventory, Dutch language version (MPIDLV). Behav Res Ther 1999;37:167-82.

33. Mannion AF, Junge A, Taimela S, Muntener M, Lorenzo K, and Dvorak J. Active therapy for chronic low back pain: part 3. Factors influencing self-rated disability and its change following therapy. Spine 2001;26:920-9.

34. McCracken LM , Gross RT, and Eccleston C. Multimethod assessment of treatment process in chronic low back pain: comparison of reported pain-related anxiety with directly measured physical capacity. Behav Res Ther 2002;40:585-94.

35. McCracken LM and Turk DC. Behavioral and cognitive-behavioral treatment for chronic pain: outcome, predictors of outcome, and treatment process. Spine 2002;27:2564-73.

36. Patrick DL, Deyo RA, Atlas SJ, Singer DE, Chapin A, and Keller RB. Assessing health-related quality of life in patients with sciatica. Spine 1995;20:1899-908; discussion 1909.

37. Pfingsten M, Franz C, Hildebrandt J, Saur P, and Seeger D. Multidisciplinary treatment program on chronic low back pain, part 3. Psychosocial aspects. Schmerz 1996;10:326-44.

38. Pocock SJ. Clinical Trials. A practical approach. Chichester, New York, Brisbane, Toronto, Singapore: John Wiley \& Sons Ltd, 1983.

39. Polatin PB, Gatchel RJ, Barnes D, Mayer H, Arens C, and Mayer TG. A psychosociomedical prediction model of response to treatment by chronically disabled workers with low-back pain. Spine 1989;14:956-61.

40. Rohling ML, Binder LM, Langinrichsen-Rohling J. Money matters: A meta-analytic review of the association between financial compensation and the experience and treatment of chronic pain. Health Psychol 1995;14:537-47.

41. Roland M and Morris R. A study of the natural history of back pain. Part I: development of a reliable and sensitive measure of disability in low-back pain. Spine 1983;8:141-4.

42. Rubin DB. Multiple Imputation for Non Response in Surveys. New York: J.Wiley \& Sons, 1987.

43. Schultz IZ, Crook J, Meloche GR et al. Psychosocial factors predictive of occupational low back disability: towards development of a return-to-work model. Pain 2004;107:77-85. 
44. Senn S. Baselines and covariate information. Statistical issues in drug development. Chicester, West Sussex, UK: John Wiley \& Sons Limited, 2002: 95-109.

45. Spinhoven P, Ter Kuile M, Kole-Snijders AM, Hutten Mansfeld M, Den Ouden DJ, and Vlaeyen JW. Catastrophizing and internal pain control as mediators of outcome in the multidisciplinary treatment of chronic low back pain. Eur J Pain 2004;8:211-9.

46. Talo S, Puukka P, Rytokoski U, Ronnemaa T, Kallio V. Can treatment outcome of chronic low back pain be predicted? Psychological disease consequences clarifying the issue. Clin J Pain 1994;10:107-21.

47. Talo S, Rytokoski U, Puukka P. Patient classification, a key to evaluate pain treatment: a psychological study in chronic low back pain patients. Spine 1992;17:998-1011.

48. Teasell RW. Compensation and chronic pain. Clin J Pain 2001;17:S46-64.

49. Triano JJ, McGregor M, Cramer GD, and Emde DL. A comparison of outcome measures for use with back pain patients: results of a feasibility study. J Manipulative Physiol Ther 1993;16:67-73.

50. Turk DC and Rudy TE. Toward an empirically derived taxonomy of chronic pain patients: integration of psychological assessment data. J Consult Clin Psychol 1988;56:233-8.

51. van Buuren S, Brand JPL, Groothuis-Oudshoorn CGM, Rubin DB. Fully Conditional Specification in Multivariate Imputation. Simulation study on the MICEalgorithm. J Stat Comput and Simulation 2006;76: 1049-1064.

52. van Buuren S, Oudshoorn CGM. Flexible multivariate imputation by MICE. Leiden: TNO Preventie en Gezondheid, TNO/VGZ/PG 99.054; 1999.

53. van der Hulst $M$, Vollenbroek-Hutten MM, and Ijzerman MJ. A systematic review of sociodemographic, physical, and psychological predictors of multidisciplinary rehabilitation-or, back school treatment outcome in patients with chronic low back pain. Spine 2005;30:813-25.

54. van der Zee K, Sanderman R, and Heyink J. De psychometrische kwaliteiten van de MOS 36item Short Form Health Survey (SF-36) in een Nederlandse populatie. T Soc Gez 1993;71:18391.

55. van der Zee K, Sanderman R, Heyink JW, and de Haes H. Psychometric qualities of the Rand 36-item health survey 1.0: a multidimensional measure of general health status. Int J Behav Med 1996;3:104-22.

56. Vlaeyen JW and Linton SJ. Fear-avoidance and its consequences in chronic musculoskeletal pain: a state of the art. Pain 2000;85:317-32.

57. Vlaeyen JW and Morley S. Cognitive-behavioral treatments for chronic pain: what works for whom? Clin J Pain 2005;21:1-8.

58. Voerman GE, Vollenbroek-Hutten MMR, Sandsjö LKR, and Hermens HJ. Prognostic factors for the effect of interventions for work-related neck-shoulder complaints: mofeedback training and ergonomic counselling. Appl Ergon 2008;39:743-53.

59. Vollenbroek-Hutten MM, Hermens HJ, Wever D, Gorter M, Rinket J, and Ijzerman MJ. Differences in outcome of a multidisciplinary treatment between subgroups of chronic low back pain patients defined using two multiaxial assessment instruments: the multidimensional pain inventory and lumbar dynamometry. Clin Rehabil 2004;18:566-79.

60. Walsh NE and Dumitru D. The influence of compensation on recovery from low back pain. Occup Med 1988;3:109-21.

61. Ware JE, Kosinski M. Norm-Based Scoring For Physical \& Mental Summary Measures. In: Ware JE, Kosinski M, eds. SF-36 Physical \& Mental Health Summary Scales: A Manual For Users of Version 1. 2nd ed. Lincoln, Rhode Island: QualityMetric Incorporated , 2002:28-34.

62. Ware JE, Kosinski M.Reliability and Statistical Power. SF-36 Physical \& Mental Health Summary Scales: A Manual For Users of Version 1. 2nd ed. Lincoln, Rhode Island: QualityMetric Incorporated , 2002:36-44.

63. Ware JE, Kosinski M. Empirical Validation. SF-36 Physical \& Mental Health Summary Scales: A Manual For Users of Version 1. 2nd ed. Lincoln, Rhode Island: QualityMetric Incorporated, 2002:45-55.

64. Ware JE Jr and Sherbourne CD. The MOS 36-item short-form health survey (SF-36). I. Conceptual framework and item selection. Med Care 1992;30:473-83. 
regel 1

regel 2

regel 3

regel 4

regel 5

regel 6

regel 7

regel 8

regel 9

regel 10

regel 11

regel 12

regel 13

regel 14

regel 15

regel 16

regel 17

regel 18

regel 19

regel 20

regel 21

regel 22

regel 23

regel 24

regel 25

regel 26

regel 27

regel 28

regel 29

regel 30

regel 31

regel 32

regel 33

regel 34

regel 35

regel 36

regel 37

regel 38
65. Woby SR, Watson PJ, Roach NK, and Urmston M. Are changes in fear-avoidance beliefs, catastrophizing, and appraisals of control, predictive of changes in chronic low back pain and disability? Eur J Pain 2004;8:201-10.

66. World Health Organization. International Classification of Functioning, Disability and Health. ICF checklist. 2001. [World Health Organisation web site]. Available at: http://www3.who.int/ icf/icftemplate.cfm. Accessed August 1, 2002.

67. Zachrisson Forsell M. The Swedish back school. Physiotherapy 1980;66:112-4. 


\section{Chapter 4}

Back muscle activation patterns

in chronic low back pain during walking: a "guarding" hypothesis

Marije van der Hulst, Miriam MR Vollenbroek-Hutten, Johan S Rietman, Leendert Schaake, Karin G Groothuis-Oudshoorn, Hermanus J Hermens

Clin J Pain (in press) 
Chapter 4

regel 1

regel 2

regel 3

regel 4

regel 5

regel 6

regel 7

regel 8

regel 9

regel 10

regel 11

regel 12

regel 13

regel 14

regel 15

regel 16

regel 17

regel 18

regel 19

regel 20

regel 21

regel 22

regel 23

regel 24

regel 25

regel 26

regel 27

regel 28

regel 29

regel 30

regel 31

regel 32

regel 33

regel 34

regel 35

regel 36

regel 37

regel 38

\begin{abstract}
Objectives: Investigate whether subjects with chronic low back pain (CLBP) show "guarded" movements during walking. It is hypothesized that guarding will be reflected by increased lumbar muscle activity during all periods of stride and secondary, by relatively less relaxation during periods of swing compared with double support. Furthermore, it is hypothesized that higher levels of perceived fear and disability are related to increased muscle activity and less relative relaxation.
\end{abstract}

Materials and methods: In a cross-sectional study sixty-three subjects with CLBP and thirtythree healthy controls walked on a treadmill at $3.8 \mathrm{~km} / \mathrm{h}$. Surface Electromyography (sEMG) data of the erector spinae were obtained and smoothed rectified sEMG (SRE) values were calculated per period of swing and double support. The ratio of SRE values in swing to double support was used as a measure of relative relaxation (SRE ratio). Additionally, the relation between SRE values, the Roland Morris Disability Questionnaire and the Tampa Scale for Kinesiophobia was analyzed in subjects with CLBP.

Results: Mean SRE values were significantly higher in subjects with CLBP than in controls both during periods of double support and swing. SRE ratios were not significantly different between groups. Results showed no influence of disability or fear of movement on either SRE values or ratios.

Conclusions: In subjects with CLBP, increased lumbar muscle activity during all periods of stride, with comparable alteration between swing and double support, suggests difficulties with total muscle relaxation. Based on this, it is concluded that subjects with CLBP show a guarding mechanism during walking. No relation is found between perceived fear, disability and muscle activity. 


\section{Introduction}

The development and maintenance of nonspecific chronic low back pain (CLBP) is complex and not well understood. It is generally accepted that nonspecific CLBP requires a multidimensional approach. Understanding possible biomechanical and psychological mechanisms in CLBP is important to improve treatment strategies. One of these underlying mechanisms may be changes in movement patterns, such as guarded movements, a concept introduced by Main and Watson ${ }^{20}$. Guarded movement has been described as abnormalities in muscle action in subjects with CLBP during physical activity, although a clear definition in subjects with CLBP has not been given in literature. Evidence for guarded movements has been found in standardized flexion-extension tasks. Subjects with CLBP show less relaxation of the lumbar muscles in full flexion (i.e. lower flexion -relaxation ratios (FRR's)) 28:551, when compared to healthy controls. It must however, be mentioned that this absence of relaxation could also be attributed to the decreased range of motion during maximal flexion ${ }^{2 ; 8}$.

Whether a guarding mechanism is present during other daily functional tasks like walking, is not clear. Literature addressing walking indicates that lumbar muscles normally show a biphasic activity pattern in double support, with relaxation during the periods of swing ${ }^{52}$. In subjects with CLBP, authors have found higher average erector spinae activity during the total stride ${ }^{1 ; 48}$ and during periods of swing ${ }^{4 ; 17}$. The absolute levels of muscle activity are 8- 48\% higher in subjects with CLBP ${ }^{17}$ than in healthy controls, which vary between $5-10 \mu \mathrm{V}^{3}$. So far, no studies have focused on the amount of activity during periods of double support in CLBP. Within the concept of guarding, it is expected that lumbar muscle activity is also higher during double support. It might even be the case that the alteration in muscle activity between periods of swing and double support (i.e. relative relaxation) is absent. Relaxation is according to the Cinderella hypothesis of great importance. The Cinderella hypothesis, which has been extensively investigated for neck and shoulder problems ${ }^{15}$, states that in case of insufficient muscle relaxation, particularly the low threshold type I motor units are continuously active, get damaged, degenerate and by this contribute to the maintenance of pain. As such, according to this hypothesis, lack of relaxation of muscles is probably most unfavorable. Applying this theory to walking, it is important to investigate whether subjects with CLBP show increased lumbar muscle activity during all periods of stride compared to controls and whether less relaxation is present during swing. The amount of relative relaxation during swing, measured as the ratio of activity in swing to double support, has not been studied so far.

From a psychological point of view, the concept of guarding has been explored to some extent, but shows inconsistent results. Fear-avoidance beliefs are significantly related to low FRR's (i.e. less relaxation) ${ }^{8}$ and reduction in fear avoidance beliefs to increased FRR's after regel 1

regel 2

regel 3

regel 4

regel 5

regel 6

regel 7

regel 8

regel 9

regel 10

regel 11

regel 12

regel 13

regel 14

regel 15

regel 16

regel 17

regel 18

regel 19

regel 20

regel 21

regel 22

regel 23

regel 24

regel 25

regel 26

regel 27

regel 28

regel 29

regel 30

regel 31

regel 32

regel 33

regel 34

regel 35

regel 36

regel 37

regel 38 
regel 1 regel 2 regel 3 regel 4 regel 5 regel 6 regel 7 regel 8 regel 9 regel 10 regel 11 regel 12 regel 13 regel 14 regel 15 regel 16 regel 17 regel 18 regel 19 regel 20 regel 21 regel 22 regel 23 regel 24 regel 25 regel 26 regel 27 regel 28 regel 29 regel 30 regel 31 regel 32 regel 33 regel 34 regel 35 regel 36 regel 37 regel 38

a pain management program ${ }^{50}$, both supporting the guarding hypothesis. In contrast, no significant differences were found between lumbar muscle activity in fearful-and non-fearful subjects with CLBP during a fear-eliciting video presentation. Additionally, during walking no significant association has been found between fear - avoidance beliefs and lumbar muscle activity ${ }^{17}$. This latter result was however based on a limited number of subjects.

Based on this, it can be concluded that the concept of guarding during a daily activity task like walking is not sufficiently clear. Knowledge of lumbar muscle activity is clinically important to better understand the underlying physical mechanisms in CLBP. This might enable the clinician to further optimize interventions to eventually reduce pain and disability. Therefore, the aim of this study is to further explore the concept of guarding from both a physiological - as well as a psychological point of view. It is hypothesized that subjects with CLBP, in comparison to asymptomatic controls, will show elevated lumbar muscle activity during all periods of stride with secondary, relative less relaxation in the periods of swing when compared to double support. Furthermore, more fear of movement and a higher disability level (i.e. more limitation of activities) are hypothesized to be related to increased lumbar muscle activity and less relative relaxation.

\section{Materials and methods}

\section{Subjects}

Subjects with CLBP, who were referred to a physician in Physical Medicine and Rehabilitation between July 2004 and July 2005, and healthy controls were asked to participate in the study. Inclusion criteria for the patient group were: age between 16-70 years and more than three months continuing or recurrent low back pain. Low back pain was defined as pain under the scapulas, above the cleft of the buttock, with or without radiation to the extremities. Exclusion criteria were: surgery of the spine in the past three months, spondylodeses, structural pathology of the spine like inflammation, active radiculopathy, tumor, severe deformities (e.g. spondylolisthesis grade 3) or neurological and/or musculoskeletal disorders that could have an effect on gait. Specific causes of low back pain were excluded by the physician's assessment (history, physical examination, if necessary blood tests and X-rays). All patients had previously undergone some form of treatment (medication or physiotherapy) without lasting relief. Controls (personnel from the rehabilitation center, their family or friends) were healthy volunteers with no history of back pain in the preceding twelve months, previous surgery of the spine, neurological and/or musculoskeletal disorders that could have an effect on gait. Healthy controls were recruited by mail. Subjects were matched on a group level for age, gender and Body Mass Index (BMI) meaning that the groups were on average comparable for 
these parameters. Due to the expected heterogeneity of the subjects with CLBP, twice as many patients were included compared to controls. Participants who met the inclusion criteria and were willing to participate gave informed consent. The study was approved by the Medical Ethical Committee of the Rehabilitation Center "het Roessingh" in Enschede.

\section{Design and procedure}

A cross-sectional study was conducted and performed on a treadmill. Participants filled out the questionnaires before the start of the experiment. Subjects were allowed to practice treadmill walking until they were accustomed to the walking conditions with a maximum of five minutes before the measurements started. They were instructed to walk as naturally as possible without using the handrail. Velocity was set at 3.8 kilometres per hour $(\mathrm{km} / \mathrm{h})$ to improve comparability with former studies $4 ; 16 ; 17 ; 4$. Data of at least twenty strides were collected to ensure a representative dataset ${ }^{33}$.

\section{Measurements}

Questionnaires

Sociodemographic (age, gender, level of education, work status), anthropometric (height, weight) and pain-related (duration, current pain intensity and site of pain) variables were collected. Current pain intensity was measured by a Visual Analogue Scale (VAS, $0=$ no pain, $100=$ most severe pain). The VAS scale is found to be valid and reliable ${ }^{40}$. Activity limitation of patients was measured with the Dutch version of the Roland Morris Disability Questionnaire (RMDQ). The Dutch RMDQ ( $0=$ no disabilities, $24=$ severe disabilities $)$ is shown to be valid ${ }^{9}$ and reliable ${ }^{6}$. Fear of movement was determined with the Tampa Scale for Kinesiophobia Dutch Version (TSK-DV) which originally consists of 17 items, each scored on a 4 point Likert scale with scoring alternatives ranging from "strongly disagree" to "strongly agree". The TSK-DV is sufficiently reliable and has predictive validity ${ }^{46}$. Psychometric studies have favored a two factor model of the TSK 10:28, labeled "activity avoidance" (AA), which reflects the belief that activity may result in (re)injury and increased pain, and pathological "somatic focus" (SF), which reflects the belief in underlying and serious medical problems. Both studies support the constructive and predictive validity of both these subscales of the TSK. Recent research supports the reliability and validity of the TSK-11 and its two subscales AA (6 items, range 6-24) and SF (5 items, range 5-20) ${ }^{29}$.

\section{Kinematics and surface electromyography (sEMG)}

Kinematical and sEMG data were collected simultaneously during walking on a motorized treadmill (Tunturi T-Track/G200) at $3.8 \mathrm{~km} / \mathrm{h}$. The investigator collecting sEMG and kinematical data was not blinded for group. A six camera optical three-dimensional gait analysis system (VICON 370, Oxford metrics Ltd., Oxford UK) was used to determine foot

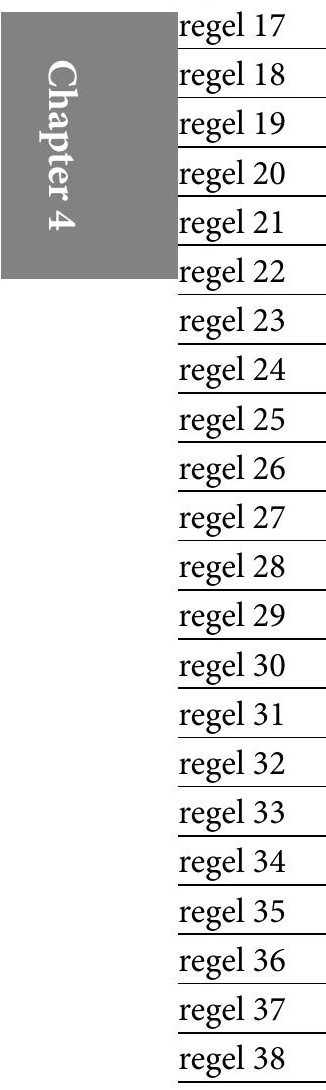

regel 1

regel 2

regel 3

regel 4

regel 5

regel 6

regel 7

regel 8

regel 9

regel 10

regel 11

regel 12

regel 13

regel 14

regel 15

regel 16

regel 17

regel 18

regel 19

regel 20

regel 21

regel 22

regel 23

regel 24

regel 25

regel 26

regel 27

regel 28

regel 29

regel 30

regel 31

regel 32

regel 33

regel 34

regel 35

regel 36

regel 37

regel 38 
regel 1 regel 2 regel 3 regel 4 regel 5 regel 6 regel 7 regel 8 regel 9 regel 10 regel 11 regel 12 regel 13 regel 14 regel 15 regel 16 regel 17 regel 18 regel 19 regel 20 regel 21 regel 22 regel 23 regel 24 regel 25 regel 26 regel 27 regel 28 regel 29 regel 30 regel 31 regel 32 regel 33 regel 34 regel 35 regel 36 regel 37 regel 38 contacts. VICON markers were placed on the second metatarsal phalangeal joint (MTP 2) and on the posterior side of the calcaneus. Marker data were collected with a sampling rate of $50 \mathrm{~Hz}$.

Muscle activity patterns of subjects were measured by using multichannel bipolar sEMG (16 channels Biotel 99, Glonner Electronic GmbH, Planegg, Germany). Bipolar sEMG was measured with solid gel electrodes (Arbo H93SG, Tyco Healthcare), placed bilaterally with an inter-electrode distance of $23 \mathrm{~mm}$ on the muscle belly after removal of hair and cleaning the subject's skin with alcohol. Electrodes were placed on the left and right side, $30 \mathrm{~mm}$ lateral to the first lumbar processus spinosus (L1), according to the SENIAM (Surface Electromyography for the Non-Invasive Assessment of Muscles) guidelines ${ }^{13}$, and $30 \mathrm{~mm}$ lateral to the fourth lumbar processus spinosus (L4) ${ }^{45}$ (in total four channels). Lumbar vertebrae were located through palpation, using the iliac crest as landmark. All wires and leads were fixed with tape to the subject's skin to diminish artifacts without limiting motion. A common reference electrode was placed over the right processus styloideus ulnae. In the pre-processed method, sEMG data were collected with a sampling rate of $1024 \mathrm{~Hz}$ and band passed filtered using a first order filter of $17-500 \mathrm{~Hz}$.

\section{Data analysis}

Temporal parameters:

The collected data were imported in the home built analysis software, developed using Labview 8.2 National Instruments (Austin, Texas, USA). Movement of markers was measured according to the coordinate system of the laboratory room. Events of the gait cycle (initial contact and toe off) were determined by calculating the displacement in the horizontal direction of the MTP 2 and calcaneus marker. A stride was defined from the first left initial contact (LIC) to the next LIC (Figure 1). Initial double support (DS1) was defined from LIC to right toe off, followed by contralateral swing (CSw) until right initial contact (RIC). Contralateral swing is equal to ipsilateral single limb stance. The second period of double support (DS2) was defined from RIC to left toe off, followed by the ipsilateral swing phase (ISw) until LIC. In summary, a stride was divided in two periods of double support and two periods of swing (contra-and ipsilateral). 


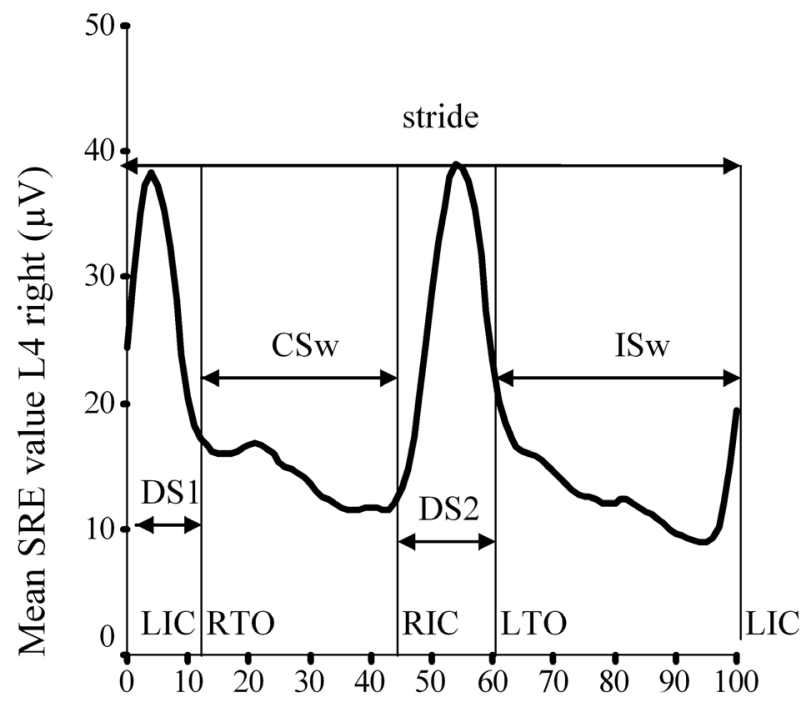

percentage gait cycle $(\%)$

Figure 1 Example of SRE pattern of erector spinae (L4 right) per stride: control group, mean value of 20 steps, $3.8 \mathrm{~km} / \mathrm{h}$. CSw indicates contralateral swing; DS1, first double support; DS2, second double support; ISw, ipsilateral swing; L(R)IC = left (right) initial contact, L(R)TO = left (right) toe off; SRE, smoothed rectified EMG

\section{Surface EMG}

In the post processed method, sEMG was high pass filtered at $20 \mathrm{~Hz}$, using a $3^{\text {rd }}$ order Butterworth filter, to remove movement artifacts. After the signal was double phase rectified, it was low pass filtered at $25 \mathrm{~Hz}$ to calculate Smooth Rectified EMG (SRE) values. To account for different cycle durations between subjects, EMG was normalized in time for each stride per subject. Averaged SRE values of approximately 20 time-normalized EMG profiles were used. For each individual, the SRE values per stride were divided in four periods (DS1, CSw, DS2 and ISw) and averaged. Main outcome parameters were:

- Averaged SRE values per stride and per period of stride (DS1, CSw, DS2 and ISw)

- The ratio between the averaged SRE value in the periods of swing- and the averaged value in double support. Two ratios were calculated: averaged SRE (CSw/DS1) and averaged SRE (ISw/DS2). A high ratio reflects relatively high activity in swing compared to double support (i.e. less relative relaxation).

sEMG data of strides were excluded from the analysis when visual inspection of the EMG signals showed movement artifacts, reflected by high amplitude and low frequency signals. The investigator performing this visual inspection was blinded for group. regel 1

regel 2

regel 3

regel 4

regel 5

regel 6

regel 7

regel 8

regel 9

regel 10

regel 11

regel 12

regel 13

regel 14

regel 15

regel 16

regel 17

regel 18

regel 19

regel 20

regel 21

regel 22

regel 23

regel 24

regel 25

regel 26

regel 27

regel 28

regel 29

regel 30

regel 31

regel 32

regel 33

regel 34

regel 35

regel 36

regel 37

regel 38 
regel 1

regel 2

regel 3

regel 4

regel 5

regel 6

regel 7

regel 8

regel 9

regel 10

regel 11

regel 12

regel 13

regel 14

regel 15

regel 16

regel 17

regel 18

regel 19

regel 20

regel 21

regel 22

regel 23

regel 24

regel 25

regel 26

regel 27

regel 28

regel 29

regel 30

regel 31

regel 32

regel 33

regel 34

regel 35

regel 36

regel 37

regel 38

\section{Statistical analysis}

The investigator performing the data analysis was blinded for group. Comparability of baseline variables of both groups was determined with Student's independent samples t-tests for continuous variables and with $\chi^{2}$ tests for categorical data. Random coefficient analysis, also known as multilevel analysis, was used to study the differences in averaged SRE values per periods of stride and ratios (CSw/DS1 and ISw/DS2) between both groups. In this study measurements were done at increasing walking velocities within an individual, of which the results will be presented in a separate paper. Random coefficient analysis was chosen because it takes into account that the repeated measures at different walking velocities within individuals are correlated. Residuals were checked for normality. If necessary, a natural logarithm (ln) transformation of the dependent variables was done to improve normal distribution of the residuals. Statistical analyses were performed using the statistical software SPSS v.11.5.

The independent variables included in the model were: group (patient/control), muscle (L1 left/right, L4 left/right), period of stride (DS1, CSw, DS2, ISw) and gender as factors; age and body mass index (BMI $\left.\left(\mathrm{kg} / \mathrm{m}^{2}\right)\right)$ as covariates. Age and gender were added because of their possible confounding effect on muscle fiber size ${ }^{21 ; 22 ; 3638}$, which in turn is likely to influence muscle activity. BMI was added because the amount of fat overlying the muscle reduces the sEMG signal. Additionally, random coefficient analysis as described above was done for the subjects with CLBP separately, to study a possible relation between SRE values or ratios and current pain intensity (VAS), fear of movement or (re)injury (TSK-AA and TSK-SF), level of activity limitation (RMDQ) and work status (full-/part-time or not working). 


\section{Results}

\section{Study population}

Of the 123 persons who were suitable for inclusion, 96 (78\%) participated (63 subjects with CLBP, 33 healthy controls). The main reason of not willing to participate was lack of sufficient time or motivation. Due to sEMG movement artifacts, 5 persons (4 subjects with CLBP, 1 control) were excluded from these 96, so 91 persons (59 subjects with CLBP, 32 controls) were included in the final analysis. Baseline characteristics are reported in Table 1. Groups were comparable in age, BMI and gender $(\mathrm{p}>0.05)$. Groups differed in educational level and work status $(p<0.01)$. Compared to controls, most subjects with CLBP had lower or intermediate vocational education and were not working. They showed a moderate level of current pain, activity limitation and fear of movement.

Table 1 Baseline characteristics of the study population

\begin{tabular}{|c|c|c|}
\hline & $\begin{array}{l}\text { Patients } \\
\mathrm{N}=63\end{array}$ & $\begin{array}{l}\text { Controls } \\
\mathrm{N}=33\end{array}$ \\
\hline Age (years) & $41(11)$ & $40(11)$ \\
\hline Male gender & $33(52 \%)$ & $16(48 \%)$ \\
\hline Body Mass Index $\left(\mathrm{kg} / \mathrm{m}^{2}\right)$ & $26(20-35)^{2)}$ & $25(18-36)$ \\
\hline $\begin{array}{l}\text { Education level } \\
\text { Elementary school } \\
\text { Lower/ intermediate vocational education } \\
\text { Higher vocational education/ academic degree }\end{array}$ & $\begin{array}{l}2(3 \%) \\
52(83 \%) \\
9(14 \%)\end{array}$ & $\begin{array}{l}0(0 \%) \\
11(33 \%) \\
22(67 \%)\end{array}$ \\
\hline $\begin{array}{l}\text { Work status } \\
\text { Full-/part-time } \\
\text { Not working }\end{array}$ & $\begin{array}{l}28(44 \%) \\
35(56 \%)\end{array}$ & $\begin{array}{l}32(97 \%) \\
1(3 \%)\end{array}$ \\
\hline Duration of complaints (mo) & $17(3-72)^{3)}$ & - \\
\hline $\begin{array}{l}\text { Location of complaints } \\
\text { left } \\
\text { right } \\
\text { bilateral }\end{array}$ & $\begin{array}{l}12(19 \%) \\
10(16 \%) \\
41(65 \%)\end{array}$ & - \\
\hline $\begin{array}{l}\text { VAS (0-100) } \\
\text { Current pain }\end{array}$ & $47(5-94)$ & - \\
\hline RMDQ (0-24) & $11(4)$ & - \\
\hline TSK activity avoidance (6-24) & $15(4)$ & - \\
\hline TSK somatic focus $(5-20)$ & $10(3)$ & - \\
\hline
\end{tabular}

Note VAS=Visual Analogue Scale; RMDQ= Roland Morris Disability Questionnaire; TSK = Tampa Scale for Kinesiofobia

$\mathrm{Ad}^{1)}$ the median value is reported if this parameter is not normally distributed.

$\mathrm{Ad}^{2)} 1$ outlier: Body Mass Index $50 \mathrm{~kg} / \mathrm{m}^{2}$ excluded due to movement artifacts.

$\mathrm{Ad}^{3)} 1$ outlier: 288 months, included because of no significant influence on SRE values. regel 1

regel 2

regel 3

regel 4

regel 5

regel 6

regel 7

regel 8

regel 9

regel 10

regel 11

regel 12

regel 13

regel 14

regel 15

regel 16

regel 17

regel 18

regel 19

regel 20

regel 21

regel 22

regel 23

regel 24

regel 25

regel 26

regel 27

regel 28

regel 29

regel 30

regel 31

regel 32

regel 33

regel 34

regel 35

regel 36

regel 37

regel 38 
regel 1 regel 2 regel 3 regel 4 regel 5 regel 6 regel 7 regel 8 regel 9 regel 10 regel 11 regel 12 regel 13 regel 14 regel 15 regel 16 regel 17 regel 18 regel 19 regel 20 regel 21 regel 22 regel 23 regel 24 regel 25 regel 26 regel 27 regel 28 regel 29 regel 30 regel 31 regel 32 regel 33 regel 34 regel 35 regel 36 regel 37 regel 38

\section{Temporal stride parameters}

All participants were able to walk at $3.8 \mathrm{~km} / \mathrm{h}$ on the treadmill. Data of the left cycle were analyzed. The duration of the stride phase is comparable between both groups (CLBP: $1.1 \pm$ 0.8 seconds; controls: $1.1 \pm 0.6$ seconds, $\mathrm{p}>0.05)$. The stance phase is relatively long in both groups (CLBP: $66.2 \pm 1.5 \%$; controls: $67.0 \pm 1.0 \%, \mathrm{p}=0.01$ ).

\section{Surface EMG}

SRE values per stride (left cycle)

In Figure 1 an example of the average sEMG profile with the different periods of stride is shown. Figure 2 presents the average SRE pattern for the recording at L4 (right) for both groups during the left cycle. The other recordings (L1, L4 left) have comparable patterns. Both groups show on average the same biphasic pattern. sEMG activity is highest in double support and lowest in ipsi- or contralateral swing. The averaged SRE values and ratios are presented in Table 2. For absolute SRE values, but not for ratios, natural logarithm transformation was needed to achieve a normal distribution of the residuals. A post hoc power analysis based on the expected increase of $39 \%$ in average sEMG activity as found in a former study ${ }^{17}$ and the averaged SRE values from Table 2, showed that 63 subjects with CLBP would have been sufficient for a power of $97 \%$.

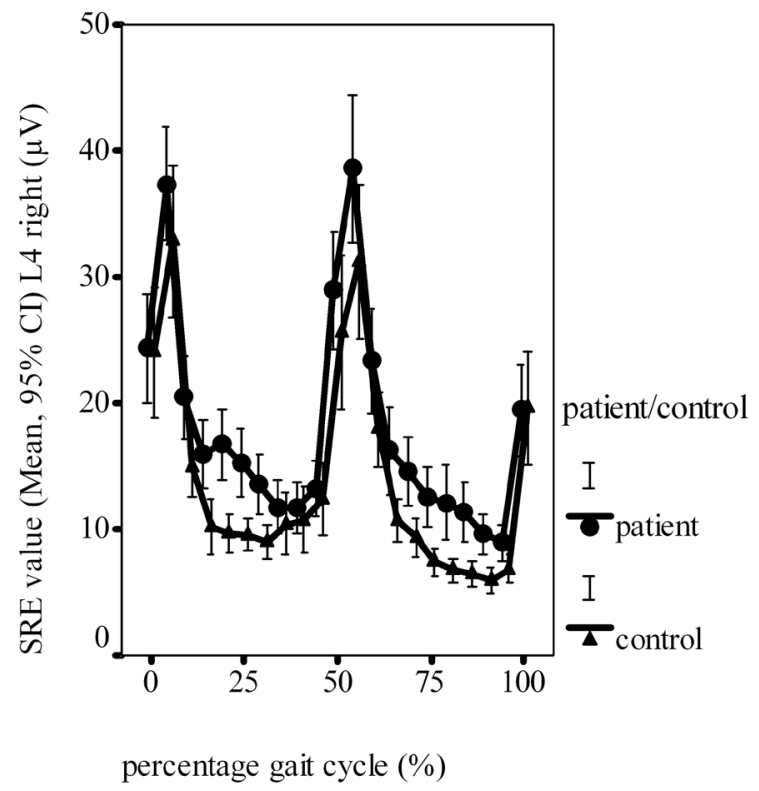

Figure 2 Average SRE pattern of erector spinae (L4 right): 20 steps, $3.8 \mathrm{~km} / \mathrm{h}$. CI indicates confidence interval; SRE, smoothed rectified EMG. 
Table 2. Averaged ( \pm SD) SRE values for subjects with CLBP and matched healthy controls: total stride, per period of stride and ratios between different periods of stride (left cycle).

\begin{tabular}{|c|c|c|c|c|c|}
\hline \multirow[t]{2}{*}{ Recording } & & \multicolumn{2}{|l|}{ L1 } & \multicolumn{2}{|l|}{$\mathrm{L4}$} \\
\hline & & Left & Right & Left & Right \\
\hline \multicolumn{6}{|c|}{ Average $( \pm$ SD) SRE $(\mu \mathrm{V})$} \\
\hline \multirow[t]{2}{*}{ Total stride } & Patient & $16.2(7.6)$ & $16.6(8.6)$ & $16.9(8.3)$ & $17.8(9.2)$ \\
\hline & Control & $13.9(5.6)$ & $12.8(3.7)$ & $14.5(4.9)$ & $13.6(4.3)$ \\
\hline \multirow[t]{2}{*}{ DS1 } & Patient & $19.3(9.0)$ & $30.2(15.8)$ & $24.6(11.7)$ & $26.0(12.8)$ \\
\hline & Control & $16.3(7.5)$ & $21.2(7.8)$ & $22.4(10.1)$ & $21.0(7.9)$ \\
\hline \multirow[t]{2}{*}{ CSw } & Patient & $10.8(5.7)$ & $13.8(9.4)$ & $11.4(7.0)$ & $14.5(8.5)$ \\
\hline & Control & $11.4(6.7)$ & $10.0(4.1)$ & $9.3(5.0)$ & $11.3(4.7)$ \\
\hline \multirow[t]{2}{*}{ DS2 } & Patient & $30.8(14.0)$ & $19.6(10.3)$ & $26.8(12.2)$ & $27.9(15.5)$ \\
\hline & Control & $22.4(8.7)$ & $14.7(5.7)$ & $22.3(7.7)$ & $21.3(9.2)$ \\
\hline \multirow[t]{2}{*}{ ISw } & Patient & $13.3(8.8)$ & $11.1(6.2)$ & $13.9(8.7)$ & $12.1(7.8)$ \\
\hline & Control & $11.0(5.7)$ & $10.0(3.8)$ & $11.3(5.0)$ & $8.0(2.6)$ \\
\hline \multirow[t]{2}{*}{ Ratio CSw/DS1 } & Patient & $0.60(0.23)$ & $0.46(0.18)$ & $0.49(0.18)$ & $0.56(0.19)$ \\
\hline & Control & $0.73(0.28)$ & $0.49(0.18)$ & $0.45(0.21)$ & $0.58(0.32)$ \\
\hline \multirow[t]{2}{*}{ Ratio ISw/DS2 } & Patient & $0.43(0.15)$ & $0.58(0.18)$ & $0.52(0.17)$ & $0.45(0.17)$ \\
\hline & Control & $0.50(0.18)$ & $0.72(0.22)$ & $0.52(0.20)$ & $0.41(0.16)$ \\
\hline
\end{tabular}

Note $\mathrm{SD}=$ standard deviation, $\mathrm{SRE}=$ smoothed rectified $\mathrm{sEMG}, \mathrm{CLBP}=$ chronic low back pain,

DS1: initial double support, CSw: contralateral swing, DS2: second double support, ISw: ipsilateral swing

SRE values per periods of stride (left cycle)

Results show that the averaged natural logarithm SRE values of the erector spinae are significantly higher in patients than in controls, for all recording sites in both periods of double support and swing (Table 3). In patients, averaged SRE values are 16 to $28 \%$ higher compared to controls. Beta coefficients for the outcome (natural logarithm) SRE value (M, $95 \% \mathrm{CI})$ are $0.15(-0.01-0.31) \mu \mathrm{V}$ to $0.25(0.09-0.41) \mu \mathrm{V}$ higher in patients than in controls. Although erector spinae activity is higher in patients in all periods of stride, the interaction between group and period of stride shows no significant results. Other variables including possible confounders are also related to average SRE values. Male gender is almost- and older age is significantly related to higher erector spinae activity and a higher BMI is significantly related to less activity.

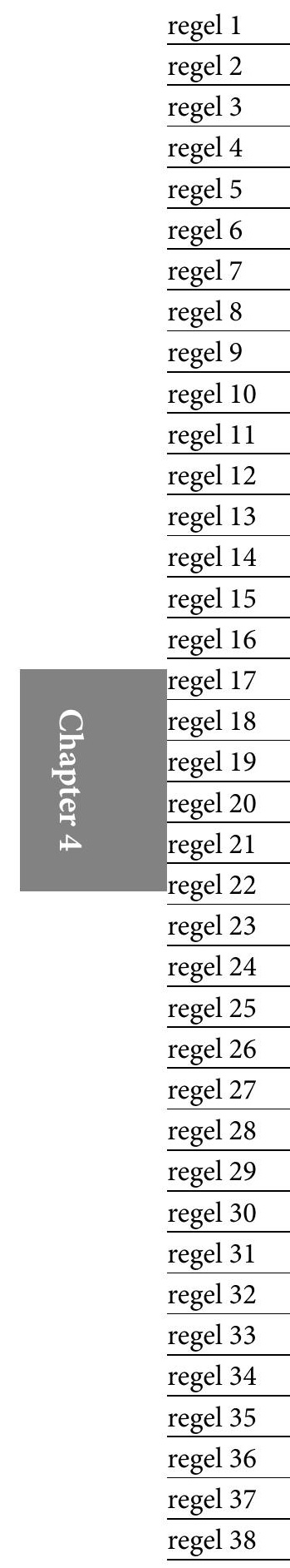


regel 1 regel 2 regel 3 regel 4 regel 5 regel 6 regel 7 regel 8 regel 9 regel 10 regel 11 regel 12 regel 13 regel 14 regel 15 regel 16 regel 17 regel 18 regel 19 regel 20 regel 21 regel 22 regel 23 regel 24 regel 25 regel 26 regel 27 regel 28 regel 29 regel 30 regel 31 regel 32 regel 33 regel 34 regel 35 regel 36 regel 37 regel 38
Table 3. Random coefficient analysis for averaged SRE values (ln transformation) between periods of stride.

\begin{tabular}{llccc}
\hline \multicolumn{2}{l}{ Average ln SRE $(\boldsymbol{\mu V})$} & Beta $(\mathrm{SE})$ & $\mathbf{9 5 \%}$ CI & $\mathbf{p}$ \\
\hline Intercept & & 2.16 & $2.02-2.30$ & 0.00 \\
Group: & Patient & 0.20 & $0.05-0.34$ & 0.01 \\
& Control & $0^{1)}$ & - & - \\
Muscle: & L1 left & -0.07 & $-0.12--0.02$ & 0.01 \\
& L1 right & -0.09 & $-0.14--0.04$ & 0.00 \\
& L4 left & -0.02 & $-0.07-0.04$ & 0.55 \\
& L4 right & $0^{1)}$ & - & - \\
Phase: & DS1 & 0.71 & $0.66-0.76$ & 0.00 \\
& CSw & 0.00 & $-0.05-0.05$ & 0.91 \\
& DS2 & 0.75 & $0.69-0.80$ & 0.00 \\
Gender: & ISw & $0^{1)}$ & - & - \\
Agle & female & 0.14 & $-0.00-0.28$ & 0.06 \\
BMI $\left(\mathrm{kg} / \mathrm{m}^{2}\right)$ & $0^{1)}$ & - & - \\
\hline \multicolumn{2}{l}{} & 0.01 & $0.00-0.02$ & 0.00 \\
& & -0.04 & $-0.06--0.02$ & 0.01 \\
\hline
\end{tabular}

Note $\mathrm{SRE}=$ smoothed rectified $\mathrm{sEMG}, \mathrm{SE}=$ standard error, $95 \% \mathrm{CI}=95 \%$ confidence interval, DS1: initial double support, CSw: contralateral swing, DS2: second double support, ISw: ipsilateral swing, BMI = Body Mass Index

$\mathrm{Ad}^{1)}$ Value is set as reference group in the analysis

SRE ratios (swing to double support, left cycle)

Ratios of averaged SRE values in the periods of swing - to double support are comparable between patients and controls (Table 4). Other variables including confounding factors also significantly influence SRE ratios. Male gender is not significantly related to differences in ratios between both groups. The influence of age and BMI is, although significant, very modest due to small beta coefficients. Older age is related to higher ratios and conversely, a higher BMI to lower ratios. 
Table 4. Random coefficient analysis for ratios of averaged SRE values between periods of stride

\begin{tabular}{|c|c|c|c|c|}
\hline \multicolumn{2}{|c|}{ Ratio CSw/DS1 } & Beta (SE) & $95 \% \mathrm{CI}$ & $\mathbf{p}$ \\
\hline \multicolumn{2}{|c|}{ Intercept } & 0.60 & $0.52-0.67$ & 0.00 \\
\hline \multirow[t]{2}{*}{ Group: } & Patient & -0.04 & $-0.11-0.04$ & 0.33 \\
\hline & Control & $0^{1)}$ & - & - \\
\hline \multirow[t]{4}{*}{ Muscle: } & L1 left & 0.08 & $0.03-0.13$ & 0.00 \\
\hline & L1 right & -0.09 & $-0.14--0.05$ & 0.00 \\
\hline & L4 left & -0.09 & $-0.14--0.04$ & 0.00 \\
\hline & L4 right & $0^{1)}$ & - & - \\
\hline \multirow{2}{*}{ Gender: } & male & -0.01 & $-0.08-0.07$ & 0.89 \\
\hline & female & $0^{1)}$ & - & - \\
\hline \multicolumn{2}{|l|}{ Age } & 0.003 & $0.00-0.01$ & 0.06 \\
\hline \multicolumn{2}{|c|}{$\operatorname{BMI}\left(\mathrm{kg} / \mathrm{m}^{2}\right)$} & 0.01 & $0.00-0.02$ & 0.03 \\
\hline \multicolumn{2}{|c|}{ Ratio ISw/DS2 } & Beta (SE) & $95 \% \mathrm{CI}$ & $\mathbf{p}$ \\
\hline \multicolumn{2}{|c|}{ Intercept } & 0.46 & $0.40-0.51$ & 0.00 \\
\hline \multirow[t]{2}{*}{ Group: } & Patient & -0.05 & $-0.10--0.00$ & 0.07 \\
\hline & Control & $0^{1)}$ & - & - \\
\hline \multirow[t]{4}{*}{ Muscle: } & L1 left & 0.01 & $-0.03-0.05$ & 0.63 \\
\hline & L1 right & 0.19 & $0.15-0.23$ & 0.00 \\
\hline & L4 left & 0.08 & $0.04-0.12$ & 0.00 \\
\hline & L4 right & $0^{1)}$ & - & - \\
\hline \multirow[t]{2}{*}{ Gender: } & male & 0.03 & $-0.03-0.08$ & 0.33 \\
\hline & female & $0^{1)}$ & - & - \\
\hline \multicolumn{2}{|c|}{ Age } & 0.00 & $-0.00-0.00$ & 0.24 \\
\hline \multicolumn{2}{|c|}{ BMI $\left(\mathrm{kg} / \mathrm{m}^{2}\right)$} & 0.01 & $0.00-0.01$ & 0.02 \\
\hline
\end{tabular}

Note $\mathrm{SRE}=$ smoothed rectified $\mathrm{sEMG}, \mathrm{SE}=$ standard error, $95 \% \mathrm{CI}=95 \%$ confidence interval, DS1: initial double support, CSw: contralateral swing, DS2: second double support, ISw: ipsilateral swing, BMI = Body Mass Index

$\mathrm{Ad}^{1)}$ Value is set as reference group in the analysis

\section{Relation between SRE values (left cycle), fear of movement and activity limitation}

Within the group of CLBP, no significant association between SRE values in the different periods of stride and current pain, disability, fear-avoidance beliefs, or work status is found. Also no significant influence of these variables is seen on ratios between the periods of swing and double support. 
regel 1

regel 2

regel 3

regel 4

regel 5

regel 6

regel 7

regel 8

regel 9

regel 10

regel 11

regel 12

regel 13

regel 14

regel 15

regel 16

regel 17

regel 18

regel 19

regel 20

regel 21

regel 22

regel 23

regel 24

regel 25

regel 26

regel 27

regel 28

regel 29

regel 30

regel 31

regel 32

regel 33

regel 34

regel 35

regel 36

regel 37

regel 38

\section{Discussion}

This study shows that subjects with CLBP and healthy controls differ in erector spinae activity during walking on a treadmill as assessed by sEMG. Subjects with CLBP show elevated absolute activity levels both in swing and double support, but similar relative relaxation in periods of swing. Besides, no relation is found between erector spinae activity and perceived disability (i.e. activity limitation) or fear of movement.

It is interesting to discuss the possible mechanisms underlying the overall increase in erector spinae activity (up to 28\%) in all periods of stride in CLBP. It could be that guarding functions to control spinal motion. As the erector spinae are normally active in double support to control trunk movement ${ }^{25 ; 52}$, the increased activity found in double support may be a mechanism to efficiently control anterior or lateral deviations of the trunk ${ }^{11}$. Literature has shown a relation between lumbar muscle activity and trunk movement in healthy subjects, namely that lumbar muscles control trunk movement in the sagittal and/or frontal plane 7;26;31:39. No studies however, have numerically expressed the relationship between lumbar muscle activity and spinal range of motion in subjects with CLBP during walking. In CLBP, range of motion of the lumbar spine during walking is comparable to healthy controls ${ }^{18 ; 30: 49}$. Relative movement between pelvis and thorax segments however, is different between subjects with CLBP and healthy controls during walking ${ }^{18 ; 32}$. These studies have found that subjects with CLBP show more rigid and less variable coordination in the transverse plane, and less tight and more variable coordination in the frontal plane. As such, it could be that the reduction in relative movement between trunk segments in CLBP is related to increased muscle activity and indicates guarded movements as well. In this case, guarding may also be expressed by an adaptation of posture to control relative range of motion.

In addition, it has been proposed that increased erector spinae activity may be compensatory for loss of deep muscle control and reduced spinal stability ${ }^{11 ; 14 ; 3741}$. For example, Hodges and Moseley ${ }^{14}$ found in a review of LBP, consistent evidence for differential effects on the deep intrinsic (mainly hypoactivity) and superficial muscles (mainly hyperactivity) of the lumbopelvic region. These changes may place an excessive demand on the superficial muscles to compensate for loss of deep muscle control ${ }^{11 ; 14 ; 3}$. Further study of, for example, selective training of the deep spinal muscles and its clinical outcome is needed to understand the function of these muscle activity changes. It is not known if these (compensatory) changes in muscle activity are beneficial or contribute to the vicious cycle of ongoing pain and disability. 
Not in line with the hypothesis of this study is that subjects with CLBP do not show higher relative ratios of erector spinae activity in swing to double support (i.e. less relative relaxation). In other words, the alteration of lumbar activity between these periods of stride is comparable to asymptomatic controls. Subjects show the same biphasic activity pattern as controls. This means that the mechanism found in CLBP can best be described as an overall elevated level of lumbar muscle activity during walking, independent of the different periods of stride. This implies that subjects with CLBP have no problems with the alteration of lumbar muscle activation between double support and swing. Subjects probably have more difficulties with the total muscle relaxation during stride, as they never reach comparable levels of relaxation as controls. The average activity in swing varies from $11-15 \mu \mathrm{V}$ in patients and from $8.0-11$ $\mu \mathrm{V}$ in controls (Table 2). It is questionable whether this relative decrease of activity in swing is sufficient to totally relax the erector spinae. It is known that continuous activation of muscles may cause musculoskeletal problems in the long run ${ }^{42}$. More sophisticated techniques such as multi-channel array electrodes to investigate whether some motor units are continuously active at these levels are needed, to determine whether subjects with CLBP reach adequate muscle relaxation.

Also not in line with our hypothesis is that no relation is found between lumbar muscle activity, activity limitation (RMDQ) and fear of movement (TSK). Lamoth et al ${ }^{17}$ also found no relation between TSK, RMDQ and sEMG parameters, albeit in a smaller number of subjects with CLBP $(\mathrm{N}=19)$. It is conceivable that pain- and fear related factors may play a role in certain fear-eliciting activities ${ }^{17}$, but not in a task like walking. It would be interesting to study specific tasks which elicit more pain-related fear than walking. It could also be that the psychological aspects measured should reflect factors which are stable across a variety of tasks, such as beliefs or coping responses. Biedermann et al. ${ }^{5}$ showed that back muscle fatigue rates during a constant force contraction were higher in patients classified as avoiders (measured with the Pain Behavior Checklist) than in those classified as confronters. Also, O'Sullivan ${ }^{24}$ and Hasenbring ${ }^{12}$ proposed a classification of subgroups, characterized by either pain avoidance - or pain provocation behavior and propose that this behavior is related to motor control impairments in CLBP. In the avoidance-endurance model of Hasenbring ${ }^{12}$, three coping responses are discerned, i.e. adaptive-, avoidance- and persistence coping. Adaptive coping is regarded as a healthy response, in which confrontation with the paineliciting stimulus is accompanied by an adaptive change between exertion and relaxation of muscles. In contrast, maladaptive persistent coping (i.e. carrying on with daily activities despite pain), may lead to physical overload of muscles, resulting in muscular hyperactivity. It may be further hypothesized that maladaptive avoidance coping will lead to higher lumbar muscle activity and less relaxation. Further study is needed to confirm possible relations between lumbar muscle activity and avoidance- or persistent coping. regel 1

regel 2

regel 3

regel 4

regel 5

regel 6

regel 7

regel 8

regel 9

regel 10

regel 11

regel 12

regel 13

regel 14

regel 15

regel 16

regel 17

regel 18

regel 19

regel 20

regel 21

regel 22

regel 23

regel 24

regel 25

regel 26

regel 27

regel 28

regel 29

regel 30

regel 31

regel 32

regel 33

regel 34

regel 35

regel 36

regel 37

regel 38 
regel 1 regel 2 regel 3 regel 4 regel 5 regel 6 regel 7 regel 8 regel 9 regel 10 regel 11 regel 12 regel 13 regel 14 regel 15 regel 16 regel 17 regel 18 regel 19 regel 20 regel 21 regel 22 regel 23 regel 24 regel 25 regel 26 regel 27 regel 28 regel 29 regel 30 regel 31 regel 32 regel 33 regel 34 regel 35 regel 36 regel 37 regel 38
In this study, no relation is found between pain intensity and averaged erector spinae activity or ratios. This is in contrast with results of Arendt-Nielsen et al ${ }^{4}$, who showed a positive association between VAS rating and erector spinae activity. The VAS ratings between both studies are comparable. Arendt-Nielsen et al ${ }^{4}$ found a VAS rating of 4.6/0.52 (M/SD, scale $0-10$ ) and in the current study the rating was 47/5-94 (median/range, scale 0-100). The main difference with the current study is that Arendt-Nielsen et al. ${ }^{4}$ excluded patients with a VAS rating of 3 or lower (scale $0-10)$ and included a smaller sample of subjects with CLBP $(\mathrm{N}=8)$. A re-analysis of the current data including subjects with a VAS score higher than $30(\mathrm{~N}=34$, median/range: 54/55-94, scale 0-100) however, did not change the results, which does not explain the discrepancy between the studies.

Male sex and higher age are both related to higher erector spinae activity levels, although sex failed to reach significance $(p=0.06)$. For age, the relation is very modest and clinically irrelevant. Gender and age do not influence the relative relaxation (i.e. ratios) between the different periods of the gait cycle. Higher erector spinae activity in males may be explained by differences in temporal stride parameters (e.g. step length) or range of motion of the trunk ${ }^{22}$.

\section{Methodological considerations}

Some limitations of this study should be noted. This study was conducted on a treadmill, to be able to control walking velocity. Treadmill walking is different from walking over ground and reduced amplitudes of kinematics of upper lumbar region and pelvis ${ }^{47}$ and differences in sagittal plane joint moments of the legs ${ }^{19}$ have been shown. Although the magnitude of the differences in kinematical, kinetic ${ }^{27}$, temporal gait parameters ${ }^{19}$ and sEMG of the lower limbs ${ }^{23}$ between treadmill and gait over ground is very small, it is not known if the results of this study are comparable with normal walking over ground.

Furthermore, in the present study we did not take the physical activity into account, although it may have influenced muscle activity levels as physical activity has an effect on muscle fiber size and type. Future studies should include physical activity levels to exclude a possible confounding effect. In literature there is conflicting evidence whether subjects with CLBP have lower aerobic fitness levels ${ }^{34,35}$. Other studies have shown that averaged physical activity levels are comparable between subjects with CLBP and healthy controls ${ }^{36 ; 33 ; 4}$. Also, including abdominal muscle activity would have strengthened the findings of this study as cocontraction of the erector spinae with trunk flexors is likely to improve trunk stability and may also reflect guarded movement. On account of the cross-sectional nature of this study no conclusions can be drawn about the fact whether these changes are a cause or a consequence of low back pain. 
Summary and clinical implications

Results from this study support the guarding hypothesis during walking in subjects with CLBP. Compared to asymptomatic controls, subjects with CLBP show elevated superficial lumbar muscle activity during all periods of stride. Although the overall higher absolute muscle activity levels in both periods of double support and swing reflects guarded movement, the relative relaxation in swing is not decreased in CLBP. No relation is found between fear of movement, activity limitation and lumbar muscle activity or relaxation. Probably subjects with CLBP do not have problems with the alteration of lumbar muscle activity between periods of double support and swing, but have difficulties with the total relaxation of the lumbar muscles during stride. The higher superficial lumbar muscle activity during all periods of stride may be compensatory for loss of deep muscle control and/or reduced spinal stability. It is not known whether these compensatory changes in lumbar muscle activity are adaptive or maladaptive. As continuous activation of muscles may cause musculoskeletal problems in the long run it should be prevented, but the question is which strategy is appropriate. If increased superficial lumbar muscle activity is an adaptive compensation for reduced activity of the deep spinal muscles, one would expect a beneficial effect of selective training of the deep spinal muscles. On the other hand, if increased lumbar muscle activity contributes to the ongoing vicious circle of pain being related to maladaptive coping strategies, other treatment strategies such as myofeedback might be beneficial to reduce the increased lumbar muscle activity. Further study is needed on the effect of changing muscle activity patterns, to understand whether the guarding mechanism is a beneficial adaptation or contributes to the vicious cycle of chronic pain.

\section{Acknowledgements}

The authors thankZonMw (the Netherlands organization for health research and development) and the Joris Foundation for their financial support. regel 1

regel 2

regel 3

regel 4

regel 5

regel 6

regel 7

regel 8

regel 9

regel 10

regel 11

regel 12

regel 13

regel 14

regel 15

regel 16

regel 17

regel 18

regel 19

regel 20

regel 21

regel 22

regel 23

regel 24

regel 25

regel 26

regel 27

regel 28

regel 29

regel 30

regel 31

regel 32

regel 33

regel 34

regel 35

regel 36

regel 37

regel 38 
regel 1

regel 2

regel 3

regel 4

regel 5

regel 6

regel 7

regel 8

regel 9

regel 10

regel 11

regel 12

regel 13

regel 14

regel 15

regel 16

regel 17

regel 18

regel 19

regel 20

regel 21

regel 22

regel 23

regel 24

regel 25

regel 26

regel 27

regel 28

regel 29

regel 30

regel 31

regel 32

regel 33

regel 34

regel 35

regel 36

regel 37

regel 38

\section{References}

1. Ahern DK, Follick MJ, Council JR, and Laser-Wolston N. Reliability of lumbar paravertebral EMG assessment in chronic low back pain. Arch Phys Med Rehabil 1986;67:762-5.

2. Ahern DK, Follick MJ, Council JR, Laser-Wolston N, and Litchman H. Comparison of lumbar paravertebral EMG patterns in chronic low back pain patients and non-patient controls. Pain 1988;34:153-60.

3. Anders C, Wagner H, Puta C, Grassme R, Petrovitch A, and Scholle HC. Trunk muscle activation patterns during walking at different speeds. J Electromyogr Kinesiol 2007;17:245-52.

4. Arendt-Nielsen L, Graven-Nielsen T, Svarrer H, and Svensson P. The influence of low back pain on muscle activity and coordination during gait: a clinical and experimental study. Pain 1996;64:231-40.

5. Biedermann HJ, Shanks GL, Forrest WJ, and Inglis J. Power spectrum analyses of electromyographic activity. Discriminators in the differential assessment of patients with chronic low-back pain. Spine 1991;16:1179-84.

6. Brouwer S, Kuijer W, Dijkstra PU, Goeken LN, Groothoff JW, and Geertzen JH. Reliability and stability of the Roland Morris Disability Questionnaire: intra class correlation and limits of agreement. Disabil Rehabil 2004;26:162-5.

7. Cromwell RL, Aadland-Monahan TK, Nelson AT, Stern-Sylvestre SM, and Seder B. Sagittal plane analysis of head, neck and trunk kinematics and electromyographic activity during locomotion. J Orthop Sports Phys Ther 2001;31:255-62.

8. Geisser ME, Ranavaya M, Haig AJ et al. A meta-analytic review of surface electromyography among persons with low back pain and normal, healthy controls. J Pain 2005;6:711-26.

9. Gommans IHB, Koes BW, and van Tulder MW. Validiteit en responsiviteit Nederlandstalige Roland Disability Questionnaire. Vragenlijst naar functionele status bij patiënten met lagerugpijn. Nederlands Tijdschrift voor Fysiotherapie 1997;2:28-33.

10. Goubert L, Crombez G, Van Damme S, Vlaeyen JW, Bijttebier P, and Roelofs J. Confirmatory factor analysis of the Tampa Scale for Kinesiophobia: invariant two-factor model across low back pain patients and fibromyalgia patients. Clin J Pain 2004;20:103-10.

11. Hammill RR, Beazell JR, and Hart JM. Neuromuscular consequences of low back pain and core dysfunction. Clin Sports Med 2008;27:449-62, ix.

12. Hasenbring M. Attentional control of pain and the process of chronification. Prog Brain Res 2000; 129:525-34.

13. Hermens HJ, Frericks B, Disselhorst-Klug C et al. Development of recommendations for SEMG sensors and sensor placement procedures. J Electromyogr Kinesiol 2000; 10:361-74.

14. Hodges PW and Moseley GL. Pain and motor control of the lumbopelvic region: effect and possible mechanisms. J Electromyogr Kinesiol 2003;13:361-70.

15. Hägg GM. Amsterdan: Static work loads and occupational myalgia: A new explanation model. Elsevier Science Publishers B.V. (Biomedical Division), 1991:141-3.

16. Lamoth CJ, Daffertshofer A, Meijer OG, and Beek PJ. How do persons with chronic low back pain speed up and slow down? Trunk-pelvis coordination and lumbar erector spinae activity during gait. Gait Posture 2006;23:230-9.

17. Lamoth CJ, Meijer OG, Daffertshofer A, Wuisman PI, and Beek PJ. Effects of chronic low back pain on trunk coordination and back muscle activity during walking: changes in motor control. Eur Spine J 2006;15:23-40.

18. Lamoth CJ, Meijer OG, Wuisman PI, van Dieen JH, Levin MF, and Beek PJ. Pelvis-thorax coordination in the transverse plane during walking in persons with nonspecific low back pain. Spine 2002;27:E92-9.

19. Lee SJ and Hidler J. Biomechanics of overground vs. treadmill walking in healthy individuals. J Appl Physiol 2008;104:747-55.

20. Main CJ and Watson PJ. Guarded movements: development of chronicity. J Musculoskeletal Pain 1996;4:163-170. 
21. Mannion AF. Fibre type characteristics and function of the human paraspinal muscles: normal values and changes in association with low back pain. J Electromyogr Kinesiol 1999;9:363-77.

22. Mannion AF, Kaser L, Weber E, Rhyner A, Dvorak J, and Muntener M. Influence of age and duration of symptoms on fibre type distribution and size of the back muscles in chronic low back pain patients. Eur Spine J 2000;9:273-81.

23. Nymark JR, Balmer SJ, Melis EH, Lemaire ED, and Millar S. Electromyographic and kinematic nondisabled gait differences at extremely slow overground and treadmill walking speeds. J Rehabil Res Dev 2005;42:523-34.

24. O'Sullivan P. Diagnosis and classification of chronic low back pain disorders: maladaptive movement and motor control impairments as underlying mechanism. Man Ther 2005;10:24255.

25. Perry J. Head, Trunk and Pelvis. In: Perry, J. Gait analysis: Normal and Pathological function. Thorofare, NJ, USA: SLACK Incorporated, 1992:131-40.

26. Richardson C, Jull G, Hodges P, Hides J. Spinal segmental stabilization in low back pain: scientific basic and clinical approach. In: Richardson C, Jull G, Hodges P, Hides J, eds. Traditional views of the function of the muscles of the local stabilizing system of the spine. Churchill Livingstone, United Kingdom: Harcourt Publishers Limited, 2000:21-40.

27. Riley PO, Paolini G, Croce UD, Paylo KW, and Kerrigan DC. A kinematic and kinetic comparison of overground and treadmill walking in healthy subjects. Gait Posture 2007;26:17-24.

28. Roelofs J, Goubert L, Peters ML, Vlaeyen JW, and Crombez G. The Tampa Scale for Kinesiophobia: further examination of psychometric properties in patients with chronic low back pain and fibromyalgia. Eur J Pain 2004;8:495-502.

29. Roelofs J, Sluiter JK, Frings-Dresen MH et al. Fear of movement and (re)injury in chronic musculoskeletal pain: Evidence for an invariant two-factor model of the Tampa Scale for Kinesiophobia across pain diagnoses and Dutch, Swedish, and Canadian samples. Pain 2007;131:181-90.

30. Rowe PJ and White M. Three dimensional, lumbar spinal kinematics during gait, following mild musculoskeletal low back pain in nurses. Gait \& Posture 1996;242-51.

31. Saunders SW, Schache A, Rath D, and Hodges PW. Changes in three dimensional lumbopelvic kinematics and trunk muscle activity with speed and mode of locomotion. Clin Biomech 2005;20:784-93.

32. Selles RW, Wagenaar RC, Smit TH, and Wuisman PI. Disorders in trunk rotation during walking in patients with low back pain: a dynamical systems approach. Clin Biomech 2001;16:175-81.

33. Shiavi R, Frigo C, and Pedotti A. Electromyographic signals during gait: criteria for envelope filtering and number of strides. Med Biol Eng Comput 1998;36:171-8.

34. Smeets RJ, Wade D, Hidding A, Van Leeuwen PJ, Vlaeyen JW, and Knottnerus JA. The association of physical deconditioning and chronic low back pain: a hypothesis-oriented systematic review. Disabil Rehabil 2006;28:673-93.

35. Smeets RJ, Wittink H, Hidding A, and Knottnerus JA. Do patients with chronic low back pain have a lower level of aerobic fitness than healthy controls? Are pain, disability, fear of injury, working status, or level of leisure time activity associated with the difference in aerobic fitness level? Spine 2006;31:90-7; discussion 98.

36. Spenkelink CD, Hutten MM, Hermens HJ, and Greitemann BO. Assessment of activities of daily living with an ambulatory monitoring system: a comparative study in patients with chronic low back pain and nonsymptomatic controls. Clin Rehabil 2002;16:16-26.

37. Sterling M, Jull G, and Wright A. The effect of musculoskeletal pain on motor activity and control. J Pain 2001;2:135-45.

38. Stokes M, Rankin G, and Newham DJ. Ultrasound imaging of lumbar multifidus muscle: normal reference ranges for measurements and practical guidance on the technique. Man Ther 2005;10:116-26.

39. Thorstensson A, Carlson H, Zomlefer MR, and Nilsson J. Lumbar back muscle activity in relation to trunk movements during locomotion in man. Acta Physiol Scand 1982;116:13-20.

40. Triano JJ, McGregor M, Cramer GD, and Emde DL. A comparison of outcome measures for use with back pain patients: results of a feasibility study. J Manipulative Physiol Ther 1993;16:67-73. 
regel 1

regel 2

regel 3

regel 4

regel 5

regel 6

regel 7

regel 8

regel 9

regel 10

regel 11

regel 12

regel 13

regel 14

regel 15

regel 16

regel 17

regel 18

regel 19

regel 20

regel 21

regel 22

regel 23

regel 24

regel 25

regel 26

regel 27

regel 28

regel 29

regel 30

regel 31

regel 32

regel 33

regel 34

regel 35

regel 36

regel 37

regel 38

41. van Dieen JH, Selen LP, and Cholewicki J. Trunk muscle activation in low-back pain patients, an analysis of the literature. J Electromyogr Kinesiol 2003; 13:333-51.

42. Veiersted KB, Westgaard RH, and Andersen P. Electromyographic evaluation of muscular work pattern as a predictor of trapezius myalgia. Scand J Work Environ Health 1993;19:284-90.

43. Verbunt JA, Seelen HA, Vlaeyen JW et al. Disuse and deconditioning in chronic low back pain: concepts and hypotheses on contributing mechanisms. Eur J Pain 2003;7:9-21.

44. Verbunt JA, Westerterp KR, van der Heijden GJ, Seelen HA, Vlaeyen JW, and Knottnerus JA. Physical activity in daily life in patients with chronic low back pain. Arch Phys Med Rehabil 2001;82:726-30.

45. Vink P and Karssemeijer N. Low back muscle activity and pelvic rotation during walking. Anat Embryol 1988;178:455-60.

46. Vlaeyen JWS, Kole-Snijders AMJ, Rotteveel AM, et al. The role of fear of movement/ (re)injury in pain disability. J Occup Rehabil 1995; 5:235-52.

47. Vogt L, Pfeifer K, and Banzer W. Comparison of angular lumbar spine and pelvis kinematics during treadmill and overground locomotion. Clin Biomech 2002;17:162-5.

48. Vogt L, Pfeifer K, and Banzer W. Neuromuscular control of walking with chronic low-back pain. Manual Therapy 2003;8:21-8.

49. Vogt L, Pfeifer K, Portscher M, and Banzer W. Influences of nonspecific low back pain on threedimensional lumbar spine kinematics in locomotion. Spine 2001;26:1910-9.

50. Watson PJ, Booker CK, and Main CJ. Evidence for the role of psychological factors in abnormal paraspinal activity in patients with chronic low back pain. Journal of Musculoskeletal Pain 1997;5:41-56.

51. Watson PJ, Booker CK, Main CJ, and Chen AC. Surface electromyography in the identification of chronic low back pain patients: the development of the flexion relaxation ratio. Clin Biomech 1997;12:165-71.

52. Winter DA and Yack HJ. EMG profiles during normal human walking: stride-to-stride and inter-subject variability. Electroencephalogr Clin Neurophysiol 1987;67:402-11. 


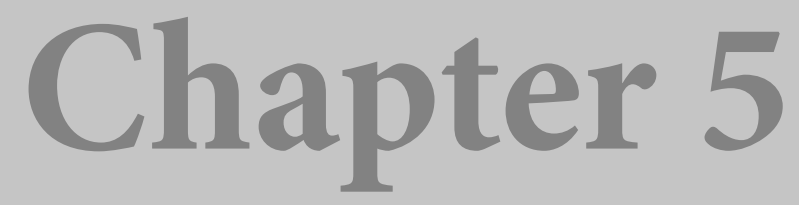

Lumbar - and abdominal muscle activity during walking in subjects with chronic low back pain: support of the "guarding" hypothesis?

Marije van der Hulst, Miriam M Vollenbroek-Hutten, Johan S Rietman, Hermanus J Hermens 
regel 1

regel 2

regel 3

regel 4

regel 5

regel 6

regel 7

regel 8

regel 9

regel 10

regel 11

regel 12

regel 13

regel 14

regel 15

regel 16

regel 17

regel 18

regel 19

regel 20

regel 21

regel 22

regel 23

regel 24

regel 25

regel 26

regel 27

regel 28

regel 29

regel 30

regel 31

regel 32

regel 33

regel 34

regel 35

regel 36

regel 37

regel 38

\begin{abstract}
Background: It has been hypothesized that changes in trunk muscle activity in chronic low back pain (CLBP) reflect an underlying "guarding" mechanism, which will manifest itself as increased superficial abdominal - and lumbar muscle activity. During a functional task like walking, it may be further provoked at higher walking velocities.
\end{abstract}

Objective: The purpose of this cross-sectional study was to investigate whether subjects with CLBP show increased co-activation of superficial abdominal - and lumbar muscles during walking on a treadmill, when compared to asymptomatic controls.

Methods: Sixty-three subjects with CLBP and 33 asymptomatic controls walked on a treadmill at different velocities. Surface electromyography data of the erector spinae, rectus abdominis and obliquus abdominis externus muscles were obtained and averaged per stride.

Results: Compared to asymptomatic controls, subjects with CLBP have increased muscle activity of the erector spinae and rectus abdominis, but not of the obliquus abdominis externus. These differences in trunk muscle activity between groups do not increase with higher walking velocities.

Conclusion: The observed increased trunk muscle activity in subjects with CLBP during walking supports the guarding hypothesis. 


\section{Introduction}

In subjects with chronic low back pain (CLBP), it has been assumed that spinal stability is reduced due to loss of its passive - (i.e. vertebrae, discs, ligaments) and/or its active control (i.e. muscles and tendons) ${ }^{31 ; 32}$. If so, changes in motor control can be expected to compensate for this loss of stability ${ }^{1 ; 221 ; 3 ; 47}$. To interpret possible changes in motor control, a functional classification system of the trunk muscles can be used, which discerns between a local and a global muscle system ${ }^{5 ; 11}$. The so called local system consists of deep intrinsic muscles and controls intervertebral motion. The global system consists of large superficial muscles with origin on the pelvis and insertions on the thoracic cage, controls gross movements of the spine and balances external loads. Both the superficial abdominal - and the superficial lumbar muscles from the global system, are thus required for stability and control of movement ${ }^{10}$.

It is hypothesized that to control spinal movement, subjects with CLBP show "guarded movements": abnormalities in muscle action in subjects with CLBP during physical activity ${ }^{25}$, although a clear definition of guarding in CLBP has not been given in literature. For instance, guarded movements in subjects with CLBP have been characterized by insufficient muscle relaxation during flexion ${ }^{2 ; 16 ; 53}$. It is considered an adaptation mechanism in response to acute pain, which in the long run may result in persistent movement changes ${ }^{48}$.

Some evidence for guarding in CLBP has been shown during flexion-extension tasks ${ }^{2 ; 16 ; 53}$, but it is not known whether this guarding mechanism also exists during other daily functional tasks like walking. During walking, it has been shown that superficial lumbar muscle activity is increased in subjects with CLBP compared to controls ${ }^{1 ; 4 ; 23 ; 52}$ [vd Hulst et al, Clin J Pain (in press)]. In the concept of guarding however, one would also expect increased activation of superficial abdominal muscles to control spinal movement. No studies have investigated coactivation of superficial abdominal and lumbar muscle activity in subjects with CLBP during walking.

Spinal motion increases with higher walking velocities ${ }^{13}$. This will in turn demand changes in trunk muscle activity to control this increased motion ${ }^{3}$. One may assume that increasing walking velocity may elicit more guarded movements. Studies however, are scarce on velocity induced changes in lumbar muscle activity in CLBP ${ }^{22 ; 23 ; 38}$.

The aim of this cross-sectional study is to investigate whether subjects with CLBP compared to asymptomatic controls, show increased lumbar- and abdominal muscle activity during walking on a treadmill at increasing velocities. It is hypothesized that subjects with CLBP will show a "guarding" mechanism, reflected by increased co-activation of superficial abdominal - regel 1

regel 2

regel 3

regel 4

regel 5

regel 6

regel 7

regel 8

regel 9

regel 10

regel 11

regel 12

regel 13

regel 14

regel 15

regel 16

regel 17

regel 18

regel 19

regel 20

regel 21

regel 22

regel 23

regel 24

regel 25

regel 26

regel 27

regel 28

regel 29

regel 30

regel 31

regel 32

regel 33

regel 34

regel 35

regel 36

regel 37

regel 38 
regel 1 regel 2 regel 3 regel 4 regel 5 regel 6 regel 7 regel 8 regel 9 regel 10 regel 11 regel 12 regel 13 regel 14 regel 15 regel 16 regel 17 regel 18 regel 19 regel 20 regel 21 regel 22 regel 23 regel 24 regel 25 regel 26 regel 27 regel 28 regel 29 regel 30 regel 31 regel 32 regel 33 regel 34 regel 35 regel 36 regel 37 regel 38

and lumbar muscles. Furthermore, it is expected that at higher walking velocities the hypothesized differences in muscle activity between subjects with CLBP and controls will become more pronounced.

\section{Materials and methods}

\section{Subjects}

Subjects with CLBP, who were referred to a physician in Physical Medicine and Rehabilitation between July 2004 and July 2005, and asymptomatic controls were asked to participate in the study. Inclusion criteria for the patient group were: age between 16-70 years and more than three months continuing or recurrent low back pain. Low back pain was defined as pain under the scapulas, above the cleft of the buttock, with or without radiation to the extremities. Exclusion criteria were: surgery of the spine in the past three months, spondylodeses, structural pathology of the spine like inflammation, active radiculopathy, tumor, severe deformities (e.g. spondylolisthesis grade 3) or neurological and/or musculoskeletal disorders that could have an effect on gait. Specific causes of low back pain were excluded by the physician's assessment (history, physical examination, if necessary blood tests and X-rays). All patients had previously undergone some form of treatment (medication or physiotherapy) without lasting relief. Controls (personnel from the rehabilitation center, their family or friends) were asymptomatic volunteers with no history of back pain in the preceding twelve months, previous surgery of the spine, neurological and/or musculoskeletal disorders that could have an effect on gait. Subjects were matched on group level for age, gender and body mass index (BMI) meaning that group averages were comparable on these parameters. Due to the expected heterogeneity of subjects with CLBP, twice as many patients were included compared to controls. Participants that met the inclusion criteria and were willing to participate gave informed consent. The study was approved by the Medical Ethical Committee of the Rehabilitation Center "het Roessingh" in Enschede.

\section{Design and procedure}

A cross-sectional study was conducted and performed on a treadmill. Participants filled out the questionnaires before the start of the experiment. Subjects were allowed to practice treadmill walking until they were accustomed to the walking conditions with a maximum of five minutes before the measurements started. They were instructed to walk as naturally as possible without using the handrail. Treadmill velocity was increased sequentially with increments of 0.8 kilometres per hour $(\mathrm{km} / \mathrm{h})$ from 1.4 to $5.4 \mathrm{~km} / \mathrm{h}$. A short rest period (approximately $2 \mathrm{~min}$ ) between trials was used to check the measurement data. Data of at least twenty strides were collected to ensure a representative dataset ${ }^{39}$. 


\section{Measurements}

Questionnaires

Sociodemographic (age, gender, level of education, work status), anthropometric (height, weight) and pain-related variables were collected (i.e. duration, current pain intensity and site of pain, level of activity limitation). Current pain intensity was measured by a Visual Analogue Scale $(0=\text { no pain, } 100=\text { most severe pain })^{46}$. Activity limitation of subjects with CLBP was measured with the Dutch version of the Roland Morris Disability Questionnaire (RMDQ). The Dutch RMDQ ( $0=$ no disabilities, $24=$ severe disabilities $)$ is shown to be valid ${ }^{18}$ and reliable ${ }^{6}$.

\section{Kinematics and surface electromyography (sEMG)}

Kinematical and sEMG data were collected simultaneously during walking on a motorized treadmill (Tunturi T-Track/G200) at the six different velocities $(1.4-5.4 \mathrm{~km} / \mathrm{h}$ ). The investigator collecting sEMG and kinematical data was not blinded for group. A six camera optical three-dimensional gait analysis system (VICON 370, Oxford metrics Ltd., Oxford, UK) was used to determine foot contacts. VICON markers were placed on the second metatarsal phalangeal joint (MTP 2) and on the posterior side of the calcaneus. Marker data were collected with a sampling rate of $50 \mathrm{~Hz}$.

Muscle activity patterns of erector spinae (ES) at two levels, rectus abdominis (RA) and obliquus externus abdominis (OE) were measured on the left and right side (in total eight channels), using multichannel, single differential, bipolar sEMG (16 channels Biotel 99, Glonner Electronic GmbH, Planegg, Germany). Bipolar sEMG was measured with solid gel electrodes (Arbo H93SG, Tyco Healthcare), with an inter-electrode distance of $23 \mathrm{~mm}$ after removal of hair and cleaning the subject's skin with alcohol. Electrodes for ES were placed bilaterally parallel with the muscle fibers at two levels, $30 \mathrm{~mm}$ lateral to the first lumbar processus spinosus, according to the SENIAM (Surface Electromyography for the Non-Invasive Assessment of Muscles) guidelines ${ }^{20}$, and $30 \mathrm{~mm}$ lateral to the fourth lumbar processus spinosus ${ }^{50}$. Lumbar vertebrae were located through palpation, using the iliac crest as landmark. Bipolar electrodes for RA were placed bilaterally, $30 \mathrm{~mm}$ lateral to the midline ${ }^{9}$, midway between the processus xyphoideus and umbilicus. Electrodes for OE were placed bilaterally, approximately $150 \mathrm{~mm}$ lateral to the midline ${ }^{9}$, in the lower $1 / 3$ part between the anterior superior iliac spines and the distal border of the rib cage. All wires and leads were fixed with tape to the subject's skin to diminish artifacts without limiting motion. A common reference electrode was placed over the right processus styloideus ulnae. In the pre-processed method, sEMG data were collected with a sampling rate of $1024 \mathrm{~Hz}$ and band passed filtered using a first order filter of $17-500 \mathrm{~Hz}$. regel 1

regel 2

regel 3

regel 4

regel 5

regel 6

regel 7

regel 8

regel 9

regel 10

regel 11

regel 12

regel 13

regel 14

regel 15

regel 16

regel 17

regel 18

regel 19

regel 20

regel 21

regel 22

regel 23

regel 24

regel 25

regel 26

regel 27

regel 28

regel 29

regel 30

regel 31

regel 32

regel 33

regel 34

regel 35

regel 36

regel 37

regel 38 
regel 1 regel 2 regel 3 regel 4 regel 5 regel 6 regel 7 regel 8 regel 9 regel 10 regel 11 regel 12 regel 13 regel 14 regel 15 regel 16 regel 17 regel 18 regel 19 regel 20 regel 21 regel 22 regel 23 regel 24 regel 25 regel 26 regel 27 regel 28 regel 29 regel 30 regel 31 regel 32 regel 33 regel 34 regel 35 regel 36 regel 37 regel 38

\section{Data analysis}

Temporal parameters:

The collected data were imported in the analysis software, developed using Labview 8.2 of National Instruments (Austin, Texas, USA). Movement of markers was measured according to the coordinate system of the laboratory room. Events of the gait cycle (initial contact and toe off) were determined by calculating the displacement in the horizontal direction of the MTP 2 and calcaneus marker. A stride was defined from the first left initial contact (LIC) to the next LIC (Figure 1). Initial double support (DS1) was defined from LIC to right toe off, followed by contralateral swing (CSw) until right initial contact (RIC). Contralateral swing is equal to ipsilateral single limb stance. The second period of double support (DS2) was defined from RIC to left toe off, followed by the ipsilateral swing phase (ISw) until LIC. In summary, a stride was divided in two periods of double support and two periods of swing (contra and ipsilateral).

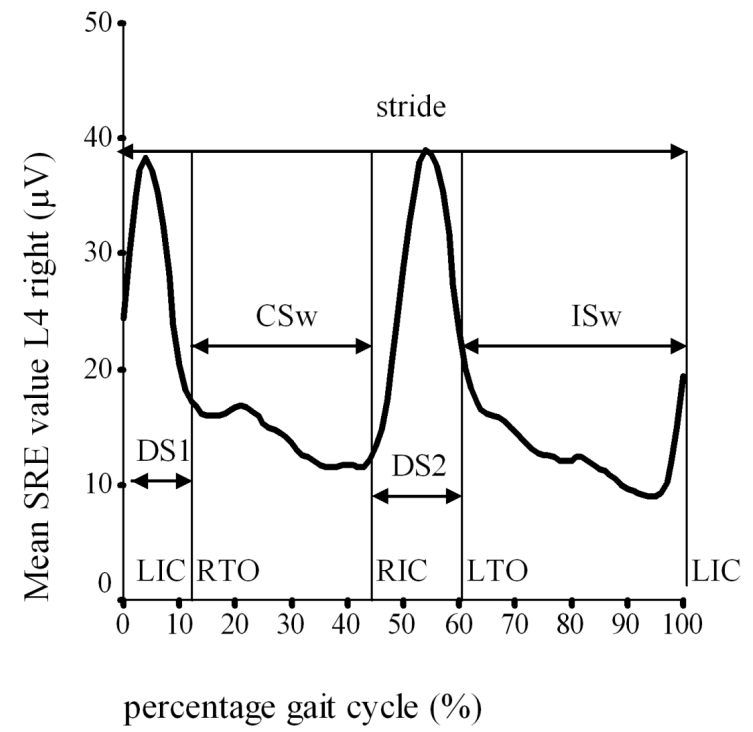

Figure 1 Example of SRE pattern of erector spinae (L4 right) per stride: control group, mean value of 20 steps, all velocities $(1.4-5.4 \mathrm{~km} / \mathrm{h})$. Note: $\mathrm{SRE}=$ smoothed rectified EMG, DS1 = first double support, $\mathrm{CSw}=$ contralateral swing, DS2 = second double support, $\mathrm{ISw}=$ ipsilateral swing, $\mathrm{L}(\mathrm{R}) \mathrm{IC}=$ left (right) initial contact, $\mathrm{L}(\mathrm{R}) \mathrm{TO}=$ left (right) toe off. 
Surface EMG

In the post processed method, sEMG was bandpass filtered at $20 \mathrm{~Hz}$, using a $3^{\text {rd }}$ order Butterworth filter, to remove movement artifacts. After the signal was double phase rectified, it was low pass filtered at $25 \mathrm{~Hz}$ to calculate Smooth Rectified EMG (SRE) values. To account for different cycle durations between subjects, EMG was normalized in time for each stride per subject. Averaged SRE values of approximately 20 time-normalized EMG profiles were used. For each individual, the SRE values per stride were divided in four periods (DS1, CSw, DS2 and ISw) and averaged. Main outcome parameters were averaged SRE values of ES, RA and OE per stride. sEMG data of strides were excluded from the analysis when visual inspection of the EMG signals showed movement artifacts, reflected by high amplitude and low frequency signals. The investigator performing this analysis was blinded for group.

\section{Statistical analysis}

Comparability of baseline variables of subjects with CLBP and asymptomatic controls was determined with Student's independent samples $t$-tests for continuous variables and with $\chi^{2}$ tests for categorical data. Random coefficient analysis, also known as multilevel analysis, was used to study the differences in averaged SRE values per stride between both groups. SRE values of ES, RA and OE were analyzed separately. Random coefficient analysis was chosen because it takes into account that repeated measures at different walking velocities within individuals are correlated. Residuals were checked for normality. If necessary, a natural logarithm (ln) transformation of SRE values was done to compensate for a non-normal distribution of the residuals. Post hoc Sidak's $t$-tests were performed if significant main or interaction effects were present ( $p<0.05$, two sided was used as significance level). Statistical analyses were performed using the statistical software SPSS v.11.5.

The regression model with average SRE values (ES/RA/OE) as dependent variables included the following independent variables: group (patient/control), muscle recording site, period of stride (DS1, CSw, DS2, ISw) and gender as factors; age, body mass index (BMI $\left.\left(\mathrm{kg} / \mathrm{m}^{2}\right)\right)$, velocity $(\mathrm{km} / \mathrm{h})$ and square velocity $\left((\mathrm{km} / \mathrm{h})^{2}\right)$, as covariates. Including velocity as a continuous variable assumed a linear relationship between velocity and sEMG. By adding square velocity to the model, a possible non linear association could be revealed. Age and gender were added as independent variables because of their possible confounding effect on muscle fiber size $27 ; 28 ; 42 ; 44$, which in turn is likely to influence muscle activity. BMI was added because the amount of fat overlying the muscle reduces the sEMG signal. Interactions between group or period of stride and (square) velocity were included in the model if significant. regel 1

regel 2

regel 3

regel 4

regel 5

regel 6

regel 7

regel 8

regel 9

regel 10

regel 11

regel 12

regel 13

regel 14

regel 15

regel 16

regel 17

regel 18

regel 19

regel 20

regel 21

regel 22

regel 23

regel 24

regel 25

regel 26

regel 27

regel 28

regel 29

regel 30

regel 31

regel 32

regel 33

regel 34

regel 35

regel 36

regel 37

regel 38 


\section{Results}

\section{Study population}

Of the 123 persons who were suitable for inclusion, 96 (78\%) participated (63 subjects with CLBP, 33 healthy controls). The main reason of not willing to participate was lack of sufficient time or motivation. Due to sEMG movement artifacts, five persons (four subjects with CLBP, one control) were excluded from these 96 , so 91 persons (59 subjects with CLBP, 32 controls) were included in the final analysis. Baseline characteristics are reported in Table 1. Groups were comparable in age, BMI and gender $(p>0.05)$. Groups differed in educational level and work status $(p<0.01)$. Compared to controls, most subjects with CLBP had lower or intermediate vocational education and were not working. They showed a moderate level of current pain and activity limitation.

Table 1 Baseline characteristics of the study population

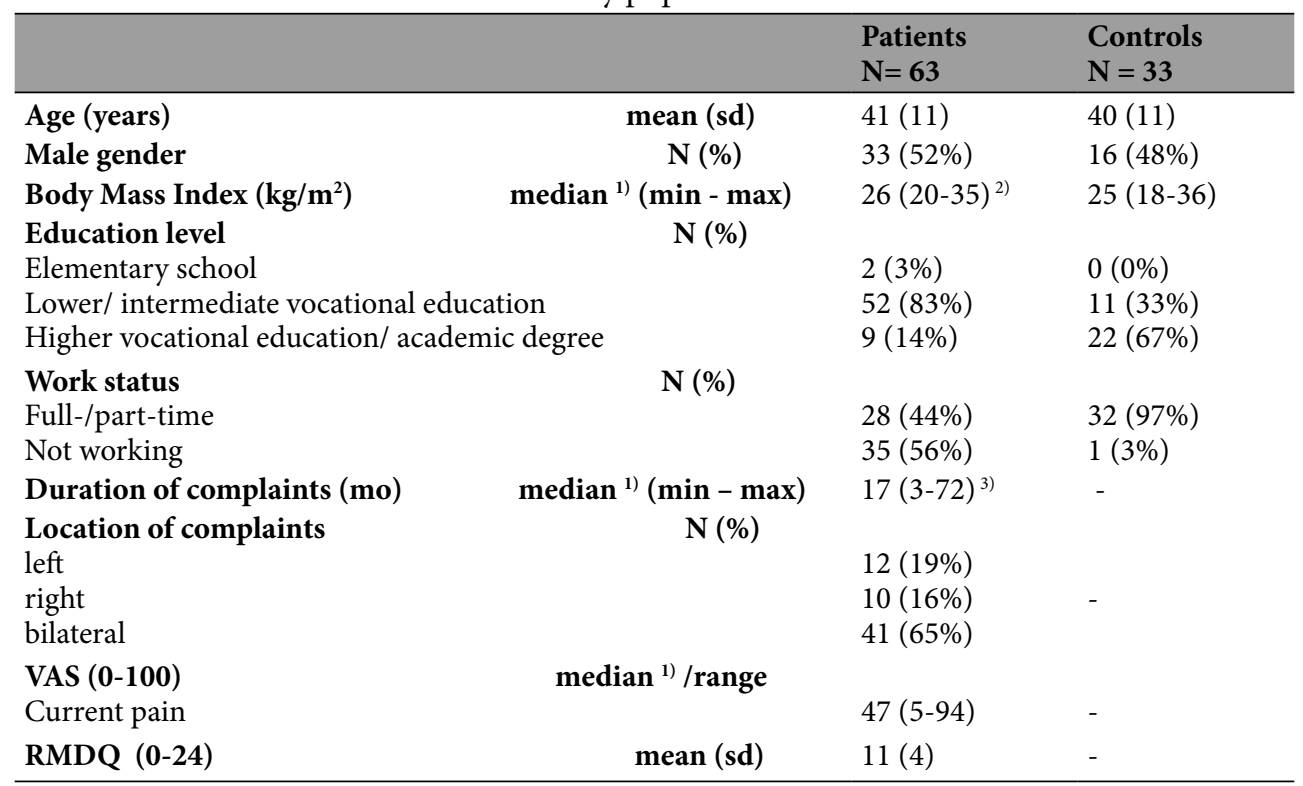

Note VAS=Visual Analogue Scale; RMDQ= Roland Morris Disability Questionnaire $\mathrm{Ad}^{1)}$ the median value is reported if this parameter is not normally distributed. $\mathrm{Ad}^{2)} 1$ outlier: Body Mass Index $50 \mathrm{~kg} / \mathrm{m}^{2}$ excluded due to movement artifacts. $\mathrm{Ad}^{3)} 1$ outlier: 288 months, included because of no significant influence on sEMG values. 


\section{Surface EMG}

All participants were able to walk at the prescribed velocities. Data of the left cycle were analyzed. In Figure 1 an example of the average sEMG profile of erector spinae (ES) during the different periods of stride is shown. Figure 2 presents an example of the average SRE pattern for the recording at L1 (right) for both groups during the left cycle, averaged over all velocities (1.4-5.4 km/h). The other recordings (L1 left, L4) have comparable patterns. Both groups show on average the same biphasic pattern. sEMG activity is highest in double support and lowest in ipsi-or contra lateral swing. Figures 3 and 4 present the average SRE pattern of rectus abdominis (RA) and obliquus abdominis externus (OE) for both groups, right side, averaged over all velocities $(1.4-5.4 \mathrm{~km} / \mathrm{h})$. Again, both groups show comparable patterns. For RA a continuous activation pattern is discerned and for $\mathrm{OE}$ a more phasic activity pattern can be seen. The recordings on the left side show comparable patterns. The averaged SRE values are presented in Table 2. For average SRE values natural logarithm transformation was needed to compensate for the non-normal distribution of the residuals.

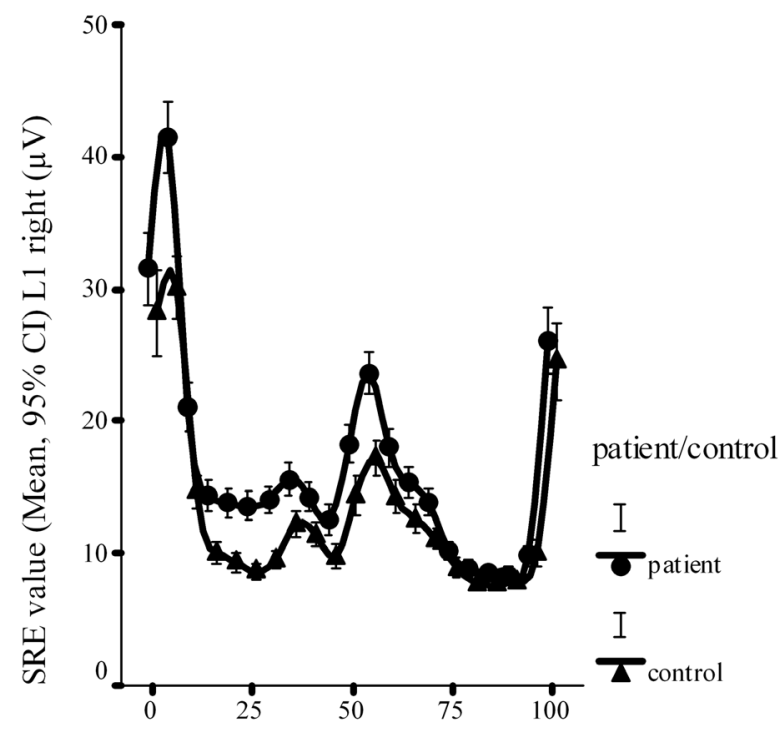

percentage gait cycle $(\%)$

Figure 2 SRE pattern of erector spinae (L1 right) per stride: Mean value of 20 steps, all velocities (1.4 $5.4 \mathrm{~km} / \mathrm{h}$ ), per group. Note: $\mathrm{SRE}=$ smoothed rectified EMG, CI = confidence interval. regel 1

regel 2

regel 3

regel 4

regel 5

regel 6

regel 7

regel 8

regel 9

regel 10

regel 11

regel 12

regel 13

regel 14

regel 15

regel 16

regel 17

regel 18

regel 19

regel 20

regel 21

regel 22

regel 23

regel 24

regel 25

regel 26

regel 27

regel 28

regel 29

regel 30

regel 31

regel 32

regel 33

regel 34

regel 35

regel 36

regel 37

regel 38 
regel 1

regel 2

regel 3

regel 4

regel 5

regel 6

regel 7

regel 8

regel 9

regel 10

regel 11

regel 12

regel 13

regel 14

regel 15

regel 16

regel 17

regel 18

regel 19

regel 20

regel 21

regel 22

regel 23

regel 24

regel 25

regel 26

regel 27

regel 28

regel 29

regel 30

regel 31

regel 32

regel 33

regel 34

regel 35

regel 36

regel 37

regel 38

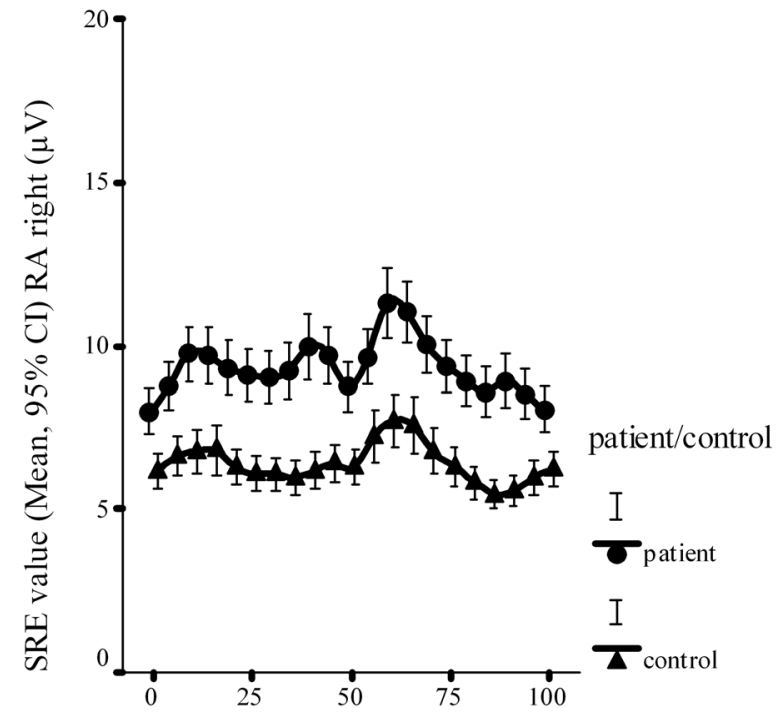

percentage gait cycle $(\%)$

Figure 3 SRE pattern of rectus abdominis (right) per stride: mean of 20 steps, all velocities (1.4 $5.4 \mathrm{~km} / \mathrm{h}$ ), per group. Note: SRE = Smoothed Rectified EMG, CI = confidence interval, RA = rectus abdominis.

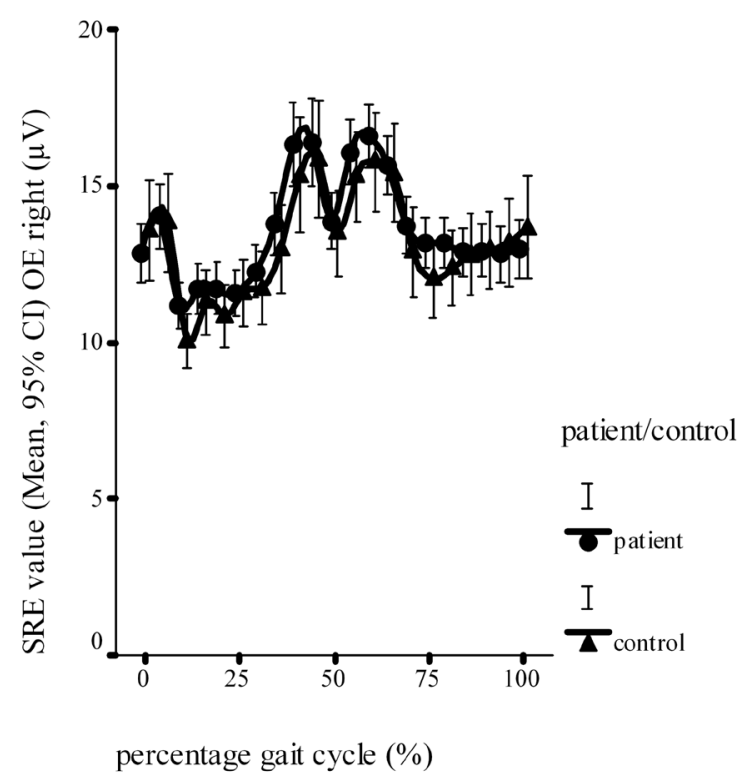

Figure 4 SRE pattern of obliquus externus abdominis (right) per stride: Mean value of 20 steps, all velocities $(1.4-5.4 \mathrm{~km} / \mathrm{h})$, per group. Note: $\mathrm{SRE}=$ smoothed rectified $\mathrm{EMG}, \mathrm{CI}=$ confidence interval, $\mathrm{OE}=$ obliquus externus abdominis.

100 
Table 2. Averaged ( $\pm 2 \times$ SD) SRE values $(\mu \mathrm{V})$ for subjects with CLBP and matched healthy controls: per stride and velocity, per muscle group (erector spinae, rectus abdominis, and obliquus externus) - left cycle.

\begin{tabular}{lllllll}
\hline Muscle group & \multicolumn{2}{l}{ Erector spinae } & \multicolumn{2}{l}{ Rectus abdominis } & \multicolumn{2}{l}{ Obliquus externus } \\
Velocity $(\mathbf{k m} / \mathbf{h})$ & Patient & Control & Patient & Control & Patient & Control \\
\hline $\mathbf{1 . 4}$ & $14.2(8.0)$ & $11.8(5.7)$ & $7.4(7.0)$ & $5.0(5.0)$ & $10.7(6.3)$ & $11.8(8.7)$ \\
$\mathbf{2 . 2}$ & $14.2(8.1)$ & $11.8(4.8)$ & $7.5(6.2)$ & $5.4(4.3)$ & $11.2(6.0)$ & $12.4(8.6)$ \\
$\mathbf{3 . 0}$ & $15.2(8.3)$ & $12.5(4.6)$ & $8.3(6.5)$ & $5.6(4.5)$ & $13.0(7.6)$ & $13.5(8.9)$ \\
$\mathbf{3 . 8}$ & $16.7(8.4)$ & $13.7(4.7)$ & $9.0(6.6)$ & $6.2(3.8)$ & $14.0(7.6)$ & $14.6(8.5)$ \\
$\mathbf{4 . 6}$ & $19.0(9.1)$ & $15.7(5.1)$ & $10.4(7.3)$ & $8.0(5.8)$ & $15.8(8.4)$ & $16.0(9.2)$ \\
$\mathbf{5 . 4}$ & $22.5(10.0)$ & $18.2(6.2)$ & $11.8(7.5)$ & $8.8(6.3)$ & $18.4(9.2)$ & $18.8(10.2)$ \\
\hline
\end{tabular}

Note $\mathrm{SD}=$ standard deviation, $\mathrm{SRE}=$ smoothed rectified $\mathrm{sEMG}, \mathrm{CLBP}=$ chronic low back pain

SRE values per stride - erector spinae (ES)

Averaged SRE values of ES are on average 1.20 times higher in subjects with CLBP when compared to controls in both periods of swing and double support. The regression coefficient for group (CLBP) for outcome ln SRE value shows that this difference is significant ( $\beta=$ $0.18(95 \% \mathrm{CI}=0.05-0.32))$. The total model explains $42.6 \%$ of the variance in $\ln$ SRE values. Except for gender, all other variables as recording site, age and BMI, are also significantly related to ln SRE values. Concerning recording site, ES activity recorded at the first lumbar processus spinosus is lower than at the fourth lumbar processus spinosus ( $\beta$ L1 vs. L4 (right) $=-0.12(-0.14$ to -0.10$))$. Older age is related to higher ES activity $(\beta$ age $=0.01(0.01-0.02))$ and a higher BMI is related to less ES activity $(\beta \mathrm{BMI}=-0.04(-0.06$ to -0.02$))$. Furthermore, within a stride, $\ln$ SRE values are significantly higher in periods of double support compared to swing ( $\beta$ (first double support/ipsilateral swing) $=0.59$ (0.57-0.61), $\beta$ (second double support/ipsilateral swing $)=0.62(0.60-0.64))$ and show a significant interaction between velocity and period of stride $(p<0.001)$. Finally, for both groups, ES activity increases with higher walking velocities following a non linear distribution (Figure 5), without a significant interaction between velocity and group. regel 1

regel 2

regel 3

regel 4

regel 5

regel 6

regel 7

regel 8

regel 9

regel 10

regel 11

regel 12

regel 13

regel 14

regel 15

regel 16

regel 17

regel 18

regel 19

regel 20

regel 21

regel 22

regel 23

regel 24

regel 25

regel 26

regel 27

regel 28

regel 29

regel 30

regel 31

regel 32

regel 33

regel 34

regel 35

regel 36

regel 37

regel 38 
regel 1

regel 2

regel 3

regel 4

regel 5

regel 6

regel 7

regel 8

regel 9

regel 10

regel 11

regel 12

regel 13

regel 14

regel 15

regel 16

regel 17

regel 18

regel 19

regel 20

regel 21

regel 22

regel 23

regel 24

regel 25

regel 26

regel 27

regel 28

regel 29

regel 30

regel 31

regel 32

regel 33

regel 34

regel 35

regel 36

regel 37

regel 38

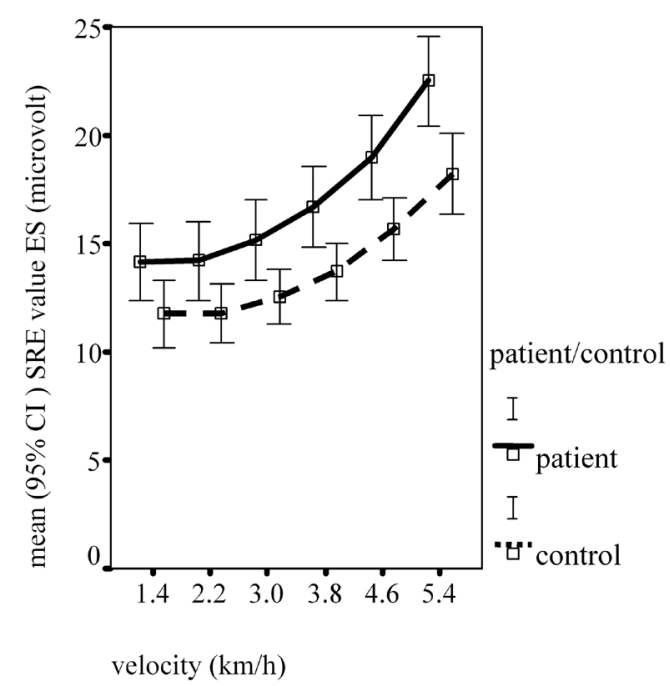

Figure $5 \mathrm{SRE}$ values of erector spinae per stride with higher velocities, mean of 20 steps per group. Note: SRE $=$ smoothed rectified EMG.

SRE values per stride - rectus abdominis (RA)

Averaged SRE values of RA are on average 1.36 times higher in subjects with CLBP than controls during the total stride. The regression coefficient for group (CLBP) for outcome $\ln$ SRE shows that this difference is significant $(\beta=0.31(95 \% \mathrm{CI}=0.09-0.53))$. The total model explains $18.8 \%$ of the variance in $\ln$ SRE values. Within a stride, RA activity is significantly higher in double support as compared to swing ( $\beta$ (first double support/ipsilateral swing) $=$ 0.07 (0.05-0.08), $\beta$ (second double support/ipsilateral swing) $=0.09(0.08-0.11)$ ). There is no significant interaction between period of stride and velocity. Ln SRE values increase with higher velocities in a non linear fashion (Figure 6) and without a significant interaction with group.

SRE values per stride - obliquus abdominis externus (OE)

Average SRE values of OE are comparable between subjects with CLBP and controls. The regression coefficient for group (CLBP) for outcome ln SRE shows that differences are not significant $(\beta=0.03(95 \% \mathrm{CI}=-0.14-0.20)$ ). The total model explains $26 \%$ of the variance in $\ln$ SRE values. Within a stride, activity in double support is significantly higher than in swing ( $\beta$ (first double support/ipsilateral swing) $=0.07(0.05-0.08)$ and (second double support/ ipsilateral swing $)=0.07(0.05-0.08)$ ). There is no significant interaction between period of stride and velocity. Ln SRE values increase in both groups following a non linear pattern with higher walking velocities (Figure 7), without a significant interaction between velocity and group. 


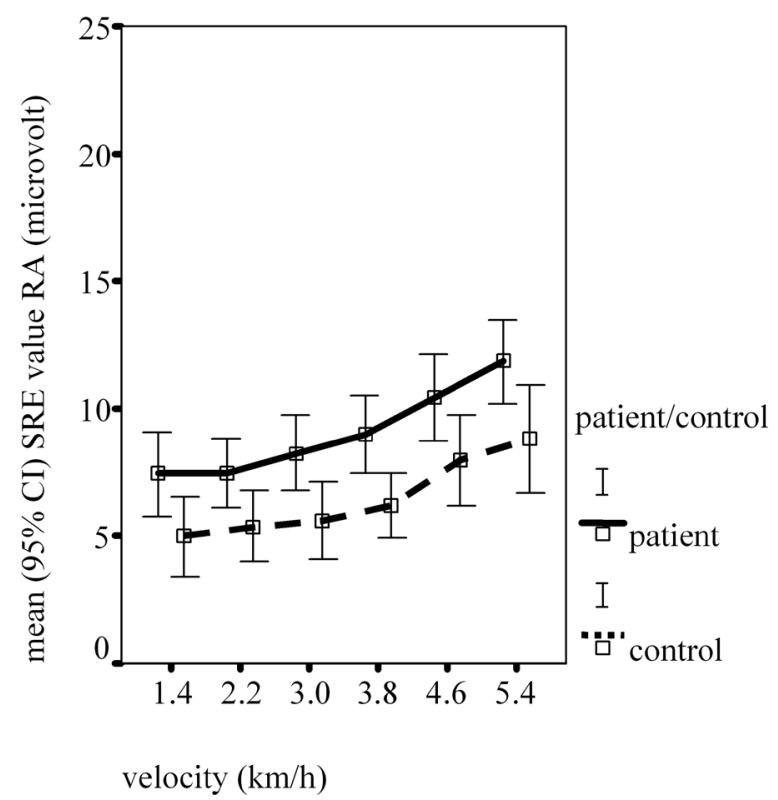

Figure 6 SRE values rectus abdominis per stride with higher velocities, mean of 20 steps per group. Note: $\mathrm{SRE}=$ smoothed rectified EMG.

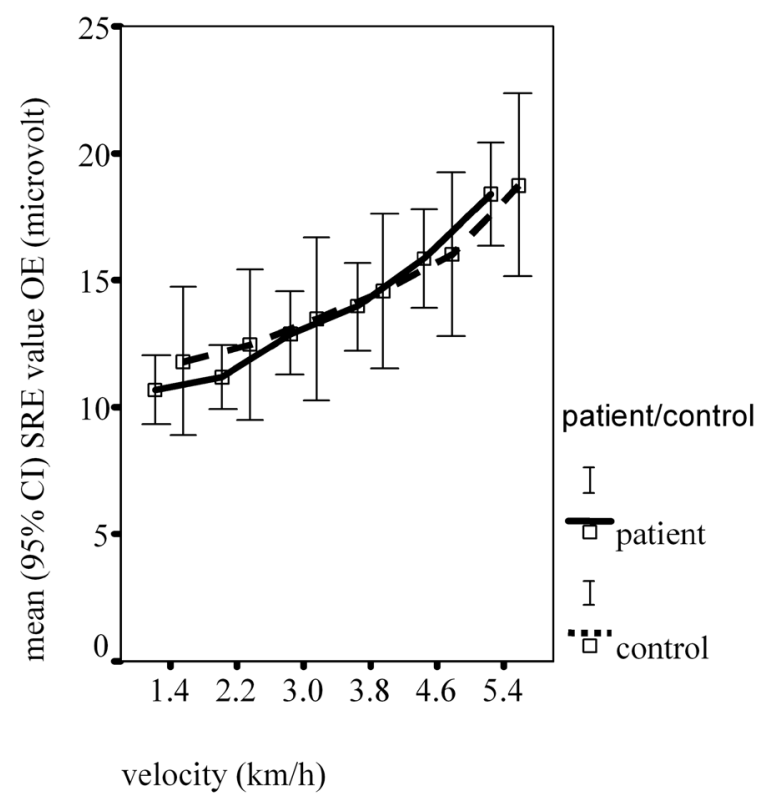

Figure 7 SRE values obliquus externus per stride with higher velocities, mean of 20 steps per group. Note: $\mathrm{SRE}=$ smoothed rectified EMG.

regel 1

regel 2

regel 3

regel 4

regel 5

regel 6

regel 7

regel 8

regel 9

regel 10

regel 11

regel 12

regel 13

regel 14

regel 15

regel 16

regel 17

regel 18

regel 19

regel 20

regel 21

regel 22

regel 23

regel 24

regel 25

regel 26

regel 27

regel 28

regel 29

regel 30

regel 31

regel 32

regel 33

regel 34

regel 35

regel 36

regel 37

regel 38 
regel 1 regel 2 regel 3 regel 4 regel 5 regel 6 regel 7 regel 8 regel 9 regel 10 regel 11 regel 12 regel 13 regel 14 regel 15 regel 16 regel 17 regel 18 regel 19 regel 20 regel 21 regel 22 regel 23 regel 24 regel 25 regel 26 regel 27 regel 28 regel 29 regel 30 regel 31 regel 32 regel 33 regel 34 regel 35 regel 36 regel 37 regel 38

\section{Discussion}

This study shows that subjects with CLBP have increased co-activation of erector spinae (ES) and rectus abdominis (RA) muscles during walking as compared to asymptomatic controls. Subjects with CLBP however, do not have higher activity levels of the obliquus abdominis externus muscles (OE). Although in both groups the overall trunk muscle activity level increases with higher velocities, differences in muscle activity levels do not become more pronounced in subjects with CLBP.

\section{Differences in lumbar and abdominal muscle activity between subjects with CLBP and asymptomatic controls}

Higher ES activity in subjects with CLBP during stride is in agreement with earlier studies 4;23 [van der Hulst et al, Clin J Pain (in press)]. RA and OE activity during walking has not been studied before in CLBP. A possible explanation for the overall increase of ES and RA, but not $\mathrm{OE}$ activity, can be found considering their function in controlling spinal movement. In healthy persons, consistent evidence has shown that the ES control trunk movement in the sagittal and/or frontal plane ${ }^{12 ; 34 ; 3 ; 45}$. Concerning the function of the RA and OE during walking, literature is inconsistent. Callaghan et al. ${ }^{9}$ did not find a clear relationship between RA, OE activity and lumbo-pelvic motion in healthy individuals. Saunders et al ${ }^{37}$ however, showed that RA activity was positively related to lumbo-pelvic movement in the sagittal plane, and $\mathrm{OE}$ activity to lumbo-pelvic movement in the transverse plane. Also from an anatomical point of view, it is plausible that ES and RA muscles function as antagonists. It could therefore be hypothesized that spinal movement in the sagittal plane is controlled by both the ES and RA, but not the OE muscles. As such, increased co-activation of ES and RA muscle activity may serve to control spinal movement and contribute to a "guarding" mechanism in CLBP. It is possible that $\mathrm{OE}$ activity does not play an important role in guarding of the spine, as was hypothesized at the beginning of the current study. Further research however, is needed to study relations between lumbar and abdominal muscle activity and trunk movement during walking.

\section{Adaptation of lumbar and abdominal muscle activity to higher walking velocities}

Unexpectedly, adaptation of trunk muscle activity to higher walking velocities is similar between subjects with CLBP and asymptomatic controls, as no significant interaction between velocity and group is found. Average ES, RA and OE activity increases with higher velocities in both groups in a similar manner. Although this result is in contrast to our hypothesis, it may be that the overall higher activity level of the ES and RA in subjects with CLBP is sufficient to control spinal motion. As such, the overall increase in trunk muscle activity in CLBP with higher velocities may reflect guarded movement controlling increased spinal motion, 
although differences between groups do not become more pronounced. Furthermore, it may be that the experimental design was insufficient to elicit increased guarding in subjects with CLBP at higher velocities. In the current study, velocity was increased in a predictable order, allowing the subject to accustom to each velocity before the measurement started. It could be that specifically unpredictable changes in velocity are needed to reveal different adaptations of trunk muscle activity. Lamoth et al. ${ }^{22}$ have measured ES activity in subjects with CLBP walking on a treadmill and changed velocity in an unpredictable order, without allowing the subject to become habituated to the new velocity. The authors have shown increased variability and earlier peak activity of ES at higher velocities in subjects with CLBP compared to asymptomatic controls. They propose that the diminished capacity to adapt ES to changing velocities may reflect an attempt to stabilize the spine, which is in line with our guarding hypothesis. Finally, another explanation may be that guarded movements are related to supraspinal (i.e. cognitive/emotional) processes. For example, several studies have confirmed a positive relation between stress, anxiety and increased lumbar muscle activity in CLBP 7:; 14;17;33;53:55. Influences of cognitive processes on trunk muscle activity are likely to be velocity independent and may explain why no different adaptations are found with higher velocities.

The average increase in ES activity with maintenance of the biphasic activity pattern, is in line with other studies ${ }^{3 ; 9 ; 23 ; 37 ; 45}$. The results show that for both RA and OE muscles the differences in average activity between double support and swing are very small. Although significant, the small absolute differences in average activity show that the RA and OE muscles do not show a comparable biphasic activity pattern as the ES. Studies of abdominal activation patterns in healthy persons during walking have shown both mono and biphasic activity patterns ${ }^{3 ; 9 ; 26 ; 36 ; 37 ; 54}$. A phasic activation of RA- and OE muscles would have been in line with their function within the global system ${ }^{5 ; 11}$, but has been not been consistently supported in literature.

It is interesting to discuss the mechanisms of increased superficial trunk muscle activity in subjects with CLBP during walking. It is not known if these (compensatory) changes are beneficial or contribute to the vicious cycle of ongoing pain and disability in the long run. In several recent reviews, both possibilities have been hypothesized. Some authors have proposed that increased ES activity may be protective by compensating for reduced spinal stability ${ }^{15 ; 47}$. Others have hypothesized that these compensatory changes in activity will place an excessive demand on the superficial muscles ${ }^{19 ; 4}$, restrict optimal trunk movement and generate high loading of the spine ${ }^{21}$. If negative cognitions or emotions like anxiety or stress also contribute to increased lumbar muscle activity 78;:14;17:33;53:55, this may plead for an underlying mechanism which is not beneficial, but part of a vicious cycle in ongoing pain. regel 1

regel 2

regel 3

regel 4

regel 5

regel 6

regel 7

regel 8

regel 9

regel 10

regel 11

regel 12

regel 13

regel 14

regel 15

regel 16

regel 17

regel 18

regel 19

regel 20

regel 21

regel 22

regel 23

regel 24

regel 25

regel 26

regel 27

regel 28

regel 29

regel 30

regel 31

regel 32

regel 33

regel 34

regel 35

regel 36

regel 37

regel 38 
regel 1 regel 2 regel 3 regel 4 regel 5 regel 6 regel 7 regel 8 regel 9 regel 10 regel 11 regel 12 regel 13 regel 14 regel 15 regel 16 regel 17 regel 18 regel 19 regel 20 regel 21 regel 22 regel 23 regel 24 regel 25 regel 26 regel 27 regel 28 regel 29 regel 30 regel 31 regel 32 regel 33 regel 34 regel 35 regel 36 regel 37 regel 38

\section{Methodological considerations}

Some limitations of this study should be noted. Due to the cross-sectional nature of this study, no conclusions can be drawn about the fact whether these changes are a cause or a consequence of low back pain. Furthermore, this study was conducted on a treadmill, to be able to control walking velocity. Treadmill walking is different from walking over ground and reduced amplitudes of kinematics of upper lumbar region and pelvis ${ }^{51}$ and differences in sagittal plane joint moments of the legs ${ }^{24}$ have been shown. Although the magnitude of the differences in kinematical, kinetic ${ }^{35}$, temporal gait parameters ${ }^{24}$ and sEMG of the lower limbs ${ }^{30}$ between treadmill and gait over ground is very small, it is not known if the results of this study are comparable with normal walking over ground.

Further, some additional remarks about the outcome measures should be made. This study did not include sEMG values normalized to a maximal voluntary contraction at a certain joint angle. Normalizing sEMG values is possible not reliable in LBP, as pain inhibits a maximal voluntary contraction ${ }^{43}$. Also, using a single reference point for normalization of sEMG activity during walking with changing joint angles will render inaccurate results ${ }^{29}$. Although normalization reduces intra individual differences, it may also mask existing differences between groups. Possible bias due to using amplitude estimation, a variable with high variance, was reduced by matching for BMI, gender and age and by standardizing electrode placement. Additionally, a large sample of subjects was measured to reduce intersubject variability. A post hoc power analysis confirmed that the sample size was adequate to find a difference in average ES activity between subjects with CLBP and asymptomatic controls. Based on the expected increase of $39 \%$ in average ES activity in CLBP found in a former study ${ }^{23}$ and the averaged SRE values of ES in the current study, 63 subjects with CLBP would have been sufficient for a power of $97 \%$.

In the present study we did not take the physical activity into account although it may have had some influence on muscle activity levels, as physical activity has an effect on muscle fiber size and muscle fiber types. Future studies should include physical activity levels to exclude a possible confounding effect. In literature there is conflicting evidence whether subjects with CLBP have lower aerobic fitness levels ${ }^{40 ; 41}$. Other studies have shown that averaged physical activity levels are comparable between subjects with CLBP and healthy controls ${ }^{42 ; 49}$ ${ }^{48}$. In addition, groups significantly differed in education level and work status. Work status however, is unrelated to erector spinae activity level [van der Hulst et al., Clin J Pain (in press)]. It is therefore unlikely that physical activity level or work status are confounders for muscle activity levels. 
Finally, it is known that the amount of fat in particular above the abdominal muscles reduces

regel 1

regel 2

regel 3

regel 4

regel 5

regel 6

regel 7

regel 8

regel 9

regel 10

regel 11

regel 12

regel 13

regel 14

regel 15

regel 16

regel 17

regel 18

regel 19

regel 20

regel 21

regel 22

regel 23

regel 24

regel 25

regel 26

regel 27

regel 28

regel 29

regel 30

regel 31

regel 32

regel 33

regel 34

regel 35

regel 36

regel 37

regel 38 
regel 1

regel 2

regel 3

regel 4

regel 5

regel 6

regel 7

regel 8

regel 9

regel 10

regel 11

regel 12

regel 13

regel 14

regel 15

regel 16

regel 17

regel 18

regel 19

regel 20

regel 21

regel 22

regel 23

regel 24

regel 25

regel 26

regel 27

regel 28

regel 29

regel 30

regel 31

regel 32

regel 33

regel 34

regel 35

regel 36

regel 37

regel 38

\section{References}

1. Ahern DK, Follick MJ, Council JR, and Laser-Wolston N. Reliability of lumbar paravertebral EMG assessment in chronic low back pain. Arch Phys Med Rehabil 1986;67:762-5.

2. Ahern DK, Follick MJ, Council JR, Laser-Wolston N, and Litchman H. Comparison of lumbar paravertebral EMG patterns in chronic low back pain patients and non-patient controls. Pain 1988;34:153-60.

3. Anders C, Wagner H, Puta C, Grassme R, Petrovitch A, and Scholle HC. Trunk muscle activation patterns during walking at different speeds. J Electromyogr Kinesiol 2007;17:245-52.

4. Arendt-Nielsen L, Graven-Nielsen T, Svarrer H, and Svensson P. The influence of low back pain on muscle activity and coordination during gait: a clinical and experimental study. Pain 1996;64:231-40.

5. Bergmark A. Stability of the lumbar spine. A study in mechanical engineering. Acta Orthop Scand Suppl 1989;230:1-54.

6. Brouwer S, Kuijer W, Dijkstra PU, Goeken LN, Groothoff JW, and Geertzen JH. Reliability and stability of the Roland Morris Disability Questionnaire: intra class correlation and limits of agreement. Disabil Rehabil 2004;26:162-5.

7. Burns JW. Arousal of negative emotions and symptom-specific reactivity in chronic low back pain patients. Emotion 2006;6:309-19.

8. Burns JW, Bruehl S, and Quartana PJ. Anger management style and hostility among patients with chronic pain: effects on symptom-specific physiological reactivity during anger- and sadness-recall interviews. Psychosom Med 2006;68:786-93.

9. Callaghan JP, Patla AE, and McGill SM. Low back three-dimensional joint forces, kinematics, and kinetics during walking. Clin Biomech 1999;14:203-16.

10. Cholewicki J, Panjabi MM, and Khachatryan A. Stabilizing function of trunk flexor-extensor muscles around a neutral spine posture. Spine 1997;22:2207-12.

11. Comerford MJ and Mottram SL. Movement and stability dysfunction--contemporary developments. Man Ther 2001;6:15-26.

12. Cromwell RL, Aadland-Monahan TK, Nelson AT, Stern-Sylvestre SM, and Seder B. Sagittal plane analysis of head, neck and trunk kinematics and electromyographic activity during locomotion. J Orthop Sports Phys Ther 2001;31:255-62.

13. Crosbie J, Vachalathiti R, and Smith R. Age, gender and speed effects on spinal kinematics during walking. Gait \& Posture 1997;5:13-20.

14. Flor H, Turk DC, and Birbaumer N. Assessment of stress-related psychophysiological reactions in chronic back pain patients. J Consult Clin Psychol 1985;53:354-64.

15. Fryer G, Morris T, and Gibbons P. Paraspinal muscles and intervertebral dysfunction: part one. J Manipulative Physiol Ther 2004;27:267-74.

16. Geisser ME, Haig AJ, Wallbom AS, and Wiggert EA. Pain-related fear, lumbar flexion, and dynamic EMG among persons with chronic musculoskeletal low back pain. Clin J Pain 2004;20:61-9.

17. Geisser ME, Ranavaya M, Haig AJ et al. A meta-analytic review of surface electromyography among persons with low back pain and normal, healthy controls. J Pain 2005;6:711-26.

18. Gommans IHB, Koes BW, and van Tulder MW. Validiteit en responsiviteit Nederlandstalige Roland Disability Questionnaire. Vragenlijst naar functionele status bij patiënten met lagerugpijn. Nederlands Tijdschrift voor Fysiotherapie 1997;2:28-33.

19. Hammill RR, Beazell JR, and Hart JM. Neuromuscular consequences of low back pain and core dysfunction. Clin Sports Med 2008;27:449-62, ix.

20. Hermens HJ, Freriks B, Disselhorst-Klug C, and Rau G. Development of recommendations for SEMG sensors and sensor placement procedures. J Electromyogr Kinesiol 2000;10:361-74.

21. Hodges PW and Moseley GL. Pain and motor control of the lumbopelvic region: effect and possible mechanisms. J Electromyogr Kinesiol 2003;13:361-70. 
22. Lamoth CJ, Daffertshofer A, Meijer OG, and Beek PJ. How do persons with chronic low back pain speed up and slow down? Trunk-pelvis coordination and lumbar erector spinae activity during gait. Gait Posture 2006;23:230-9.

23. Lamoth CJ, Meijer OG, Daffertshofer A, Wuisman PI, and Beek PJ. Effects of chronic low back pain on trunk coordination and back muscle activity during walking: changes in motor control. Eur Spine J 2006;15:23-40.

24. Lee SJ and Hidler J. Biomechanics of overground vs. treadmill walking in healthy individuals. J Appl Physiol 2008;104:747-55.

25. Main CJ and Watson PJ. Guarded movements: development of chronicity. J Musculoskeletal Pain 1996;4:163-170.

26. Mann RA, Moran GT, and Dougherty SE. Comparative electromyography of the lower extremity in jogging, running, and sprinting. Am J Sports Med 1986;14:501-10.

27. Mannion AF. Fibre type characteristics and function of the human paraspinal muscles: normal values and changes in association with low back pain. J Electromyogr Kinesiol 1999;9:363-77.

28. Mannion AF, Kaser L, Weber E, Rhyner A, Dvorak J, and Muntener M. Influence of age and duration of symptoms on fibre type distribution and size of the back muscles in chronic low back pain patients. Eur Spine J 2000;9:273-81.

29. Mirka GA. The quantification of EMG normalization error. Ergonomics 1991;34:343-52.

30. Nymark JR, Balmer SJ, Melis EH, Lemaire ED, and Millar S. Electromyographic and kinematic nondisabled gait differences at extremely slow overground and treadmill walking speeds. J Rehabil Res Dev 2005;42:523-34.

31. Panjabi MM. The stabilizing system of the spine. Part I. Function, dysfunction, adaptation, and enhancement. J Spinal Disord 1992;5:383-9; discussion 397.

32. Panjabi MM. The stabilizing system of the spine. Part II. Neutral zone and instability hypothesis. J Spinal Disord 1992;5:390-6; discussion 397.

33. Quartana PJ, Burns JW, and Lofland KR. Attentional strategy moderates effects of pain catastrophizing on symptom-specific physiological responses in chronic low back pain patients. J Behav Med 2007;30:221-31.

34. Richardson C, Jull G, Hodges P, Hides J. Spinal segmental stabilization in low back pain: scientific basic and clinical approach. In: Richardson C, Jull G, Hodges P, Hides J, eds. Traditional views of the function of the muscles of the local stabilizing system of the spine. Churchill Livingstone, United Kingdom: Harcourt Publishers Limited, 2000:21-40.

35. Riley PO, Paolini G, Croce UD, Paylo KW, and Kerrigan DC. A kinematic and kinetic comparison of overground and treadmill walking in healthy subjects. Gait Posture 2007;26:17-24.

36. Saunders SW, Rath D, and Hodges PW. Postural and respiratory activation of the trunk muscles changes with mode and speed of locomotion. Gait Posture 2004;20:280-90.

37. Saunders SW, Schache A, Rath D, and Hodges PW. Changes in three dimensional lumbopelvic kinematics and trunk muscle activity with speed and mode of locomotion. Clin Biomech 2005;20:784-93.

38. Selles RW, Wagenaar RC, Smit TH, and Wuisman PI. Disorders in trunk rotation during walking in patients with low back pain: a dynamical systems approach. Clin Biomech 2001;16:175-81.

39. Shiavi R, Frigo C, and Pedotti A. Electromyographic signals during gait: criteria for envelope filtering and number of strides. Med Biol Eng Comput 1998;36:171-8.

40. Smeets RJ, Wade D, Hidding A, Van Leeuwen PJ, Vlaeyen JW, and Knottnerus JA. The association of physical deconditioning and chronic low back pain: a hypothesis-oriented systematic review. Disabil Rehabil 2006;28:673-93.

41. Smeets RJ, Wittink H, Hidding A, and Knottnerus JA. Do patients with chronic low back pain have a lower level of aerobic fitness than healthy controls? Are pain, disability, fear of injury, working status, or level of leisure time activity associated with the difference in aerobic fitness level? Spine 2006;31:90-7; discussion 98.

42. Spenkelink CD, Hutten MM, Hermens HJ, and Greitemann BO. Assessment of activities of daily living with an ambulatory monitoring system: a comparative study in patients with chronic low back pain and nonsymptomatic controls. Clin Rehabil 2002;16:16-26.

regel 1

regel 2

regel 3

regel 4

regel 5

regel 6

regel 7

regel 8

regel 9

regel 10

regel 11

regel 12

regel 13

regel 14

regel 15

regel 16

regel 17

regel 18

regel 19

regel 20

regel 21

regel 22

regel 23

regel 24

regel 25

regel 26

regel 27

regel 28

regel 29

regel 30

regel 31

regel 32

regel 33

regel 34

regel 35

regel 36

regel 37

regel 38 
regel 1

regel 2

regel 3

regel 4

regel 5

regel 6

regel 7

regel 8

regel 9

regel 10

regel 11

regel 12

regel 13

regel 14

regel 15

regel 16

regel 17

regel 18

regel 19

regel 20

regel 21

regel 22

regel 23

regel 24

regel 25

regel 26

regel 27

regel 28

regel 29

regel 30

regel 31

regel 32

regel 33

regel 34

regel 35

regel 36

regel 37

regel 38
43. Sterling M, Jull G, and Wright A. The effect of musculoskeletal pain on motor activity and control. J Pain 2001;2:135-45.

44. Stokes M, Rankin G, and Newham DJ. Ultrasound imaging of lumbar multifidus muscle: normal reference ranges for measurements and practical guidance on the technique. Man Ther 2005;10:116-26.

45. Thorstensson A, Carlson H, Zomlefer MR, and Nilsson J. Lumbar back muscle activity in relation to trunk movements during locomotion in man. Acta Physiol Scand 1982;116:13-20.

46. Triano JJ, McGregor M, Cramer GD, and Emde DL. A comparison of outcome measures for use with back pain patients: results of a feasibility study. J Manipulative Physiol Ther 1993;16:67-73.

47. van Dieen JH, Selen LP, and Cholewicki J. Trunk muscle activation in low-back pain patients, an analysis of the literature. J Electromyogr Kinesiol 2003; 13:333-51.

48. Verbunt JA, Seelen HA, Vlaeyen JW et al. Disuse and deconditioning in chronic low back pain: concepts and hypotheses on contributing mechanisms. Eur J Pain 2003;7:9-21.

49. Verbunt JA, Westerterp KR, van der Heijden GJ, Seelen HA, Vlaeyen JW, and Knottnerus JA. Physical activity in daily life in patients with chronic low back pain. Arch Phys Med Rehabil 2001;82:726-30.

50. Vink P and Karssemeijer N. Low back muscle activity and pelvic rotation during walking. Anat Embryol 1988;178:455-60.

51. Vogt L, Pfeifer K, and Banzer W. Comparison of angular lumbar spine and pelvis kinematics during treadmill and overground locomotion. Clin Biomech 2002;17:162-5.

52. Vogt L, Pfeifer K, and Banzer W. Neuromuscular control of walking with chronic low-back pain. Manual Therapy 2003;8:21-8.

53. Watson PJ, Booker CK, and Main CJ. Evidence for the role of psychological factors in abnormal paraspinal activity in patients with chronic low back pain. Journal of Musculoskeletal Pain 1997;5:41-56.

54. White SG and McNair PJ. Abdominal and erector spinae muscle activity during gait: the use of cluster analysis to identify patterns of activity. Clin Biomech 2002;17:177-84.

55. Wolff B, Burns JW, Quartana PJ, Lofland K, Bruehl S, and Chung OY. Pain catastrophizing, physiological indexes, and chronic pain severity: tests of mediation and moderation models. J Behav Med 2008;31:105-14. 


\section{Chapter 6}

Relationships between coping strategies and lumbar muscle activity in subjects with chronic low back pain

Marije van der Hulst, Miriam M Vollenbroek-Hutten, Karlein M Schreurs, Johan S Rietman, Hermanus J Hermens Submitted for publication 2009 
regel 1

regel 2

regel 3

regel 4

regel 5

regel 6

regel 7

regel 8

regel 9

regel 10

regel 11

regel 12

regel 13

regel 14

regel 15

regel 16

regel 17

regel 18

regel 19

regel 20

regel 21

regel 22

regel 23

regel 24

regel 25

regel 26

regel 27

regel 28

regel 29

regel 30

regel 31

regel 32

regel 33

regel 34

regel 35

regel 36

regel 37

regel 38

\begin{abstract}
Background: Concerning chronic low back pain (CLBP), different cognitive-behavioral models have hypothesized that coping strategies play a role in the chronification of pain by changes in physical activity. Strategies such as avoidance - or persistent coping may be related to changes in (lumbar) muscle activity.
\end{abstract}

Objectives: Investigate the different coping strategies present in CLBP and whether these are differentially related to lumbar muscle activity during walking.

Methods: In a cross-sectional study, sixty-three subjects with CLBP walked on a treadmill at $3.8 \mathrm{~km} / \mathrm{h}$. Coping strategies were measured with the Dutch version of the Coping Strategies Questionnaire and three factors were identified with principal component analysis. Surface electromyography data of the erector spinae were obtained and smooth rectified electromyography (SRE) values were averaged per periods of swing and double support. The ratio of SRE values (swing/double support) was used as a measure of relaxation. The relation between SRE values and coping strategies was analysed with random coefficient analysis.

Results: Three coping strategies (i.e. "catastrophizing", "distraction" and "persistence and control") could be discerned. "Catastrophizing" was positively related to (natural logarithm) SRE values ( $\left.\beta=0.06,95 \% C I=0.01-0.10 ; R^{2}=7.7 \%\right)$. "Distraction" was negatively associated with SRE ratios $\left(B=-0.03,95 \% \mathrm{CI}=-0.05--0.01 ; \mathrm{R}^{2}=7.5 \%\right)$. No relation was found between "persistence and control" and SRE values or ratios.

Conclusions: In CLBP, a maladaptive coping strategy like "catastrophizing" is related to increased lumbar muscle activity, and an adaptive strategy like "distraction" to increased lumbar muscle relaxation during walking. 


\section{Introduction}

The development and maintenance of chronic low back pain (CLBP) is complex and not well understood. Different pain models such as the fear-avoidance model ${ }^{19 ; 41}$ and the avoidanceendurance model ${ }^{11}$, hypothesize that pain coping strategies play a role in the chronification of pain by changes in physical activity. Strategies such as avoidance (i.e. avoiding daily activities because of fear of pain/ (re)injury) - or endurance/persistent coping (i.e. carrying on with daily activities despite pain) are assumed to lead to maintenance of pain. In contrast, confrontation with the fear-eliciting stimulus ${ }^{41}$ or distraction from pain ${ }^{11}$, is considered to result in a flexible change between exertion and relaxation and eventually in pain reduction. Both pain models hypothesize that catastrophizing and related fear of movement are the factors leading to avoidance coping, which is assumed to result in disuse (i.e. a decreased level of physical activity) and deconditioning (i.e. a low level of physical fitness). Additionally, in the avoidance -endurance model, suppressive or minimizing thoughts are hypothesized to lead to endurance/persistent coping. This may result in physical overload and muscular hyperactivity.

As described, both the strategies avoidance and persistent coping are assumed to provoke physical changes. Although the relation between physical changes and fear-avoidance coping has been extensively studied, results are inconsistent. Several studies of subjects with CLBP have focused on the possible relationship between fear-avoidance beliefs, catastrophizing, avoidance behavior on one side and disuse/deconditioning, the amount of lumbar muscle activity, relaxation or fatigue on the other side. These studies have shown either no relation ${ }^{16}$ ${ }^{38 ; 39 ; 42}$ [van der Hulst et al., Clin J Pain (in press)], an association with deconditioning ${ }^{4 ; 25}$, less physical performance ${ }^{24}$, less muscle relaxation ${ }^{9 ; 44}$, increased resting tension ${ }^{26 ; 46}$ or higher muscle fatigue ${ }^{2}$. Concerning the hypothesized relation between persistent coping and physical variables, only one study has been performed ${ }^{13}$. In this study, subjects with persistent coping strategies had comparable levels of physical activity to those with adaptive coping strategies, measured with an accelerometer.

So at this moment, there is insufficient evidence available to either support or reject a possible relationship between avoidance- and persistent coping and physical performance. More insight in these relationships however, is important and can be used to further improve multidisciplinary treatments, based on these biopsychosocial pain models. Therefore, the aim of this cross-sectional study is to investigate the different coping strategies present in a population of patients with CLBP referred for multidisciplinary rehabilitation treatment, and whether these coping strategies are differentially related to physical performance, measured as lumbar muscle activity during walking. In line with literature on fear-avoidance coping regel 1

regel 2

regel 3

regel 4

regel 5

regel 6

regel 7

regel 8

regel 9

regel 10

regel 11

regel 12

regel 13

regel 14

regel 15

regel 16

regel 17

regel 18

regel 19

regel 20

regel 21

regel 22

regel 23

regel 24

regel 25

regel 26

regel 27

regel 28

regel 29

regel 30

regel 31

regel 32

regel 33

regel 34

regel 35

regel 36

regel 37

regel 38 
regel 1 regel 2 regel 3 regel 4 regel 5 regel 6 regel 7 regel 8 regel 9 regel 10 regel 11 regel 12 regel 13 regel 14 regel 15 regel 16 regel 17 regel 18 regel 19 regel 20 regel 21 regel 22 regel 23 regel 24 regel 25 regel 26 regel 27 regel 28 regel 29 regel 30 regel 31 regel 32 regel 33 regel 34 regel 35 regel 36 regel 37 regel 38

and the assumptions in the avoidance-endurance model, it is hypothesized that higher scores for maladaptive "avoidance" and "persistent" coping strategies are related to increased lumbar muscle activity, whereas this relationship is absent for adaptive coping strategies such as confrontation or distraction.

\section{Methods}

\section{Patients}

Subjects with CLBP, who were referred to a physician in Physical Medicine and Rehabilitation between July 2004 and July 2005, were asked to participate in the study. Inclusion criteria were: age between 16-70 years and more than three months continuing or recurrent low back pain. Low back pain was defined as pain under the scapulas, above the cleft of the buttock, with or without radiation to the extremities. Exclusion criteria were: surgery of the spine in the past three months, spondylodeses, structural pathology of the spine like inflammation, active radiculopathy, tumor, severe deformities (e.g. spondylolisthesis grade 3) or neurological and/ or musculoskeletal disorders that could have an effect on gait. Specific causes of low back pain were excluded by the physician's assessment (history, physical examination, if necessary blood tests and X-rays). All patients had previously undergone some form of treatment (medication or physiotherapy) without lasting relief. Participants who met the inclusion criteria and were willing to participate gave informed consent. The study was approved by the Medical Ethical Committee of the Rehabilitation Center "het Roessingh" in Enschede.

\section{Design and procedure}

A cross-sectional study was conducted and surface electromyography (sEMG) data were collected during walking on a treadmill. Participants filled out the questionnaires before the start of the experiment. Subjects were allowed to practice treadmill walking until they were accustomed to the walking conditions with a maximum of five minutes before the measurements started. They were instructed to walk as naturally as possible without using the handrail. Velocity was set at $3.8 \mathrm{~km} / \mathrm{h}$ to improve comparability with former studies $1 ; 15 ; 16 ; 43$. Data of at least twenty strides were collected to ensure a representative dataset ${ }^{29}$.

\section{Measurements \\ Questionnaires}

Sociodemographic (age, gender, level of education, work status), anthropometric (height, weight), pain- and disability related variables were collected as descriptive variables. Current pain intensity was measured by a Visual Analogue Scale $(0=$ no pain, $100=$ most severe 
pain). The VAS scale is found to be valid and reliable ${ }^{36}$. Activity limitation of patients was measured with the Dutch version of the Roland Morris Disability Questionnaire (RMDQ). The Dutch RMDQ ( $0=$ no disabilities, $24=$ severe disabilities $)$ is shown to be valid ${ }^{10}$ and reliable ${ }^{3}$. Coping strategies were measured with the Dutch version of the Coping Strategies Questionnaire (CSQ), the Coping met Pijn Vragenlijst (CPV), which has shown sufficient reliability and construct validity in subjects with CLBP ${ }^{31}$. The main difference between the original CSQ ${ }^{28}$ and the CPV is the number of items of the behavioral coping subscale (two for the CPV, six for the CSQ), and the use of a different answering format. In the CPV, subjects marked ten centimeter visual analogue scales with the end points defined as the original seven point Likert-type scale, as "never do" and "always do that". The last two questions of the CPV concern two ratings of the overall effectiveness (pain control and ability to decrease pain).

\section{Kinematics and surface electromyography (sEMG)}

Kinematical and sEMG data were collected simultaneously during walking on a motorized treadmill (Tunturi T-Track/G200). A six camera optical three-dimensional gait analysis system (VICON 370, Oxford metrics Ltd., Oxford UK) was used to determine foot contacts. VICON markers were placed on the second metatarsal phalangeal joint (MTP 2) and on the posterior side of the calcaneus. Marker data were collected with a sampling rate of $50 \mathrm{~Hz}$. Muscle activity patterns of the erector spinae were measured using multichannel, single differential, bipolar sEMG (16 channels Biotel 99, Glonner Electronic GmbH, Planegg, Germany). Bipolar sEMG was measured with solid gel electrodes (Arbo H93SG, Tyco Healthcare), placed bilaterally with an inter-electrode distance of $23 \mathrm{~mm}$ on the muscle belly after removal of hair and cleaning the subject's skin with alcohol. Electrodes were placed bilaterally parallel with the muscle fibers at two levels, $30 \mathrm{~mm}$ lateral to the first lumbar processus spinosus, according to the SENIAM (Surface Electromyography for the Non-Invasive Assessment of Muscles) guidelines ${ }^{14}$, and $30 \mathrm{~mm}$ lateral to the fourth lumbar processus spinosus ${ }^{40}$. Lumbar vertebrae were located through palpation, using the iliac crest as landmark. All wires and leads were fixed with tape to the subject's skin to diminish artifacts without limiting motion. A common reference electrode was placed over the right processus styloideus ulnae. In the pre-processed method, sEMG data were collected with a sampling rate of $1024 \mathrm{~Hz}$ and band passed filtered using a first order filter of $17-500 \mathrm{~Hz}$.

\section{Data analysis}

Temporal parameters:

The collected sEMG and kinematical data were imported in the home built analysis software, developed using Labview 8.2 National Instruments (Austin, Texas, USA). Movement of markers was measured according to the coordinate system of the laboratory room. Parameters regel 1

regel 2

regel 3

regel 4

regel 5

regel 6

regel 7

regel 8

regel 9

regel 10

regel 11

regel 12

regel 13

regel 14

regel 15

regel 16

regel 17

regel 18

regel 19

regel 20

regel 21

regel 22

regel 23

regel 24

regel 25

regel 26

regel 27

regel 28

regel 34

regel 35

regel 36

regel 37

regel 38 
regel 1 regel 2 regel 3 regel 4 regel 5 regel 6 regel 7 regel 8 regel 9 regel 10 regel 11 regel 12 regel 13 regel 14 regel 15 regel 16 regel 17 regel 18 regel 19 regel 20 regel 21 regel 22 regel 23 regel 24 regel 25 regel 26 regel 27 regel 28 regel 29 regel 30 regel 31 regel 32 regel 33 regel 34 regel 35 regel 36 regel 37 regel 38 of the gait cycle (initial contact and toe off) were determined by calculating the displacement in the horizontal direction of the MTP 2 and calcaneus marker. A stride was defined from left initial contact (LIC) to the next LIC (Figure 1) and divided in four periods: initial double support, contralateral swing, second period of double support and ipsilateral swing (DS1, CSw, DS2, ISw). Initial double support was defined from LIC to right toe off, followed by contralateral swing until right initial contact (RIC). Contralateral swing is equal to ipsilateral single limb stance. The second period of double support was defined from RIC to left toe off, followed by the ipsilateral swing phase until LIC. In summary, a stride was divided in two periods of double support and two periods of swing (contra-and ipsilateral).

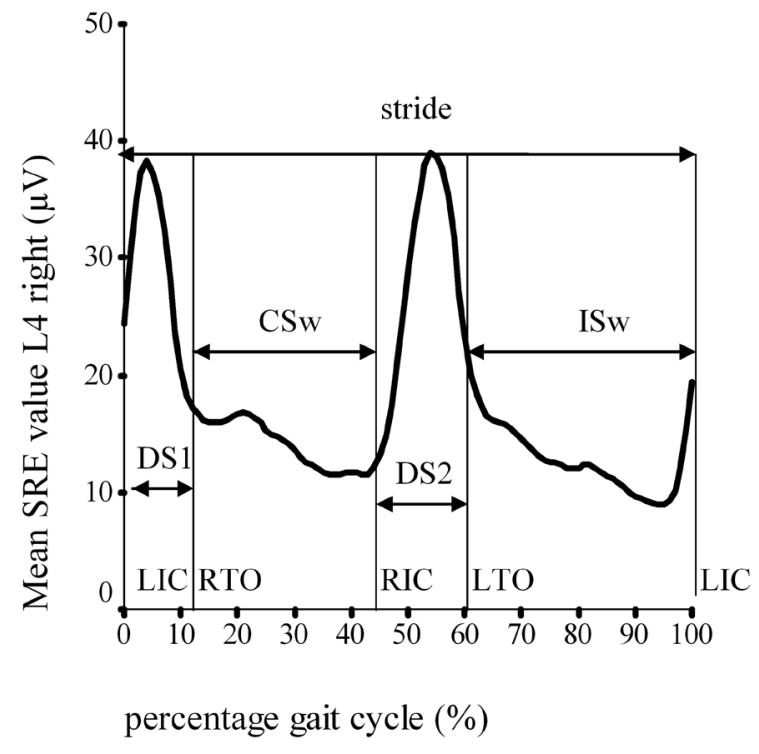

Figure 1. Example of averaged erector spinae activity pattern per stride

Note: $\mathrm{SRE}=$ smoothed rectified electromyography, DS1 = first double support, CSw = contralateral swing, DS2 = second double support, ISw = ipsilateral swing, L(R) IC = left (right) initial contact, $\mathrm{L}(\mathrm{R}) \mathrm{TO}=$ left (right) toe off.

\section{Surface EMG}

In the post processed method, sEMG was bandpass filtered at $20 \mathrm{~Hz}$, using a $3^{\text {rd }}$ order Butterworth filter, to remove movement artifacts. After the signal was double phase rectified, it was low pass filtered at $25 \mathrm{~Hz}$ to calculate smooth rectified EMG values (SRE). To account for different cycle durations between subjects, sEMG was normalized in time for each stride per subject. Averaged SRE values of approximately 20 time-normalized sEMG profiles were used. For each individual, the SRE values per stride were divided in the four periods of stride 
(DS1, CSw, DS2 and ISw) and averaged. To reduce variability in EMG measures, groups were matched for BMI, gender, age and electrode placement was standardized. Main outcome parameters were:

- Averaged SRE values of the erector spinae per stride ${ }^{23}$.

- The ratio between the averaged SRE values of the erector spinae in the periods of swingand the averaged activation in double support (SRE ratio). Two ratios were calculated: averaged SRE (CSw/DS1) and averaged SRE (ISw/DS2). A high ratio reflects relatively high activity in swing compared to double support (i.e. less relaxation) [van der Hulst et al, Clin J Pain (in press)].

sEMG data of strides were excluded from the analysis when visual inspection of the sEMG signals showed movement artifacts, reflected by high amplitude and low frequency signals.

\section{Statistical analysis}

\section{Classification of coping strategies}

The different dimensions of coping activity, as measured by scales from the CSQ, have varied across investigations. To examine specific coping strategies in a new sample, factor analysis of the individual CSQ items is recommended ${ }^{17}$. In line with this recommendation, factors (i.e. coping strategies) of the CPV were identified with principal component analysis (PCA). Intercorrelations between the 44 items were calculated and factors with eigenvalues greater than one and less than two were retained. Additionally, a scree plot was examined, which is a secondary method to determine the optimal number of factors ${ }^{35}$. After determining the number of factors, an item was included in the factor fit if (1) it correlated with the factor at a level of 0.35 or larger, and (2) it had a loading lower than 0.35 on any other factor. To improve interpretability of the factors these were rotated by the Varimax procedure. To determine the internal consistency of each of the factors, Cronbach's alphas were computed. A Cronbach's alpha above 0.70 was considered to be sufficient.

\section{Analysis of relations between sEMG and coping strategies}

First, Pearson's correlations $\left(r_{p}\right)$ were applied to examine the relations between averaged CPV factor scores, descriptive variables and averaged SRE values or ratios. In case of a nonnormal distribution, Spearman's correlations were calculated. Second, the relations between averaged CPV factor scores and SRE values or ratios were controlled for possible confounding variables by using random coefficient analysis, also known as multilevel analysis ${ }^{37}$. Random coefficient analysis was chosen because it takes into account that multiple measurements within individuals are correlated. The dependent values were averaged SRE values or ratios (contralateral swing/first double support and ipsilateral swing/ second double support). The independent variables included in the regression model were: recording site (L1 left/right, L4 left/right) and gender as factors; age, BMI $\left(\mathrm{kg} / \mathrm{m}^{2}\right)$ and averaged $\mathrm{CPV}$ factor scores as regel 1

regel 2

regel 3

regel 4

regel 5

regel 6

regel 7

regel 8

regel 9

regel 10

regel 11

regel 12

regel 13

regel 14

regel 15

regel 16

regel 17

regel 18

regel 19

regel 20

regel 21

regel 22

regel 23

regel 24

regel 25

regel 26

regel 27

regel 28

regel 29

regel 30

regel 31

regel 32

regel 33

regel 34

regel 35

regel 36

regel 37

regel 38 
regel 1 regel 2 regel 3 regel 4 regel 5 regel 6 regel 7 regel 8 regel 9 regel 10 regel 11 regel 12 regel 13 regel 14 regel 15 regel 16 regel 17 regel 18 regel 19 regel 20 regel 21 regel 22 regel 23 regel 24 regel 25 regel 26 regel 27 regel 28 regel 29 regel 30 regel 31 regel 32 regel 33 regel 34 regel 35 regel 36 regel 37 regel 38 covariates. Nominal variables were included as factors and continuous variables as covariates. Age and gender were added because of their possible confounding effect on muscle fiber size ${ }^{20 ; 21 ; 30 ; 33}$ which in turn is likely to influence muscle activity. BMI was added because the amount of fat overlying the muscle reduces the sEMG signal. Descriptive variables were added if significant univariate associations were found with CPV factor scores. Residuals were checked for normality. If necessary, a natural logarithm $(\ln )$ transformation of the dependent variables was done to compensate for the non-normal distribution of the residuals. Statistical analyses were performed using the statistical software SPSS v.11.5.

\section{Results}

\section{Study population}

Of the 99 subjects who were suitable for inclusion, 63 (64\%) participated. The main reason for not being willing to participate was lack of sufficient time or motivation. Due to missing items on the CPV, 2 subjects were excluded from these 63, leaving 61 subjects (97\%) for the principal component analysis. Due to sEMG movement artifacts, three additional subjects were excluded from these 61 , so 58 subjects (92\%) were included in the final analysis relating the different coping strategies to SRE values. Baseline characteristics are reported in Table 1. Most subjects had lower or intermediate vocational education and the distribution between workers and non workers was comparable. Subjects showed a moderate level of pain intensity and activity limitation. 
Table 1 Baseline characteristics of the study population

\begin{tabular}{|c|c|}
\hline & $\begin{array}{l}\text { Subjects with CLBP } \\
\mathrm{N}=63\end{array}$ \\
\hline Age (years) & $41(11)$ \\
\hline Male gender & $33(52 \%)$ \\
\hline Body Mass Index $\left(\mathrm{kg} / \mathrm{m}^{2}\right)$ & $26(20-35)^{2)}$ \\
\hline $\begin{array}{l}\text { Education level } \\
\text { Lower vocational education }\end{array}$ & $\begin{array}{l}25(40 \%) \\
29(46 \%) \\
9(14 \%)\end{array}$ \\
\hline $\begin{array}{l}\text { Work status } \\
\text { Full-/part-time } \\
\text { Not working }\end{array}$ & $\begin{array}{l}28(44 \%) \\
35(56 \%)\end{array}$ \\
\hline Duration of complaints (mo) & $17(3-72)^{3)}$ \\
\hline $\begin{array}{l}\text { VAS }(\mathbf{0}-\mathbf{1 0 0}) \\
\text { Current pain intensity } \\
\text { RMDQ (0-24) }\end{array}$ & $\begin{array}{l}47(5-94) \\
11(4)\end{array}$ \\
\hline
\end{tabular}

Note $:$ CLBP = chronic low back pain ; sd = standard deviation, VAS=Visual Analogue Scale; RMDQ= Roland Disability Questionnaire

$\mathrm{Ad}^{1)}$ the median value is reported if this parameter is not normally distributed.

$\mathrm{Ad}^{2)} 1$ outlier: Body Mass Index $50 \mathrm{~kg} / \mathrm{m}^{2}$ excluded due to movement artifacts.

$\mathrm{Ad}^{3)} 1$ outlier: 288 months, included because of no significant influence on lumbar muscle activity.

\section{Coping strategies present in subjects with CLBP}

The PCA resulted in three factors with eigenvalues greater than one and less than two. Analysis of the scree plot also revealed a clear 3-factor structure. The loadings of individual items on the factors are presented in Table 2. With a cut-off point of 0.35 for inclusion of an item, 22 of the 44 items did not meet the before mentioned criteria. The PCA, with a 3 factor solution, accounted for $48.3 \%$ of the variance in questionnaire responses.

- The first factor accounted for $18.5 \%$ of the total variance in scores on the CPV items. Individuals with high scores on the first factor use a wide variety of distracting strategies, which include mental - (e.g. "I try to think of something pleasant") and behavioral distraction (e.g. "I leave the house and do something, such as going to the movies or shopping"). This factor was labeled "distraction".

- The second factor explained $15.5 \%$ of the variance. Subjects with high scores on this factor show signs of catastrophizing thoughts (e.g. "I feel terrible and I feel it's never going to get any better"). This factor was named "catastrophizing".

- The third factor accounted for $14.3 \%$ of the variance. Individuals with high scores on this factor try to suppress their pain (e.g. "I tell myself I can't let the pain stand in the way of what I have to do") or try to control their pain (e.g. "Are you able to decrease the trouble caused by pain if you apply strategies you normally use to cope with pain?"). This factor was labeled "persistence and control".

regel 1

regel 2

regel 3

regel 4

regel 5

regel 6

regel 7

regel 8

regel 9

regel 10

regel 11

regel 12

regel 13

regel 14

regel 15

regel 16

regel 17

regel 18

regel 19

regel 20

regel 21

regel 22

regel 23

regel 24

regel 25

regel 26

regel 27

regel 28

regel 29

regel 30

regel 31

regel 32

regel 33

regel 34

regel 35

regel 36

regel 37

regel 38 
regel 1

regel 2

regel 3

regel 4

regel 5

regel 6

regel 7

regel 8

regel 9

regel 10

regel 11

regel 12

regel 13

regel 14

regel 15

regel 16

regel 17

regel 18

regel 19

regel 20

regel 21

regel 22

regel 23

regel 24

regel 25

regel 26

regel 27

regel 28

regel 29

regel 30

regel 31

regel 32

regel 33

regel 34

regel 35

regel 36

regel 37

regel 38

The internal consistency of the factors of the CPV was investigated. The factors were sufficiently reliable (Cronbach's a "distraction" $=0.84$, "catastrophizing" $=0.82$, "persistence and control" $=0.73)$.

Table 2 The Varimax 3-factor solution of the 44 items of the Dutch version of the Coping Strategies Questionnaire ( $\mathrm{n}=63)$. Loadings under 0.35 were replaced by --.

\begin{tabular}{|c|c|c|c|c|}
\hline \multirow[t]{2}{*}{ Factor } & \multirow[t]{2}{*}{ When I feel pain... } & \multicolumn{3}{|c|}{ Factor loading } \\
\hline & & 1 & 2 & 3 \\
\hline \multirow[t]{10}{*}{1} & Distraction & & & \\
\hline & I think of things I enjoy to do & .781 & -- & -- \\
\hline & I do anything to get my mind off the pain & .729 & -- & -- \\
\hline & I try to think of something pleasant & .712 & -- & -- \\
\hline & $\begin{array}{l}\text { I count numbers in my head or run a song through my } \\
\text { mind }\end{array}$ & .648 & -- & -- \\
\hline & $\begin{array}{l}\text { I do something I enjoy, such as watching TV or listening } \\
\text { to music }\end{array}$ & .612 & -- & -- \\
\hline & $\begin{array}{l}\text { I leave the house and do something, such as going to } \\
\text { movies or shopping }\end{array}$ & .603 & -- & -- \\
\hline & I try to be around other people & .532 & -- & .417 \\
\hline & I tell myself that I can overcome the pain & .613 & -- & -- \\
\hline & $\begin{array}{l}\text { I know someday someone will be here to help me and it } \\
\text { will go away for a while }\end{array}$ & .510 & -- & -- \\
\hline \multirow[t]{7}{*}{2} & Catastrophizing & & & \\
\hline & I feel terrible and I feel it's never going to get any better & -- & .837 & -- \\
\hline & I feel awful and I feel that it overwhelms me & -- & .850 & -- \\
\hline & I feel I can't stand it anymore & -- & .771 & -- \\
\hline & I feel like I can't go on & -- & 639 & -- \\
\hline & I worry all the time about whether it will end & -- & .622 & -- \\
\hline & I pray for the pain to stop & -- & .565 & -- \\
\hline \multirow[t]{8}{*}{3} & Persistence and control & & & \\
\hline & $\begin{array}{l}\text { Are you able to decrease the pain intensity if you apply } \\
\text { strategies you normally use to cope with pain? }\end{array}$ & -- & -- & .728 \\
\hline & I just go on as if nothing happened & -- & -- & .729 \\
\hline & $\begin{array}{l}\text { I tell myself that I can't let the pain stand in the way of } \\
\text { what I have to do }\end{array}$ & -- & -- & .639 \\
\hline & I see it as a challenge and don't let it bother me & -- & -- & 616 \\
\hline & $\begin{array}{l}\text { I try to feel distant from the pain, almost as if the pain } \\
\text { was in somebody else's body }\end{array}$ & -- & -- & .601 \\
\hline & $\begin{array}{l}\text { Are you able to decrease the trouble caused by pain if } \\
\text { you apply strategies you normally use to cope with pain? }\end{array}$ & -- & -- & .462 \\
\hline & I ignore it & -- & -- & .465 \\
\hline
\end{tabular}

Note: "I try to be around other people" (Factor 1) was not excluded despite the criterion of 0.35 as factor loading, as Cronbach's alpha decreased when omitting this item. A separate analysis after omitting this item, showed no influence on the relation between factor scores and lumbar muscle activity. 
Relations between coping strategies and baseline characteristics

Results presented in table 3 show that "distraction" and "catastrophizing" are significantly positively related to both pain intensity and disability levels, whereas "persistence and control" is not related to these variables. On the other hand, "persistence and control" is the only strategy that is significantly positively related to age. No relations are found between the different coping strategies and pain duration. Overall average CPV factor scores were low.

Table 3. Average factor scores (CSQ-Dutch version) and univariate Pearson's correlations $\left(r_{p}\right)$ between the three coping strategies and descriptive variables

\begin{tabular}{lllll}
\hline & Distraction & Catastrophizing & $\begin{array}{l}\text { Persistence and } \\
\text { control }\end{array}$ \\
\hline \multirow{2}{*}{ Correlations $\left(r_{p}\right)$} & Average $(\mathbf{s d})$ & $4.8(2.1)$ & $3.1^{1)}$ & $5.1(1.8)$ \\
& range & $0.1-10$ & $0-8.7$ & $0.3-8.9$ \\
& Age (years) & 0.04 & -0.01 & $0.40^{* *}$ \\
& Pain duration (months) & 0.10 & 0.07 & 0.10 \\
& VAS (0-100) & $0.17^{* *}$ & $\left.0.14^{*}\right)$ & -0.02 \\
& RMDQ (0-24) & $\left.0.13^{*}\right)$ & $0.48^{* *}$ & 0.11 \\
\hline
\end{tabular}

Ad ${ }^{1)}$ the median value is presented if the parameter is not normally distributed; ${ }^{*} \mathrm{P}<0.05$; ${ }^{* *}$ ) $\mathrm{P}<0.01$ (twotailed)

Note: CSQ = Coping Strategies Questionnaire; sd = standard deviation; VAS=Visual Analogue Scale; RMDQ=Roland and Morris Disability Questionnaire

\section{Relations between coping strategies and erector spinae activity}

Table 4 presents univariate correlations between the average CPV factor scores and average (natural logarithm) SRE values/ratios of the erector spinae. Figures 2 and 3 illustrate the relation between the average CPV factor score and average (natural logarithm) SRE values and ratios of the erector spinae, corrected for gender, age, BMI and muscle recording site.

Table 4. Univariate Pearsons correlations $\left(r_{p}\right)$ between average factor scores (CSQ-Dutch version) and erector spinae activity (SRE) per stride

\begin{tabular}{lllll}
\hline & Distraction & Catastrophizing & Persistence and control \\
\hline Correlations $\left(\boldsymbol{r}_{\boldsymbol{p}}\right)$ & Ln SRE ES $(\boldsymbol{\mu V})$ & -0.04 & $\left.0.26^{* *}\right)$ & 0.02 \\
& Ratio CSw/DS1 & $\left.-0.31^{* *}\right)$ & -0.01 & $\left.-0.14^{*}\right)$ \\
& Ratio ISw/DS2 & $\left.-0.19^{* *}\right)$ & 0.04 & -0.08 \\
\hline
\end{tabular}

$\left.\mathrm{Ad}^{*}\right) \mathrm{P}<0.05 ;{ }^{* *} \mathrm{P}<0.01$ (two-tailed)

Note: $\mathrm{CSQ}=$ Coping Strategies Questionnaire, $\mathrm{SRE}=$ smoothed rectified electromyography, Ln = natural logarithm, $\mathrm{ES}=$ erector spinae, $\mathrm{CSw}=$ contralateral swing, $\mathrm{DS} 1=$ first double support, $\mathrm{ISw}=$ ipsilateral swing, DS2 = second double support regel 1

regel 2

regel 3

regel 4

regel 5

regel 6

regel 7

regel 8

regel 9

regel 10

regel 11

regel 12

regel 13

regel 14

regel 15

regel 16

regel 17

regel 18

regel 19

regel 20

regel 21

regel 22

regel 23

regel 24

regel 25

regel 26

regel 27

regel 28

regel 29

regel 30

regel 31

regel 32

regel 33

regel 34

regel 35

regel 36

regel 37

regel 38 
regel 1

regel 2

regel 3

regel 4

regel 5

regel 6

regel 7

regel 8

regel 9

regel 10

regel 11

regel 12

regel 13

regel 14

regel 15

regel 16

regel 17

regel 18

regel 19

regel 20

regel 21

regel 22

regel 23

regel 24

regel 25

regel 26

regel 27

regel 28

regel 29

regel 30

regel 31

regel 32

regel 33

regel 34

regel 35

regel 36

regel 37

regel 38

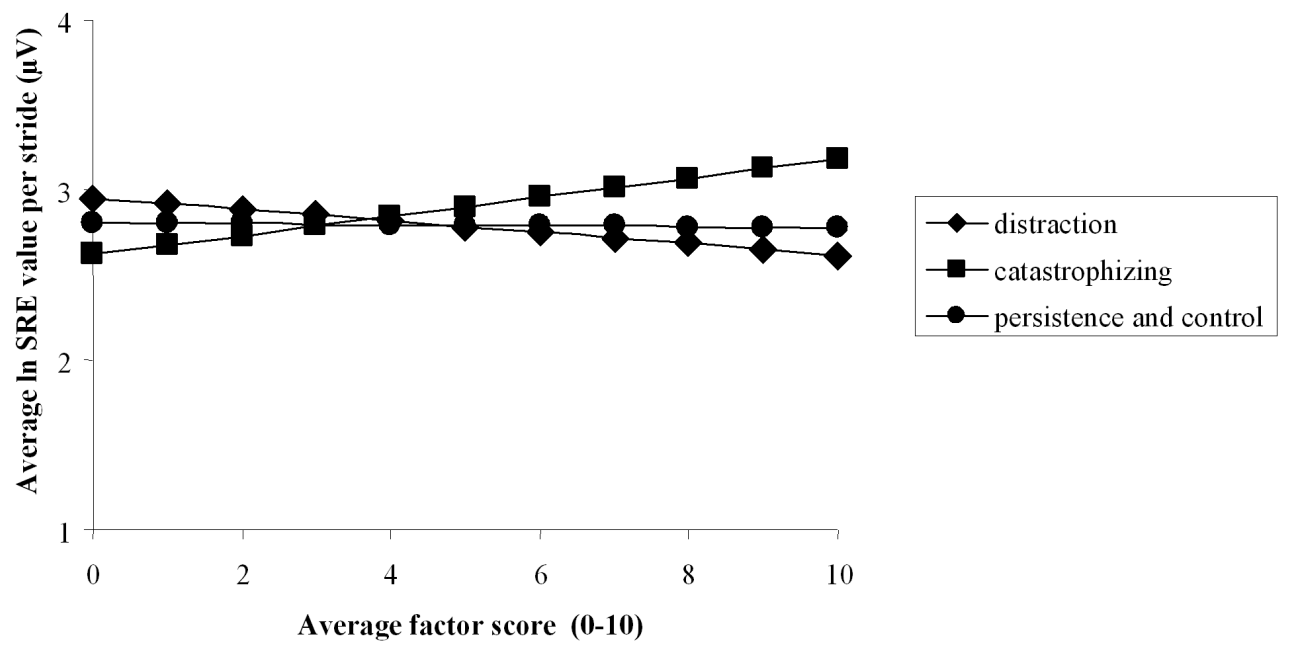

Figure 2. Relation between averaged erector spinae activity and average factor scores (CSQ-Dutch version)

Note: presentation of regression model, after correction for gender, recording site, age and Body Mass Index (BMI); CSQ = Coping Strategies Questionnaire, $\mathrm{Ln}=$ natural logarithm, SRE = smooth rectified electromyography.

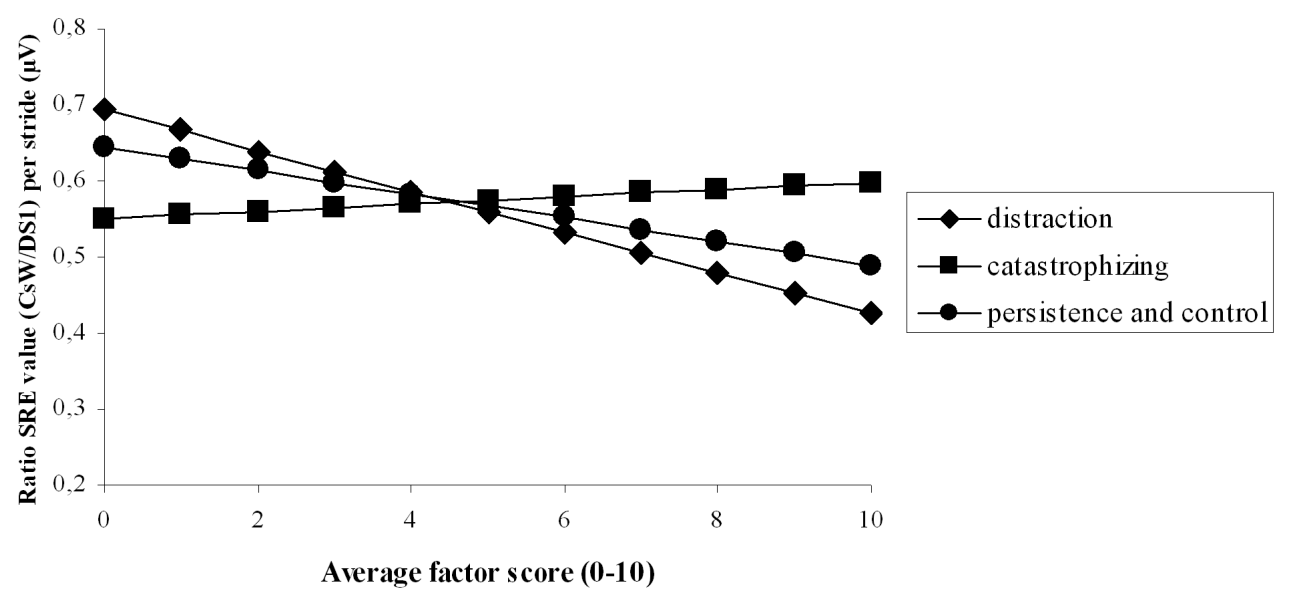

Figure 3. Relation between ratios of averaged erector spinae activity (swing/double support) and average factor scores (CSQ-Dutch version)

Note: presentation of regression model, after correction for gender, recording site, age and Body Mass Index (BMI). Figure of ratio (ipsilateral swing/ second double support) is comparable. CSQ = Coping Strategies Questionnaire, $\mathrm{SRE}=$ smooth rectified electromyography, CSw= contralateral swing, DS1= first double support.

122 


\section{Distraction}

Average scores on the factor "distraction" are not related to averaged (natural logarithm) SRE values, but are significantly negatively associated with SRE ratios (SRE swing/ SRE double support) (Table 4). This means that higher scores for distractive coping are related to increased variation between activation of the lumbar muscles in swing compared to double support. After correcting for the possible influence of other independent variables on SRE values, the negative relation between distraction and the ratio contralateral swing/first double support (CSw/DS1) remains significant $(\beta=-0.03,95 \% \mathrm{CI}=-0.05--0.01$ ), but the relation with the ratio ipsilateral swing/second double support (ISw/DS2) slightly fails to reach significance ( $\beta$ $=-0.02,95 \% \mathrm{CI}=-0.03-0.00)$. This means that a one point higher score for distraction $(0-$ 10 ) is related to a decrease of 0.03 in the ratio of activity in swing to double support (Figure 3). Including the independent variables pain intensity and disability did not change the beta coefficients and these variables were left out of the final model. The variance of the SRE ratios explained by the total model is $13.9 \%$ for the ratio CsW/DS1 and $14.5 \%$ for the ratio IsW/DS2. The additional variance explained by distraction is $7.5 \%$ for the ratio CsW/DS1 and $2.7 \%$ for the ratio IsW/DS2.

\section{Catastrophizing}

Results show that average scores on the factor "catastrophizing" are significantly positively associated with averaged (natural logarithm) SRE values, but not with SRE ratios (Table 4). After correcting for a possible influence of other independent variables on SRE values, the positive relation between catastrophizing and average (natural logarithm) SRE values remains significant $(\beta=0.06,95 \% \mathrm{CI}=0.01-0.10)$. This means that an increase of one point on the average factor score catastrophizing (0-10) is related to an increase of $1.1 \mu \mathrm{V}$ in averaged SRE value per stride (Figure 2). Including the independent variables pain intensity and disability did not change the beta coefficients and these variables were left out of the final model. The total variance of (natural logarithm) SRE values explained by the model is $22.6 \%$, of which $7.7 \%$ by the average factor score catastrophizing.

\section{Persistence and control}

Average scores for "persistence and control" are not related to averaged (natural logarithm) SRE values, but are significantly negatively associated with the SRE ratio of contralateral swing/ first double support (Table 4). After correcting for a possible influence of other independent variables on SRE values, the significant relation disappears. regel 1

regel 2

regel 3

regel 4

regel 5

regel 6

regel 7

regel 8

regel 9

regel 10

regel 11

regel 12

regel 13

regel 14

regel 15

regel 16

regel 17

regel 18

regel 19

regel 20

regel 21

regel 22

regel 23

regel 24

regel 25

regel 26

regel 27

regel 28

regel 29

regel 30

regel 31

regel 32

regel 33

regel 34

regel 35

regel 36

regel 37

regel 38 
regel 1 regel 2 regel 3 regel 4 regel 5 regel 6 regel 7 regel 8 regel 9 regel 10 regel 11 regel 12 regel 13 regel 14 regel 15 regel 16 regel 17 regel 18 regel 19 regel 20 regel 21 regel 22 regel 23 regel 24 regel 25 regel 26 regel 27 regel 28 regel 29 regel 30 regel 31 regel 32 regel 33 regel 34 regel 35 regel 36 regel 37 regel 38

\section{Other independent variables}

Concerning the other independent variables, no significant influence is seen of gender or recording site (L1/L4, left/right) on average (natural logarithm) SRE values. Age however, is positively related to (natural logarithm) SRE values $(\beta=0.01,95 \% \mathrm{CI}=0.002-0.02)$ and $\mathrm{BMI}$ is negatively related to (natural logarithm) SRE values $(\beta=-0.05,95 \% \mathrm{CI}=-0.07--0.02)$. For the SRE ratio (SRE swing/SRE double support), no influence is seen of gender, age or BMI. For the SRE ratios significant differences are found between the left and right recording site: SRE ratio contralateral swing/first double support ( $\beta$ L1 (left) vs. L4 (right) $=-0.10(-0.14--0.05), \beta$ L4 (left) vs L4 (right) $=-0.07(-0.11--0.02)$; SRE ratio ipsilateral swing/second double support $(\beta$ L1 (left) vs. L4 (right) $=0.14(0.09-0.18) ; \beta$ L4 (left) vs L4 (right) $=0.07(0.02-0.12)$.

\section{Discussion and conclusions}

The results of this study show that in line with the cognitive behavioral models, subjects with CLBP reveal three coping strategies (i.e. "distraction", "catastrophizing", "persistence and control"). Two of these coping strategies are differentially related to lumbar muscle activity during walking. "Distraction" is negatively associated with SRE ratios of the lumbar muscles in periods of swing compared to double support, which can be interpreted in line with our hypothesis. Also in line with our hypothesis is that a positive relation between "catastrophizing" and increased lumbar muscle activity is found. In contrast to expectation, no association is found between "persistence and control" and lumbar muscle activity.

A new and interesting finding from this study is that "distraction" is associated with the ratio of lumbar muscle activity during swing compared to double support, whereas there is no relation for this coping strategy with the total amount of lumbar muscle activity during stride. This means that higher scores on distraction are related to increased relative relaxation during swing. In other words, distraction is associated with an adequate change between exertion and relaxation of the lumbar muscles during stride. As this change between exertion and relaxation is comparable to the normal, healthy biphasic activity pattern of lumbar muscles during walking ${ }^{45}$, distraction might be considered an adaptive coping strategy as hypothesized in the avoidance - endurance model ${ }^{11}$.

"Catastrophizing" is associated with increased lumbar muscle activity, whereas no relation with the SRE ratio between periods of swing and double support is shown. This means that more catastrophizing results in an overall higher muscle activity level during all periods of stride. It adds to the evidence of the relation between catastrophizing and physical variables, which also has been shown by others. Catastrophizing has been associated with reduced 
exercise capacity ${ }^{25}$ and lower perceived level of activity ${ }^{39}$. In addition, a reduction in catastrophizing thoughts has been related to increased physical performance ${ }^{24}$. In theory, it is conceivable that catastrophizing is therefore associated with increased lumbar muscle activity to compensate for reduced physical performance. Another possibility is that increased muscle activity may serve to avoid excessive lumbar motion, as has been shown in subjects with painrelated fear ${ }^{8}$. As catastrophizing is assumed to be related to avoidance behavior, subjects with high levels of catastrophizing would preferable have avoided the walking task. In this study however, they were not able to avoid this task which may have caused a reaction of higher lumbar muscle activity during walking.

It is, however, debatable whether catastrophizing always leads to fear of pain and avoidance behavior ${ }^{18}$. As such, catastrophizing may not reflect avoidance coping and in those cases another explanation for the positive relation with lumbar muscle activity should be sought. It is plausible that catastrophizing may be better conceptualized as a psychological distress response, distinct from other cognitive coping strategies like distraction or ignoring pain 17:22. The positive relation between stress, anxiety and increased lumbar muscle activity is confirmed in literature ${ }^{5-7 ; 9 ; 4}$. In addition, subjects with CLBP who catastrophize have shown higher lumbar muscle activity levels during a cold pressor task ${ }^{26}$ or during anger and sadness recall interviews ${ }^{46}$. It would be interesting to study the relation between catastrophizing and muscle activity distant from the site of pain, to understand if catastrophizing is related to "sitespecific muscle tension" of the lumbar muscles or not.

In contrast to expectation, no relation is found between "persistence and control" and lumbar muscle activity. "Persistence and control" reflects pain-related suppressive thoughts ("I tell myself that I can't let the pain stand in the way of what I have to do"), suppressive behavior ("I just go on as if nothing happened") and self efficacy beliefs of the ability to control and decrease pain (Table 2). As such, high scores on "persistence and control" may be caused by either (maladaptive) suppressive coping, or by (adaptive) self efficacy beliefs, or both. Persistent coping as measured in this study may thus partly reflect an adaptive coping strategy. In this case, one would not expect increased muscular tension, which would explain why no relation is found. This explanation may be supported by the finding that in the univariate analysis, "persistence and control" is significantly negatively related to the SRE ratio. An adequate alternation between muscle activity and - relaxation during walking is considered a normal activity pattern of the lumbar muscles ${ }^{45}$. Another explanation may be that those subjects scoring higher on "persistence and control" coping are better trained and therefore need less effort of the lumbar muscles during walking. Finally, it is possible that it is simply not related to lumbar muscle activity, or that the walking task was too short or nonspecific to exhibit different muscle activity patterns for those with high scores on "persistence and control". regel 1

regel 2

regel 3

regel 4

regel 5

regel 6

regel 7

regel 8

regel 9

regel 10

regel 11

regel 12

regel 13

regel 14

regel 15

regel 16

regel 17

regel 18

regel 19

regel 20

regel 21

regel 22

regel 23

regel 24

regel 25

regel 26

regel 27

regel 28

regel 29

regel 30

regel 31

regel 32

regel 33

regel 34

regel 35

regel 36

regel 37

regel 38 
regel 1

regel 2

regel 3

regel 4

regel 5

regel 6

regel 7

regel 8

regel 9

regel 10

regel 11

regel 12

regel 13

regel 14

regel 15

regel 16

regel 17

regel 18

regel 19

regel 20

regel 21

regel 22

regel 23

regel 24

regel 25

regel 26

regel 27

regel 28

regel 29

regel 30

regel 31

regel 32

regel 33

regel 34

regel 35

regel 36

regel 37

regel 38
Further study of a homogeneous measure of persistent coping is needed. Very recently, Hasenbring et al ${ }^{12}$ have presented the Avoidance -Endurance Questionnaire, derived from the Kiel Pain Inventory, which is a promising reliable and valid measure to assess endurance (e.g. persistent) coping.

In a comparable study of walking, lumbar muscle activity has been shown to be higher in subjects with CLBP when compared to asymptomatic controls [van der Hulst et al., Clin J Pain (in press)]. The average range of lumbar muscle activity in controls from that study is comparable to the average muscle activity level related to the factors "persistence and control" and "distraction" in the current study. On the other hand, the average muscle activity level found for "catastrophizing" in the current study is higher than in controls. This comparison may further support the interpretation that "catastrophizing" reflects a maladaptive coping strategy with increased lumbar muscle activity, and that distraction and "persistence and control " reflect an adaptive coping strategy with muscle activity similar to asymptomatic subjects.

Higher age is related to higher lumbar muscle activity levels, although the relation is very modest and clinically irrelevant. A higher BMI is related to lower muscle activity levels, which is conform expectation as fat tissue reduces the sEMG signal. Recording site is differentially related to the amount of relative relaxation between periods of swing and double support, which could be explained by different locations of pain, which was not analyzed in this study.

\section{Methodological considerations}

Different authors have shown latent dimensions of the CSQ, although results vary from a 2 to 5 factor solution ${ }^{17 ; 28,27 ; 32 ; 34}$. A latent three dimensional structure of the CSQ however, has proven robust across different populations of chronic pain. Most studies have consequently shown the factors "cognitive coping", including ignoring pain sensations/cognitive selfstatements and "distraction" 17:27;28. The current study also revealed these two dimensions, of which "distraction" consists of both cognitive and behavioral strategies, shown before in a comparable analysis of individual CSQ items ${ }^{34}$. The third dimension in this study, "catastrophizing", has not consistently been found across studies. Catastrophizing may more closely reflect emotional distress than a coping strategy ${ }^{1722}$ and thus be reflected by different coping dimensions across studies. Most authors have performed a factor analysis on the individual subscales, with the exception of Swartzman et al. ${ }^{34}$ who analyzed individual CSQ items. In the current study, a factor analysis of the CPV subscales was unable to discriminate between different latent coping dimensions, in contrast to a factor analysis of the individual $\mathrm{CPV}$-items. It is, however, not known whether the factor structure is dependent on sample characteristics which might hamper generalizability of the results. 
A limitation of the current study is performing a factor analysis on a relatively small sample of 63 subjects. Rosenstiel and Keefe ${ }^{28}$ however, also analyzed a small sample $(\mathrm{N}=61)$ and found comparable factors as the current study (i.e. "cognitive coping", "diverting attention" and "helplessness", including catastrophizing cognitions). Retrospectively, including other validated measures of catastrophizing thoughts would have increased comparability across studies and contributed to the external validity. Finally, given the knowledge that "catastrophizing" is positively related to "depression" ${ }^{28}$, it must also be noted that the amount of depressive thoughts may have confounded the relation between catastrophizing and muscle activity.

The percentage of explained variance of lumbar muscle activity by the three coping dimensions is modest (up to 7.7\%); although the relative contribution to the total explained variance (13.9 to 22.6\%) is high. Different explanations may have contributed to this. There may be other important factors determining lumbar muscle activity that were not investigated in this study, such as lumbar range of motion during walking, foregoing physical activity level, or other sociopsychological factors (e.g. stress, beliefs, adjustment). Furthermore, the studied population had moderate disability -, pain - and CPV scores and it would be desirable to include subjects with more severe scores to induce a higher variability in the scores. Although average $\mathrm{CPV}$ factor scores were significantly associated with pain intensity and level of disability, a separate multivariate analysis including these variables did not influence the relation between lumbar muscle activity and coping strategies. Therefore, a possible confounding effect of these variables was excluded. Finally, differences in lumbar muscle activity may have become more pronounced during tasks of longer duration and intensity, provoking the use of the measured coping strategies.

\section{Conclusion}

The current study shows that in subjects with chronic low back pain, coping strategies are related to lumbar muscle activity during walking. A new finding is that "distractive coping" is associated with increased lumbar muscle relaxation, which may reflect an adaptive strategy. "Catastrophizing" is related to increased lumbar muscle activity, which may reflect a maladaptive strategy. No relation is found between "persistence and control" and lumbar muscle activity.

\section{Acknowledgements}

The authors thank M.van Beugen for her contribution to the analysis of the data from the Coping Strategies Questionnaire and L. Schaake for his contribution to the development of software for sEMG data analysis. Financial support was given by the Joris Foundation and ZonMw (the Netherlands organization for health research and development), who had a role

regel 1

regel 2

regel 3

regel 4

regel 5

regel 6

regel 7

regel 8

regel 9

regel 10

regel 11

regel 12

regel 13

regel 14

regel 15

regel 16

regel 17

regel 18

regel 19

regel 20

regel 21

regel 22

regel 23

regel 24

regel 25

regel 26

regel 27

regel 28

regel 29

regel 30

regel 31

regel 32

regel 33

regel 34

regel 35

regel 36

regel 37

regel 38 in the study design. 
regel 1

regel 2

regel 3

regel 4

regel 5

regel 6

regel 7

regel 8

regel 9

regel 10

regel 11

regel 12

regel 13

regel 14

regel 15

regel 16

regel 17

regel 18

regel 19

regel 20

regel 21

regel 22

regel 23

regel 24

regel 25

regel 26

regel 27

regel 28

regel 29

regel 30

regel 31

regel 32

regel 33

regel 34

regel 35

regel 36

regel 37

regel 38

\section{References}

1. Arendt-Nielsen L, Graven-Nielsen T, Svarrer H, Svensson P. The influence of low back pain on muscle activity and coordination during gait. A clinical and experimental study. Pain 1996; 64: 231-240.

2. Biedermann HJ, Shanks GL, Forrest WJ, Inglis J. Power spectrum analyses of electromyographic activity. Discriminators in the differential assessment of patients with chronic low-back pain Spine 1991; 16: 1179-1184.

3. Brouwer S, Kuijer W, Dijkstra PU, Goeken LN, Groothoff JW, Geertzen JH. Reliability and stability of the Roland Morris Disability Questionnaire: intra class correlation and limits of agreement. Disabil Rehabil 2004; 26: 162-165.

4. Brox JI, Storheim K, Holm I, Friis A, Reikeras O. Disability, pain, psychological factors and physical performance in healthy controls, patients with sub-acute and chronic low back pain: a case-control study. J Rehabil Med 2005; 37: 95-99.

5. Burns JW. Arousal of negative emotions and symptom-specific reactivity in chronic low back pain patients. Emotion 2006; 6: 309-319.

6. Burns JW, Bruehl S, Quartana PJ. Anger management style and hostility among patients with chronic pain: effects on symptom-specific physiological reactivity during anger- and sadnessrecall interviews. Psychosom Med 2006; 68: 786-793.

7. Flor H, Turk DC, Birbaumer N. Assessment of stress-related psychophysiological reactions in chronic back pain patients. J Consult Clin Psychol 1985; 53:354-364.

8. Geisser ME, Haig AJ, Wallbom AS, Wiggert EA. Pain-related fear, lumbar flexion, and dynamic EMG among persons with chronic musculoskeletal low back pain. Clin J Pain, 2004; 20: 61-69.

9. Geisser ME, Ranavaya M, Haig AJ, Roth RS, Zucker R, Ambroz C, Caruso M. A meta-analytic review of surface electromyography among persons with low back pain and normal, healthy controls. J Pain 2005; 6: 711-726.

10. Gommans IHB, Koes BW, van Tulder MW. Validiteit en responsiviteit Nederlandstalige Roland Disability Questionnaire. Vragenlijst naar functionele status bij patiënten met lage rugpijn. Nederlands Tijdschrift voor Fysiotherapie 1997; 2:28-33.

11. Hasenbring M. Attentional control of pain and the process of chronification. Prog Brain Res 2000; 129: 525-534.

12. Hasenbring MI, Hallner D, Rusu AC. Fear-avoidance- and endurance-related responses to pain: development and validation of the Avoidance-Endurance Questionnaire (AEQ). Eur J Pain 2009; 13: 620-628.

13. Hasenbring MI, Plaas H, Fischbein B, Willburger R. The relationship between activity and pain in patients 6 months after lumbar disc surgery: Do pain-related coping modes act as moderator variables? Eur J Pain 2006; 10: 701-709.

14. Hermens HJ, Freriks B, Disselhorst-Klug C, Rau G. Development of recommendations for sEMG sensors and sensor placement procedures. J Electromyogr Kinesiol 2000; 10:361-374.

15. Lamoth CJ, Daffertshofer A, Meijer OG, Beek PJ. How do persons with chronic low back pain speed up and slow down? Trunk-pelvis coordination and lumbar erector spinae activity during gait. Gait Posture 2006; 23: 230-239.

16. Lamoth CJ, Meijer OG, Daffertshofer A, Wuisman PI, Beek PJ. Effects of chronic low back pain on trunk coordination and back muscle activity during walking: changes in motor control. Eur Spine J 2006; 15: 23-40.

17. Lawson K, Reesor KA, Keefe FJ, Turner JA. Dimensions of pain-related cognitive coping: crossvalidation of the factor structure of the Coping Strategy Questionnaire. Pain 1990; 43: 195-204.

18. Leeuw M, Goossens ME, Linton SJ, Crombez G, Boersma K, Vlaeyen JW. The fear-avoidance model of musculoskeletal pain: current state of scientific evidence. J Behav Med 2007; 30:77-94.

19. Lethem J, Slade PD, Troup JD, Bentley G. Outline of a Fear-Avoidance Model of exaggerated pain perception-I. Behav Res Ther 1983; 21: 401-408.

20. Mannion AF. Fibre type characteristics and function of the human paraspinal muscles: normal values and changes in association with low back pain. J Electromyogr Kinesiol 1999; 9: 363-377. 
21. Mannion AF, Kaser L, Weber E, Rhyner A, Dvorak J, Muntener M. Influence of age and duration of symptoms on fibre type distribution and size of the back muscles in chronic low back pain patients. Eur Spine J 2000; 9: 273-281.

22. McCracken LM and Gross RT. Does anxiety affect coping with chronic pain? Clin J Pain 1993; 9: 253-259.

23. Merletti, R. and Hermens HJ. Introduction to the special issue on the SENIAM European Concerted Action. J Electromyogr Kinesiol 2000; 10:283-286.

24. Moseley, GL. Evidence for a direct relationship between cognitive and physical change during an education intervention in people with chronic low back pain. Eur J Pain 2004; 8:39-45.

25. Nijs J, Van de Putte K, Louckx F, Truijen S, De Meirleir K. Exercise performance and chronic pain in chronic fatigue syndrome: the role of pain catastrophizing. Pain Med 2008; 9:1164-1172.

26. Quartana PJ, Burns JW, Lofland KR. Attentional strategy moderates effects of pain catastrophizing on symptom-specific physiological responses in chronic low back pain patients. J Behav Med 2007; 30: 221-231.

27. Riley JL, Robinson ME, Geisser ME. Empirical subgroups of the Coping Strategies QuestionnaireRevised: a multisample study. Clin J Pain 1999; 15:111-116.

28. Rosenstiel AK and Keefe FJ. The use of coping strategies in chronic low back pain patients: relationship to patient characteristics and current adjustment. Pain 1983; 17: 33-44.

29. Shiavi R, Frigo C, Pedotti A. Electromyographic signals during gait: criteria for envelope filtering and number of strides. Med Biol Eng Comput 1998; 36: 171-178.

30. Spenkelink CD, Hutten MM, Hermens HJ, Greitemann BO. Assessment of activities of daily living with an ambulatory monitoring system: a comparative study in patients with chronic low back pain and nonsymptomatic controls. Clin Rehabil 2002; 16:16-26.

31. Spinhoven P and Linssen ACG. Coping met Pijn Vragenlijst [Dutch version of the Coping Strategies Questionnaire]. Lisse, the Netherlands: Swets and Zeitlinger B.V.; 1994.

32. Spinhoven P, Ter Kuile MM, Linssen AC, Gazendam B. Pain coping strategies in a Dutch population of chronic low back pain patients. Pain 1989; 37: 77-83.

33. Stokes M, Rankin G, Newham DJ. Ultrasound imaging of lumbar multifidus muscle: normal reference ranges for measurements and practical guidance on the technique. Man Ther 2005; 10: 116-126.

34. Swartzman LC, Gwadry FG, Shapiro AP, Teasell RW. The factor structure of the Coping Strategies Questionnaire 1994; 57: 311-316.

35. Tabachnik BG, Fidell LS. Using Multivariate Statistics, $5^{\text {th }}$ ed. Boston, United States of America: Alynn and Bacon; 2001.

36. Triano JJ, McGregor M, Cramer GD, Emde DL. A comparison of outcome measures for use with back pain patients: results of a feasibility study. J Manipulative Physiol Ther 1993; 16: 67-73.

37. Twisk JW. Longitudinal data analysis. A comparison between generalized estimating equations and random coefficient analysis. Eur J Epidemiol 2004; 19: 769-776.

38. Verbunt JA, Seelen HA, Vlaeyen JW, van der Heijden GJ, Knottnerus JA. Fear of injury and physical deconditioning in patients with chronic low back pain. Arch Phys Med Rehabil 2003; 84: 1227-1232.

39. Verbunt JA, Sieben JM, Seelen HA, Vlaeyen JW, Bousema EJ, van der Heijden GJ, Knottnerus JA. Decline in physical activity, disability and pain-related fear in sub-acute low back pain. Eur J Pain 2005; 9: 417-425.

40. Vink $P$ and Karssemeijer N. Low back muscle activity and pelvic rotation during walking. Anat Embryol 1988; 178: 455-460.

41. Vlaeyen JW, Kole-Snijders AM, Boeren RG, van Eek H. Fear of movement/(re)injury in chronic low back pain and its relation to behavioral performance. Pain 1995; 62: 363-372.

42. Vlaeyen JW, Seelen HA, Peters M, de Jong P, Aretz E, Beisiegel E, Weber WE. Fear of movement/ (re)injury and muscular reactivity in chronic low back pain patients: an experimental investigation. Pain 1999; 82: 297-304.

43. Vogt L, Pfeifer K, Banzer W. Neuromuscular control of walking with chronic low-back pain. Manual Therapy 2003; 8: 21-28. 
regel 1

regel 2

regel 3

regel 4

regel 5

regel 6

regel 7

regel 8

regel 9

regel 10

regel 11

regel 12

regel 13

regel 14

regel 15

regel 16

regel 17

regel 18

regel 19

regel 20

regel 21

regel 22

regel 23

regel 24

regel 25

regel 26

regel 27

regel 28

regel 29

regel 30

regel 31

regel 32

regel 33

regel 34

regel 35

regel 36

regel 37

regel 38
44. Watson PJ, Booker CK, Main CJ. Evidence for the role of psychological factors in abnormal paraspinal activity in patients with chronic low back pain. Journal of Musculoskeletal Pain 1997; 5: 41-56.

45. Winter DA and Yack HJ. EMG profiles during normal human walking: stride-to-stride and inter-subject variability. Electroencephalogr Clin Neurophysiol 1987; 67: 402-411.

46. Wolff B, Burns JW, Quartana PJ, Lofland K, Bruehl S, Chung OY. Pain catastrophizing, physiological indexes, and chronic pain severity: tests of mediation and moderation models. J Behav Med 2008; 31: 105-114. 


\section{Chapter 7}

General discussion

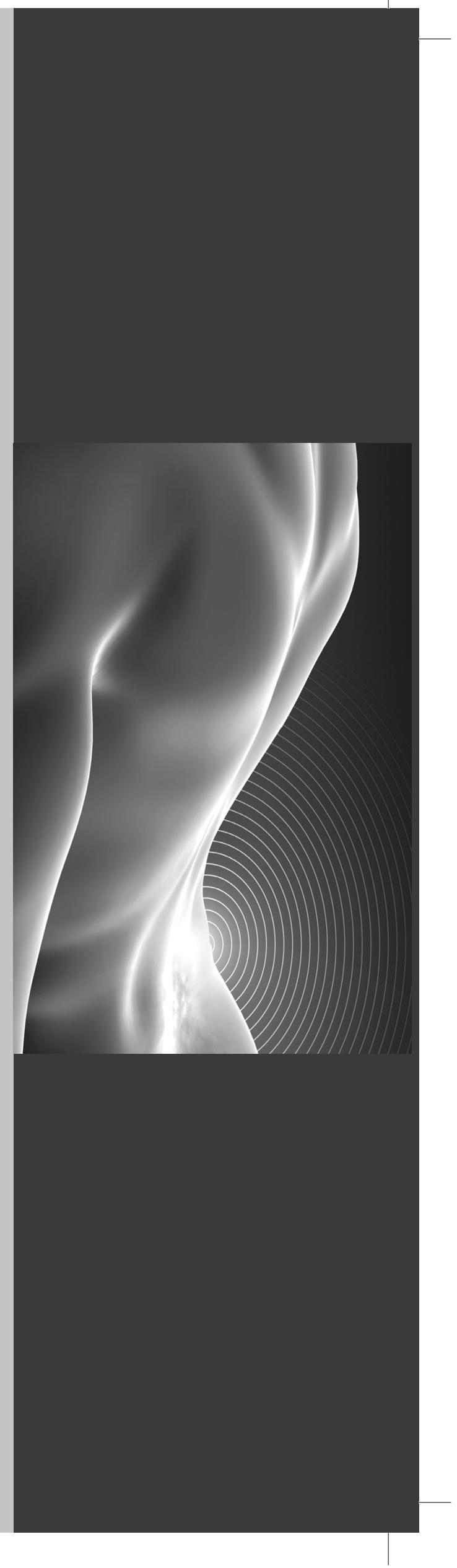


regel 1

regel 2

regel 3

regel 4

regel 5

regel 6

regel 7

regel 8

regel 9

regel 10

regel 11

regel 12

regel 13

regel 14

regel 15

regel 16

regel 17

regel 18

regel 19

regel 20

regel 21

regel 22

regel 23

regel 24

regel 25

regel 26

regel 27

regel 28

regel 29

regel 30

regel 31

regel 32

regel 33

regel 34

regel 35

regel 36

regel 37

regel 38

\section{Objective}

This thesis has been carried out to gain insight in biopsychological mechanisms in subjects with nonspecific chronic low back pain (CLBP). For this purpose both prognostic factors for rehabilitation treatment outcome and underlying biopsychological mechanisms in CLBP have been investigated. Insight in these mechanisms can contribute to future optimization of multidisciplinary treatments.

\section{Background of the thesis}

General consensus exists to approach the problem of CLBP from a biopsychosocial perspective ${ }^{46 ; 4}$. A variety of multidisciplinary treatments have been developed but in general, these treatments for CLBP have not been proven effective in improving function in the long term ${ }^{40}$. One of the explanations for this limited effectiveness is the heterogeneity of the CLBP population, which makes it unlikely that one treatment benefits all. Subjects with the same medical diagnosis of CLBP are not likely to be similar with respect to their biopsychosocial characteristics and thus might need different approaches ${ }^{38}$. Besides understanding which prognostic factors predict the outcome of treatment, also the concepts of treatments need to be further optimized to the individual patient's characteristics. Therefore, more insight is needed in the underlying biopsychosocial mechanisms contributing to pain, activity limitation and participation restriction ${ }^{52}$.

\section{Biopsychosocial prognostic factors for multidisciplinary rehabilitation treatment outcome}

In chapter 2, a systematic review of biopsychosocial predictors of multidisciplinary rehabilitation- or back school treatment outcome in subjects with CLBP was performed. Surprisingly, the expected multidimensionality of predictive factors across various domains (i.e. sociodemographic, physical and psychological) was not found. Consistent predictive factors for treatment outcome, measured as activity limitation and participation restriction, are pain, work related and psychological (i.e. coping) factors. Other sociodemographic and physical factors consistently lack predictive value. In chapter 3 , a confirmative study of the consistent predictors from chapter 2 was performed. The results confirm the prognostic value of pain-related and cognitive factors (e.g. fear-avoidance beliefs), although the explained variance for treatment outcome is rather low. The explained variance varies from 18.5 to $43.8 \%$ depending on the length of follow-up evaluation, treatment group and outcome variable of interest. These low percentages have also been found in other multivariate prognostic models for treatment outcome in chronic (low back) pain ${ }^{6 ; 11 ; 12 ; 25 ; 26 ; 28 ; 34 ; 36}$. A few authors however, have 
shown percentages of explained variance up to $60-70 \%^{2 ; 13 ; 18 ; 50}$. Woby et al ${ }^{50}$ were able to explain $71 \%$ of variance. The main difference with our study is that these authors studied changes in predictors during treatment instead of using baseline values and did not include a control group. It is likely that including changes in predictors contributes to a higher level of explained variance, because the effects of treatment processes are included in the prognostic model. As these changes in treatment processes cannot be used in the admission procedure in clinical practice, the value of prediction models is too low to set rules for clinical practice. Besides, due to the large heterogeneity in patient characteristics (e.g. (un)employed, duration of pain, level of disability), assessment methods and treatments used in these studies, the evidence from chapter 2 and 3 is not strong enough to provide the clinician with a useful tool to select the patient for the most suitable treatment. Prognostic factors should be tested and compared for the same population, treatment and outcome measures before it is possible to develop a generic prediction model. This underlines the importance of (inter)national consensus about treatment modality and outcome measures in rehabilitation of subjects with CLBP

It is striking that baseline physical factors are not prognostic for treatment outcome, although increasing physical activity is an important element in most rehabilitation treatments. It may be that changes in physical activity attained during treatment are more predictive for outcome than baseline physical measures. Given the prognostic value of cognitive factors in a multidisciplinary treatment including physical training, it is necessary to understand the interrelationship between physical and cognitive processes in CLBP. Does treatment exert its effect by changing physical, or cognitive factors, or both? Controlled studies ${ }^{25 ; 32}$ and a systematic review ${ }^{49}$ have shown that changes in pain intensity and particularly cognitive factors, but not physical factors, account for changes in disability after non-operative treatment of subjects with CLBP. This emphasizes the importance of obtaining a better understanding of the role of physical factors in CLBP and how these are related to pain and cognitive factors.

Besides the assumption that physical changes are part of the mechanism through which treatment exerts it effect, it could also be that not the quantity - (e.g strength, endurance), but the functional performance of physical activity (i.e. how subjects perform their activities during a task or during the day) is more important. To give an example, although average daily physical activity levels are comparable between subjects with CLBP and healthy controls ${ }^{33 ; 41 ; 43}$, subjects with CLBP show different patterns, with lower levels of activity in the evening $33 ; 41$. regel 1

regel 2

regel 3

regel 4

regel 5

regel 6

regel 7

regel 8

regel 9

regel 10

regel 11

regel 12

regel 13

regel 14

regel 15

regel 16

regel 17

regel 18

regel 19

regel 20

regel 21

regel 22

regel 23

regel 24

regel 25

regel 26

regel 27

regel 28

regel 29

regel 30

regel 31

regel 32

regel 33

regel 34

regel 35

regel 36

regel 37

regel 38 
regel 1 regel 2 regel 3 regel 4 regel 5 regel 6 regel 7 regel 8 regel 9 regel 10 regel 11 regel 12 regel 13 regel 14 regel 15 regel 16 regel 17 regel 18 regel 19 regel 20 regel 21 regel 22 regel 23 regel 24 regel 25 regel 26 regel 27 regel 28 regel 29 regel 30 regel 31 regel 32 regel 33 regel 34 regel 35 regel 36 regel 37 regel 38

\section{Biopsychosocial mechanisms in CLBP: physical and cognitive factors}

In line with the last hypothesis concerning the importance of functional performance of physical activity during treatment, the second part of this thesis studied changes in trunk muscle activity between subjects with CLBP and controls. In theoretical pain models, hypotheses of changes in trunk muscle activity and their relation with pain and disability have been described. Some pain models have described changes in muscle activity from a biomechanical view ${ }^{19 ; 23 ; 37}$, others from a cognitive-behavioral view ${ }^{15 ; 22,44}$. As cognitive/ coping factors were found to be consistently predictive for treatment outcome, it was also considered important to study a possible relation between trunk muscle activity and cognitive variables.

\section{Physical factors: a guarding mechanism during walking}

In chapter 4 and 5, it was hypothesized that subjects with CLBP would show changes in trunk muscle activity during walking reflecting a "guarding" mechanism. The term guarded movement was introduced by Main and Watson ${ }^{24}$ and reflects abnormalities in muscle activity and/or the adaptation of posture in subjects with CLBP during physical activity. A clear definition of guarding in CLBP has not been given in literature, although there is some evidence from scientific studies showing lack of muscle relaxation ${ }^{1 ; 9 ; 8}$. When considering this lack of muscle relaxation to be an adaptation mechanism in response to acute pain, which possibly results in persistent movement changes and restriction of motion ${ }^{42}$, it is hypothesized that guarding is present in subjects with CLBP. It is expected that during walking, guarding will express itself by increased superficial lumbar and abdominal muscle activity during all periods of stride. In addition, as a secondary effect, it was predicted that guarding would be reflected by a decreased relative relaxation of the lumbar muscles during swing with respect to double support, because subjects with CLBP would be more reluctant to de-activate the muscles to avoid more motion and consequently more pain. Finally, it was expected that with an increase of the walking velocity and consequently an increase in the biomechanical forces, the guarding mechanism would become more visible in the trunk muscle activity patterns.

The results described in chapter 4 , show that subjects with CLBP, compared to asymptomatic controls, have increased erector spinae activity during both periods of double support and swing. Higher erector spinae activity in swing is in agreement with earlier studies ${ }^{3 ; 20}$, but higher activity in double support is a new finding. These results clearly support the guarding hypothesis. It was, however, also found that subjects with CLBP show comparable ratios (i.e. relative relaxation) between the average erector spinae activity in swing to double support. Probably patients reveal an overall elevated level of lumbar muscle activity during walking, independent of the different periods of the stride. Although at first glance these comparable 
ratios seem to be in contrast with the guarding hypothesis, the continuous higher absolute levels of erector spinae activity in CLBP shows that the erector spinae do not have moments of total muscle relaxation. Therefore, the results from chapter 4 support a guarding mechanism in subjects with CLBP.

The guarding hypothesis is also supported by the results from chapter 5 . The study in chapter 5 investigated the superficial lumbar- and abdominal muscle activity and the influence of greater walking velocities. In the concept of guarding, changes in trunk muscle activity serve to control spinal movement. It was hypothesized that co-activation of the superficial abdominal (i.e. rectus abdominis and obliquus externus abdominis) and lumbar (i.e. erector spinae) muscles would be increased in CLBP. Furthermore, greater walking velocity was expected to elicit greater increases in trunk muscle activity in CLBP, as guarding may become more pronounced at higher ranges of motion. The study in chapter 5 shows that the activity of the rectus abdominis- and erector spinae muscles is indeed increased in CLBP during all periods of stride in comparison to controls. From an anatomical point of view, it is plausible that both muscle groups function as antagonists. As such, increased co-activation of erector spinae and rectus abdominis activity may serve to control spinal movement and contribute to a "guarding" mechanism in CLBP.

In contrast to what was expected, the adaptation of trunk muscle activity patterns to higher velocities is similar to controls. We expected increasing differences in trunk muscle activity between CLBP and controls at higher velocities, but probably the overall higher activity level of the erector spinae and rectus abdominis is sufficient to control spinal motion at the velocities investigated. Another explanation for not finding increasing differences between subjects and controls might be the ability to become gradually accustomed to higher walking velocities. In this way, enough confidence was gained, so subjects with CLBP did not need to further adapt their level of trunk muscle activity to higher velocities. As such, guarding is reflected by an overall increase in muscle activity of both the erector spinae and rectus abdominis and this increased level is sufficient to control the increased biomechanical forces at higher velocities.

It is concluded that subjects with CLBP show guarded movements during walking reflected by increased superficial lumbar- and abdominal muscle activity, without losing the normal biphasic activity pattern or velocity induced adaptations. What could be the function of increased trunk muscle activity, or "guarding" during walking in subjects with CLBP? For a better understanding, different theories underlying a guarding mechanism should be considered. As already mentioned, trunk muscle activity changes in CLBP have been described in the literature from both a biomechanical - and a cognitive - behavioral point of view. From a biomechanical point of view, several authors have argued that changes in trunk regel 1

regel 2

regel 3

regel 4

regel 5

regel 6

regel 7

regel 8

regel 9

regel 10

regel 11

regel 12

regel 13

regel 14

regel 15

regel 16

regel 17

regel 18

regel 19

regel 20

regel 21

regel 22

regel 23

regel 24

regel 25

regel 26

regel 27

regel 28

regel 29

regel 30

regel 31

regel 32

regel 33

regel 34

regel 35

regel 36

regel 37

regel 38 
regel 1 regel 2 regel 3 regel 4 regel 5 regel 6 regel 7 regel 8 regel 9 regel 10 regel 11 regel 12 regel 13 regel 14 regel 15 regel 16 regel 17 regel 18 regel 19 regel 20 regel 21 regel 22 regel 23 regel 24 regel 25 regel 26 regel 27 regel 28 regel 29 regel 30 regel 31 regel 32 regel 33 regel 34 regel 35 regel 36 regel 37 regel 38 muscle activity serve to compensate for dysfunction of the spinal stabilizing system ${ }^{14 ; 17 ; 35 ; 39}$, which is assumed to be the case in CLBP ${ }^{27}$. If a guarding mechanism indeed compensates for reduced spinal stability, one would expect that increased lumbar muscle activity is related to a decreased range of motion of the spine. In CLBP, range of motion of the lumbar spine during walking however, has been found to be within normal limits ${ }^{21 ; 30 ; 45}$, although timing differences have been demonstrated between pelvis and thorax rotations ${ }^{21 ; 31}$. These studies have found that subjects with CLBP are not able to establish an out-of-phase coordination pattern between thorax and pelvis at higher walking speeds ${ }^{21 ; 31}$. The more rigid coordination in CLBP may be related to increased muscle activity and reflect guarded movement. As such, guarding may be defined as an adaptation of posture to control spinal motion. This may either be expressed by changes in relative- (i.e. between segments) or absolute spinal range of motion. Up to date, no studies have expressed the relationship between lumbar muscle activity and spinal range of motion in subjects with CLBP during walking, which would improve insight in a possible guarding mechanism. It is not known if these trunk muscle activity changes are beneficial or not. In literature of biomechanics, several authors plead that changes in trunk muscle activity are adaptive in reducing spinal instability ${ }^{8 ; 39}$, whereas others believe that these changes contribute to the vicious cycle of ongoing pain ${ }^{14 ; 1735}$. The hypothesis that superficial trunk muscles serve to compensate for reduced spinal stability may be tested clinically, by selective training of the deep spinal muscles and observing clinical outcome.

\section{Cognitive factors: coping strategies and relation to guarding}

Returning to the biopsychosocial perspective of CLBP, chapter 6 focused on a possible relation between trunk muscle activity changes and cognitive/coping factors in subjects with CLBP as assumed in the cognitive-behavioral models ${ }^{15 ; 22 ; 4}$. In chapter 4 , a first exploration had shown that fear-avoidance beliefs in subjects with CLBP are not related to lumbar muscle activity. On the other hand, in chapter 6 it was shown that coping mechanisms are significantly related to changes in lumbar muscle (i.e. erector spinae) activity. Catastrophizing, which reflects a maladaptive coping response, is related to increased lumbar muscle activity during stride. In contrast, distractive coping, which reflects an adaptive coping strategy, is associated with increased variation between activation of the lumbar muscles in swing compared to double support. The percentage of explained variance of lumbar muscle activity by coping mechanisms is modest (up to 7.7\%), although the relative contribution to the total explained variance ( 13.9 to $22.6 \%$ ) is high. The association between coping and lumbar muscle activity supports the concept that cognitive factors are related to changes in muscle activity. 
What is the possible mechanism behind the positive relation between lumbar muscle activity and catastrophizing? It has been suggested that catastrophizing can be conceptualized as an emotional coping strategy, being part of a psychological distress response with anxiety symptoms. Support for this explanation comes from several studies showing a positive relation between stress, anxiety and increased lumbar muscle activity 4;5;:710;29;48;51. Catastrophizing is generally considered to be a maladaptive coping strategy in handling chronic pain. Although average scores on catastrophizing were low (median/range: 3.1/0-9), they almost covered the total possible range (0-10). Subjects who scored high showed marked increase in lumbar muscle activity, compared to subjects who scored low. Considering the positive relationship between catastrophizing and lumbar muscle activity, this relationship suggests that increased muscle activity is a part of the vicious cycle of ongoing pain and disability.

The finding that catastrophizing is related to trunk muscle activity, but fear-avoidance beliefs are not, is surprising and puzzling. There may be several reasons for this paradox. It may be that catastrophizing is not task specific, whereas fear-avoidance beliefs are. In other words, walking on a treadmill may not have provoked fear in subjects with CLBP. This explanation is supported by an additional measurement of fear of walking on a treadmill (unpublished data). Subjects with CLBP were asked to rate fear of walking on a treadmill by means of a Visual Analogue Scale (VAS, 0-100) before the experiment started. The VAS rating was low (median/range: 10/0-51), which implied that fear was not likely to be elicited through walking. It is conceivable that fear-avoidance beliefs lead to avoidance of certain activities, but not specifically of walking ${ }^{20}$. In contrast, catastrophizing may be a general distress response which is present across a variety of tasks. In that case, one would expect that catastrophizing is also expressed during walking.

Distractive coping is considered an adaptive coping response in the avoidance-endurance model ${ }^{15}$. In this model, distractive coping strategies include distractive thoughts, positive phantasies and an adequate variation between activation and relaxation of muscles. Subjects with distractive coping strategies are at low risk of developing chronic pain. This hypothesis is in line with the finding from chapter 6 , in which distractive coping is associated with increased variation between activation and relaxation of the lumbar muscles. It may seem paradoxical that subjects develop chronic pain despite adaptive distractive coping strategies. A plausible explanation is that besides coping, other biopsychosocial mechanisms like negative emotions or social influences, contribute to the development of chronic pain.

Counter to expectation, persistent coping is not related to muscle activity. Persistent coping (i.e. carrying on with daily activities despite of pain) in the avoidance-endurance model, is assumed to be maladaptive and leads to maintenance of pain ${ }^{15}$. Persistent coping is regel 1

regel 2

regel 3

regel 4

regel 5

regel 6

regel 7

regel 8

regel 9

regel 10

regel 11

regel 12

regel 13

regel 14

regel 15

regel 16

regel 17

regel 18

regel 19

regel 20

regel 21

regel 22

regel 23

regel 24

regel 25

regel 26

regel 27

regel 28

regel 29

regel 30

regel 31

regel 32

regel 33

regel 34

regel 35

regel 36

regel 37

regel 38 
regel 1

regel 2

regel 3

regel 4

regel 5

regel 6

regel 7

regel 8

regel 9

regel 10

regel 11

regel 12

regel 13

regel 14

regel 15

regel 16

regel 17

regel 18

regel 19

regel 20

regel 21

regel 22

regel 23

regel 24

regel 25

regel 26

regel 27

regel 28

regel 29

regel 30

regel 31

regel 32

regel 33

regel 34

regel 35

regel 36

regel 37

regel 38

hypothesized to cause physical overload of muscles, resulting in muscular hyperactivity. There are several possible explanations why no relation is found between persistent coping and lumbar muscle activity in this thesis. Up to date, there is no consensus how to measure persistent coping. Hasenbring, who postulated the avoidance-endurance model, measured persistent coping by using the Kiel Pain Inventory, an extensive questionnaire in German ${ }^{16}$. In chapter 6, persistent coping was measured using the Coping Strategies Questionnaire Dutch version. The factor "persistent coping" in chapter 6 reflected not only (maladaptive) pain related suppressive thoughts ("I tell myself that I can't let the pain stand in the way of what I have to do") and suppressive behavior ("I just go on as if nothing happened"), but also (adaptive) self efficacy beliefs of the ability to control and decrease pain. As such, high scores on persistent coping may be caused by either (maladaptive) suppressive coping, or by (adaptive) self efficacy beliefs, or both. Persistent coping as measured in this thesis may have partly reflected an adaptive coping strategy, which explains why no relation is found with increased lumbar muscle activity. Further study of a validated measure for persistent coping is needed, as persistent coping behavior is an important concept in clinical practice.

Another explanation may be that those subjects scoring higher on persistent coping are better trained and have not yet reached the point of physical overload of the muscles. In that case, subjects would have an adequate physical activity - and fitness level and therefore need less effort of the lumbar muscles during walking. If true, persistent coping would not be related to muscle hyperactivity as postulated in the avoidance-endurance model, but associated with "normal" levels of lumbar muscle activity. When comparing average lumbar muscle activity levels in case of persistent - or distractive coping in subjects with CLBP (chapter 6) to asymptomatic controls (chapter 4), lumbar muscle activity levels are indeed comparable. In contrast, average lumbar muscle activity levels related to catastrophizing coping are higher than levels of asymptomatic controls. This comparison may further support the current interpretation that persistent - and distractive coping reflect an adaptive coping strategy with muscle activity similar to asymptomatic subjects. In contrast, catastrophizing may reflect a maladaptive coping strategy with increased lumbar muscle activity, reflecting a guarding mechanism.

In conclusion, the study in chapter 6 shows a relation between cognitive factors and lumbar muscle activity, namely a positive relation between catastrophizing and lumbar activity (i.e. guarding) on one side, and distractive coping and adequate alteration of lumbar muscle activity on the other side. From a cognitive-behavioral point of view, increased muscle guarding as related to catastrophizing may contribute to the vicious cycle of ongoing pain. Future longitudinal studies of the transition from acute to chronic pain should include cognitions and trunk muscle activity to understand the sequence of events and their 
(mal)adaptiveness. Additionally, experimental studies of changing trunk muscle activity (e.g. myofeedback, selective muscle training) on one side, or coping strategies (e.g. cognitivebehavioral interventions) on the other side, should be evaluated to understand the role of physical and cognitive factors during treatment.

\section{Synthesis of findings}

The scientific work described in this thesis provides better insight in biopsychosocial mechanisms in subjects with nonspecific CLBP. The results of the studies described in chapters 2 and 3 show that pain and cognitive related variables play an important role in the prognosis of multidisciplinary treatment outcome. The explained variance of baseline prognostic factors for treatment outcome however, is rather low. This means that the evidence is not strong enough to provide the clinician with a useful tool to select the patient for the most suitable treatment at baseline. Furthermore, evidence for underlying biopsychological mechanisms in CLBP has been found, which is considered important for future treatment modules. Subjects with CLBP show physical changes reflected by increased superficial lumbar- and abdominal muscle activity during walking, which is supportive of a "guarding" mechanism. Less relative relaxation in swing or a different adaptation to higher velocities, as was predicted to be a secondary reflection of guarding, however, was not found. As such, guarding is expressed as elevated trunk muscle activity during the total stride. Lumbar muscle activity during walking is also related to cognitive factors (i.e. coping strategies). Catastrophizing is positively related to activity of the lumbar muscles (i.e. "guarding"). In contrast, distractive coping is related to increased alteration between lumbar muscle activity in periods of swing, compared to double support. Clinically, guarding of superficial trunk muscles in CLBP is regarded to be a functional compensation for loss of intrinsic muscle control and/or reduced spinal stability, which in the long run may either adaptive or maladaptive. As continuous activation of muscles may cause musculoskeletal problems in the long run it should be prevented, but the question is which strategy is appropriate. If guarding is an adaptive compensation for reduced activity of the intrinsic trunk muscles, one would expect a positive effect of selective training of these muscles. On the other hand, guarding may contribute to the ongoing vicious circle of pain being related to maladaptive coping strategies. In that case, other treatment strategies such as myofeedback might be beneficial in reducing elevated levels of superficial trunk muscle activity. In this thesis a first step is made to unravel these interrelationships. Further studies of the effect of changing physical or cognitive processes during treatment are needed. It is plausible that disability may be reduced through both changes in trunk muscle activity, as through changes in cognitive processes. Eventually this knowledge will enable the clinician to match treatment modules to individual patient characteristics. regel 1

regel 2

regel 3

regel 4

regel 5

regel 6

regel 7

regel 8

regel 9

regel 10

regel 11

regel 12

regel 13

regel 14

regel 15

regel 16

regel 17

regel 18

regel 19

regel 20

regel 21

regel 22

regel 23

regel 24

regel 25

regel 26

regel 27

regel 28

regel 29

regel 30

regel 31

regel 32

regel 33

regel 34

regel 35

regel 36

regel 37

regel 38 
regel 1

regel 2

regel 3

regel 4

regel 5

regel 6

regel 7

regel 8

regel 9

regel 10

regel 11

regel 12

regel 13

regel 14

regel 15

regel 16

regel 17

regel 18

regel 19

regel 20

regel 21

regel 22

regel 23

regel 24

regel 25

regel 26

regel 27

regel 28

regel 29

regel 30

regel 31

regel 32

regel 33

regel 34

regel 35

regel 36

regel 37

regel 38

\section{References}

1. Ahern DK, Follick MJ, Council JR, Laser-Wolston N, and Litchman H. Comparison of lumbar paravertebral EMG patterns in chronic low back pain patients and non-patient controls. Pain 1988;34:153-60.

2. Altmaier E.M, Russell DW, Kao CF, Lehmann T, and Weinstein JN. Role of self-efficacy in rehabilitation outcome among chronic low back pain patients. Journal of Counseling Psychology 1993;40:335-9.

3. Arendt-Nielsen L, Graven-Nielsen T, Svarrer H, and Svensson P. The influence of low back pain on muscle activity and coordination during gait: a clinical and experimental study. Pain 1996;64:231-40.

4. Burns JW. Arousal of negative emotions and symptom-specific reactivity in chronic low back pain patients. Emotion 2006;6:309-19.

5. Burns JW, Bruehl S, and Quartana PJ. Anger management style and hostility among patients with chronic pain: effects on symptom-specific physiological reactivity during anger- and sadness-recall interviews. Psychosom Med 2006;68:786-93.

6. Fisher $\mathrm{K}$ and Johnston M. Emotional distress and control cognitions as mediators of the impact of chronic pain on disability. British Journal of Health Psychology 1998;3:225-36.

7. Flor H, Turk DC, and Birbaumer N. Assessment of stress-related psychophysiological reactions in chronic back pain patients. J Consult Clin Psychol 1985;53:354-64.

8. Fryer G, Morris T, and Gibbons P. Paraspinal muscles and intervertebral dysfunction: part one. J Manipulative Physiol Ther 2004;27:267-74.

9. Geisser ME, Haig AJ, Wallbom AS, and Wiggert EA. Pain-related fear, lumbar flexion, and dynamic EMG among persons with chronic musculoskeletal low back pain. Clin J Pain 2004;20:61-9.

10. Geisser ME, Ranavaya M, Haig AJ et al. A meta-analytic review of surface electromyography among persons with low back pain and normal, healthy controls. J Pain 2005;6:711-26.

11. Goossens ME, Vlaeyen JW, Hidding A, Kole-Snijders A, and Evers SM. Treatment expectancy affects the outcome of cognitive-behavioral interventions in chronic pain. Clin J Pain 2005;21:1826; discussion 69-72.

12. Grahn B, Ekdahl C, and Borgquist L. Motivation as a predictor of changes in quality of life and working ability in multidisciplinary rehabilitation. A two-year follow-up of a prospective controlled study in patients with prolonged musculoskeletal disorders. Disabil Rehabil 2000;22:639-54.

13. Haazen IWCJ, Vlaeyen JWS, Kole-Snijders AMJ, van Eek H, van Es FD. Behavioral rehabilitation of chronic low back pain: searching for predictors of treatment outcome. Journal of Rehabilitation Sciences 1994:34-43.

14. Hammill RR, Beazell JR, and Hart JM. Neuromuscular consequences of low back pain and core dysfunction. Clin Sports Med 2008;27:449-62, ix.

15. Hasenbring M. Attentional control of pain and the process of chronification. Prog Brain Res 2000; 129:525-34.

16. Hasenbring MI, Plaas H, Fischbein B, and Willburger R. The relationship between activity and pain in patients 6 months after lumbar disc surgery: Do pain-related coping modes act as moderator variables? Eur J Pain 2006;10:701-9.

17. Hodges PW and Moseley GL. Pain and motor control of the lumbopelvic region: effect and possible mechanisms. J Electromyogr Kinesiol 2003;13:361-70.

18. Jensen MP, Turner JA, and Romano JM. Correlates of improvement in multidisciplinary treatment of chronic pain. J Consult Clin Psychol 1994;62:172-9.

19. Johansson H and Sojka P. Pathophysiological mechanisms involved in genesis and spread of muscular tension in occupational muscle pain and in chronic musculoskeletal pain syndromes: a hypothesis. Med Hypotheses 1991;35:196-203. 
20. Lamoth CJ, Meijer OG, Daffertshofer A, Wuisman PI, and Beek PJ. Effects of chronic low back pain on trunk coordination and back muscle activity during walking: changes in motor control. Eur Spine J 2006;15:23-40.

21. Lamoth CJ, Meijer OG, Wuisman PI, van Dieen JH, Levin MF, and Beek PJ. Pelvis-thorax coordination in the transverse plane during walking in persons with nonspecific low back pain. Spine 2002;27:E92-9.

22. Lethem J, Slade PD, Troup JD, and Bentley G. Outline of a Fear-Avoidance Model of exaggerated pain perception--I. Behav Res Ther 1983;21:401-8.

23. Lund JP, Donga R, Widmer CG, and Stohler CS. The pain-adaptation model: a discussion of the relationship between chronic musculoskeletal pain and motor activity. Can J Physiol Pharmacol 1991; 69:683-94.

24. Main CJ, Watson PJ. Guarded movements: development of chronicity. Musculoskeletal Pain Emanating from the Head and the Neck: Current Concepts in Diagnosis, Managment and Cost Containment. The Haworth Medical Press, 1996:163-70.

25. Mannion AF, Junge A, Taimela S, Muntener M, Lorenzo K, and Dvorak J. Active therapy for chronic low back pain: part 3. Factors influencing self-rated disability and its change following therapy. Spine 2001;26:920-9.

26. McCracken LM, Gross RT, and Eccleston C. Multimethod assessment of treatment process in chronic low back pain: comparison of reported pain-related anxiety with directly measured physical capacity. Behav Res Ther 2002;40:585-94.

27. Panjabi MM. The stabilizing system of the spine. Part I. Function, dysfunction, adaptation, and enhancement. J Spinal Disord 1992;5:383-9; discussion 397.

28. Pfingsten M, Franz C, Hildebrandt J, Saur P, and Seeger D. Multidisciplinary treatment program on chronic low back pain, part 3. Psychosocial aspects. Schmerz 1996;10:326-44.

29. Quartana PJ, Burns JW, and Lofland KR. Attentional strategy moderates effects of pain catastrophizing on symptom-specific physiological responses in chronic low back pain patients. J Behav Med 2007;30:221-31.

30. Rowe PJ and White M. Three dimensional, lumbar spinal kinematics during gait, following mild musculoskeletal low back pain in nurses. Gait \& Posture 1996;242-51.

31. Selles RW, Wagenaar RC, Smit TH, and Wuisman PI. Disorders in trunk rotation during walking in patients with low back pain: a dynamical systems approach. Clin Biomech 2001;16:175-81.

32. Smeets RJ, Vlaeyen JW, Kester AD, and Knottnerus JA. Reduction of pain catastrophizing mediates the outcome of both physical and cognitive-behavioral treatment in chronic low back pain. J Pain 2006;7:261-71.

33. Spenkelink CD, Hutten MM, Hermens HJ, and Greitemann BO. Assessment of activities of daily living with an ambulatory monitoring system: a comparative study in patients with chronic low back pain and nonsymptomatic controls. Clin Rehabil 2002;16:16-26.

34. Spinhoven P, Ter Kuile M, Kole-Snijders AM, Hutten Mansfeld M, Den Ouden DJ, and Vlaeyen JW. Catastrophizing and internal pain control as mediators of outcome in the multidisciplinary treatment of chronic low back pain. Eur J Pain 2004;8:211-9.

35. Sterling M, Jull G, and Wright A. The effect of musculoskeletal pain on motor activity and control. J Pain 2001;2:135-45.

36. Talo S, Puukka P, Rytokoski U, Ronnemaa T, Kallio V. Can treatment outcome of chronic low back pain be predicted? Psychological disease consequences clarifying the issue. Clin J Pain 1994;10:107-21.

37. Travell J, Rinzter S, and Herman M. Pain and disability of the shoulder and arm. JAMA 1942;120:417-22.

38. Turk DC. The potential of treatment matching for subgroups of patients with chronic pain: lumping versus splitting. Clin J Pain 2005;21:44-55; discussion 69-72.

39. van Dieen JH, Selen LP, and Cholewicki J. Trunk muscle activation in low-back pain patients, an analysis of the literature. J Electromyogr Kinesiol 2003; 13:333-51.

40. van Tulder MW, Koes B, and Malmivaara A. Outcome of non-invasive treatment modalities on back pain: an evidence-based review. Eur Spine J 2006;15 Suppl 1:S64-81. 
regel 1

regel 2

regel 3

regel 4

regel 5

regel 6

regel 7

regel 8

regel 9

regel 10

regel 11

regel 12

regel 13

regel 14

regel 15

regel 16

regel 17

regel 18

regel 19

regel 20

regel 21

regel 22

regel 23

regel 24

regel 25

regel 26

regel 27

regel 28

regel 29

regel 30

regel 31

regel 32

regel 33

regel 34

regel 35

regel 36

regel 37

regel 38

41. van Weering MG, Vollenbroek-Hutten MM, Tonis TM, and Hermens HJ. Daily physical activities in chronic lower back pain patients assessed with accelerometry. Eur J Pain 2008 Aug 26; [Epub ahead of print]

42. Verbunt JA, Seelen HA, Vlaeyen JW et al. Disuse and deconditioning in chronic low back pain: concepts and hypotheses on contributing mechanisms. Eur J Pain 2003;7:9-21.

43. Verbunt JA, Westerterp KR, van der Heijden GJ, Seelen HA, Vlaeyen JW, and Knottnerus JA. Physical activity in daily life in patients with chronic low back pain. Arch Phys Med Rehabil 2001;82:726-30

44. Vlaeyen JW, Kole-Snijders AM, Boeren RG, and van Eek H. Fear of movement/(re)injury in chronic low back pain and its relation to behavioral performance. Pain 1995;62:363-72.

45. Vogt L, Pfeifer K, Portscher M, and Banzer W. Influences of nonspecific low back pain on threedimensional lumbar spine kinematics in locomotion. Spine 2001;26:1910-9.

46. Waddell G. Biopsychosocial analysis of low back pain. Baillieres Clin Rheumatol 1992;6:523-57.

47. Waddell G. The biopsychosocial model. In: Waddell G, ed. The back pain revolution. Edinburgh: Churchill Livingston, 2004.

48. Watson PJ, Booker CK, and Main CJ. Evidence for the role of psychological factors in abnormal paraspinal activity in patients with chronic low back pain. Journal of Musculoskeletal Pain 1997;5:41-56.

49. Wessels T, van Tulder M, Sigl T, Ewert T, Limm H, and Stucki G. What predicts outcome in non-operative treatments of chronic low back pain? A systematic review. Eur Spine J 2006;15 :1633-44.

50. Woby SR, Watson PJ, Roach NK, and Urmston M. Are changes in fear-avoidance beliefs, catastrophizing, and appraisals of control, predictive of changes in chronic low back pain and disability? Eur J Pain 2004;8:201-10.

51. Wolff B, Burns JW, Quartana PJ, Lofland K, Bruehl S, and Chung OY. Pain catastrophizing, physiological indexes, and chronic pain severity: tests of mediation and moderation models. J Behav Med 2008;31:105-14.

52. World Health Organization. International Classification of Functioning, Disability and Health. ICF checklist. 2001. [World Health Organisation web site]. Available at: http://www.who.int/ classifications/icf/en/. Accessed March, 2009. 
Summary

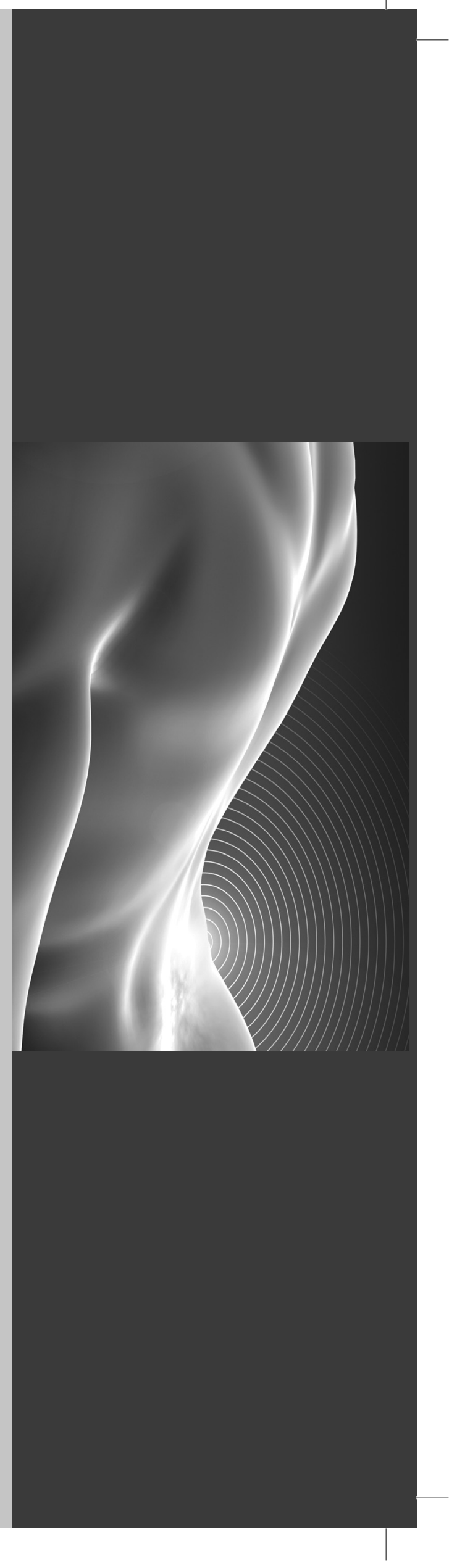


regel 1

regel 2

regel 3

regel 4

regel 5

regel 6

regel 7

regel 8

regel 9

regel 10

regel 11

regel 12

regel 13

regel 14

regel 15

regel 16

regel 17

regel 18

regel 19

regel 20

regel 21

regel 22

regel 23

regel 24

regel 25

regel 26

regel 27

regel 28

regel 29

regel 30

regel 31

regel 32

regel 33

regel 34

regel 35

regel 36

regel 37

regel 38

Nonspecific chronic low back pain (CLBP) is generally approached from a biopsychosocial perspective. A variety of multidisciplinary treatments has been developed aimed at improving activity and participation of subjects with CLBP, but effectiveness is limited. One of the explanations could be the heterogeneity of the CLBP population, which makes it unlikely that all patients will benefit from the same generic treatment. As such, more insight is needed in the role of underlying biopsychosocial mechanisms in subjects with CLBP. Knowledge of these aspects is expected to provide a better match of treatment to the patient's characteristics and improve the effectiveness of multidisciplinary treatments. The main aim of this thesis is to gain insight in these mechanisms, both in relation to treatment outcome, as in differences with respect to asymptomatic controls.

The first part of this thesis explores which biopsychosocial variables are prognostic for treatment outcome in CLBP (chapters 2 and 3). Knowledge of these prognostic factors will facilitate individual selection for the most suitable treatment.

In addition to biopsychosocial prognostic factors, insight in underlying physical and psychological mechanisms in subjects with CLBP is important. Rehabilitation treatment of CLBP is based on hypotheses regarding these processes.

The second part of this thesis focuses on underlying physical mechanisms, in subjects with CLBP, measured as changes in trunk muscle activity (chapters 4, 5 and 6). It is hypothesized that trunk muscle activity in subjects with CLBP may reflect a "guarding" mechanism with increased muscle activity when compared to healthy controls. Within the biopsychosocial concept of chronic pain, the "guarding" hypothesis and the possible association with psychological variables needs to be explored further.

In chapter 2, a systematic review of biopsychosocial predictors of multidisciplinary rehabilitation- or back school treatment outcome in subjects with nonspecific CLBP was performed. Outcomes were classified as activity limitation and/or participation restriction. Conclusions were based on seventeen internally valid studies, which all explored the value of prognostic factors (Phase I or II), while none tested a prognostic model (Phase III). Study heterogeneity necessitated a qualitative summary of the results and limited evidence. Surprisingly, the expected multidimensionality of predictive factors across various domains (i.e. sociodemographic, physical and psychological) was not found. Consistent evidence was found for the predictive value of pain intensity (more pain predicted worse outcome), several work-related parameters (e.g., high satisfaction predicted better outcome), and coping style (less active coping predicted better outcome). Other sociodemographic and physical variables consistently lacked predictive value and no consistent evidence was found for other psychological variables. Based on these results, it was concluded that it is not yet possible 
to define a generic set of predictors of outcome of multidisciplinary rehabilitation and back schools for subjects with CLBP.

A confirmatory study, needed to test the value of these predictors, was performed in chapter 3. It was determined if rehabilitation treatment outcome in nonspecific CLBP could be predicted by a predefined multivariate prognostic model based on consistent predictors from the literature (i.e. pain intensity, work status, and coping, measured by Multidimensional Pain Inventory subgroup membership). Second, the value of potentially prognostic factors (i.e. sick leave, compensation, depression, and fear-avoidance beliefs) was explored further. Data were derived from a randomized controlled trial on the effect of a multidisciplinary rehabilitation program for subjects with CLBP. The primary outcome measure was the Roland and Morris Disability Questionnaire and secondary outcomes were the Physical and Mental Component Summary Scales, derived from the Short Form Health Survey. One hundred and sixty-three patients participated in the study. More pain was prognostic for more improvement in the rehabilitation group. No value was found for work status or the Multidimensional Pain Inventory subgroups. In addition, more depression and fear-avoidance beliefs predicted more improvement following rehabilitation. The explained variance ranged from $18.5 \%$ to $43.8 \%$ depending on the length of follow-up evaluation, the treatment group, and the outcome variable of interest. Although the results of these studies do not support the construction of a clinical prediction model, both chapter 2 and 3 have shown that pain and cognitive related variables play an important role in the prognosis of multidisciplinary treatment outcome in CLBP.

Besides cognitive variables, physical performance was hypothesized to be also important within the biopsychosocial concept of chronic pain. In the study described in chapter 4 , it was investigated whether subjects with CLBP show differences in trunk muscle activity, reflected by a "guarding" mechanism during walking. It was hypothesized that guarding would be reflected by increased lumbar muscle activity during all periods of stride and secondary, by relatively less relaxation during periods of swing compared to double support. In normal walking, the lumbar muscles relax during periods of swing and this relaxation may be less in CLBP. Furthermore, it was hypothesized that higher levels of perceived fear and disability would be related to increased guarding.

In a cross-sectional study, sixty-three subjects with CLBP and 33 healthy controls walked on a treadmill at 3.8 kilometres per hour $(\mathrm{km} / \mathrm{h})$. Surface Electromyography $(\mathrm{sEMG})$ data of the musculus erector spinae were obtained and smoothed rectified sEMG (SRE) values were calculated per period of swing and double support. The ratio of SRE values in swing to double support was used as a measure of relative relaxation (SRE ratio). Additionally, the relation between SRE values, the Roland Morris Disability Questionnaire and the Tampa Scale for

regel 1

regel 2

regel 3

regel 4

regel 5

regel 6

regel 7

regel 8

regel 9

regel 10

regel 11

regel 12

regel 13

regel 14

regel 15

regel 16

regel 17

regel 18

regel 19

regel 20

regel 21

regel 22

regel 23

regel 24

regel 25

regel 26

regel 27

regel 28

regel 29

regel 30

regel 31

regel 32

regel 33

regel 34

regel 35

regel 36

regel 37

regel 38 
regel 1

regel 2

regel 3

regel 4

regel 5

regel 6

regel 7

regel 8

regel 9

regel 10

regel 11

regel 12

regel 13

regel 14

regel 15

regel 16

regel 17

regel 18

regel 19

regel 20

regel 21

regel 22

regel 23

regel 24

regel 25

regel 26

regel 27

regel 28

regel 29

regel 30

regel 31

regel 32

regel 33

regel 34

regel 35

regel 36

regel 37

regel 38

Kinesiophobia was analyzed in subjects with CLBP. Mean SRE values were significantly higher in subjects with CLBP than in controls, both during periods of double support and swing. SRE ratios were not significantly different between groups. Results showed no influence of disability or fear of movement on either SRE values or ratios. It was concluded that subjects with CLBP have an elevated level of lumbar muscle activity during walking, independent of the different periods of the stride. Although at first glance the comparable SRE ratios between groups seem to be in contrast with the guarding hypothesis, the continuous higher levels of m.erector spinae activity in CLBP might indicate that the m.erector spinae do not have moments of total muscle relaxation. Therefore, the results from chapter 4 support the guarding hypothesis.

The guarding hypothesis was further explored in chapter 5 by investigating the amount of superficial lumbar and abdominal muscle activity and the influence of greater walking velocities in subjects with CLBP, compared to asymptomatic controls. It was hypothesized that activation of the superficial abdominal (i.e. m.rectus abdominis and m.obliquus externus abdominis) and lumbar (i.e. m.erector spinae) muscles would be increased in CLBP. Furthermore, greater walking velocity was expected to elicit greater increases in trunk muscle activity in the CLBP group, as guarding may become more pronounced at higher ranges of motion.

Sixty-three subjects with CLBP and 33 asymptomatic controls walked on a treadmill at different velocities (1.4 till $5.4 \mathrm{~km} / \mathrm{h}$ ). sEMG data of the m.erector spinae, m.rectus abdominis and m.obliquus abdominis externus muscles were obtained and SRE values were calculated per period of swing and double support. Results showed that, compared to asymptomatic controls, subjects with CLBP had increased muscle activity of the m.erector spinae and m.rectus abdominis, but not of the m.obliquus abdominis externus. These differences in trunk muscle activity between groups did not increase with higher walking velocities. In conclusion, the observed increased lumbar and abdominal muscle activity in subjects with CLBP during walking supports the guarding hypothesis, which is in line with the results from the study described in chapter 4 .

In chapter 6, a possible relation between muscle activity and cognitive variables was explored in subjects with CLBP. Different cognitive-behavioral models have hypothesized that pain coping strategies (i.e. purposeful efforts to manage the negative impact of stress) play a role in the chronification of pain by changes in physical activity. Strategies such as avoidance (i.e. avoiding daily activities because of fear of pain/ (re)injury) or persistent coping (i.e. carrying on with daily activities despite pain), may be related to changes in (lumbar) muscle activity. It was investigated whether avoidance and persistent coping strategies are present in subjects with CLBP and whether these strategies are differentially related to lumbar muscle activity 
during walking. In a cross-sectional study, sixty-three subjects with CLBP walked on a treadmill at $3.8 \mathrm{~km} / \mathrm{h}$. Coping strategies were measured with the Dutch version of the Coping Strategies Questionnaire and three coping strategies (i.e "catastrophizing", "distraction" and "persistence and control") were identified with principal component analysis. Surface electromyography data of the m.erector spinae were obtained and average SRE values were calculated per periods of swing and double support. The ratio of SRE values (swing/double support) was used as a measure of relaxation (SRE ratio). "Catastrophizing" was positively related to SRE values. "Distraction" was negatively associated with SRE ratios. No relation was found between "persistence and control" and SRE values or ratios. In conclusion, in subjects with CLBP a maladaptive coping strategy like catastrophizing is related to increased lumbar muscle activity (i.e. "guarding"), and an adaptive strategy like distraction to increased variation between activation and relaxation of the lumbar muscles. The association between coping strategies and lumbar muscle activity supports the concept that cognitive factors are related to changes in lumbar muscle activity.

In the general discussion (chapter 7) the main findings are summarized. Methodological issues and recommendations for future research are provided. Pain intensity and cognitive related variables like coping strategies have shown to play an important role in the prognosis of multidisciplinary rehabilitation treatment outcome. The explained variance of baseline prognostic factors for treatment outcome however, is rather low. This means that the evidence is not strong enough to provide the clinician with a useful tool to select the patient for the most suitable treatment at baseline.

Evidence for differences in biopsychological mechanisms between subjects with CLBP and asymptomatic controls has been found. Subjects with CLBP show physical changes reflected by increased superficial lumbar and abdominal muscle activity during walking, which is supportive of a "guarding" mechanism.

Lumbar muscle activity during walking is related to cognitive factors (i.e. coping strategies). Catastrophizing is positively related to activity of the lumbar muscles (i.e. "guarding"). In contrast, distractive coping is related to increased alteration between lumbar muscle activity in periods of swing compared to double support.

Clinically, guarding of superficial trunk muscles in CLBP may be a functional compensation for loss of intrinsic muscle control and/or reduced spinal stability, but also may contribute to the ongoing vicious cycle of pain. Future studies of changing physical (e.g. trunk muscle activity) and psychological (e.g. coping) mechanisms in subjects with LBP are needed to better understand underlying biopsychological mechanisms in CLBP. Eventually, this knowledge will enable the clinician to match treatment modules to individual patient characteristics. 
regel 1

regel 2

regel 3

regel 4

regel 5

regel 6

regel 7

regel 8

regel 9

regel 10

regel 11

regel 12

regel 13

regel 14

regel 15

regel 16

regel 17

regel 18

regel 19

regel 20

regel 21

regel 22

regel 23

regel 24

regel 25

regel 26

regel 27

regel 28

regel 29

regel 30

regel 31

regel 32

regel 33

regel 34

regel 35

regel 36

regel 37

regel 38 
Samenvatting

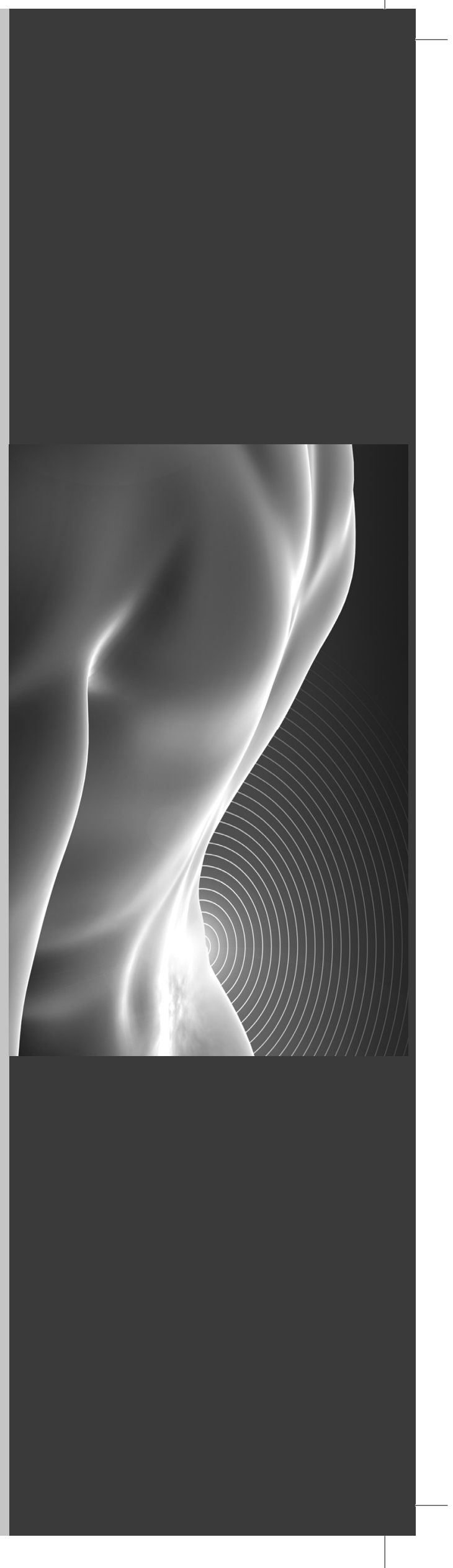


regel 1

regel 2

regel 3

regel 4

regel 5

regel 6

regel 7

regel 8

regel 9

regel 10

regel 11

regel 12

regel 13

regel 14

regel 15

regel 16

regel 17

regel 18

regel 19

regel 20

regel 21

regel 22

regel 23

regel 24

regel 25

regel 26

regel 27

regel 28

regel 29

regel 30

regel 31

regel 32

regel 33

regel 34

regel 35

regel 36

regel 37

regel 38

\section{Prognostische factoren en onderliggende mechanismen in chronische lage rugpijn}

Aspecifieke chronische lage rugpijn (CLRP) wordt veelal benaderd vanuit een biopsychosociaal perspectief. Er zijn veel verschillende multidisciplinaire behandelingen ontwikkeld, gericht op het verhogen en verbeteren van het functioneren (activiteiten niveau) en deelname aan het maatschappelijk leven (participatie niveau). De effectiviteit van deze behandelingen is echter vrij beperkt. Eén van de verklaringen hiervoor zou de heterogeniteit van de CLRP populatie kunnen zijn, waardoor het onwaarschijnlijk is dat alle patiënten zullen profiteren van eenzelfde, algemene behandeling. Er is daarom meer kennis nodig over de rol van de onderliggende biopsychosociale mechanismen bij patiënten met CLRP. Inzicht in deze mechanismen zal de behandeling beter kunnen laten aansluiten bij de specifieke kenmerken van de patiënt en daarmee de effectiviteit van multidisciplinaire behandelingen verhogen. Het doel van dit proefschrift is inzicht te verkrijgen in deze mechanismen, zowel in relatie met de uitkomst van behandeling, als in verschillen tussen patiënten en gezonde proefpersonen.

Het eerste deel van dit proefschrift onderzoekt welke biopsychosociale variabelen voorspellend zijn voor de uitkomst van behandeling in CLRP (hoofdstuk 2 en 3). Kennis van voorspellende factoren zal bijdragen aan een betere fit van een individuele patiënt aan een specifieke behandeling.

Daarnaast is inzicht in onderliggende fysieke en psychologische mechanismen in patiënten met CLRP belangrijk. De revalidatiebehandeling van CLRP is gebaseerd op theorieën over deze mechanismen. Het tweede deel van dit proefschrift richt zich daarom op één van de onderliggende fysieke mechanismen in patiënten met CLRP, namelijk de veranderingen die optreden bij de aansturing van de rompspieren (hoofdstuk 4,5 en 6). Gehypothetiseerd wordt dat de rompspieractiviteit van patiënten met CLRP een "guarding" mechanisme reflecteert, met een verhoogde spieractiviteit ten opzichte van gezonde proefpersonen. Daarnaast wordt de mogelijke associatie tussen het "guarding" mechanisme en psychologische variabelen verder onderzocht.

In hoofdstuk 2 werd een systematische literatuuronderzoek beschreven over biopsychosociale voorspellende factoren van multidisciplinaire revalidatiebehandeling in patiënten met aspecifieke CLRP. Uitkomsten waren geclassificeerd als beperkingen in activiteiten en/of participatie. Conclusies werden gebaseerd op 17 intern valide studies, die allen exploratief van aard waren (fase I of II). Geen enkele studie toetste een prognostisch model (fase III). Vanwege de heterogeniteit van de geïncludeerde studies was alleen een kwalitatieve analyse mogelijk en was de bewijskracht beperkt. Tegen verwachting in werden er geen consistente 
voorspellende factoren gevonden voor alle 3 de onderzochte domeinen (sociodemografisch, fysiek en psychologisch). Consistent bewijs werd gevonden voor de voorspellende waarde van pijn intensiteit (meer pijn voorspelde een slechtere uitkomst); verscheidende werkgerelateerde parameters (o.a. hoge werktevredenheid voorspelde een betere uitkomst); en coping stijl (een minder actieve coping stijl voorspelde een betere uitkomst). Er werd consistent bewijs gevonden dat andere sociodemografische en fysieke variabelen geen voorspellende waarde hadden. Er was onvoldoende consistent bewijs voor de voorspellende waarde van de overige gemeten psychologische variabelen. Op basis van deze resultaten werd geconcludeerd dat het nog niet mogelijk is om een generieke set voorspellende factoren te definiëren voor de uitkomst van multidisciplinaire revalidatiebehandeling van patiënten met CLRP.

Er zijn dus studies nodig die de waarde van potentiële voorspellende factoren toetsen. Een dergelijk onderzoek werd verricht en beschreven in hoofdstuk 3. Hierin werd onderzocht of de uitkomst van revalidatiebehandeling in aspecifieke CLRP voorspeld kon worden door een voorafopgesteld prognostisch model. Dit model was gebaseerd op de consistente voorspellende factoren gevonden in de literatuur (pijn intensiteit, werkstatus en coping, gemeten met de Multidimensional Pain Inventory subgroep classificatie). Daarnaast werd de waarde van andere potentiële voorspellende factoren (ziekteverzuim en uitkering, depressie en angstvermijdings gedachten) geëxploreerd. Gegevens werden verkregen uit een gerandomiseerde gecontroleerde studie naar het effect van een multidisciplinaire revalidatiebehandeling voor patiënten met CLRP. De primaire uitkomstmaat was de Roland and Morris Disability Questionnaire. Secundaire uitkomstmaten waren de Physical and Mental Component Summary Scales, afgeleid van de Short Form Health Survey. In totaal namen 163 patiënten deel aan de studie. Meer pijn was voorspellend voor verbetering na revalidatiebehandeling. Er werd geen voorspellende waarde gevonden voor werkstatus of één van de subgroepen van de Multidimensional Pain Inventory. Verder waren depressieve gedachten en angst-vermijdings gedachten voorspellend voor verbetering na revalidatiebehandeling. De verklaarde variantie variëerde tussen $18.5 \%$ en $43.8 \%$, afhankelijk van de follow-up duur, de behandelgroep en de uitkomstmaat. Ondanks dat de resultaten een klinisch prognostisch model niet ondersteunen, laten hoofdstuk 2 en 3 beiden zien dat pijn en cognitief gerelateerde variabelen een belangrijke rol spelen in de prognose van de uitkomst van multidisciplinaire revalidatiebehandeling in CLRP.

Behalve cognitieve variabelen, werd vanuit het biopsychosociale perspectief verondersteld dat fysiek prestatievermogen ook van belang is. In hoofdstuk 4 werd onderzocht of de rompspieractiviteit van patiënten met CLRP verschilt van gezonde proefpersonen tijdens het lopen. De hypothese werd getoetst of er in CLRP een "guarding" mechanisme bestaat, dat tot uiting komt in een verhoogde rompspieractiviteit tijdens alle fasen van het lopen. Daarnaast regel 1

regel 2

regel 3

regel 4

regel 5

regel 6

regel 7

regel 8

regel 9

regel 10

regel 11

regel 12

regel 13

regel 14

regel 15

regel 16

regel 17

regel 18

regel 19

regel 20

regel 21

regel 22

regel 23

regel 24

regel 25

regel 26

regel 27

regel 28

regel 29

regel 30

regel 31

regel 32

regel 33

regel 34

regel 35

regel 36

regel 37

regel 38 
regel 1

regel 2

regel 3

regel 4

regel 5

regel 6

regel 7

regel 8

regel 9

regel 10

regel 11

regel 12

regel 13

regel 14

regel 15

regel 16

regel 17

regel 18

regel 19

regel 20

regel 21

regel 22

regel 23

regel 24

regel 25

regel 26

regel 27

regel 28

regel 29

regel 30

regel 31

regel 32

regel 33

regel 34

regel 35

regel 36

regel 37

regel 38

werd de hypothese onderzocht of de rugspieren in patiënten met CLRP tijdens de swing fase relatief minder zouden ontspannen ten opzichte van de dubbele stand fase. De gedachte was dat de normale ontspanning in de swing fase bij patiënten met CLRP relatief minder zou zijn dan bij gezonde proefpersonen. Tenslotte werd onderzocht of een hoger niveau van angst en ervaren beperkingen positief gerelateerd was aan het guarding mechanisme.

In een cross-sectionele studie werden 63 patiënten met CLRP en 33 gezonde proefpersonen gemeten tijdens lopen op een loopband met een snelheid van 3.8 kilometer per uur $(\mathrm{km} / \mathrm{u})$. Oppervlakte ElectroMyoGrafie (sEMG) data van de musculus erector spinae werden verzameld. Smoothed rectified sEMG (SRE) waarden werden afzonderlijk berekend voor de swing- en dubbele stand fasen. De ratio's van de SRE waarden in swing ten opzichte van de dubbele stand fasen werden gebruikt als maat voor de relatieve relaxatie (SRE ratio). Daarnaast werd in de CLRP groep de relatie tussen SRE waarden, de Roland Morris Disability Questionnaire en de Tampa Scale for Kinesiophobia geanalyseerd. Gemiddelde SRE waarden waren significant hoger in de CLRP groep in vergelijking met de controle groep. SRE ratio's waren niet significant verschillend tussen de groepen. Er was geen relatie tussen de hoeveelheid angst of ervaren beperkingen enerzijds en de SRE waarden of ratio's anderzijds. Concluderend hebben patiënten met CLRP een verhoogd niveau van rugspieractiviteit tijdens lopen, onafhankelijk van de verschillende fasen van een schrede. De vergelijkbare SRE ratio's tussen de groepen lijkt in eerste instantie in tegenspraak te zijn met de guarding hypothese. Daarentegen zou de continu verhoogde activiteit van de m.erector spinae erop kunnen wijzen dat periodes van volledige relaxatie ontbreken. Derhalve wordt de guarding hypothese ondersteund door deze resultaten.

De guarding hypothese werd verder onderzocht in hoofdstuk 5. Hierin werd de hoeveelheid spieractiviteit van de oppervlakkige rug- en buikspieren vergeleken tussen patiënten met CLRP en gezonde proefpersonen. Daarnaast werd de invloed van hogere loopsnelheden op de hoeveelheid spieractiviteit bestudeerd. De hypothese was dat de spieractiviteit van de oppervlakkige buik- (m.rectus abdominis en m.obliquus externus abdominis) en rugspieren (m.erector spinae) in patiënten met CLRP verhoogd zou zijn. Verder werd verwacht dat in de CLRP groep een hogere loopsnelheid een grotere toename in rompspieractiviteit zou geven, aangezien guarding waarschijnlijk zou toenemen bij grotere bewegingsuitslagen.

63 Patiënten en 33 gezonde proefpersonen werden gemeten tijdens lopen op verschillende snelheden ( 1.4 tot $5.4 \mathrm{~km} / \mathrm{h}$ ) op een loopband. sEMG data van de m. erector spinae, m.rectus abdominis en m.obliquus externus abdominis werden verzameld en SRE waarden werden afzonderlijk berekend voor de swing- en dubbele stand fasen van een schrede. De resultaten lieten zien dat patiënten met CLRP, vergeleken met gezonde proefpersonen, een verhoogde spieractiviteit hadden van de m.erector spinae en de m.rectus abdominis, maar niet van de m.obliquus externus abdominis. De verschillen in spieractiviteit namen niet toe met hogere 
loopsnelheden. Concluderend ondersteunt de verhoogde buik- en rugspieractiviteit in patiënten met CLRP de guarding hypothese, wat in lijn is met de resultaten die beschreven zijn in hoofdstuk 4 .

In hoofdstuk 6 werd de relatie tussen spieractiviteit en cognitieve variabelen in patiënten met CLRP geëxploreerd. Verschillende cognitief-gedragsmatige modellen veronderstellen dat coping strategieën met pijn een rol spelen in het ontstaan van chronische pijn, o.a. door veranderingen in fysieke activiteit. Strategieën zoals vermijding (het vermijden van dagelijkse activiteiten wegens angst voor pijn of letsel), of overbelasting (het doorgaan met dagelijkse activiteiten ondanks de pijn), zijn mogelijk gerelateerd aan veranderingen in (rug)spieractiviteit. In hoofdstuk 6 is onderzocht of coping strategieën zoals vermijding en overbelasting toegepast worden door patiënten met CLRP en zo ja, of deze zijn gerelateerd aan rugspieractiviteit tijden lopen.

In een cross-sectionele studie werden 63 patiënten met CLRP gemeten tijdens lopen op een loopband met een snelheid van 3.8 kilometer per uur $(\mathrm{km} / \mathrm{u})$. Coping strategieën werden gemeten met de Nederlandse versie van de Coping Strategies Questionnaire en drie coping strategieën ("catastrophizing", "distraction" en "persistence and control") werden gevonden middels principale component analyse. sEMG data van de m. erector spinae werden verzameld en SRE waarden werden afzonderlijk berekend voor de swing- en dubbele stand fasen van een schrede. De ratio's van de SRE waarden in swing ten opzichte van de dubbele stand fasen werden gebruikt als maat voor de relatieve relaxatie (SRE ratio). "Catastrophizing" was positief gerelateerd aan SRE waarden. "Distraction" was negatief geassocieerd met SRE ratio's. Er werd geen relatie gevonden tussen "persistence and control" en SRE waarden of ratio's.

Geconcludeerd kan worden dat bij patiënten met CLRP een maladaptieve coping strategie zoals catastroferen, gerelateerd is aan een verhoogde rugspieractiviteit ("guarding"). Daarnaast is een adaptieve coping strategie zoals afleiding, gerelateerd aan een toegenomen afwisseling tussen activatie en relaxatie van de rugspieren. De associatie tussen coping strategieën en rugspieractiviteit ondersteunt het concept dat cognitieve factoren gerelateerd zijn aan veranderingen in rugspieractiviteit.

In de discussie (hoofdstuk 7) worden de belangrijkste bevindingen samengevat. Methodologische problemen worden genoemd en aanbevelingen voor toekomstig onderzoek worden gegeven. Pijn intensiteit en cognitief gerelateerde variabelen zoals coping strategieën blijken een belangrijke rol te spelen in de prognose van uitkomst van multidisciplinaire revalidatiebehandeling. De verklaarde variantie van de prognostische factoren voor uitkomst van behandeling is echter vrij laag. Dit betekent dat er onvoldoende bewijs is om de clinicus een bruikbaar instrument te geven om de patiënt vóór aanvang te selecteren voor de meest geschikte behandeling. regel 1

regel 2

regel 3

regel 4

regel 5

regel 6

regel 7

regel 8

regel 9

regel 10

regel 11

regel 12

regel 13

regel 14

regel 15

regel 16

regel 17

regel 18

regel 19

regel 20

regel 21

regel 22

regel 23

regel 24

regel 25

regel 26

regel 27

regel 28

regel 29

regel 30

regel 31

regel 32

regel 33

regel 34

regel 35

regel 36

regel 37

regel 38 
regel 1 regel 2 regel 3 regel 4 regel 5 regel 6 regel 7 regel 8 regel 9 regel 10 regel 11 regel 12 regel 13 regel 14 regel 15 regel 16 regel 17 regel 18 regel 19 regel 20 regel 21 regel 22 regel 23 regel 24 regel 25 regel 26 regel 27 regel 28 regel 29 regel 30 regel 31 regel 32 regel 33 regel 34 regel 35 regel 36 regel 37 regel 38
Er is bewijs gevonden voor verschillen in biopsychosociale mechanismen tussen patiënten met CLRP en gezonde proefpersonen. In patiënten met CLRP zijn fysieke veranderingen aanwezig, meetbaar als verhoogde activiteit van de oppervlakkige rug- en buikspieren tijdens lopen, die mogelijk een "guarding" mechanisme reflecteren.

Rugspieractiviteit tijdens lopen is gerelateerd aan cognitieve factoren (coping strategieën). Catastroferen is positief gerelateerd aan rugspieractivieit ("guarding"). Daarentegen is een afleidende coping strategie gerelateerd aan een toegenomen afwisseling tussen activatie en relaxatie van de rugspieren in de swing- ten opzichte van de dubbele stand fase.

Vanuit klinisch perspectief zou guarding van de oppervlakkige rompspieren in CLRP een functionele compensatie kunnen zijn voor het controleverlies van de intrinsieke rugspieren en het voor het verlies aan stabiliteit van de wervelkolom. Anderzijds zou guarding negatief bij kunnen dragen aan de vicieuze cirkel van chronische pijn. Toekomstige studies naar veranderingen in fysieke (bijv. rompspieractiviteit) en psychologische (bijv. coping) mechanismen bij patiënten met CLRP zijn nodig om onderliggende biopsychologische mechanismen in CLRP beter te begrijpen. Uiteindelijk zal dit inzicht de clinicus helpen om de behandeling beter aan te laten sluiten bij de kenmerken van de individuele patiënt. 
Dankwoord

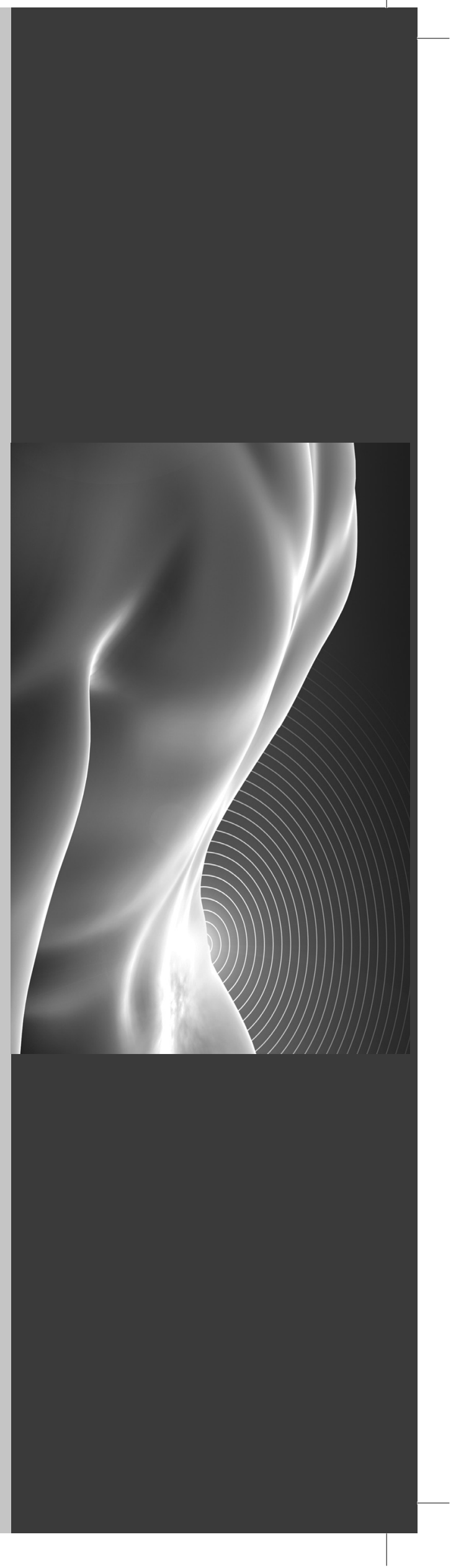


regel 1

regel 2

regel 3

regel 4

regel 5

regel 6

regel 7

regel 8

regel 9

regel 10

regel 11

regel 12

regel 13

regel 14

regel 15

regel 16

regel 17

regel 18

regel 19

regel 20

regel 21

regel 22

regel 23

regel 24

regel 25

regel 26

regel 27

regel 28

regel 29

regel 30

regel 31

regel 32

regel 33

regel 34

regel 35

regel 36

regel 37

regel 38
Met dit laatste hoofdstuk wil ik een belangrijke periode van mijn leven afsluiten - een 8 jarig traject tot het voltooien van mijn proefschrift, mijn gezin, de opleiding tot revalidatiearts en epidemioloog. De afgelopen jaren zijn te beschrijven als een reis op een trein: sommigen die opstapten, zijn weer uitgestapt; soms stonden we stil, soms gingen we in een sneltreinvaart de heuvel af. Terugkijkend op de afgelopen 8 jaar moet ik zeggen: ik had deze reis nooit willen missen. Degenen die hierin een rol hebben gespeeld wil ik graag bedanken, al realiseer ik me dat ik het risico loop dat iemand zich vergeten voelt.

Prof. dr. M.M.R. Vollenbroek-Hutten, beste Miriam, jij was voor mij de motor achter mijn gehele promotietraject. Ik kon altijd op je rekenen. Je tomeloze energie, optimisme en gedrevenheid is bewonderingswaardig. Je gaf me de ruimte me te ontwikkelen als onderzoeker en mijn eigen voorkeur te volgen, waarbij je me hielp het overzicht te houden. Je belangstelling voor mijn persoonlijk leven is voor mij ook waardevol geweest. Ik ben vereerd als eerste onder jouw hoogleraarschap te mogen promoveren!

Prof. dr. ir. H.J. Hermens, beste Hermie, zonder jouw wetenschappelijke kennis en creatieve ideeën op het gebied van EMG had ik dit onderzoek nooit goed kunnen verrichten. Je kwam "even buurten" als je aanvoelde wanneer dat nodig was; deze momenten waren minstens zo belangrijk.

Prof. dr. J.S. Rietman, beste Hans, je klinische blik als revalidatiearts was een zeer waardevolle toevoeging bij de interpretatie van de gegevens en het schrijven van de artikelen. Je humor, met een charmant vleugje chaos, maakte dat ik altijd glimlachend en met nieuwe ideeën de kamer na een werkoverleg verliet.

Overige leden van de promotiecommissie: prof. dr. J.M. Pieters, prof. dr.med.sci.T.GravenNielsen, prof.dr. J.H. van Dieën en prof.dr.R.J.E.M.Smeets, dank ik voor de tijd en aandacht die zij bereid waren te geven aan de beoordeling van dit proefschrift.

De grootste dank ben ik verschuldigd aan de patiënten met chronische lage rugpijn en de vrijwilligers, die bereid waren om deel te nemen aan de experimenten. Zonder hen had ik dit proefschrift niet kunnen afronden.

Dank gaat ook uit naar de medeauteurs buiten de begeleidingsgroep. Maarten IJzerman, dank voor je steun bij het aanvragen van de ZonMW subsidie, die een belangrijke basis voor dit onderzoek is geweest. Leendert Schaake, veel dank voor de intensieve betrokkenheid bij de opzet, ontwikkeling en uitwerking van het technische deel van dit onderzoek. In al je bescheidenheid altijd op de achtergrond, maar je kennis en betrouwbaarheid is voor mij 
onmisbaar geweest. Karin Groothuis, je hebt mij vele uren ondersteund met uitleg en hulp bij de data-analyse. Daarnaast waren de regelmatige gesprekken over thuis een prettige afleiding. Karlein Schreurs, als psycholoog heb je me aan het einde van de rit geholpen een brug te slaan tussen de psychologie en bewegingsanalyse.

Degenen die ik zeker niet mag vergeten, zijn de studenten die meegeholpen hebben aan de metingen en data-analyse. Louis Kupers, dankzij jouw ondersteuning bij het meten en analyseren van de EMG data van een groot deel van de proefpersonen kon de trein doorrijden tijdens mijn klinische fase. Je klinische blik als fysiotherapeut was van aanvullende waarde. Mark Landhuis, dank voor je hulp bij het "enerverend" labelen van een groot deel van de VICON data en het meedenken in de analyse en interpretatie hiervan.

Ook mijn paranimfen wil ik bedanken. Judith Fleuren, voor mij een maatje tijdens het traject van agiko tot aiosko en uiteindelijk tot revalidatiearts en epidemioloog. We delen onze wortels in de "grijze keet" van het RRD. Je bent voor mij een belangrijk klankbord geweest met je relativerende kijk en humor. Mirjam, ook al kennen we elkaar relatief kort, ik heb genoten van je gezelligheid en de salsa uitjes. Ik hoop dat er nog meer zullen volgen.

De opleiders revalidatiegeneeskunde, in de afgelopen 8 jaar Karel Maathuis, Bertjo Renzenbrink, Govert Snoek en Hans Rietman, wil ik bedanken voor het vertrouwen en de medewerking waarmee dit "aiosko" traject mogelijk is gemaakt. In het bijzonder wil ik Bertjo als hoofdopleider noemen, op wiens flexibiliteit ik veelvuldig een beroep heb gedaan. Ik ben je erg dankbaar dat je altijd bereid was om mijn wensen in de zoveelste aanpassing van het opleidingsschema mee te nemen.

De overige collega's van het RRD, altijd belangstellend en betrokken, wil ik bijzonder bedanken voor de prettige samenwerking. Zonder de ondersteuning van de lab- en systeembeheerders op de meest onverwachte momenten had ik niet gekund: Wil, Jos, Thijs, Rick en zoals reeds genoemd, Leendert. Wiebe, je hebt een aanzienlijke bijdrage geleverd aan het ontwikkelen van de software voor de data-analyse, bedankt hiervoor. Laura, bedankt voor de gezellige wandelingen in de pauzes.

In dezelfde lijn wil ik ook de leden van de WIRR en LOBADIS, de onderzoekslijn van ZonMW voor chronische lage rugklachten, bedanken voor de feedback op mijn onderzoeksresultaten en de discussies die stof gaven tot nadenken.

Ook vanuit het Revalidatiecentrum Het Roessingh zijn medewerkers van de pijndivisie inhoudelijk en ondersteunend betrokken geweest: Daan Wever, Rina Warmerdam, Frank 
regel 1

regel 2

regel 3

regel 4

regel 5

regel 6

regel 7

regel 8

regel 9

regel 10

regel 11

regel 12

regel 13

regel 14

regel 15

regel 16

regel 17

regel 18

regel 19

regel 20

regel 21

regel 22

regel 23

regel 24

regel 25

regel 26

regel 27

regel 28

regel 29

regel 30

regel 31

regel 32

regel 33

regel 34

regel 35

regel 36

regel 37

regel 38
Geerdink, Michiel Gorter, René ter Meer, Lucas Slot, Annika Bekmann, Peter Nijhoff, Elise Meijerink en Wilma van Staaveren. Daarnaast wil ik ook mijn collega revalidatieartsen en assistenten bedanken voor het rekruteren van patiënten met chronische lage rugpijn. Caro Bédorf en Sacha Jagt, dank voor jullie hulp bij het bemachtigen van de benodigde artikelen.

Mijn collega (oud-) assistenten, dank voor jullie collegialiteit en gezelligheid die ik heb gehad tijdens 8 jaar opleiding in het Roessingh. Marieke en Muriël, jullie hebben mij ondersteund door een belangrijk deel van de gebruikte psychologische vragenlijsten te ontrafelen, in te voeren en te analyseren. Mijn collega aiosko's, het delen van jullie ervaringen heeft me behoed voor bekende valkuilen en het gehele promotietraject helpen relativeren.

Mijn familie wil ik bedanken. Mam, zonder jou relativerende kijk en vele oppasuurtjes was dit proefschrift niet afgerond. Pap, bedankt voor het beoordelen van de tekst op haar leesbaarheid en de Engelse taal. Rogier en Tjeerd, bedankt voor jullie betrokkenheid. In het bijzonder wil ik Tjeerd bedanken voor het prachtige ontwerp van de omslag van mijn proefschrift.

En natuurlijk: Timon, Jelmar en Leanne, bedankt voor jullie onbevangen vrolijkheid, iedere dag weer. Sjak, zonder jouw praktische en emotionele steun was ik nooit aan deze reis begonnen, laat staan dat ik de eindbestemming had bereikt. 


\section{Over de auteur}

Marije van der Hulst werd op 15 mei 1974 geboren te Groningen. Van 1986 tot 1988 doorliep zij de middelbare school an het Menso Alting College te Hoogeveen, van 1988 tot 1992 aan het Maartenscollege te Haren en sloot af met haar gymnasium diploma. Tijdens haar studie geneeskunde aan de Rijksuniversiteit te Groningen heeft ze onderwijs gegeven aan medestudenten en diverse buitenlandse wetenschappelijke stages gevolgd. In 1999 behaalde ze haar artsexamen met het predicaat cum laude. Na werkzaam geweest te zijn als artsassistent neurologie in het Universitair Medisch Centrum te Nijmegen, vervolgde zij haar weg in de revalidatiegeneeskunde. In 2001 startte zij met de opleiding tot revalidatiearts in revalidatiecentrum Het Roessingh in Enschede, welke in 2002 werd gecombineerd met een promotietraject bij Roessingh Research and Development ("aiosko"). Tijdens de opleiding organiseerde zij het circuit-gebonden onderwijs voor de revalidatieartsen in opleiding en was zij landelijk vertegenwoordiger van de aiosko's revalidatiegeneeskunde. In 2007 behaalde zij bij het instituut voor Extramuraal Geneeskundig Onderzoek haar Master of Epidemiology, toegekend door de Vrije Universiteit te Amsterdam. Momenteel werkt Marije als revalidatiearts in de Sint Maartenskliniek en het Canisius-Wilhelmina Ziekenhuis te Nijmegen met als aandachtsgebied de neurologische revalidatie. regel 1

regel 2

regel 3

regel 4

regel 5

regel 6

regel 7

regel 8

regel 9

regel 10

regel 11

regel 12

regel 13

regel 14

regel 15

regel 16

regel 17

regel 18

regel 19

regel 20

regel 21

regel 22

regel 23

regel 24

regel 25

regel 26

regel 27

regel 28

regel 29

regel 30

regel 31

regel 32

regel 33

regel 34

regel 35

regel 36

regel 37

regel 38 
regel 1

regel 2

regel 3

regel 4

regel 5

regel 6

regel 7

regel 8

regel 9

regel 10

regel 11

regel 12

regel 13

regel 14

regel 15

regel 16

regel 17

regel 18

regel 19

regel 20

regel 21

regel 22

regel 23

regel 24

regel 25

regel 26

regel 27

regel 28

regel 29

regel 30

regel 31

regel 32

regel 33

regel 34

regel 35

regel 36

regel 37

regel 38 


\section{Progress range}

The following publications have also been published in the Progress range by Roessingh Research and Development, Enschede, the Netherlands. Copies can be ordered, when available, via info@rrd.nl.

1. Pot JWGA, Boer H, van Harten WH, Hermens HJ, Seydel ER. Comprehensive Need-Assessment. Ontwikkeling van een meetinstrument voor zorgbehoeften en kwaliteitsbeoordeling door patiënten. Roessingh Research and Development, The Netherlands, September 1994, ISBN 90-25452-01-2

2. Van Leerdam NGA, Hermens HJ. Revalidatietechnologie in Euregio. Roessingh Research and Development, The Netherlands, July 1995, ISBN 90-75452-02-0

3. Duda L, van Noort LO, Röseler S, Greitemann BOL, van Harten WH, Klazinga NS. Rehabilitation in Germany and the Netherlands, A comparison of two rehabilitationsystems. Roessingh Research and Development, The Netherlands, August 1995, ISBN 90-75452-03-9

4. Hermens HJ, Nene AV, Zilvold G. Electrophysiological Kinesiology. Proceedings of the 11th congress of the International Society of Electrophysiology and Kinesiology in Enschede, Roessingh Research and Development, The Netherlands, October 1996, ISBN 90-75452-04-7

5. Van Harten WH. Bouwen aan een kwaliteitssysteem in de revalidatiezorg. Een poging tot constructieve technology assessment van een kwaliteitssysteem in een gezondheidszorginstelling. Roessingh Research and Development, The Netherlands, December 1997, ISBN 90-75452-07-1

6. Baardman G, IJzerman MJ. Design and evaluation of a hybrid orthosis for people with paraplegia. Roessingh Research and Development, The Netherlands, November 1997, ISBN 90-75452-08-X

7. Hutten MMR. Lumbar Dynamometry: A useful method for assessment of patients with chronic low back pain? Roessingh Research and Development, The Netherlands, November 1999, ISBN 90-75452-13-6

8. Van der Salm A, van Harten WH, Maathuis CGB. Ketenkwaliteit Cerebrale Parese Zorg. Een beschrijving van de cerebrale parese zorg en mogelijke verbeteringen hierin. Roessingh Research and Development, The Netherlands, April 2001, ISBN 90-7545219-5

9. Nederhand MJ. Muscle activation patterns in post traumatic neck pain. Roessingh Research and Development, The Netherlands, March 2003, ISBN 90-75452-27-6

10. Jannink MJA. Usabillity of custom-made orthopaedic shoes in patients with degenerative disorders of the foot. Roessingh Research and Development, the Netherlands, September 2004, ISBN 90-75452-28-4. regel 1

regel 2

regel 3

regel 4

regel 5

regel 6

regel 7

regel 8

regel 9

regel 10

regel 11

regel 12

regel 13

regel 14

regel 15

regel 16

regel 17

regel 18

regel 19

regel 20

regel 21

regel 22

regel 23

regel 24

regel 25

regel 26

regel 27

regel 28

regel 29

regel 30

regel 31

regel 32

regel 33

regel 34

regel 35

regel 36

regel 37

regel 38 
Progress range

regel 1 regel 2 regel 3 regel 4 regel 5 regel 6 regel 7 regel 8 regel 9 regel 10 regel 11 regel 12 regel 13 regel 14 regel 15 regel 16 regel 17 regel 18 regel 19 regel 20 regel 21 regel 22 regel 23 regel 24 regel 25 regel 26 regel 27 regel 28 regel 29 regel 30 regel 31 regel 32 regel 33 regel 34 regel 35 regel 36 regel 37 regel 38
11. Blokhorst M. State-dependent factors and attention in whiplash associated disorder. Roessingh Research and Development, The Netherlands, December 2005, ISBN 90 365-2140-8

12. Buurke JH. Walking after stroke; co-ordination patterns \& functional recovery. Roessingh Research and Development, The Netherlands, February 2005, ISBN 90-3652140-8

13. Van der Salm A. Spasticity reduction using electrical stimulation in the lower limb of spinal cord injury patients. Roessingh Research and Development, The Netherlands, October 2005, ISBN 90-365-2253-6

14. Snoek GJ. Patient preferences for reconstructive interventions of the upper limb in tetraplegia. Roessingh Research and Development, The Netherlands, December 2005, ISBN 90-365-2255-2

15. De Kroon J. Therapeutic electrical stimulation of the upper extremity in stroke. Roessingh Research and Development, The Netherlands, December 2005, ISBN 90365-2269-2

16. Van Dijk H. Motor skill learning, age and augmented feedback. Roessingh Research and Development, The Netherlands, March 2006, ISBN 90-365-2302-9

17. Mes CAJ. Improving non-optimal results in chronic pain treatment. Roessingh Research and Development, The Netherlands, January 2007, ISBN 90-365-2435-0

18. Voerman GE. Musculoskeletal neck-shoulder pain: a new ambulant myofeedback intervention approach. Roessingh Research and Development, The Netherlands, March 2007, ISBN 90-365-2460-1

19. Kallenberg LAC. Multi-channel array EMG in chronic neck-shoulder pain. Roessingh Research and Development, The Netherlands, March 2007, ISBN 90-365-2459-8

20. Huis in 't Veld MHA. Work-related neck-shoulder pain: The role of cognitivebehavioural factors and remotely supervised treatment. Roessingh Research and Development, The Netherlands, December 2007, ISBN 978-90-365-2584-8

21. Fleuren JFM. Assessment of spasticity - from EMG to patients' perception. Roessingh Research and Development, The Netherlands, October 2009, ISBN 978-90-365-2869-6

22. Reenalda J. Dynamic sitting to prevent pressure ulcers in spinal cord injured. Roessingh Research and Development, The Netherlands, October 2009, ISBN 978-90-365-2884-9

23. Prange GB. Rehabilitation robotics - stimulating restoration of arm function after stroke. Roessingh Research and Development, The Netherlands, October 2009, ISBN 978-90-365-2901-3

24. Vos-van der Hulst M. Prognostic factors and underlying mechanisms in chronic low back pain. Roessingh Research and Development, The Netherlands, November 2009, ISBN 978-90-365-2881-8 
regel 1

regel 2

regel 3

regel 4

regel 5

regel 6

regel 7

regel 8

regel 9

regel 10

regel 11

regel 12

regel 13

regel 14

regel 15

regel 16

regel 17

regel 18

regel 19

regel 20

regel 21

regel 22

regel 23

regel 24

regel 25

regel 26

regel 27

regel 28

regel 29

regel 30

regel 31

regel 32

regel 33

regel 34

regel 35

regel 36

regel 37

regel 38 
regel 1

regel 2

regel 3

regel 4

regel 5

regel 6

regel 7

regel 8

regel 9

regel 10

regel 11

regel 12

regel 13

regel 14

regel 15

regel 16

regel 17

regel 18

regel 19

regel 20

regel 21

regel 22

regel 23

regel 24

regel 25

regel 26

regel 27

regel 28

regel 29

regel 30

regel 31

regel 32

regel 33

regel 34

regel 35

regel 36

regel 37

regel 38 